\title{
Perfectly Boring?
}

\author{
The Public Afterlife of Private Films
}

by

Rosina Catherine Hickman

A thesis submitted to the Victoria University of Wellington

in fulfilment of the requirements for the degree of

Doctor of Philosophy

Victoria University of Wellington 



\begin{abstract}
Home movies are now viewed in a variety of public contexts, a shift that entails a loss of their original meanings. In order to consider the impact of exhibiting these private documents, this thesis analyses the use of home movies within recycled footage productions, archival curation and online video-sharing. Investigating a variety of formal and informal screening contexts through close readings and archival research, it asks: what meanings do home movies acquire in new contexts? How might the reuse of home movies affect our understandings of their production and the past they portray? Does a perception that home movies could appear boring influence how they are framed or altered for public audiences?

Due to their form and content, home movies may seem ill-suited to public exhibition. Popular discourses about home movies during their heyday of production reveal a widespread belief that they were boring (for outsiders) to watch. While recent literature has assessed home movies more favourably, it has tended to overlook their potential to bore viewers who have no personal relationship to them. Drawing upon theories of boredom, this study argues meaningfulness is the principal factor determining whether a viewer finds a particular film interesting or boring. In their original form, home movies may appear relatively meaningless and therefore boring to public audiences. Recycled footage films re-edit images, however, to create engaging viewing experiences through narrative and affect. While more experimental productions frequently question the evidential value of home movie images, television documentaries tend to encourage audiences to perceive footage as authentic or nostalgic. Narrative and affect also feature in the exhibition strategies of moving image archives. Curated public programmes provide informative and enjoyable viewing for general audiences, but almost inevitably promote certain understandings of the past by offering specific interpretations of selected films. Moreover, the affective appeal of home movie images may outweigh other forms of meaning for viewers, particularly in community or participatory screening contexts. Online video-sharing platforms such as YouTube, which are curated by algorithms rather than human expertise, feature numerous home movies without any kind of framing or description. While this might seem profoundly boring, viewer comments suggest meaninglessness can foster imaginative and empathetic responses to home movies, often expressed as nostalgic longing. This propensity of home movie footage within different screening contexts to encourage nostalgic sentiments, or a belief that life was better in the past, has implications for collective memory and understandings of history. Moreover, the ability of at least some viewers to enjoy home movies in relatively contextless spaces suggests that in certain instances qualities associated with boredom may not be a significant impediment to meaningful experience after all.
\end{abstract}




\section{Acknowledgements}

Many individuals and organisations have assisted me in the writing of this thesis over the past three and a bit years. Firstly, I must thank my supervisors, Minette Hillyer and Thierry Jutel, for their invaluable advice and support. I would also like to thank Kirsten Thompson and Geoffrey Batchen for their suggestions during the early stages of this project, and Tim Groves for his assistance.

Secondly, I must express my deep gratitude to the staff of the archives I visited during a research trip to Europe, especially Graham Relton, Sue Howard and Megan McCooley of the Yorkshire Film Archive, Dorette Schootemeijer at EYE Filmmuseum, Ellen Ryckx at Huis van Alijn, Lisa Kerrigan and the other organisers of London Home Movie Day 2017 along with the participants who shared their films and stories. I am also grateful for the generosity of my hosts in Europe whilst undertaking my research: John and Jane Luxton, John and Anne Hopkins, Ian and Maureen Brough, Ewan Munro and Kerry Lambeth, Nick Weinhold and Rebecca Cotton, and especially Richard and Fay Hickman for being my home away from home in the UK.

Thirdly, I wish to acknowledge the financial support I have received from Victoria University in the form of two scholarships and research committee grants for overseas travel and conference attendance.

Lastly, on a more personal note, I am very grateful to the friends who have trodden this path before me for their support and helpful suggestions along the way, especially Simin Littschwager, Robert Hurley and Emma Kelly. I would also like to thank Campbell Walker and Malcom Duffy for their encouragement, Mum and Dad for forty years of love (and for being such generous landlords to a grad student) and 'Pickle', my daily visitor who has faithfully slept beside me as I toiled away at the computer. Doubtless I would never have finished without the reassurance of his constant companionship.

This study is dedicated to Jane Paul (1958-2018) for her tireless effort over many years to archive, exhibit and document the history of home moviemaking in New Zealand. 


\section{Contents}

i. List of Illustrations

$\begin{array}{lr}\text { ii. Note on Text } & 10\end{array}$

0 . Introduction

'HM 97177: Unidentified' and the problem of boring films

$\begin{array}{ll}\text { Personal movies for private communication } & 14\end{array}$

$\begin{array}{ll}\text { The oscillating fortunes of home movies } & 16\end{array}$

Boredom: a peculiarly modern problem? 18

Nothing happens: cinema and boredom 19

Something is happening: home movies in the twenty-first century 20

$\begin{array}{ll}\text { Home movies leaving home } & 21\end{array}$

\section{The anatomy of boredom}

$\begin{array}{ll}\text { Medium without a message } & 27\end{array}$

Synonymous with boredom $\quad 29$

Make your movie tell a story (and be sure to pan slowly) 32

Medium without a message $\quad 35$

The golden age of home movies $\quad 36$

Long and boring, or uniquely fascinating? 39

'even if their dramatic merit and social vision is slight' 42

Boredom, modernity and the vigorous pursuit of excitement 44

Information overload and the deficiency of meaning $\quad 47$

Cinematic time and viewer engagement 49

2. 'Almost anything else seems preferable'

The home movie which is boring in its boringness 52

Cinematic time and Heidegger's three forms of boredom 53

$\begin{array}{ll}\text { A ruminative mode of spectatorship } & 58\end{array}$

$\begin{array}{ll}\text { The home movie which is boring in its boringness } & 60\end{array}$

$\begin{array}{ll}\text { Technical difficulties, extended snapshots and patterned eliminations } & 62\end{array}$

$\begin{array}{ll}\text { All personal sound } & 67\end{array}$

$\begin{array}{ll}\text { A question of presentation } & 70\end{array}$

'on the edge of your seat as you contemplate what does this all mean?' 72

3. The alchemist's touch 
Home movie footage and different kinds of alchemy 84

Recycling home movies: aesthetics, evidence, contingency 86

'Home movies' and the construction of credibility 94

$\begin{array}{ll}\text { Television and authenticity: home movies as national history } & 101\end{array}$

Personal reminiscence, collective nostalgia and the 'home movie effect' 104

$\begin{array}{ll}\text { Auto/biographical cinema, memory and problematic evidence } & 109\end{array}$

$\begin{array}{ll}\text { Trespassing upon intimate moments and voyeuristic pleasure } & 117\end{array}$

$\begin{array}{ll}\text { Fictional biography and the universal image } & 120\end{array}$

$\begin{array}{ll}\text { Experimental micro-history and the affect of historical presence } & 122\end{array}$

$\begin{array}{ll}\text { Against the narrative impulse: uninflected footage as worthy subject } & 127\end{array}$

\section{Archival capital, information overload and not being bored with home movies in the archive}

$\begin{array}{ll}\text { Making history accessible: collections and stories } & 134\end{array}$

Describing and interpreting home movies in the archive 137

$\begin{array}{ll}\text { Placing a film in its right context } & 141\end{array}$

Negotiating messy contingency: separating archival noise and information $\quad 147$

$\begin{array}{ll}\text { Making selections and framing home movies in different ways } & 152\end{array}$

Platforms and effects I: getting people's attention via social media 157

Platforms and effects II: installations and (inter)active experiences 161

Platforms and effects III: community screenings and affective engagement 169

Platforms and effects IV: Co-curation, remixing film history

$\begin{array}{ll}\text { and the 'clearing house' of meaning } & 177\end{array}$

$\begin{array}{ll}\text { Serving a certain vision of history? } & 181\end{array}$

$\begin{array}{ll}\text { The perfect unmanageable and incomplete history-making project } & 183\end{array}$

\section{Conclusion}

Home movies in the 21 st century $\begin{array}{ll}\text { and (mind) wandering through cyberspace } & 187\end{array}$

$\begin{array}{ll}\text { Getting the presentation right? } & 189\end{array}$

$\begin{array}{ll}\text { The greatest archive of noise and detritus } & 196\end{array}$

If I could take a train back in time... $\quad 200$

Curation by code and the mind-wandering cyber-flâneur 204

Ideal archive of the perfectly boring, or watch on your smartphones $\begin{array}{ll}\text { and laptop screens as we sink...? } & 208\end{array}$

6. Bibliography 212

$\begin{array}{ll}\text { Audiovisual sources } & 227\end{array}$ 


\section{List of illustrations}

0.1. Bruce in 'Home Movie 97177: Unidentified'.

1.1. Robert Benchley and his wife appear disconcerted by the disappearance of all but one of their guests during an after-dinner screening in Home Movies (1940).

1.2. Punch cartoon reprinted in Marion Gleason's Scenario Writing and Producing for the Amateur (1929).

1.3. Suggestions for filming'Little Miss Muffet' at home in Junior Scenarios for Home Movies (Eastman Kodak 1928).

2.1. Irritating failure to keep the subject in frame or good use of a wide angle lens? Headless subject in Robert Benchley's Home Movies.

$2.2 \&$ 3. One Christmas looks much the same as another in 'Raikes Family Christmas home movies'.

2.4. 'Knock it off back there!' Participants appear less than enamoured of the cumbersome microphone in the midst of a family Christmas in Fred McLeod's All Personal Sound Movies.'

2.5 \& 6. Monochrome photography imparts a documentary feel in 'The Good Old Days'.

$2.7 \&$ 8. Interweaving agricultural and personal history in'Progress in Farm Technology'. The dark shadow in the corn wagon is the narrator as a child.

2.9. Ordinary family moments abound in 'Morris Family Home Movies'.

3.1-3. Central sprocket holes, focal dips and side-to-side slippage draw attention to the materiality of the film in Malcolm Le Grice's Little Dog for Roger. Its home movie subject remains visible, however.

$3.4 \& 5$. Home movie nostalgia is undercut by critical reflection from the filmmaker in Home Movie: An American Folk Art.

$3.6 \& 7$. Subject and statement align: a woman stares at the camera ('How hard I find it to see what is right in front of my eyes!') and a writhing pig ('The horrors of hell can be experienced within a single day. That's plenty of time') in Wittgenstein Tractatus.

3.8 \& 9. Family scenes in Jonas Mekas's A Visit to Stan Brakhage.

$3.10 \& 11$. Home movie imagery evokes nostalgia, wholesomeness and sincerity in Tesco's 2013 Christmas advertisement.

$3.12 \& 13$. Just like any other home movie family? A young queen and her son, Prince Charles, in a home movie and watching films at home many years later in Elizabeth at 90: A Family Portrait. 
3.14-21. Slowed down and repeated a simple act captured in a home movie becomes an intrusive, controlling gesture in Daughter Rite.

$3.22 \& 23$. Hitler appears uncomfortably human in the banal home movie scenes of Swastika. The same footage takes on a much eerier quality as grainy black-and-white images in Human Remains.

$3.24 \& 25$. Stories recalled on the soundtrack of The Family Album provide a counterpoint to generic images of home movie subjects partaking in happy events.

$3.26 \& 27$. Daily life continues in home movies of the Salvans family in El Perro Negro and passengers aboard The Queen Elizabeth in Danube Exodus despite impending war.

3.28. Digital compositing combines images from different home movies in Disappearance.

3.29. Highway as empty as the soundtrack of Rick Prelinger's No More Road Trips?

4.1-3. Online clip of 'Personal record. Hayward, R. [Wellington NZ October 1916]' showing pronounced signs of deterioration characteristic of early nitrate film stock.

4.4. Webpage with curatorial notes for Hayward's home movie in online exhibition, ANZAC Sights and Sounds of World War I.

4.5. Home movie showing German PoWs working on the land in Yorkshire during World War II on Films From the Home Front.

4.6. Interactive finding aid on Amateur Filmmakers Record the New York World's Fair and Its Period.

4.7 \& 8. 'Apparently there's supposed to be color'. 'Home Movies: Paris, Times Square, China, etc.'

4.9-12. Dietrich consciously posing for the camera and in less guarded moments.

4.13. Home movies as film history. The selection of home movies made by professional filmmakers, the Tilley Brothers, complicates the notion of amateur film. Amateur Auteurs online exhibit, Texas Archive of the Moving Image.

$4.14 \& 15$. Social media promotion of home movies: Facebook posts by NFSA and NTSV.

$4.16 \& 17$. Social media promotion of home movies: Facebook post by TAMI and Twitter post by National Library of Scotland's Moving Image Archive.

4.18. 'CineSecrets', an interactive series of questions that encourage viewers to respond in the comments section, is used regularly by NEFA and YFA to build audience interest prior to an event.

4.19. Huis van Alijn's Homeless Movies viewing booth.

4.20. Patrons of London HMD watching an $8 \mathrm{~mm}$ film.

4.21. Archives 2.0 at its simplest: add your suggestion in the comments section. NFSA Facebook post. 
4.22. Appealing for information via social media. YFA Facebook post.

$4.23 \& 24$. Gentle nostalgia in Stevie Gee's Playing Out contrasts with themes of paranoia and alienation in Nicola Jaberi's London! A Guide for the Anxious. Finalists in London Recut.

5.0. Bruce turns four in 'Home Movie 97177: Unidentified'.

5.1. Birthday cake 'searching' for the dining table seemingly lost in the under-lit scene. Bruce is barely visible in the lower righthand corner of the frame. 'Home Movie 97177: Unidentified'.

5.2. The ubiquity of the banal in amateur recordings as seen in Wreck and Salvage's mash-up,'Golden Gates'.

5.3. Generic Yuletide scenes in 'Vintage Christmas Movie' seemingly accord with viewer sensibilities in spite of decidedly blurry images.

5.4. Braun becomes an attractive heroine leading an idyllic lifestyle amongst the Nazi elite in popular YouTube mash-up,'The Life and Death of Eva Braun'.

5.5. 'All of them get along quite nicely, which is really nice', according to Spuzz. 'Home Movie 98543: January 1929'.

$5.6 \& 7$. Freezing winter and hot summer work: horses arouse the sympathy of contemporary viewers in 'Amateur film: Ice Harvest, Pocono Manor, 1919' and 'Home Movie of The Good Old Days America 1940's'.

5.8. 'So What? Nothing at all interesting or informative. Just a clip showing a group of men being served food outdoors in the 1930s' (according to one viewer)... or prelude to more sinister goings on...? 'Amateur film: Bohemian Grove'.

5.9. 'Could be interesting with some theorizing. The film itself is not much, but imagining the surroundings, people watching from off camera, what happened before and after the shoot will make it interesting [...] Take a look'. Viewer comment, 'Amateur film: Dog Cart'. 


\section{Note on Text}

All emphasis in quotations is in the original, unless otherwise stated. The official title of a work (usually conferred by its creator) is given in italics; those in inverted commas indicate titles subsequently assigned to unnamed or unattributed recordings for purposes of identification, archival cataloguing, uploading to the Internet, YouTube mash-ups of footage etc. 
Introduction

\section{'HM 97177: Unidentified' and the problem of boring films}

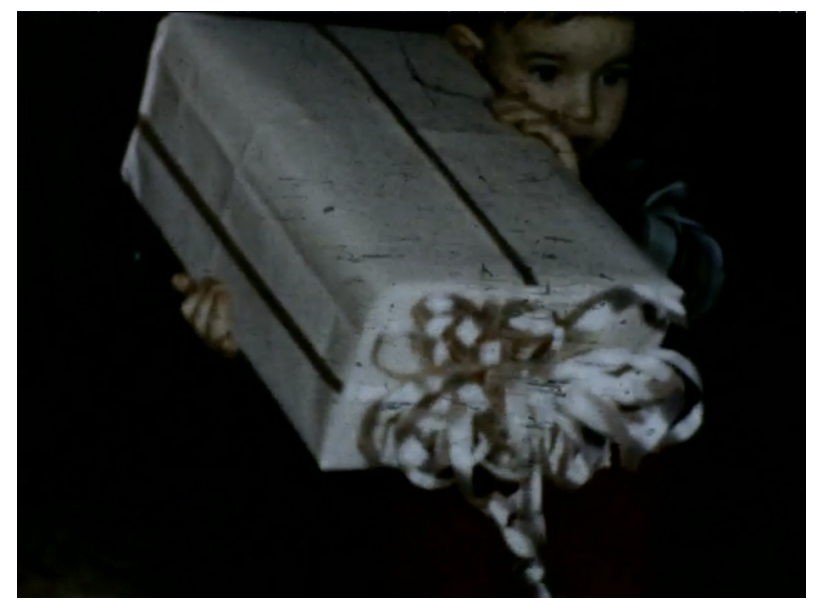

Light flickers on the edge of frame indicating the film is rolling. Out of silent blackness looms a large box covered in white wrapping paper with an enormous bow. A small boy loses his grasp upon this cumbersome object, holds up three fingers and grins at the camera. The child proceeds to tear the paper from the box and, smiling, removes a stuffed dog. Disembodied hands reach into frame, turning the toy to face the camera. A cake hovers in the darkness, barely illuminated by its candles. From its neat decoration we learn it is Bruce's third birthday, the only identifying information we acquire about this otherwise anonymous child and his presumably middle-class American family. We go on to witness Bruce posing with his snowman, drinking water from a hose in the back garden, helping to mow the lawn, emptying his Christmas stocking... A year flashes by - condensed into the space of a few minutes - and Bruce turns four.

'Home Movie 97177: Unidentified' is one of hundreds, if not thousands, of old home movies now inhabiting cyberspace. This kind of public afterlife has become the fate of a great many of the more-or-less infinite number of private films recorded by enthusiastic, albeit not always competent, amateurs around the world in the twentieth century. 'Home Movie 97177', which is part of the Prelinger Collection viewable on the Internet Archive, is a less than stellar example of filmmaking technique even by home movie standards. Most of its twenty-eight minutes were shot inside. The resulting footage ably demonstrates why many amateurs chose to film primarily 
outdoors. Shadowy figures lurk in one under-lit sequence after another, rarely coming into clear view. The camera pans wildly, seeking any reflective object in the relentless gloom, setting the Christmas tree lights on a merry dance. Visual information is scarce. Even the approximate date of filming is difficult to discern. The family seems to devour one elaborately decorated cake after another, little else being considered worthy of filmic posterity. What could anyone unrelated to this apparently unremarkable child and his family possibly find of interest in these rather clumsy recordings of humdrum domestic rituals? Perfectly boring is a description that readily springs to mind.

We live in an age of cinema dominated by the action-packed narratives, frenzied editing and ever more spectacular special effects of Hollywood productions. Such techniques seem to imply a belief that the contemporary attention span is likely to be a short one, requiring constant and clamorous excitement to be sustained. Admittedly, traditional cinema faces significant competition for the attention of twenty-first century viewers. A myriad of entertainment options - many at our disposal at the click of a mouse - also want to lay claim to our eyes (and our wallets). Walter Benjamin's notion of reception 'in a state of distraction' characteristic of modernity $(2008,34)$ has arguably evolved into reception in a state of hyper-distraction characteristic of postmodernity. In a digital world of sensory stimuli, ceaselessly available, it might seem doubtful that the everyday antics of little Bruce and history's legions of home movie micro-stars can command attention. Why should this even matter?

This thesis investigates the afterlife of private films such as 'Home Movie 97177' in the public sphere. Like other home movies, Bruce's birthday film was made to be watched at home by his family and perhaps their friends, not by strangers via the Internet. The World Wide Web is just one of many places old home movies might be encountered. More official cultural spaces within the public sphere are also 'home' to home movies. Many archives and museums now collect and exhibit them. Filmmakers reuse home movies within their own films. Home movies appear in television programmes. They are incorporated into video installations. There is even an international event specifically devoted to screening home movies. Whatever their shortcomings, home movies clearly have found a place within certain public forums. They have been championed by scholars, filmmakers and archivists as historical records of everyday life, while digital technologies have somewhat ironically made them more accessible as digital surrogates easily circulated without specialised projection equipment. Practicalities aside, home 
movies simply do not seem very well suited to public screenings if one considers their form and content. As the example above illustrates, the value of a home movie once it has left (its own) home can be difficult to discern. Home movies are not usually self contained; most do not tell a coherent story as such. They fail to communicate as intended. Torn from their domestic circle of participant-narrators, they fall silent, both literally and figuratively. Watching 'Home Movie 97177', we learn little about Bruce: he turned three, ate cake with his family, played in the backyard and turned four. What is the meaning or significance of this brief record of early childhood? It is difficult to say in its orphaned afterlife on the Internet. Refusing to offer us anything of substance or magnitude in this (rather contextless) context, 'Home Movie 97177' in its apparent meaninglessness seems destined only to bore.

As much as they have come to be valued by those with an interest in historical images of daily life and vernacular media practices, from a more general viewing perspective home movies continue to present a number of obstacles to audience engagement. Whether home movies receive broader public recognition might ultimately be deemed rather inconsequential were it not for the fact that film preservation, production and exhibition are all costly activities. Audiences pay, directly or indirectly, to watch films or television programmes, attend exhibitions and - perhaps most importantly from the perspective of those concerned about history and the conservation of its material artefacts - for the public repositories that collect moving images. If the allocation of funding is linked to perceptions of public interest in archival materials, 'boring films' represent at the very least a certain kind of problem in the public sphere. Filmmakers, television producers, artists, curators and archivists seeking an audience (and financial support) for new works, screening programmes or other archive initiatives have good reason to communicate the value of footage that might otherwise appear dull, minus obvious points of interest, or simply rather meaningless to many viewers.

With this in mind, this study draws upon close readings and archival research in order to ask: what meanings do home movies acquire in new contexts? How might the reuse of home movies affect our understandings of their production and the past they portray? Does a perception that home movies could appear boring influence how they are framed or altered for public audiences? Although the majority of this thesis deals with more official or formal contexts of presentation, including archives and productions that incorporate archival footage, the presence of films such as 'Home Movie 97177' in comparatively unregulated online spaces will also be 
revisited. In thinking about the kinds of discursive framings used to present home movies to audiences very different from their original ones, it should be noted that while the public dissemination of home movies is a fairly recent phenomenon, public discourse about them actually has a much longer history, even if the films themselves were initially seldom seen outside the home. If one was to accept popular opinion on the subject, this did not matter very much, however, as home movies were generally held to be terribly boring. This kind of perception, which arose at a time when home movies essentially stayed at home, seemingly evolved from a misconception about who exactly was watching them and why.

\section{Personal movies for private communication}

Home movies are an example of what Richard Chalfen refers to as the 'home-mode of visual communication'. Home-mode images are recorded for 'private and personal' purposes rather than the 'public and impersonal' ones of mass communications such as journalism, advertising or television broadcasts. The home-mode is defined according to the function of images rather than how or where they were recorded $(1975,19-20)$. Home movies were shot on a variety of formats (usually $16 \mathrm{~mm}, 9.5 \mathrm{~mm}, 8 \mathrm{~mm}$ or Super-8) and were in fact often filmed in public spaces such as the beach or vacation spots. They were viewed, however, in a private, domestic setting by gatherings of participants, family and friends who had an intimate connection with what was onscreen. The establishment of popular online video-sharing platforms such as YouTube has now blurred the former divide between private and public image-making practices. Home-mode nonetheless remains a useful means of delineating personal documents from other kinds of visual records within historical contexts of production and circulation.

Understanding home movies within a sphere of home-mode communication helps to distinguish them not only from professional cinema for public audiences, but also from amateur films intended for screening outside the home. Most people who made home movies were indeed amateurs in the sense they were not involved in filmmaking for financial remuneration. Confusion arises, however, from the fact that amateurs also produced films using similar equipment for contexts such as ciné-clubs, amateur film festivals, galleries or other community spaces. Many of these films may not have anticipated a general public audience but neither were they made for a solely domestic one. Some amateurs made both home movies and other kinds of films, while people employed in the film industry sometimes shot movies for their own 
personal viewing, that is, in an essentially amateur, home-mode capacity. Private purpose is therefore the simplest way to distinguish home movies from other types of film.

The term home-mode has subsequently been taken up by James Moran in There's No Place Like Home Video (2002). As the medium that superseded home movies, home video fulfils a similar role within private communication practices, but can be distinguished in a number of respects. The most obvious point of difference is that home movies are usually silent, whereas direct sound is easily recorded on video. As in the example above, home movie formats favour recording outdoors. By comparison, video is somewhat more forgiving in low light conditions. Home movies are short, shot on rolls of film typically lasting around three minutes; a video tape format such as VHS may be up to three hours. Film is a relatively expensive, single-use medium requiring processing that usually took place in a professional laboratory, whilst video is cheap, reusable and instantly available for viewing. Home movies require special screening equipment; video is viewed on whatever screen is available. Given these ontological differences, the reuse of home video in a public context may raise a range of different concerns to those associated with home movies. Moreover, whilst there was some overlap in the use of home recording technologies during the 1980 s as moviemakers shifted from film to video, they essentially document separate periods of time. The earliest surviving home movies shot on $16 \mathrm{~mm}$, the first format released specifically for amateur use, are now nearly one hundred years old, recorded at a time very few people alive today can remember. Home movies were seldom recorded after the 1980s, the world they portray one of increasingly distant personal and collective memory. In view of these formal and historical distinctions, home movies and home videos are in many respects better suited to separate consideration within their own specialised studies, this thesis focusing solely upon the former.

Moran's study predates the YouTube era, which has collapsed any clear-cut distinction between private and public moving image cultures. During their heyday of production in the midtwentieth century home movies rarely ventured beyond the domestic sitting room, remaining firmly embedded within an exclusively private realm of communication. As noted above, this does not mean that home movies were not discussed in the public sphere. Far from it in fact. Public discourse about home movies actually began not long after many amateurs first got the chance to try their hand at filmmaking in the early 1920s. There were plenty of opinions about home movies it seems, a great many of which were not very complimentary. 


\section{The oscillating fortunes of home movies}

Home movies have a chequered history in terms of popular appraisal. Despite millions of rolls shot by keen amateurs during the middle years of the twentieth century (or perhaps in part because of their ubiquity), home movies were frequently decried as boring by humorists and advice-proffering experts alike, films to be patiently endured rather than enjoyed by relatives, friends and neighbours. Boring films were a problem, yet the solution was apparently simple: home movies should be improved so that they were more entertaining. Well-intentioned advice on how to do so seemingly had a tendency to fall upon deaf ears, however, if one is to judge by the prevalent style of home movies, which does not accord with the recommendations of most guidebooks on the subject.

The twenty-first century has proven a little kinder, witnessing a significant u-turn in the appreciation of amateur moviemaking efforts. In a rather prescient observation, Fred Camper suggested that technological obsolescence might 'awaken us all to an appreciation of what is surely a major aspect of American [and other] folk-art' $(1986,10)$. Events such as Home Movie Day, which is celebrated around the world, and the outpouring of scholarship on amateur film testify to popular and academic enthusiasm for the private, everyday media objects of a now bygone era. The demise of celluloid and other physical media appears to have created a 'technostalgic' fascination with the material properties of technologies rendered obsolete by digitisation. Contemporary desires to recover a seemingly more tangible past, or simulacrum thereof, have in turn been exploited by new media. ' $8 \mathrm{~mm}$ ' mobile phone applications or desktop editing software,${ }^{1}$ which attempt to mimic the visual qualities of home movie footage in digital form, have made the characteristic aesthetic accessible to a generation of amateur imagemakers who do not necessarily even recall firsthand recording or watching analogue films.

Academic interest in home movies has transpired within a broader context of histories 'from below' and studies in popular media, folk art and other marginalised social practices by all manner of cultural theorists and historians. Sporadic attempts by anthropologists to explore the social value of home movies actually began in the 1970s. Richard Chalfen's early work dates from this period, as does Star and Zeitlin's documentary for the Smithsonian Folk Festival, Home Movie: An American Folk Art. With the shift to video formats for domestic use and

1 There are numerous apps for both iPhone and Android such as Nexvio's ' $8 \mathrm{~mm}$ Vintage Camera'. Standard desktop video-editing software such as Adobe Premier or Final Cut Pro also enable users to create a vintage look, either using native filters or with the addition of plug-ins such as DigiEffects' 'Aged Film'. 
subsequent discarding of projection equipment, many families were no longer able to screen films at home, often depositing them instead in public archive collections. Scholarly emphasis logically moved beyond the role of home movies within the family to their significance outside it. In the past three decades, literature on home movies (or amateur film more broadly) from a growing number of scholars has embraced a diverse range of approaches. These include analyses of public discourses about amateur film (most notably in the early work of Patricia Zimmermann), the value of amateur film as historical evidence (Heather Norris Nicholson and Efrén Cuevas, for example) and home moviemaking as a particular kind of filmmaking practice (Alexandra Schneider and Elizabeth Czach, for example). Most importantly perhaps, home movies have come to be viewed as a legitimate object within the discipline of film studies itself.

The celebratory tone of much of this work, focused as it is on rescuing amateurism from the rubbish dump of cinematic history, has tended to elide any consideration that many (perhaps even most) amateur films are in fact relatively mundane and repetitive. The history of private filmmaking is one of yawning monotony and clichéd ritual as much as individual experience and personal expression. Recent enthusiasm for amateur film's potential to democratise film history with personal visions drawn from everyday life masks the difficulties of dealing with countless, insipid films likely to clog the narrative wheels of recounting the cinematic past.

General film histories are perhaps a little more telling in this respect. A standard introductory text such as Corrigan and White's The Film Experience (4rd edition 2015), for example, devotes a mere paragraph (somewhat ironically) to the acknowledgement of 'films [including home movies] that have been neglected by canonical film histories and need to be recovered materially as well as critically' (395). Values such as originality and innovation expressed within teleological models of progress and the attributable authorship practices of pioneering artists remain in many ways a mainstay of film history. Derived from art historical models, such frameworks once conferred respectability upon both a fledgling art form and scholarly pursuit. Films that failed to fit such haloed categories might conveniently be forgotten. The repetitive, the banal, the ubiquitous, the boring - films that stubbornly pointed towards a history of cinema as much utilitarian as artistic in aspiration - did little to solidify appreciation of the seventh art as art. 


\section{Boredom: a peculiarly modern problem?}

Curiously, boredom itself appears to have become a source of interest, if the development of what might be termed 'boredom studies' is any indication to go by. Elizabeth Goodstein, Patrice Petro and Lars Svendsen, among others, have contributed to a growing body of literature on the topic that attempts to account for boredom, or at least our contemporary understanding of it, as a 'peculiarly modern experience' (Petro 2002, 58). A connection between boredom and modernity was recognised much earlier, by number of cultural theorists and philosophers in the first half of the twentieth century, including such luminaries as Walter Benjamin, Siegfried Kracauer, Martin Heidegger, Bertrand Russell and (slightly later) Henri Lefebvre. With the exception of Heidegger, none of these writers produced a systematic analysis of boredom. It was consistently recognised as a feature of modern existence, one that was newly democratic, affecting both workers and leisured classes alike. Although industrialisation created repetitive, unfulfilling labour routines for many, the monotony of such employment was at least accompanied by an expansion of leisure time amongst urban workers. The resulting need for distraction from idle hours and the mundane realities of daily life was readily exploited by the commercialised logic of the entertainment industry. In short, modern work and leisure patterns combined to create specifically modern manifestations of boredom, along with a range of new responses or solutions to the phenomenon.

News media, flânerie, gambling and, perhaps most importantly, cinema-going were all ways of alleviating the tedium of modern urban existence. Yet even excitement had its drawbacks. The quest to keep boredom at bay might easily double back on itself. Sensory overload could leave one benumbed and indifferent. Modern writers saw other, more inspirational, possibilities as well, however. Rather than affirming surrender to the relatively mindless 'cult of distraction' (Kracauer 1995) or hyper-stimulation of the urban milieu, boredom offered the afflicted individual pause for thought, providing the relaxed disposition properly necessary to listen, cogitate, dream, or gain a level of self or historical awareness. Consequently, far from simply fueling the passive consumption of information and sensation, boredom might actually induce a state of critical reflection. For Benjamin, it was 'the threshold to great deeds... a warm gray fabric lined on the inside with the most lustrous and colorful of silks' in which the dreamer might wrap his or herself $(1999,105)$. At its most utopian, boredom becomes an experience replete with latent emancipatory possibility. 


\section{Nothing happens: cinema and boredom}

In view of cinema's status as a medium of mass entertainment, it is perhaps to be expected that sustained analysis of the relationship between film and boredom has been less than forthcoming. People attend films in order to be not bored. Yet entertainment is not always entertaining. Films can, and do, fail to provide spectators with adequate diversion. While admittedly more-or-less any film can bore a particular viewer, boringness, if you will, tends to be most readily perceptible within modes of filmmaking that subvert the immersive qualities of commercial cinema. Audiences unfamiliar with formal techniques that deliberately seek to create a critical distance or more contemplative connection between viewer and image may reject slow or experimental films as tedious or dull. Unsurprisingly, it is here that analysis of cinematic boredom typically locates itself. Art cinema's propensity to elicit boredom is alluded to in the very title of Ivone Margulies's book on Chantal Akerman: Nothing Happens (1996), nothing much, that is, in comparison with Hollywood-style narratives. More precisely, this description of uneventfulness correlates to a perceived excess of duration accorded to banal or trivial content: 'Too much celluloid, too many words, too much time, is devoted to "nothing of interest $^{\text {'n }}$ (21, added emphasis).

Nothing of interest happens could be taken for a fair description of 'Home Movie 97177' and any number of others in a similar vein. Avant-garde minimalism that inspires boredom is quite distinct of course from the typical form of home movies. The preponderance of shots of doorways and other largely empty framings featuring little or no onscreen action (or even a human presence) recorded in takes often lasting several minutes in duration in Akerman's final film, No Home Movie (2015), for instance, clearly distinguishes its aesthetic from that of an actual home movie. Equipped with rolls of moderately expensive film around three minutes in length, the amateur filmmaker usually strove to capture as much, not as little as possible onscreen. From this perspective, movement or activity in home movies ideally takes place directly in frame, however clumsily or ineffectually this might occur in practice.

Yet even when it does occur squarely in frame, daily life - the stuff of home movies - is inclined to be tedious. 'It escapes. It belongs to insignificance,' wrote Maurice Blanchot, 'Nothing happens; this is the everyday.' Recaptured, it loses its power to reach us, becoming mere spectacle and description $(1987,14-15)$. Blanchot was not thinking specifically of home movies. Their rendition of the everyday does not lend it obvious significance or meaning. 
Watching the lives of others unfold in fractured moments on a movie screen can be unrewarding voyeurism if it offers us nothing more than the outward appearance of ordinariness. 'Boredom,' Blanchot concluded, 'is the everyday become manifest: as a consequence of having lost its essential - constitutive - trait of being unperceived' (16).

\section{Something is happening: home movies in the twenty-first century}

What this brief sketch has hopefully served to illustrate is that boredom as a pervasive experience of modernity and, more significantly for our purposes, home movie-inspired boredom in particular were regarded problems to be resolved. The solution in both instances was greater stimuli, be it the distractions of the city, or more exciting home movies, if only amateurs would be more attentive to their filmmaking technique. Alternatively, boredom (and boringness) can be re-conceptualised. It may be relished as mental space for reflection. 'Nothing of interest' can inspire contemplative viewing. The determined amateur film historian can overlook the more irksome aspects of humdrum movies in order to insist upon their merits. Assuming we accept for now that home movies are, or (at the very least) can be boring, enthusiasm on the part of the historian admittedly involves a certain 'glossing over' the possibility of being bored rather than a more favourable stance toward boredom itself. Yet it might be wondered if, in denying what is arguably an integral element of the home movie, namely its potential to bore, amateur film scholars are unwittingly doing their subject a disservice.

The approach this thesis takes may initially seem counterintuitive, perhaps even perverse. Why write about films if one is to accept a priori they may not be terribly interesting? Moreover, whatever they might tell us about objects (or their observers), boring and interesting necessarily remain subjective judgements of taste or value. It will be suggested, however, that the rather unusual conjunction of amateur film analysis and theories of boredom invites a rewarding, new perspective on home movies as they find their way into public spaces. By embracing boredom, at least to the extent of giving it full acknowledgement, this study deliberately swims against the tide of recent writings on amateur film. As a mode of reception, boredom is usually considered undesirable, a thing to be avoided or suppressed, if at all possible. With this recognition, the presentation of home movies gains a certain clarity. Home movies were made neither to inform (as in a documentary), nor to entertain in a conventional cinematic sense. Vivian Sobchack refers to them as film-souvenirs, mnemonic devices for recalling the past $(1999,247)$. Not just 
any past of course, but a very personal one. Publicly, we want them to do other things. To enlighten us, to amuse us, to emotionally move us as twenty-first century voyeurs of private histories are undertakings extrinsic to the purpose of home movies. Today's documentarians, found footage artists, curators and archivists who work with home movies - even the casual uploaders of YouTube videos - are all to some degree concerned with making films interesting, interesting enough, that is, to be worth watching. This involves, in Blanchot's words, transforming the everyday's 'nothing happens' into history's 'something is happening' (18). In the case of home movies, this must be something onscreen of sufficient interest or magnitude to warrant our attention in an ocean of twenty-first century distractions.

What Bill Nichols refers to as 'alchemy' - turning the detritus of private films into gold worthy of public appreciation (2011, vii) - takes many forms, some of which will be addressed in the chapters that follow. Modifying home movies for screening in public is a compensatory measure for spectators quite unlike their intended family audiences. The alchemist of home movies reframes them as something different, something less mundane, something of significance. This something is always in some respect ideological, serving a particular desire or need, or the perception of one. To interest an audience is effectively to mitigate the possibility of boredom. Examining what occurs when home movie recyclers try (and perhaps sometimes fail) to do this is not merely an esoteric exercise. Rather, it is one ultimately concerned with the potential ramifications of unleashing personal images of the past in the public domain, a place they were never intended to be. The focus here is not so much ethical questions surrounding the making public of what was supposed to be private as the light in which films may be interpreted. How do home movies (mis)inform us or affect us transplanted into contexts alien to their original form and purpose? What do they intimate about the past when screened in particular settings or different kinds of presentations? What can they make us think and feel in the present? ${ }^{2}$

\section{Home movies leaving home}

Something is happening to home movies as they leave home. Each of the following chapters explores their experience in a different kind of public space. CHAPTER ONE contrasts a history of the 'boring home movie' with its subsequent counter-history of the 'interesting home movie'.

2 It should be noted that while viewer responses to films and forms of contextualisation are a central concern, empirical audience reception studies are beyond the scope of the present study. Consequently, when accounting for potential reactions to individual works in the absence of hard-and-fast evidence a certain amount of caution is exercised throughout, hence a frequent recourse to tentative rather than definite statements in this regard. 
In so doing, it outlines three general discourses relevant to this study: the assumption home movies were dull, the revised stance that they are interesting, and what ultimately determines the difference between interest and boredom. Whether suggesting technical refinements or merely poking fun, public discussion of home movies during their heyday of production seemed fixated on one particular point: the value of films as entertainment. Home movies were persistently characterised as cinematic failures that did not accord with the expectations of modern audiences attuned to the aesthetics of professional cinema. Looking at a range of examples from popular culture and filmmaking advice literature aimed at amateurs, it is readily apparent that comparisons with professional films were distinctly detrimental to wider perceptions of home movies. Moreover, although not conceived in an entirely uniform manner, the private audiences of home movies were not distinguished adequately from their public cinema counterparts in terms of their requirements as viewers. Recognition of the particular relationship between films and viewers has been instrumental in the subsequent reassessment of home movies by scholars since the 1970s. Now widely celebrated as valuable cultural artefacts, home movies have on the surface finally extinguished their spectre of boringness. Close examination of key work in the field by authors such as Patricia Zimmermann, Richard Chalfen and Heather Norris Nicholson nonetheless reveals a somewhat inconsistent attitude regarding the merits of home movies buried within studies premised upon their social and cultural value. Lastly, the chapter is rounded out with an attempt to account for boredom itself as a problem of (post)modernity. Through a preliminary analysis of boredom it becomes evident that the satisfaction of meaning is a crucial factor, separating what interests and what bores a particular individual. In the case of home movies, this is as true for contemporary viewers as it was for original family audiences. Whether in the form of private memories or historical evidence of some kind, something meaningful to individual viewers is needed to sustain interest in a film for its duration.

CHAPTER TWO teases out the relation between spectators, films and boredom in more detail, with particular reference to the significance of time. Drawing upon Heidegger's one-hundredpage analysis of boredom in The Fundamental Concepts of Metaphysics, it also introduces the structuring device for the case studies of the subsequent chapters. Heidegger examines what actually occurs when we become bored, identifying three forms of boredom ranging from superficial to profound. Although he did not discuss cinema specifically, Heidegger's interest in time has an obvious correlation with film as a time-based medium. The passing of time is in fact 
a central feature of boredom. If we feel bored watching a film time seems to pass slowly, leaving us in limbo for the duration of the screening. This is Heidegger's first notion of boredom. In his second, we are left empty by an experience that fills time but in a manner that is, upon reflection, unsatisfying. A film might adequately distract us and yet still feel inconsequential afterwards, leaving us with the impression our time has been wasted. Unlike in the first form, this sensation persists beyond the experience itself and is therefore more encompassing than the first. Heidegger's third form, profound boredom, has a less straightforward relationship with cinema, but might be likened to the 'mind wandering' that can occur when we are not wholly absorbed into a film's diegesis. This taxonomy of boredoms offers a loose platform for exploring audience engagement with home movies in different contexts in chapters 3, 4 and 5. Heidegger is careful to stress that boredom is a subject-object relation between a person who is bored and a thing perceived to be boring. Following Heidegger's suggestion that certain things must nonetheless have at least some kind of latent propensity to bore, the 'irritant properties' of home movies are examined, including the effects of sound and silence. Finally, the chapter introduces the issue of presentation by looking at some amateur efforts to 'improve' home movies for online distribution. Courtesy of YouTube, the misplaced recommendations of guidebooks examined in the first chapter curiously appear to have acquired a belated relevance now that home movie audiences are likely to include viewers with no personal connection to the films.

CHAPTER THREE looks at the reuse of home movie footage within other films and television series. Proceeding from an assumption filmmakers do not usually wish audiences to find themselves in meaningless limbo for the duration of a screening - Heidegger's first form of boredom - the chapter investigates some strategies for making home movies engaging when recycled within a new production. The range of moving image works that incorporate home movie footage is diverse: television history documentaries, biographical or autobiographical films, fictional narratives, experimental cinema, video art, music videos. Other productions contain footage that deliberately resembles the appearance of home movies. The imitation of their characteristic look in another context is in fact quite revealing with regard to perceptions of actual home movies. By recreating the seemingly spontaneous, naïve quality of home movies, filmmakers impart a sense of authenticity or nostalgia, encouraging viewers to accept the truthfulness of what they see onscreen. Taking this into account, chapter 3 questions the effects of reusing actual home movie images within various kinds of productions in terms of understandings of the past they may inspire. While television documentaries tend to rely upon 
the presumed veracity of amateur footage as historical evidence, other productions probe the evidential claims attributable to home movie images. Some works show much less regard for the 'truthfulness' of home movies as evidence, using images in a more imaginative fashion to illustrate fictional narratives or simply evoke a general sense of pastness. Regardless of their objectives, most filmmakers manipulate footage substantially, using narrative and affect $^{3}$ to create engaging viewing experiences. Whether used to illustrate a story, deconstruct their status as evidence or simply play upon the emotional responses of spectators, the recycling of home

3 In the discussion of home movies affect has been used to describe a range of reactions to a film that are not purely cognitive or intellectual in nature. Examining the relationship between home movies and spectators, Roger Odin notes, for example, that ' $[\mathrm{m}]$ eaning is not everything: affect and the interactions during production and reception must be analyzed' (added emphasis). He does not elaborate any specific definition of the term affect, but describes a number of possible 'affective relationships' that can be 'established with the spectator' of a film. Examples include 'the thrill of fictively recounted events' a film provokes or 'the rhythm of images and sounds stir[ring] the spectator' $(2008,255)$. The relationship is contextual. In their original private settings, home movies involve the 'pleasure of gathering the members of a family', along with individual and collective remembering building 'toward celebration' $(256,260)$. In a subsequent context (such as an archive or documentary) in which a home movie is considered an historical document, a non-family viewer's responses will differ and may concern intellectual inquiry (what can I learn about the past from this film?). However, Odin also notes such viewers can have an 'emotional relation' to a home movie, particularly if they identify with it in some manner (264). Similarly, Jaime Baron describes the 'tragic sense of loss' viewers feel anticipating the fate of home movie subjects in Peter Forgacs' Holocaust films as affect $(2013,87)$. This usage does not appear to take into account more specialised understandings of the term affect arising in the field of affect theory that distinguish between feelings, emotions and affects. Eric Shouse argues, for example, that while 'feeling and affect are routinely used interchangeably', one should not 'confuse affect with feelings and emotions' (2005). In brief, feelings or sentiments are considered personal, sensations related to previous experiences, whereas emotions are social in orientation, a physical display of feelings (which may or may not be genuinely felt). Within this trajectory, Shouse describes affect as a more abstract concept, 'a non-conscious experience of intensity' involving bodily reactions over which we have little control; affect is 'what determines the intensity (quantity) of a feeling'. He suggests intensity can 'mean' more to people than actual meaning (the way music 'moves' people, for example) (ibid.). Extending from Baruch Spinoza's concern with the body's ability to affect and be affected by another body, affect theory has described the passage of these non-conscious intensities or bodily reactions. This kind of demarcation is much more precise than that which Odin employs in the context of home movie analysis above (or a term such as 'evocation' as used by Vivian Sobchack (1999, 247 ) to describe the relationship between home movies and their original family viewers). Odin refers to both bodily reactions and emotional responses to a film but does not establish a clear dividing line where one ends and the other begins. However, Seigworth and Gregg point out in their introduction to The Affect Theory Reader there is 'no single, generalizable theory of affect', identifying two dominant angles - one stemming from the psychobiology of Silvan Tomkins (initiated by Eve Sedgwick and Adam Frank), the other from Gilles Deleuze's Spinozan ethology of 'bodily capacities' (initiated by Brian Massumi) - along with a further eight general approaches $(2010,3,5)$. Ideally, given the slightly slippery nature and variable usage of the term in different fields of inquiry, this thesis would have avoided using the word affect altogether. Unfortunately, there does not appear to be a more satisfactory alternative in the English language that fully captures the kinds of responses a viewer may experience when watching a (home) movie that go beyond (or are intermeshed with) purely intellectual interest. As home movies in both their original settings and subsequent contexts of circulation frequently arouse reactions in the general order of feelings, emotions, sensations and/or affects, it is perhaps surprising home movies have not been (to the best of my knowledge) examined in any detail with specific reference to affect theory (a situation possibly related to their marginal status within film studies). The potential application of affect theory in home movie analysis is, however, well beyond the theoretical scope of the present thesis. Consequently, the use of the term affect here is aligned with its current, more wide-ranging deployment within existing literature on home movies - the theoretical terrain the thesis engages with - rather than anticipating any usage a scholar versed in both affect theory and amateur film studies may conceivably invoke in some future study. Regardless of whether affect is understood as 'irreducibly bodily and autonomic' 
movies is an ideological venture. Interesting audiences in a private view of the past involves reconciling the personal with collective history, instigating coherence and communicating meanings that have the potential to resonate with viewers.

CHAPTER FOUR investigates the place of home movies within contemporary cultural heritage institutions. Many film archives and museums have amassed sizeable collections of home movies, particularly regional repositories that specialise in the preservation of local history. As documents in an archive, home movies tend to lose their associations with personal memories, becoming instead categories of historical subjects. While digitisation and the Internet have improved access to many archival collections, access in itself does not ensure that we experience the remains of the past in a way that is satisfying and meaningful, particularly when faced with large volumes of information. Although catalogues and databases are practical tools for research, standard archival arrangement may be less than inviting for those without specific inquiries. Given this, many archives now engage in a range of curatorial activities to address the needs of different kinds of users who may include both researchers with specialised interests and more general audiences. Chapter 4 explores some of the screening platforms archives use and the ways in which they select, contextualise and interpret home movies in their collections. The selection of institutions aims to represent a range of collection types and curatorial activities including terrestrial exhibitions and screenings at a number of archives I visited in person, as well as web content. Examples include repositories with a national orientation (Ngā Taonga Sound and Vision, Deutsche Kinemathek, EYE Filmmuseum) and with a regional focus (Yorkshire Film Archive, Texas Archive of the Moving Image). The exhibition of home movies within the more specialised collections of Berlin's Jewish Museum and Ghent's museum of everyday life, Huis van Alijn, are also examined. The use of home movies within curated exhibitions, community screening programmes, social media, and participatory projects again reveals a reliance upon narrative and the affective qualities of images to create meaningful connections between private films and public audiences. Curation can condense film history into representative examples suitable for general viewing. The shift from archival classification to historiographic narrative has implications in terms of understanding the past. By offering specific interpretations of their documents, archives almost inevitably espouse a particular view of history at the expense of other possible perspectives. Furthermore, within certain contexts of presentation, the emotive

(Massumi 2002, 28) or is not differentiated from emotion, different approaches to the term affect assume that the significance of human responses involve more than, and cannot be reduced simply to, cognition, reasoning or intellect. 
appeal of home movies may outweigh other forms of meaning for viewers. The exhibition of home movie footage therefore offers an insightful example of how archival images may influence the shaping of collective memory.

CHAPTER FIVE closes this study with a brief speculation regarding a platform that has facilitated the return of home movies to the home. Popular video-sharing websites such as YouTube have afforded home movies a re-entry into the domestic sphere. Whilst this is arguably the most appropriate setting for watching home movies, courtesy of the World Wide Web audiences are now just as likely to comprise complete strangers from any corner of the globe as a film's original participants or other family members. Unlike the professional productions and curated spaces of the previous chapters, video-sharing platforms feature innumerable home movies without any kind of framing, context or even the most basic description. In this sense, viewers have an entirely free rein when it comes to interpreting films such as 'Home Movie 97177' on the Internet Archive. This might sound like a recipe for profound boredom, if 'Home Movie 97177' is in any way representative of the unwanted cultural flotsam and jetsam - unwanted, that is, by more official archives - that accumulates on participatory video sites, which are 'curated' by algorithms rather than human expertise, offering viewers selections based upon (usually) undisclosed data collected about their previous viewing choices. User comments attached to home movies on YouTube and the Internet Archive reveal a somewhat different story, however. Chapter 5 charts some of the directions the minds of viewers wander watching home movies adrift in cyberspace. The perfectly boring may seemingly be transformed into the perfectly boring with a little imagination and empathy on the part of viewers. Yet while meaninglessness in this context may have a favourable aspect, it also appears to have more unsettling possibilities. Affective engagement may take precedence over other kinds of responses to home movies. The use of amateur images to remember or imagine a 'Kodachrome-tinted' past seemingly more attractive than the present has repercussions for collective memory and understandings of history. 


\title{
Chapter 1
}

\section{The anatomy of boredom Medium without a message}

\begin{abstract}
The era of home movies had begun with a bang. Lord knows, there were plenty of cameras. Almost everyone in the family had one, except me. Hand-cranked cameras, spring-wound cameras. They swept the façades of buildings. They cut off heads and feet. No action ever followed through. There were sight gags that had nothing to do with Greek temples. The equipment was primitive. No variations in speed, no choice of lenses. The spring gave out in the middle of shots and the laboratories were equipped only to develop. Optical effects were out of the question. What was missing in these feverish stutterings? Discipline? Technique? A sustained idea?
\end{abstract}

- Jerome Hill (1972)

Boredom: the state of being weary and restless through lack of interest.

Writing during the Weimar Republic, Siegfried Kracauer bemoaned that even in leisure time one seldom finds 'the peace and quiet necessary to be as thoroughly bored with the world as it ultimately deserves' (1995, 332). Like many of his contemporaries in the early twentieth century, Kracauer displayed a pronounced skepticism towards the hyper-stimulation of modernity that 'assaults all the senses using every possible means' (324). 'Palaces of distraction', best exemplified by the opulent movie theatres of the time, and even radio broadcasts were geared to inducing a 'state of permanent receptivity' (332) in the modern urban citizen. Yet the sensorial bombardment of the modern city reaches saturation point. Moreover, distraction - at least in the form of novelty - has a brief shelf-life in terms of arousing curiosity. The new becomes commodified, no longer able to provoke wonder or surprise. Minus this shock appeal, commodities cease to excite, resulting in feelings of apathy, indifference, or a 'perception of a universal equality of things' amongst consumers (Petro 2002, 65). Bertrand Russell deplored the drug-like effects of excitement, whereby ever stronger stimuli are required to achieve a satisfactory thrill $(1930,62)$. In a similar vein, Henri Lefebvre would later conclude that the relentless search for novelty provokes 'lightning transitions from interest to tedium' $(1995,165-$ 
6). What Russell described as a 'special kind of boredom' (68) was a well-recognised phenomenon, widely held to have arisen with the modern urban experience of life.

Three decades after astonished audiences witnessed moving images at the first public screenings, a somewhat different cinematic novelty made its entry into modern life. With the release of $16 \mathrm{~mm}$ and $9.5 \mathrm{~mm}$ film equipment in 1923 , ordinary citizens (or more precisely, the sufficiently affluent among them) could at last record and screen movies in the comfort of their own homes. Instead of passive retreat into the vacuum of an illusory world, cinema now offered the hobbyist filmmaker exactly the kind of focused leisure activity Lefebvre would espouse in Critique of Everyday Life (1947) to lead one 'back towards the feeling of presence', reawakening senses presumably deadened by commercial cinema's ceaseless barrage of stimuli $(32,41-2)$. Not everyone was similarly enthused. Banal in subject and incompetent in execution, home movies quickly became an object of ridicule. Given the sheer number of home movies ever recorded, it may be assumed many amateurs took a great deal of pleasure in producing their own films. Nevertheless, if discourses that circulated about home movies are taken as an indication, comparable appreciation by spectators attuned to sensory excitement as part of their cinematic experience was far from unwavering.

The following pages offer a brief summary of the 'fall and rise' of home movies. This is not a history of the films themselves, but of their status in the eyes of (sometimes reluctant) viewers with regard to their entertainment or interest value. That is to say, this chapter does not seek to establish 'boring home movies' as a given entity in any factual sense; rather, it is concerned with the extent to which home movies have been perceived as inducers of boredom within public discourses about them. One could of course be forgiven for thinking that the boringness of home movies was an established fact during their half century of production. Certainly popular humour relied upon audiences making this kind of assumption, whilst the very existence of 'how-to' publications for amateurs implied there was a right and a wrong way to go about making home movies - and that many people presumably were doing the latter. It should be noted, however, that even though they were an object of public discussion, home movies were seldom viewed in public. It was not until home movies actually began to appear in places outside the home that popular opinion shifted considerably. Yet the more favourable public reception of home movies in recent years ultimately reveals itself as somewhat paradoxical. Appreciation of home movies soared at the very moment they suffered a loss of personal meaning by entering 
the public sphere. This new enthusiasm undoubtedly has as much to do with increased accessibility - and perhaps its happy combination with 'technostalgia' - as the movies themselves. One has to be able to see home movies after all in order to enjoy them, while their obsolescence defines them as artefacts imbued with the aura of a bygone era. Yet, as the analysis of boredom that concludes the chapter suggests, not being bored is very closely connected with the personal meaning any object may impart. Moreover, while the reputation of home movies has certainly improved, some of this praise has a more ambivalent character upon closer examination than might initially seem to be the case.

\section{Synonymous with boredom}

Professional cinema appeared to have come of age in the late silent and early sound periods. By comparison, home movies displayed a truculent disposition, obstinately refusing it seemed to evolve much beyond their initial faltering stammer. Admittedly, one of the Lumières' first films to screen in public, Le Repas de Bébé (1895), seemingly recorded - in the words of John Grierson - in the 'careless rapture' characteristic of the amateur $(1979,199)$, was a home movie of sorts, but the 1920s were not the 1890s. Audiences had come to expect something more than random shots of everyday life at the cinema. Seemingly out of step with the moment of their inception, home movies, lacking as they were in technical sophistication, appeared a poor relation to professional films of the era. Commentary on the subject was inclined to focus upon either the supposedly soporific effects of home movies, or the necessity to improve them in order to align with the sensibilities of spectators expected to tolerate the hapless cinematic efforts of friends or relations. Both humorists and those advising aspiring amateurs on good filmmaking technique appeared to concur that the average home movie possessed little to recommend it, beyond the perfect excuse for a quick nap, that is.

Sleep is precisely the recourse of the sole guest who manages to endure in its entirety an afterdinner screening of Robert Benchley's Home Movies (1940). This seven-minute short, directed by Basil Wrangell for MGM, is presented in the form of a faux instructional film in which Benchley, then a relatively well-known comedian, offers advice 'on the more technical points of picture making' so that those watching who wish to make their own home movies will 'know just how to go about it'. Although positioning himself as something of an expert on 'the art of making pictures in your own home', Benchley proves to be an inept bungler who insists any fault lies with the equipment rather than his inability to use it competently. 
The sitting room screening of last summer's vacation footage opens with a 'rather difficult shot to make' in which four people can be identified - in spite of 'the focus getting out of order' loading a vehicle parked in front of a house. Benchley attributes the poor clarity of this image to 'some negligence on the part of the camera manufacturer'. Likewise, in the following shot, this same group walk backwards into (rather than forwards out of) the house 'probably due to some fault in the reel'. Other gaffes include overexposed images (due to the use of a red filter), cut-off heads and other awkward framings that fail to capture their subject effectively (baby Joe, for example, is always obscured from view), erratic pans and tilts, inconsistent frame rates resulting in the appearance of excessively fast or slow motion, and largely empty shots minus any obvious point of interest. Furthermore, Benchley and his wife dispute the details of their holiday. Unable to identify where certain shots were taken or even what is going on in them, the couple fail to add any semblance of narrative coherence to the disjointed series of images that appear onscreen. Without this potential source of engagement, the assembled audience apparently finds Benchley's film sufficiently tedious to warrant slipping away before the end of the screening, with the exception of an elderly man who instead falls asleep, only to be roused when the lights are switched on, revealing an otherwise empty sitting room.

content unavailable

please consult print version

Fig. 1.1. Robert Benchley and his wife appear disconcerted by the disappearance of all but one of their guests during an after-dinner screening in Home Movies (1940).

This compendium of common mistakes relies of course upon the viewer's familiarity with the typical shortcomings of home movies for its humorous effect. In her discussion of Home Movies, Elizabeth Czach notes that the film also alludes to a more significant underlying problem with 
amateur recordings. It is not simply their clumsy execution that is inclined to bore viewers; a more fundamental difficulty precedes the actual filming. Home Movies opens with Benchley, caught seemingly off-guard, seated at an editing desk covered in a tangle of unspooled film stock, hinting that his filmmaking habits are far from professional. Struggling to find something to say, he informs the audience that 'you can take pictures of any interesting events that may happen to take place in your own household, if any interesting events ever do happen in your own household', the tone of his voice casting a significant shadow of doubt that this is likely to be the case. That is to say, in order to be able to film interesting events, they must actually occur in the first place $(2008,31-2)$. Nevertheless, having intimated that domestic activities may offer less-than-exciting filming opportunities, Benchley confidently assures viewers that on the occasion of screening his home movies to friends, 'all were genuinely entertained' (albeit 'several of them had to leave early to telephone and catch trains and things'). Like his unjustified faith in his own abilities, the discrepancy between Benchley's perception of his guests' enjoyment and their actual disgruntlement at being expected to sit through blurry shots of unidentified places contributes to the film's humour. Although he and his wife appear somewhat nonplussed by the unnoticed departure of their guests, Benchley seemingly remains convinced nonetheless that his slipshod handiwork is in fact worthy viewing (ibid.).

Popular belief that home movies suffered from a dearth of stimulating subject material and good filmmaking technique was clearly well established by 1940. Humour pertaining to the underwhelming nature of other people's home movies had already appeared more than a decade earlier, however. A Punch cartoon reprinted in Marion Gleason's Scenario Writing and Producing for the Amateur (1929) may be taken as an indication of just 'how quickly home movie production became synonymous with boredom', that is, within only a few years of the release of $16 \mathrm{~mm}$ equipment (Czach 2008, 29). The black-and-white cartoon depicts a well-dressed hostess poised beside a film projector. Smiling delightedly at her male guest, who is seen only in profile, she asks, 'Which shall we have first, my husband leaving for town in the new car, or my sister-in-law's children playing with their dolls' house?' The guest replies, presumably without enthusiasm, 'Well, which has the more exciting plot?' Behind the woman a second gentleman, possibly her husband, can be seen glancing rather anxiously over his glasses, perhaps to imply he is well versed in the discomfort imposed by his wife's insistence upon 'entertaining' visitors with her films. The guest's response suggests an awareness that these recordings of trivial domestic occurrences are unlikely to offer much in the way of entertainment value. To do so, they would 
need to have an 'exciting plot', something usually absent from home movies (Czach, ibid.). The unfavourable comparison with narrative cinema is further underlined by the context in which the cartoon was reprinted, one of the many advice manuals available to amateurs on how to improve their techniques for scripting, shooting and editing films.

content unavailable

please consult print version

Fig. 1.2. Punch cartoon reprinted in Marion Gleason's Scenario Writing and Producing for the Amateur (1929).

\section{Make your movie tell a story (and be sure to pan slowly)}

There were a great number of publications offering advice to amateurs in circulation from the 1920s onwards. Amateur cinéastes could enjoy regular installments of periodicals such as Home Movies (1934-1959) or the Amateur Cinema League's journal, Movie Makers (1926-1953), as well as guidebooks like Eastman Kodak's How to Make Good Movies (1938, subsequently reprinted and revised). Further to this, a plethora of other home movie-related paraphernalia was available including titling kits, records with music and sound effects suitable to accompany screenings, costumes, props and scripts. Such peripherals could apparently even be purchased together, combined as a boxed 'home movie kit' enabling keen amateurs to stage ready-made scenarios (Czach 2008, 22). What all these artefacts had in common was an emphasis upon the need to enliven home movies with a dramatic touch beyond what the humdrum of everyday activity was likely to provide. 
The discursive model of filmmaking formulated within the pages of advice literature targeted at the amateur hobby market has been widely discussed elsewhere, most notably in Patricia Zimmermann's Reel Families: A Social History of Amateur Film (1995). What is probably most pertinent to note here is the emergence of a persistent, overriding theme, namely, an assumption that 'home movies are badly made, and worse still, boring' (Czach 2008, 24, added emphasis). Responding to this belief, what Czach describes as a 'discourse of amelioration' counselled amateurs on the necessity to improve the standard of their filmmaking, a theme that endured for decades within the hobby press (only to be subsequently reformulated for home video-makers) (20-1). The advice provided was relatively consistent between publications, consequently, a handful of examples will suffice to illustrate the general ethos of such literature.

Junior Scenarios for Home Movies (1928), published by Eastman Kodak, provides a selection of twelve scenes based on familiar nursery rhymes or fairy stories (Little Miss Muffet, Red Riding Hood, Hansel and Gretel et cetera) prefaced with general advice on how to stage and record 'photoplays' at home. Having noted that children 'are frequently the reason why families buy home motion picture equipment', the introduction to the volume informs parents the 'next step beyond simply making movies of the children as they grow up is photographing them in playlets, so that their pictures will show them doing more interesting things than merely posing or performing unrelated actions' (added emphasis). Not only 'the most delightful records for parents to keep', junior photoplays stimulated children's imaginations and were 'best of all, great fun to make!' (5).

The introduction goes on to explain how to select suitable locations, types of costumes to be worn and ways to direct the audience's attention by utilising a range of different shot sizes from establishing shots to close ups (which are subsequently indicated in each scenario). Tips for producing visually pleasing compositions and making 'certain movie refinements', such as attending to continuity between scenes, the direction of the performers and basic editing techniques, are also included. Evidently, it is assumed the way to make home movies engaging is by following the conventions of narrative cinema. Whilst the booklet does not mention boredom specifically as an explicit concern, Junior Scenarios seems to imply that its suggestions for 'refinements' will ensure home movies are not only enjoyable to make, they will also (presumably) be a pleasure to watch afterwards. 


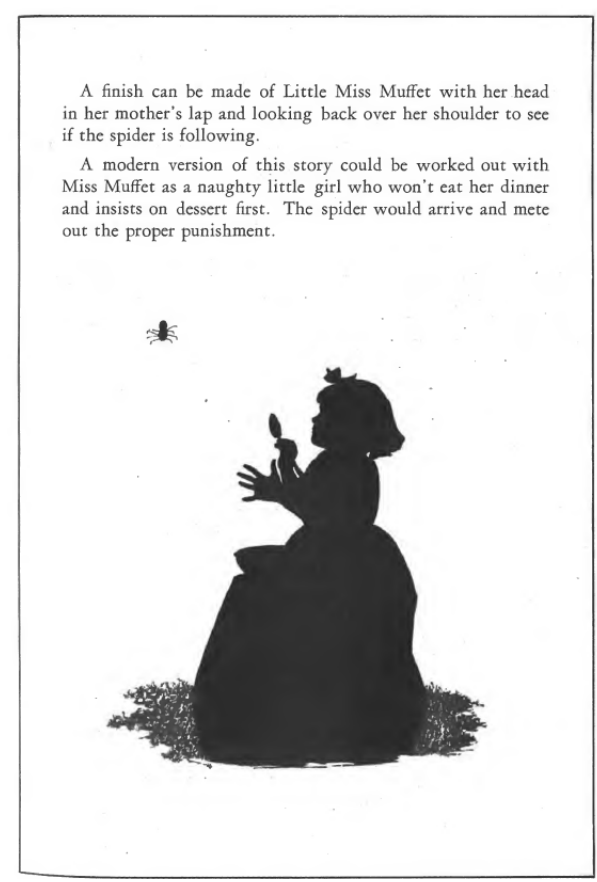

Fig. 1.3. Suggestions for filming 'Little Miss

Muffet' at home in Junior Scenarios for

Home Movies (Eastman Kodak 1928, 19).

Not all publications were as detailed or imaginative in their recommendations; some merely advised how to improve basic shooting technique or use various filmmaking gadgets. The instructional film, an appropriately cinematic variation on the guidebook or magazine article, offered the added bonus of being able to illustrate the benefits of 'good technique' directly onscreen. A 1963 Kodak film, Using the Camera, utilises a split screen effect to demonstrate the difference in image quality between a shot of the same subject recorded, for example, by a handheld camera and one placed on a tripod. Seemingly concerned the instructional film format might itself prove boring, Your Movie Camera and How to Use It (Paul Burnford 1948) employs a more lighthearted approach. The comic mishaps of a proud camera buyer who refuses to read the instruction manual before trying out his new toy is contrasted with the 'correct way' to record images and scenes explained by a friend-cum-narrator. The film nonetheless imparts fairly standard filmmaking advice: use a tripod, pan slowly, make your shots interesting... and, most important of all, read your camera manufacturer's guide.

Regardless of the specificity of advice or its mode of presentation, there appeared to be one overall purpose in mind, summed up in the title of an article in a 1944 issue of Home Movies magazine: 'Make Your Movie Tell a Story'. Good cinematography alone was not enough to sustain a film; individual scenes 'must be strung together in an attractive pattern'. Without continuity, 'that far too little understood cinematic element', even a simple sequence of shots, such as those of a child eating breakfast followed by her riding a tricycle on the sidewalk, would 
not provide a 'complete and comprehensive tale', leaving audiences to 'wonder how it all happened' (Foster 1944, 13). Such difficulties could be overcome by planning films carefully in advance, ideally drafting a script or scenario initially on paper.

This kind of advice ignores of course the likelihood that participants and spectators were one and the same. Instead, someone from outside the immediate family circle is positioned as the intended audience of such scenes. Family members were likely to be able to negotiate any absence of continuity, filling the gaps between images from memory (Odin 2008, 260) or familiarity with the locations and daily habits of their relations. Viewers without this knowledge might conceivably be frustrated in the manner suggested. In this respect, humour about home movies, such as the Punch cartoon described above, actually demonstrates a more insightful response to their alleged shortcomings. That is to say, such humour recognises what is a dull viewing experience for other people may nevertheless be quite compelling for a film's participants. Infatuation with their own home movies may even render family members oblivious to the boredom their films inflict upon others, $\grave{a} l a$ Benchley and his wife.

\section{Medium without a message}

Although offering similar advice to other instructional films or guide literature, How to Make Home Movies Your Friends Will Want to See Twice (c.1970s) recognises a distinction between types of viewers in its title. To maintain the interest of friends, so it alludes, a more polished film is required compared with what presumably might be acceptable to family members who appear in the footage. Nevertheless, the short film's suggestions for dramatising a child's birthday party and a family camping trip are arguably less than compelling, as well as somewhat contradictory. (Action should be candid or natural, for example, but you may also want to script it.) Given its title, the film's advice does at least appear less misplaced. It might be wondered how many home moviemakers would actually want to record their child's birthday utilising such an intrusive number of different camera set ups (31 in the example given) on even one occasion. Be that as it may, the possibility that 'fun to make' and 'fun (for other people) to watch' might not neatly coincide does not appear to have been a major consideration for those advising on how to advance the art of home moviemaking.

Interestingly, the ornately explicit title of a 1972 guidebook added family members to those likely to be afflicted by home movie-induced boredom. In How to Make Exciting Home Movies 
\& Stop Boring Your Friends and Relatives, the authors, Ed and Dodi Schultz, present an argument that home audiences, due to their familiarity with television and New Hollywood cinema, had become more sophisticated viewers by the 1970s. Consequently, not only friends but also relatives would expect, if not exactly a quasi-professional production, at least something reasonably entertaining. That is to say, 'they don't expect to be bored' (x-xi). Rather less concerned with technical imperfections than other advice literature, How to Make Exciting Home Movies nevertheless describes the film without a story as 'the anatomy of boredom', good storytelling being (in the authors' opinion) the most important as well as most often neglected aspect of home moviemaking. In other words, the problem of home movies is one of a 'medium without a message'. While most people can sit 'happily enthralled' for two hours at a cinema, these same viewers are liable to 'find an acute attack of sleeping sickness coming on halfway through a ten-minute home movie' (14). In order to be engaging, home movies should impart a message of some kind or, better still, have an exciting plot.

Over the course of nearly five decades popular notions about home movies proved as resistant to change as the films themselves. For the most part, the discourse of amelioration seemingly fell on deaf ears, failing to resonate with the majority of home moviemakers who continued to make films that lacked technical refinement and did not tell a coherent story or even feature the most basic semblance of continuity. During the 1970s a very different kind of discourse arose on the subject of home movies, one that recognised and celebrated the specificity of their cinematic form rather than sought to change it.

\section{The golden age of home movies}

The 1970s proved something of a watershed as far as critical understandings of home movies were concerned. Anthropologists led the way. In 1975 Richard Chalfen published an article describing a method of examining 'pictures that are made as part of everyday life' in terms of their function as 'home-mode communication' (19). Noting 'it is a pointed criticism of a budding young filmmaker to say that his rushes look like home-movies', Chalfen argued that whilst home-mode images are not valued for their artistic merits, they have nevertheless been devalued for their non-artistic attributes. For the intended audiences however, home movies are valuable due to the personal relationship between images and viewers, not a film's technical sophistication or artistic aspirations. Chalfen concluded that the 'complex formal organisation' 
characteristic of mass visual communications for impersonal, heterogeneous audiences is therefore unnecessary within intimate social contexts of circulation (20).

From this new perspective, it became clear that successful home-mode communication actually had little to do with the kind of disciplined filmmaking advocated by publications such as How to Make Exciting Home Movies. On this note, Chalfen argued that when recording 'personal images of reality' $(1987,135)$ spontaneity was valued first and foremost. Carefully planning a film amounted to an 'undesirable conflict' with this in the minds of home moviemakers. For family participants, 'planning a home movie just did not make sense'; it seemed too 'contrived' (51). More importantly perhaps, attention to conventional film aesthetics, particularly if it involved editing, was likely to 'represent an unwelcome intrusion of 'work' into what is classified by most people as 'play" (55). Making a 'good' movie as such was neither important, nor even necessarily desirable.

Recognition that domestic images, which might appear banal, repetitive and disorganised to an outsider, are nonetheless important to certain groups of people, such as members of a family or other small community of viewers, clearly distinguishes Chalfen's work from earlier (mis)interpretations of the relationship between the form and function of home movies. In other words, home movies can abound with instances of 'poor technique' (according to the standards of professional filmmaking) and yet remain perfectly functional within their intended settings, discontinuous sequences of images accommodating the needs of small, private audiences quite adequately.

Home Movie: An American Folk Art, a twenty-minute documentary produced under the auspices of the Smithsonian Institute, screened at the 1975 Festival of American Folklife. Made by students Ernst Star and Steven Zeitlin, Home Movie considers how families choose to record themselves and use their films to recall the past at a later date. The film comprises excerpts of home movies and interviews with filmmakers or their relatives (discussed further in chapter 3). A montage of images shown in the film roughly corresponds to the typical range of subjects Chalfen identified as exemplifying white middle-class filmmaking. Vacation activities, holidays (particularly Christmas), special events (birthdays, weddings, outings) and other (often not quite everyday) aspects of domestic life (playing in the snow, for example) $(1975,24)$ were all deemed suitably worthy subjects to become an index of 'good times' (1987, 138). Seemingly 
with this in mind, Zeitlin, who narrates Home Movie, concludes that 'by attempting to preserve that which is most beautiful in his life, the home moviemaker might be seen as partaking in what seems to be a universal desire to create a golden age', or more specifically, what might later serve as a private golden age for individual families. Despite its nostalgic overtones, Star and Zeitlin's documentary, like Chalfen's work, represented a significant step forward in terms of a critical reappraisal of home movies as a personal image-making practice with its own unique form and purpose, quite distinct from more public modes of visual communication. The golden age was no longer a private one. Inside a tent at the Smithsonian's annual festival, the celebration of home movies entered the public realm.

Calls such as that issued by Fred Camper in 'Some Notes on the Home Movie' (1986) to rewrite film history to include a more representative range of filmmaking practices, as well as develop archival collections that would facilitate scholarship in the field, gained momentum during the final decades of the twentieth century. Obsolescence proved a decisive factor. In response to the demise of small-gauge formats, many archives not only broadened their acquisition criteria, but also actively solicited amateur works through organised salvage operations to rescue films that might otherwise be discarded, lost or damaged. In turn, this wealth of resources has enabled an ever growing number of scholars, including Patricia Zimmermann, Roger Odin, Heather Norris Nicholson, Alexandra Schneider and Efrén Cuevas amongst many others, to study home movies as private media practices and micro-histories documenting personal experiences and historical change in various national and regional contexts.

That home movies offer only certain kinds of historical evidence heavily inscribed with the ideological attitudes of their makers has done little to temper the current spate of enthusiasm for them as objects of analysis. Quite the contrary, their technical limitations and often parochial content have in fact distinguished them as a distinctive cinematic form, one that differs from other modes of filmmaking and more official record-keeping practices. What resonates most strongly within contemporary literature is an overarching belief that home movies are worthy, valuable and interesting historical artefacts. In her seminal work Reel Families (1995), Zimmermann quotes from a 1956 Parents Magazine that 'it isn't the beauty of the place that makes the picture good-it's your family's response to it' (135). Sixty years on, a scholar's response makes a movie 'good': good history, good folk art, good social praxis, or more 
precisely, a good source for researchers, albeit one partial and contingent. Nor is it only scholars displaying an interest in home movies. Appreciation of small-gauge cinema has expanded beyond academic circles to popular audiences. Events such as Home Movie Day (established 2002), which is now held at local venues around the world, demonstrate more general public interest in the history of private filmmaking. In the opening decades of the twenty-first century the celebratory mood that surfaced tentatively during the 1970s is very much in full swing.

\section{Long and boring, or uniquely fascinating?}

In the rush to extol the merits of amateur filmmaking, boredom as a potential viewing difficulty has not proved to be an overriding concern. This is not to say that there are no suggestions to this effect (intentional or otherwise) to be found within the work of certain scholars. In fact, it may be quite illuminating to consider a few examples. In reference to the early work of Chalfen and Zimmermann, Ryan Shand makes the perhaps unexpected suggestion (given their vanguard status in amateur film studies) that although theoretically 'excited by the possibilities of individualist filmmaking', both authors appear in fact 'ultimately disappointed by the films they find' $(2008,46)$. By what reasoning does Shand reach this conclusion? Neither author discusses examples of actual films in much breadth or detail. Both are largely critical of the ideological domination of leisure pursuits by publications promoting a prescriptive discourse encouraging amateurs to reproduce the aesthetics of commercial narrative cinema at home, albeit for different reasons. Chalfen notes, for example, that amateurs did in fact usually ignore such advice, his frustration stemming primarily from the rather limited anthropological data home movies appear to offer. Having studied the range of typical subject material and the behaviour patterns of participants, he concludes:

\footnotetext{
The structure of selection and manipulation in home movies rules out the possibility that home movies document a reality of everyday life. Instead, we find a special reality documented in the home movie. Commonplace behaviour, mundane activities, and everyday happenings do not get recorded. Just as we can not easily see our own culture, we tend not to find it with our cameras' $(1987,69)$.
}

Evidently, this 'special reality' is deemed to be of lesser interest than more regular activities, at least from an ethnographic perspective. Granted 'uninteresting' and 'boring' do not necessarily coincide exactly as perceptions of objects, yet the scant cultural insight home movies provide in comparison with what they could theoretically offer is discouraging to the researcher. On this particular point, Chalfen refers to a rather unusual advice column entitled 'A Good Home 
Movie is Not Necessarily 'Well Made', which argued 'there are nevertheless dozens of dreary routines that you might someday be glad you filmed' (ibid., 61). Whether or not the majority of filmmakers would agree in hindsight is open to conjecture. Nonetheless, ethnographer could seemingly be substituted for filmmaker as far as subsequent appreciation is concerned. While the 'special reality' of home movies might indicate much about domestic communication practices, the paucity of 'dreary routines' is a source of disappointment for anyone wanting to know more about everyday life in times gone by.

Chalfen is nonetheless careful to underline that families in his study saw moviemaking as a 'fun' activity (132-3), reiterating the popular view that participants were enamoured with the production of images of themselves. In this sense, advice for 'better home movies', which Zimmermann quotes, suggesting that 'a mediocre movie is one that only your family can enjoy' (1995, 126) bears a certain kind of relevance vis-à-vis the (disheartened) researcher of human daily habits. Films need not be 'well made' as such, but should at least aspire to rise above endless shots of family members simply waving at the camera, if they are to be of interest to anyone else. Yet Zimmermann's disillusionment with home movies lies in quite a different direction, namely that amateur filmmaking as a practice came essentially (in her view) to mean home movies.

Referring to a range of publications and ephemera, Zimmermann argues that amateur filmmaking was 'gradually squeezed into the nuclear family' becoming an 'innocuous, frivolous' and 'almost silly' hobby $(121,157)$. Whilst admitting 'amateur cameras did, in a very minimal way, democratize media production', she concludes her study with the hope that the 'future may liberate [amateur filmmaking] as a more accessible and meaningful form of personal expression and social and political intervention' (157). Given this position, Shand suggests that Zimmermann, along with Chalfen, might be considered 'as working with a less subversive and more romantic tendency' (46). That is to say, both writers sought to find an inspirational source of personal expression, one that captures the breadth of private experience or individualist impulses in all their intricacy and vagaries. Instead, they were faced with works that appeared little more than formulaic exercises in white middle-class conservatism. In short, films that had the potential to be interesting but quite simply weren't.

In view of the narrow selection of empirical examples of filmmaking upon which Chalfen and 
Zimmermann draw, the applicability of their conclusions to the general realm of amateur practice is questionable. Subsequent research (including Norris Nicholson's and my own) has uncovered examples that document activities such as work (paid or unpaid), which obviously exceed the boundaries of Chalfen's categories of subjects deemed appropriate for home movies. The circumscribed nature of Chalfen's study aside, its principal significance in terms of discourses about boredom is obviously its recognition of who is likely to be bored:

The frequent cartoon of "reluctant" and bored viewers of home movies depicts an "inappropriate choice" of participants for an exhibition event. In other words, the distressed viewer is outside the appropriate collection of participants (58).

Home movies were made for their participants and other intimately connected viewers to watch, not outsiders. Acquaintances who do not appear in films and researchers looking for something that was not deemed important to record are 'inappropriate' viewers. This recognition also features in the work of Vivian Sobchack (1999) and Roger Odin (2008). Referring to the work of Jean-Pierre Meunier, Sobchack argues that the home movie's structure of identification is 'essentially one of evocation', that is, images act as a mnemonic device evoking an absent past and are not therefore 'apprehended for themselves' (247). While it is of course possible to use someone else's images to engage in an equivalent act of reverie, the filmsouvenir that recalls an event not immediately familiar to the viewer is more likely to bore than one that conjures a recognisable past (248). The diegesis exists in the minds of spectators - if they choose to engage actively in its construction - not the film itself. The home movie does not seek to inform viewers (as does a documentary) but to enable them to remember. For this reason, Odin describes the home movie as a counter-document, its silence and incompleteness encouraging the recounting of family history as supplementary narration at screenings. Any attempt to read the home movie as a document therefore violates its original function and is not without its difficulties. The ritualised and socially sanctioned behaviours that appear in so many home recordings may reveal relatively little about their subjects and become wearisome to those watching for purposes unrelated to private recollection (260-1).

Most scholars have acknowledged boredom only peripherally, if at all, in their examinations of home movies. Unsurprisingly, the majority of those writing about amateur film have been more keen to embrace its points of interest than any absence of such. Elizabeth Czach's research, which attempts to bridge earlier discourses about boring home movies and their subsequent 
celebration, is an exception in this respect. Her doctoral dissertation, Careless Rapture (2008), includes perhaps the most comprehensive discussion to date of the relationship between home movies and their perceived boringness. As might be expected, she describes in some detail various examples of disparaging attitudes towards typical amateur filmmaking techniques (including some of those mentioned above), juxtaposing these against discussions of the specific functionality of home movie form. Consequently, she arrives at the now orthodox position that home movies, despite 'their reputation for being long and boring' (13), are actually 'fascinating precisely for the manner in which they demonstrate their own unique rhetorical qualities' (256). She does not specify to whom exactly this statement might apply (beyond presumably herself). The readers of academic film texts (perhaps rather more than ethnographers, for example) might be assumed to feature amongst those likely to find home movie aesthetics interesting.

Moreover, having dismissed 'boring home movie' discourses as premised upon inappropriate comparisons with narrative cinema, Czach appears to assume events such as Home Movie Day, along with the increase in academic studies, are self-evident confirmation that home movies have indeed become a source of fascination to a wider community (38-9). This kind of assumption, which might readily be accepted at face value, nonetheless warrants slightly closer examination. Leaving aside for the moment popular interest in home movies, two recent academic monographs on the subject illustrate some rather curious properties of the contemporary valorization of amateur film.

\section{'even if their dramatic merit and social vision is slight'}

In Amateur Film: Meaning and Practice 1927-77 (2012) Heather Norris Nicholson surveys filmmaking in the northwest of England over a fifty-year period, including ciné-club formation, the British hobby press, and community-oriented and private modes of production. Despite this broad scope (or perhaps because of it), the number of actual films described in any detail is fairly limited. In fact, where specific examples are cited at all, they are often simply listed in endnotes, thereby demonstrating their existence, should any reader care to go to the effort of seeking them out for subsequent appraisal. While this clearly negates the ponderous task of describing in words what in many instances may very well be relatively mundane visual documents of arguably limited appeal, this approach does tend to shift attention away from film history per se in favour of social history. Reduced to brief descriptions of their principal subjects, 
films become historical evidence of the places, objects and activities they record, valued first and foremost for their content rather than their cinematic form. On this note, Norris Nicholson suggests that by recording on location ciné-clubs ultimately endowed films 'with historical significance even if their dramatic merit and social vision is slight' (213). In other words, the primary point of interest of an amateur production may be the incidental details it contains, not the film itself.

Norris Nicholson's emphasis upon evidential value is not unusual. ${ }^{4}$ Amateur footage is often deployed precisely in this way, recalling Umberto Eco's distinction between interpreting a text to discover 'something about its nature' and using a text 'in order to get something else' from it $(1991,57)$. It might of course be noted, as does Odin, that viewing home movies as documents necessarily involves using them for purposes that are essentially alien to the films themselves. Yet this need not limit critical interpretation. On the contrary, from an analytical perspective, separating home movies and private memories can be productive, enabling viewers to concentrate on other aspects of the films $(2008,261-3)$. Yet by focusing upon the historical value of content rather than the formal qualities of films, Norris Nicholson seems to imply inadvertently that the latter may well be in short supply; that is to say, amateur films display a pronounced lack of quality. Given this, her discussion creates a general impression that amateur films are interesting as historical evidence, but possibly somewhat dull as cinema.

Another recent monograph on the subject, Charles Tepperman's Amateur Cinema: The Rise of North American Moviemaking, 1923-1960 (2014) is much more concerned with the aesthetics of amateur production. Noting at the outset that ' $[\mathrm{w}]$ hen we think about amateur cinema, it is perhaps the rough home movies of birthdays and family vacations that come first to mind', Tepperman purposefully chooses a somewhat different object, the work of 'advanced amateurs' (16). Although usually shot on the same small-gauge formats as home movies, advanced amateur films display a more polished aesthetic and narrative or thematic continuity. Perhaps most significantly, such films were frequently intended for exhibition outside the home (22). By limiting his scope to these exemplary amateur works, Tepperman effectively illuminates a cultural middle ground between the casual snap-shooters of home movies and professional cinema, a distinction that is not necessarily clarified elsewhere. (Ishizuka and Zimmermann's

4 In his overview of approaches to amateur film, Shand discusses their use as visual evidence of the past at some length $(2008,46-51)$. Examples of home movie footage used as evidence within other productions are also discussed in chapter 3 . 
anthology, Mining the Home Movie (2008), for example, includes some discussion of amateur films that may have been intended for a wider audience than a domestic one.) With the exception of the works of a select number of avant-garde filmmakers (such as Stan Brakhage and Maya Deren), advanced amateur practices have been as regularly overlooked as home movies by film historians, perhaps even more so. Consequently, Tepperman's study makes a valuable contribution to amateur film scholarship by delving at length into yet another dimension of a nascent field. The parameters of the study do hint - quite without any intention to do so - at an alternative strategy for negotiating the problem of countless 'boring films', that is, simply to ignore altogether the more amateurish of amateur efforts. Whilst both authors - like so many others engaged in the recent celebration of amateur film - doubtless intend to valorize amateurism as academically worthy, they also arguably intimate that the majority of examples of non-professional cinema are perhaps less than interesting for both viewer and reader alike.

A celebratory ethos is more evident (and arguably more successful) within the numerous short articles that have been published on the subject. Within a space necessarily restricted in scope, the selection of one or two examples that suffice to illustrate salient points of interest is by far the most common technique for discussing amateur film. In this way, the film(s) chosen need not be representative of home movies more generally. Rather, a film may be selected on the basis that it adequately demonstrates whatever features are deemed of particular relevance to the theme under discussion. In such circumstances, a film that is unusually interesting in some respect becomes an obvious choice. Home movies that are overly monotonous, technically poor (even by amateur standards) or contain little in the way of historical information can be conveniently put aside for such exercises. That is to say, the film that is likely to bore (the researcher or reader) due to its very boringness can be overlooked in favour of one that is deemed to be more interesting. But what exactly determines this difference - if indeed there is one - between the 'boring film' and the 'interesting film'? What precisely constitutes boringness in the realm of film watching? In order to think about this, it is first necessary to consider a broader and more fundamental question: what is boredom?

\section{Boredom, modernity and the vigorous pursuit of excitement}

An emerging field, contemporary 'boredom studies' has built upon the observations of those writing about the subject during the twentieth century. Works such as Elizabeth Goodstein's Experience Without Qualities (2005) have traced a discursive history of boredom, suggesting it is 
possible to chart its interpretation as a form of spiritual malaise (Gardiner 2012, 40). In $A$ Philosophy of Boredom (2005), Lars Svendsen describes the condition as 'the 'privilege' of modern man' not so much to imply that boredom did not exist prior to modernity, but rather that it 'lost its exclusiveness' as leisure time became more widespread throughout society (212). ${ }^{5}$ Moreover, he suggests boredom found an appropriate mode of expression with the advent of Romanticism, before which 'it seems to have been a marginal phenomenon, reserved for monks and the nobility' (21). More specifically, Walter Benjamin claimed boredom was experienced in 'epidemic proportions' from the 1840s onwards (1999, 108). Perhaps more insightful is Bertrand Russell's suggestion that given the isolation of premodern village life, it is likely 'we are less bored than our ancestors were, but we are more afraid of boredom' (1930, 58). That is to say, in the modern world boredom was no longer accepted as 'the natural lot of man' but could (and should) be avoided via a 'sufficiently vigorous pursuit of excitement' (60). It might be concluded therefore that it is only with the rise of modernity that boredom assumes the proportions of a pervasive problem to be remedied.

What is the nature of this supposedly modern problem? If asked, few people today would probably claim they do not ever feel bored. Likewise, most people can presumably recognise when they are bored. Isolating the general features of boredom is perhaps a little more complex, however. Returning to the epigraph at the beginning of this chapter, Merriam-Webster's definition suggests there are two significant aspects to boredom:

the state of being weary and restless through lack of interest

Firstly, boredom appears to be characterised by a certain lassitude and inattentiveness. Failing to fix upon an adequately engaging object, the sufferer's mind roams, desperately seeking something that may arouse curiosity. Feelings of irritation, impatience, apathy or fatigue may accompany this dearth of stimulation. What the bored person desperately desires is a diversion of some kind.

The perpetual search for sources of distraction in order to stave off the dreaded affliction is a prominent, recurring feature of discussions about boredom and modernity. In order to avoid

5 It is notable that the word boredom is in fact not recorded in the English language before the 1760s, while the German word Langeweile appears only slightly earlier. Svendsen also notes the earlier existence of other related words in various languages, but does not regard these entirely synonymous with the usage of the word boredom in English (24). Given its etymology, boredom might reasonably be presumed to have emerged as a prevalent cause for concern only since the eighteenth century. 
being bored, one must find some object that will satisfactorily retain one's attention. In other words, this object must be interesting to the subject who would otherwise suffer boredom. According to the above definition, interest, or rather its absence, is the second aspect of boredom. Indeed, in the common sense of everyday language something that is boring is essentially held to be not interesting, while a thing that is interesting is presumably not boring. It is difficult to talk of one without at least indirectly invoking the other. ${ }^{6}$ Discourses about home movies are in fact a good example of this. Popular belief home movies are boring has seemingly been replaced by a conviction that they are indeed interesting. On the surface, this seems to suggest home movies must be taken as one or the other. The possibility they could be both boring and interesting (or perhaps even interesting because they are boring) is seldom articulated within the same space. Humorists did of course acknowledge that home movies could be of interest to those who made them and boring to 'inappropriate' viewers (to use Chalfen's term). For their effect, Robert Benchley's Home Movies or the Punch cartoon discussed earlier rely upon an audience's acceptance that home movies actually are boring. That is to say, in order to find such humour amusing we must identify with the position of the diegetic viewers who are bored, not the filmmakers who fail to recognise that their movies are tedious to watch; the films are clumsy and dull, the makers deluded that they are offering anything resembling entertainment for their guests. The possibility that home moviemaking could be a fulfilling and pleasurable pastime from the point of view of the participants - one that might even alleviate boredom - is largely beside the point.

Other people's home movies were of course just one possible source of boredom. Modernity supplied many others in the form of monotonous work routines and empty leisure hours. Situationist philosopher Raoul Vaneigem even suggested that with the comforts of modern technology the risk of dying of starvation came to be replaced with that of dying of boredom (Moran 2003, 170)..$^{7}$ While home movie technology was allegedly part of the problem, so was commodity culture more generally. The 'cult of distraction' favoured consumption and spectacle that was transient and superficial, Kracauer complaining that 'stimulations of the senses succeed one another with such rapidity that there is no room left between for even the slightest

6 Svendsen concludes that the word boring is 'bound up' with the word interesting, the use of both words becoming widespread at roughly the same time and increasing in frequency at a similar rate (28). According to the Oxford English Dictionary, the first recorded usage of the words 'interesting' and 'bore' (as a verb) actually occur in the same year, 1768 (Gamsby 2012, 94).

7 This suggestion is perhaps rather less facetious than it appears. Recent research in the field of psychology has confirmed there may in fact be a correlation between an individual's propensity to experience boredom and early mortality, perhaps due to the kinds of distractions sought to alleviate the condition (Weir 2013). 
contemplation' (1995, 326). In such circumstances, blasé indifference forms a suitable defence screen against overstimulation (Petro 2002, 64). A culture of distraction is therefore both a compensatory response to and further occasion for boredom.

\section{Information overload and the deficiency of meaning}

Andrew Benjamin describes distraction as 'an organizing mood of modernity' $(2005,159)$. Yet capitalist logic requires both workers and consumers to remain attentive, either to their duties or to available commodities. To this extent, attentiveness became a fundamental modern issue. As Jonathan Crary notes, attention and distraction are in fact intimately linked: attentiveness requires filtering out competing distractions in order to make a selection from a 'larger background of possible attractions'. To be attentive to one thing is to be inattentive to others. Perception, according to Crary, is therefore an activity of exclusion (1999, 24). Anything that interferes with this filtering process is effectively 'noise', either nonsense or simply information that is irrelevant or counterproductive in a given context (Klapp 1986, 127). When reception, as in Benjamin's words, occurs 'in a state of distraction', the individual's ability to ignore undesirable noise may be thwarted. Sensory overload, like sensory deprivation, is conducive to inattentiveness (Petro 2002, 20). Boredom typically transpires at either end of the sensory spectrum; that is to say, it occurs at the extremes of experience (Schneider 2016, 85).

Perhaps the most detailed model accounting for this dynamic in modern societies was developed by the sociologist Orrin Klapp. On an axis of under-stimulation (banality) and overload (noise), there are two ways of being bored:

One is by redundancy, that is, too much information that is so similar that it tells little that is interesting and new. The other is by overload of variety so insignificant and noisy that it tells little of interest and does not fit into a meaningful pattern $(1986,118)$.

In this model boredom represents 'a signal that one has veered too far either way', that is, towards monotonous sameness or chaotic confusion of stimuli (121). Klapp complicates this schema, however, noting that there is in fact also 'good' redundancy in the form of customs, rituals or familiar objects, which 'is most often unappreciated and even misunderstood' (118).

Looking at its functions, one sees that redundancy is an exceedingly important component of social life [providing] the basis of continuity as memory and culture; of communication as the meaning of 
symbols; of resonance in relations with others... of identity as playback of memories telling who one was (119-20).

This description is noticeably reminiscent of an anthropological description of a family home movie screening, the function of which is, like other forms of 'good' redundancy, to 'give a feeling of closeness to those who share it' and is therefore not boring (118-20). Yet the same films might well appear repetitive and banal, or random and insignificant, viewed under different conditions, in which case they are quite likely to bore spectators. What acts as information in one context may simply represent noise and confusion in another (127).

Just as redundancy may be reassuring, variety also has a positive function, inspiring discovery, innovation and progress (118-20). In other words, we are likely to be attentive to experiences we find meaningful in some respect. Interest, in Klapp's view, transpires between the two poles of boredom or, to rearrange these terms, meaningfulness is what distinguishes the interesting from the boring. The prescience of Klapp's hypothesis (made in 1986) that 'although the amount of information in modern culture has increased vastly, the meaning of that information has not' (126) is striking over thirty years later. As the Internet floods society with quantities of information that dwarf beyond all measure individual human capacity even 'to wade through it all' (van Leeuwen 2009, 188), much less make intelligible sense of it, the distinction between significant and insignificant blurs. In this regard, Svendsen suggests that in modernity 'everything becomes equally interesting and as a result equally boring' (61). Boredom might even be viewed as a 'default setting' or 'affectual base-line' so familiar that we must be jolted in order to recognise 'the cosy embrace of Benjamin's 'warm grey cloth". This 'comfortable' psychic layer 'envelops and benumbs', insulating the wearer against uncertainties but at the expense of a fulfilling engagement with life, according to Michael Gardiner (2012, 50, 56). From this perspective, it could be construed that our awareness of boredom is perhaps not so immediate after all, should we forget the colourful lining of our reassuring security blanket.

Benjamin considered the passive consumption of information an aspect of modernity that eroded meaningful experience $(2007,88-9)$. In the twenty-first century, Svendsen attributes this problem to modern technology more generally. As technology 'more and more makes us passive observers and consumers, and less and less active players', a 'meaning deficit' develops (29). He continues: 
Human beings are addicted to meaning. We all have a great problem: Our lives must have some sort of content. We cannot bear to live our lives without some sort of content that we can see as constituting a meaning. Meaninglessness is boring... Boredom can be understood as a discomfort which communicates that the need for meaning is not being satisfied. In order to remove this discomfort, we attack the symptoms rather than the disease itself, and search for all sorts of meaningsurrogates (30).

Palliative distractions ('meaning-surrogates') ward off the immediate discomfort. This does not resolve the issue of boredom indefinitely, however. Meaning in such instances is presumably quickly exhausted or found insufficient. Lefebvre seemingly had this in mind when he asked, 'How does it come about when something is interesting, boredom is always lurking in the background? How incredibly swiftly does the one turn into the other!' (1995, 194-5). For Svendsen, boredom ultimately results from an absence of personal meaning (31). This suggests a very specific kind of subject-object relation, one that exceeds passing curiosity. In comparison with superficial distractions, experiences that are perceived to be personally meaningful are likely to hold the individual's attention for a longer period of time. Whilst the novelty of mere spectacle wanes quickly, experiences that resonate with the individual tend not only to arouse interest but also to sustain it.

\section{Cinematic time and viewer engagement}

What separates meaningful experience from superficial distraction in the quest to escape boredom? There is no simple answer. What is meaningful to one person may not be so to another. Good forms of redundancy such as those associated with private memories, according to Klapp's model, provide one form of resonance, but this is certainly not the only type of personally meaningful experience. If human interest did not extend beyond an individual's firsthand encounters, the only films in existence, for example, would most likely be home movies or videos. This is clearly not the case. Nor is film watching an activity solely motivated by a need for short-term respite from boredom via spectacle and excitement. While simple distraction may account for a significant portion of consumption, there are obviously many types of films and therefore many different viewing experiences. Art films and documentaries are less likely to afford novelty in the form of spectacle (such as innovative special effects), yet still attract audiences, albeit on a smaller scale in comparison with Hollywood blockbusters. The viewers of such films are presumably not seeking suspenseful entertainment. 'Exciting' is probably not the first adjective that springs to mind to describe the experience of watching a 
film by Carl Theodor Dreyer or Ingmar Bergman, for example, nor a three-hour documentary by Frederick Wiseman. Unless exciting is understood in this instance to equate to intellectually or emotionally stimulating (or perhaps emotionally draining), 'meaningful' or 'boring' depending upon whether or not the film resonates with the viewer - would seem to be more likely descriptors. The film that neither excites nor bores presumably interests. In other words, the interesting film is one that the viewer regards sufficiently meaningful to maintain his or her attention for the span of its duration.

Duration has not featured prominently within this discussion so far, yet obviously has a significant relationship with boredom. Time is in fact integral to boredom. In order to become bored by something, time must pass. More precisely, the thing that bores imposes an experience of passing time upon us. Cinema, a time-based medium, is one such thing. If a film bores us, it inflicts this experience for a fixed duration. In his discussion of cinema and boredom, Richard Misek draws a comparison between still photography and film in order to demonstrate this point. Should a photographic exhibition fail to arouse our interest, we need not dwell upon any particular image. We can simply pass on to the next one to avoid becoming bored. If, however, we attend the exhibition with someone who insists upon studying each image at length, the duration of the experience is no longer under our control, hence we may become bored. Similarly, when watching a film at a cinema the length of the experience is not determined by us, unless of course we become so bored we walk out $(2010,778)$. In this sense, whilst a photograph may seem boring, film has a kind of precedence as far as experiencing boredom in relation to an object is concerned.

At domestic screenings families could of course control the duration of a screening event, selecting as many or as few films as they wanted to watch on any given occasion. Interest was maintained via personal meaning arising in the form of 'good' redundancy. Although homemode cinema admittedly did offer the novelty of seeing oneself onscreen, for participants and their relatives, home screenings were primarily concerned with private memories and the strengthening of familial bonds. As noted above, public discussion about home movies during their time of production consistently failed to recognise who the actual audiences of films were likely to be and their requirements as viewers, resulting in an erroneous perception that home movies were boring to those expected to watch them. Scholarship in amateur film has since offered a corrective to this view, even if it involves negotiating a degree of disappointment that 
home movies are not as interesting or informative as they could be in certain respects. It is of course quite likely many families contained members who were also not entirely enamoured with the making or watching of films, yet by and large home movies functioned perfectly well within their intended settings. Boredom in home movie watching is therefore largely the domain of such inappropriate viewers as Robert Benchley's friends. When home movies enter the public realm this situation changes dramatically. Essentially all viewers beyond a film's participants and their relatives might be deemed 'inappropriate'. With the emptying out of original personal meanings, home movies run the risk of ticking all the boxes Klapp associated with boredom. Whether perceived as banal and repetitive, or random and insignificant, the home movies of strangers have the potential to appear dull and meaningless. Moreover, the boredom arising from any apparent absence of meaning is likely to be exacerbated if home movies are encountered in a context where the viewer does not determine the length of the screening. The following chapter considers the relationship between cinema, time and boredom in more detail, along with some of the specific attributes of home movies that might exacerbate viewer disinterest. Considering boredom 'an integral element of the taking of time to engage with time' (777), Misek extrapolates from Martin Heidegger's series of Freiburg lectures (192930) published as The Fundamental Concepts of Metaphysics. Although cinema is not addressed specifically within the lectures, given his particular interest in time, Heidegger's expansive examination of boredom suggests productive ways of understanding boring films and the experience of watching them. 
Chapter 2

\title{
'Almost anything else seems preferable' The home movie which is boring in its boringness
}

\begin{abstract}
We must therefore initially try to strip the concept of the boring (and its experience) of any axiological overtones and bracket the whole question of aesthetic value. It is a paradox one can get used to: if a boring text can also be good (or interesting, as we now put it), exciting texts, which incorporate diversion, distraction, temporal commodification, can also perhaps sometimes be "bad".
\end{abstract}

- Fredric Jameson $(1997,72)$

Fredric Jameson suggests that when a space of time 'not terribly long in other contexts' grows to be almost insufferable in certain viewing situations, boredom itself becomes 'an interesting problem'. Although Jameson's particular example involves minimalist video art, a home movie screening - at least if Benchley's Home Movies is to be believed - is a comparable scenario in which spectators might think 'almost anything else seems preferable' to sitting through a (relatively short) film for the entirety of its duration (ibid.). Boredom it seems is not just a specific relationship between a person who is bored and an object that is found boring; it is also intimately concerned with the length of time these two must do battle with one another. This relationship is described by Martin Heidegger in The Fundamental Concepts of Metaphysics (1995). By separating the issue into three distinct notions of boredom varying from superficial to profound, Heidegger reveals complex associations between subject, object and time, finally arriving (after no less than one-hundred pages) at a surprisingly affirmative understanding of boredom, one that finds echoes in the writings of his contemporaries Kracauer and Benjamin. As perverse as it may seem, certain manifestations of boredom might be considered productive or beneficial. More than just the simple antagonism of enforced under-stimulation for a prolonged period, boredom has a potentially creative or reflective dimension as well.

Although Heidegger's discussion does not specifically address cinema, authors such as Richard Misek and Chris Fujiwara have subsequently demonstrated its relevance to the experience of watching a film that underwhelms or does not afford immersive viewing. In so doing, it becomes apparent that 'boring films' can actually be of interest as Jameson suggests above, while 
'exciting films' may be deemed 'bad' or inconsequential. As will be seen however, boredom is not an homogenous experience; it is always a specific disjuncture, a mismatch between individual desires and a film's capacity to fulfil them, which plays out within a space of time. This chapter draws upon the work of Heidegger, Misek, Fujiwara and others to investigate when and how films are likely to bore spectators, and what could potentially make a home movie in particular boring. Depending upon who is watching and with what purpose in mind, various aspects of the style, content and technical qualities of home movies might be perceived dull. Many of these 'deficiencies' were criticised in home moviemaking literature. Aside from the emphasis upon storytelling discussed in the previous chapter, guide manuals also contained plenty of advice for smaller, technical refinements that would supposedly make films more engaging, especially for the non-family members they tended to imply would be part of the audience. Yet home movies can prove counterintuitive in this regard; films that might on the surface seem to ameliorate typical shortcomings, it will be argued, are not necessarily less tedious to watch. Bearing this in mind, the chapter concludes by pondering whether films likely to bore could be transformed into ones that interest simply through some expedient attention to elements of their presentation. Looking at examples of digitised home movies on YouTube, the advice of guidebooks seems curiously more appropriate now than when it was written. With the aid of digital technologies, amateur uploaders (rather than filmmakers) can easily make minor alterations to home movies and screen them to a public audience. Again, 'improvements' are seldom as straightforward as adding sound, for example, where once there was silence. Just as home movies themselves vary substantially in terms of their attributes, it appears the tweaking of films for public dissemination yields more favourable results in some instances than others. Despite the intentions of uploaders to make home movies presumably livelier and more engaging, modifications have as much potential to exacerbate boredom as alleviate it.

\section{Cinematic time and Heidegger's three forms of boredom}

Time is boredom's constant companion. Heidegger notes that in boredom time 'becomes drawn out, becomes long' $(1995,78)$. Boredom therefore has 'an almost obvious relation to time, a way in which we stand with respect to time, a feeling of time' (80). If time feels drawn out when watching a film, we are likely to become bored. Why does a particular object such as a film affect us in this way? Boredom seemingly arises 'precisely from out of things themselves'. Apparently 'seated in what is boring', it 'creeps into us from the outside', at least according to everyday speech (83). In other words, boring things cause us to experience boredom. Yet to say 
that boring films cause viewers to become bored is clearly not very insightful in itself. Unsurprisingly, Heidegger recognises the limitations of such circular logic, noting that 'as soon as we start with what is boring, we find ourselves saying: it is whatever bores us and thus causes boredom' (83). Likewise, he observes that 'boringness is what makes something boring what it is whenever it is boring us' (82). Faced with the dead end of such tautological explanations, Heidegger duly separates the conundrum into several components: '[1.] that which is boring in its boringness; [2.] becoming bored by this boring thing and being bored with such a thing; [3.] boredom itself' (83). How do these aspects relate to one another?

The previous chapter established some general conditions of boredom: too much or too little stimulation and an absence of (personal) meaningfulness. Heidegger similarly concurs that in its failure to excite or stimulate the boring object seemingly 'does not give anything, has nothing to say to us, does not concern us in any way' (84). To say that a film is boring implies boringness is an objective characteristic of the film itself rather than a subjective value we bestow upon it. But can a film which is boring in its boringness really be so in any truly objective sense? Heidegger suggests otherwise, arguing that 'properties do not accrue to things themselves'; rather, we transfer 'those attunements which things cause in us onto the things themselves'. Without our reaction, an object cannot itself be boring as such. Yet our response 'does not happen by chance or arbitrarily'; there is something about an object that provokes it (84-5). Heidegger therefore concludes that boringness 'belongs to the object and is at the same time related to the subject' (84). In this way boringness does in fact concern us after all.

Following Heidegger's line of reasoning, Richard Misek argues that to assert a film is boring may be 'a means of simultaneously concealing and lending weight to our subjective response of boredom'. The attribution of boringness hereby acts as a form of self-defence, implying 'that it is not our fault we were bored, but the fault of the work' $(2010,778)$. In a similar vein, Fredric Jameson suggests this kind of reaction may be a symptom of our own ideological or cultural limitations. Viewed through this lens, boredom in response to the style or content of a particular work could be 'productively' interpreted as 'an index of what has to be refused in the way of other people's cultural practices and their threat to our own rationalizations about the nature and value of art' $(1997,72)$. Perhaps boredom therefore only indicates something about the subject who is bored, not the object that is boring. Yet Heidegger holds that there must still be something about a particular object that has at least the potential to bore, that is, some kind 
of propensity towards boringness within it that might explain why we are bored by one object and not another. In this way, he concludes that boredom has a hybrid character, which is 'partly objective, partly subjective' (88). This proposition enables Heidegger to focus upon what actually occurs when a subject is bored by a given object.

Heidegger initially distinguishes two experiences of boredom, namely, becoming bored by a boring thing and being bored with a boring thing. In the first form of boredom the primary sensation is one of 'being held in limbo', whilst the second form describes a pervasive feeling of 'being left empty'. Since cinematic boredom potentially encompasses both these forms, it is worth considering each in turn. In order to illustrate his first concept of boredom, Heidegger describes the experience of waiting four hours for a train in a 'tasteless station of some lonely minor district'. Try as we might we cannot think of any satisfactory way to pass the time in such surroundings. Quickly fed up with waiting for the train to arrive, we find ourselves constantly glancing at the clock to see how many minutes have gone by since we last looked (93). In this way time appears to drag and becomes oppressive, hence we seek something that will divert our attention in order 'not to be occupied with time, not to dwell upon time or to ponder it' (99). In short, in this boring situation we desire not simply to fill time but to kill it, that is, to make it pass more quickly 'not because the progress of time is slow' but because it is 'too slow for us' (97). In effect, we wish to be taken in by something so completely that we become lost in it and, consequently, pay no attention to time, for when captivated by things 'in a certain way we forget time altogether' (100-1). When fully occupied, we cease to be aware of time as it seemingly 'disappears in favour of whatever fills it' (Svendsen 2005, 118).

In his application of this particular notion of boredom to cinema, Misek argues that feature films typically attempt to 'kill time' in various ways to provide an entertaining experience (780). In order to avoid boring audiences, most films foreshorten time, filling their duration with action such as complex plots, dramatic conflict and the pursuit of goals, thereby enabling viewers to escape their own lives in favour of those belonging to fictional characters (779). Misek shrewdly observes that while 'railway stations are indifferent to the effect that imposed duration has on us, filmmakers are not' (779). Given the prevalence of time-killing techniques in commercial films, he suggests that dominant cinema displays an 'apprehensive attitude towards boredom' (777). Not all films that seek to kill time do so successfully, however. On the contrary, we may become bored by a film even as 'it manifests a fear of boredom'. Fast-paced 
narratives, frenetic editing and camerawork, or spectacular special effects do not ensure viewers will find a particular film engaging, particularly if the time-killing techniques used have become overly familiar to audiences (782).

Conversely, slow-paced films that 'refuse to kill time' may be pleasurable for some viewers. Misek describes art films that focus on daily routines or characters without apparent goals, for example, as 'conscientious objectors to the time-killing strategies of dominant cinema'. Rather than killing time, these films 'encourage us instead to feel time passing' (783). Whether such films 'bore to death' depends largely upon our individual expectations as viewers. If there is a mismatch between the pace we want a film to move and the speed at which it actually progresses, we are likely to become bored (781). As Heidegger notes, boredom is only possible 'because each thing, as we say, has its time. If each thing did not have its time, then there would be no boredom' (105). This is essentially the crux of the matter: the discrepancy between our time and that of an object such as a film (Misek 2010, 781).

If what is at hand offers us nothing of interest we are thus held in limbo, yet we are also left empty by the boring object (Heidegger 1995, 103). In Heidegger's second notion of boredom, which he distinguishes as being bored with something, the latter sensation becomes the primary feeling. Again, he sketches a scene from everyday life, namely, a dinner party where the food and conversation 'is not only very tasty, but tasteful as well'. The discussion is lively and the time passes quickly and unobtrusively. We return home feeling 'quite satisfied' with our evening's entertainment and yet upon reflection realise we were in fact bored after all (109). Only in retrospect do we become aware of 'a repeated, though suppressed yawning' throughout the evening (110). Having indulged in this pleasant but superficial diversion, we find ourselves robbed of time that might otherwise have been devoted to some more profitable activity. Thus, even though we did not consciously count the minutes until such time we could politely excuse ourselves to leave, we are nonetheless left empty by our engagement.

In this second form of boredom, we are not afflicted by the paralysis of time. Instead, time is filled but in a way that proves ultimately unfulfilling. Heidegger describes time in this instance as standing still; we step out of our lives temporarily and leave ourselves behind (122). This is remarkably similar to Kracauer's evocative description of being lured into a movie screening by an advertisement, whereupon '[o]ne forgets oneself in the process of gawking, and the huge 
dark hole is animated with the illusion of a life that belongs to no one and exhausts everyone' (1995, 332). Rather than seeking fulfilment in our own lives, we let ourselves be taken in by fictional lives for the duration of the movie (Misek 2010, 779). Even a film that appears largely inconsequential can provide sufficient distraction to liberate us from the continuity of our dayto-day lives. If, however, a film merely fills time, we may feel afterwards that the experience was hollow and unsatisfying. Because it involves leaving 'our proper self behind' (and the flow of our time) so to speak, Heidegger considers this a more profound form of boredom than the first, which evaporates the moment we are released from the grasp of the boring object that hinders the passing of time (119).

Heidegger also identifies a third, deeper form of boredom, which he calls 'profound boredom'. This is a more existential, all embracing feeling of emptiness whereby we are 'elevated beyond the particular situation... and beyond the specific beings surrounding us there' with the effect that 'everything appears indifferent to us' (137). Given the very nature of this sensation, it is not possible to provide a concrete example equivalent to those used to illustrate the first and second forms of boredom. Instead, Heidegger suggests an occasion when such a feeling might arise: "it is boring for one' to walk through the streets of a large city on a Sunday afternoon' (135). Yet in this particular mood the streets do not appear intrinsically boring to us. Rather, we are detached from them as time becomes a 'yawning empty expanse' (Boss 2009, 102). Just as it makes no sense to ask what 'it' is in the statement 'it is raining', the absence of any determinate object obscures what exactly 'it' is that bores us (100).

This indeterminate 'it is boring for one' has no specific object and therefore a less obvious relationship with cinema than the first and second forms of boredom. Heidegger argues that the pervasive emptiness of profound boredom offers 'the possibility of an exceptional understanding', if we do not confuse it with a more 'superficial kind of boredom' (136) and try to remedy it with distraction, that is. In deep boredom we are left alone with ourselves. By listening to what this mood 'has to tell us', we have the potential to gain greater awareness of our being-in-theworld (139). This correlates with Kracauer's advocacy of 'radical boredom' as a way of recovering a sense of self (331). Unfortunately (in Kracauer's opinion) the distractions of the modern city are apt to impinge upon 'one's modest right to personal boredom' (333), that sense of 'unfulfillment from which a fullness could sprout' (332). Contending that '[i]f one were never bored, one would presumably not really be present at all', Kracauer advised hanging about 
the train station or surrendering to boredom on the sofa in order to regain control of one's existence. Moreover, in such a state of idleness, creative thoughts have the chance to take root (334). In a similar vein, Benjamin described the mental relaxation of boredom as the 'dream bird that hatches the egg of experience' (2007, 91). From this perspective, cinema as an immersive distraction is likely to expunge the possibility of profound boredom, along with its creative potential. Certainly, films that attempt to kill time do not typically offer space for contemplation or encourage self-awareness. Those that 'bore to death' may evoke quite different viewing experiences in this respect.

\section{A ruminative mode of spectatorship}

As a leisure activity that aims to provide entertainment and aesthetic stimulation, cinema is perhaps more readily viewed as the antithesis of boredom. Spectators do not after all attend a film screening in order to be bored (Çağlayan 2016, 63). In this sense, boredom does represent an appropriate response to a film's failure to kill time effectively or provide a satisfying experience. In other instances, cinema may transform boredom into a rewarding, perhaps even insightful, experience. 'Slow cinema', for example, often foregrounds dead time and dramatic ambiguity, focusing on mundane or monotonous activities, or even the absence of activity (64). The anti-immersive quality of extended sequences depicting events that appear inconsequential in narrative terms may provoke simple irritation or impatience. Alternatively, the apparent meaninglessness of such scenes may induce a 'ruminative mode of spectatorship' (74).

'Mind wandering' occurs when engaged in a task not requiring one's full attention. Consequently, the aesthetically boring film may become a source of creative or reflective viewing activity, producing a critical or introspective space between film and spectator $(69,82)$. Distanced from the film's diegetic world, the viewer may attend more closely to stylistic features than plot details, for example, or even contemplate matters devoid of any direct relationship to the film (75). In such cases boredom acts as an antidote to losing oneself in distraction, the boring film potentially creating an ideal mental space for one's thoughts to 'wander freely' (Fujiwara 2007, 256-7). Once an initial 'threshold of discomfort' is transcended, the viewer enters 'a state of pure film watching'. Freed from identification with the film or desire for conventional cinematic entertainment, the viewer is more likely to be attuned to his or her own mental drifting (242-3). 'Boring' experimental films such as Michael Snow's Wavelength or Andy Warhol's Blow Job (which declines to display the act referred to in its provocative title) 
'return us to our bodies', according to Ara Osterweil, 'impregnating us with apprehension, imagination, and desire. When we are bored, our minds are saturated with thought: we feel ourselves thinking' (2004, 452-3). Experienced in such a way, boredom might even be pleasurable (Fujiwara 2007, 243).

Whether or not boredom is an intentional effect of slow films, faced with duration rather than distraction (Çağlayan 2016, 75), the viewer may experience the kind of fulfillment championed by Heidegger and Kracauer when boredom is countenanced rather than suppressed. In Heidegger's view, profound boredom forces us to recognise the meaningless emptiness of life, as well as its accompanying possibilities. We are not merely disengaged but also estranged from our surroundings, which fail to offer us anything. In such a state we have 'the possibility of getting to know how things stand with regard to our existence' (Slaby 2010, 15). Warhol actually claimed his early films helped audiences to 'get more acquainted with themselves' (Osterweil 2004, 450). Durational exercises in under-stimulation, films like Sleep (six hours of a man sleeping) or Empire (an eight-hour view of the Empire State Building) provide the resilient spectator ample time for introspection. Further to their protracted length and absence of anything resembling a conventional filmic event, and perhaps more importantly, Warhol's films frustrate the spectator by failing to posit any readily accessible meaning. In this way, the unsatisfactory (or under-satisfying) film makes spectators create their satisfaction. In effect, bored viewers must 'find their own way' to entertain themselves (ibid., 450-1).

When cinematic slowness and profound boredom (on as well as offscreen) coincide, so Misek argues, we may be reconciled to our inability to control time. That is to say, we cannot actually 'kill time' as such. Time passes and so do our lives, which are of finite duration. By drawing attention to the passing of time, slow films may leave us 'better equipped to appreciate the various temporalities that exist beyond our own'. Misek concludes therefore that the film that risks being boring by giving 'people and things their time' is 'profoundly ethical' (783-4). Moreover, in deep boredom we become aware of what we could do in the world precisely because we are not immediately confronted with its distractions. In this way, the very meaninglessness of profound boredom, according to Heidegger, becomes a call to take charge of one's existence, endowing it with meaning (Slaby 2010, 102). Likewise, bored spectators might very well take charge of their own viewing experience, potentially endowing it with personal forms of meaning, rather than being absorbed into a prescribed filmic world. 


\section{The home movie which is boring in its boringness}

Whether conceived 'as a villain to be fought against or as something to be cultivated' (Schneider 2016, 80), boredom clearly has a significant relationship with cinema. Even the film that kills time successfully has an inverse connection with boredom, the thing it assiduously seeks to avoid. Perhaps because films are more often discussed in terms of interest or entertainment value rather than any lack thereof, boredom has received relatively little attention within film studies (a handful of discussions on avant-garde and slow cinema aside). More specifically, the almost blanket suppression of boringness and boredom is particularly noticeable in contemporary literature on home movies. Boringness would of course hardly seem to offer justification for the reappraisal of a much maligned genre. Why write about films if they are simply boring and nothing much else? Yet to neglect their potential for boredom may be to overlook some of the essential traits of home movies, their 'perceived shortcomings' arguably constituting their 'defining features' (Czach 2008, 10). Much of the humour of Robert Benchley's Home Movies lies after all in its very accuracy. Its accumulation of mishaps presumably familiar to any viewer previously acquainted with home movies is largely premised upon audience recognition for its effect. Even as (tech)nostalgia shifts popular perceptions of home movies, Benchley's comedy is nonetheless still amusing. That is to say, one need only accept that amateur footage can be clumsy and boring to enjoy the film. It might even be argued what is most intriguing about home movies is their very boringness, their essential banality and stubborn refusal to change or evolve as did other forms of cinema.

Specifically according to Heidegger's taxonomy, Benchley's guests become bored by his boring film. Time passes so slowly for those present the tedium presumably becomes insufferable. Hence, the only viewer who fails to slip away during the screening is the one who falls asleep, weary due to lack of interest. The dragging of time is probably the most likely (or at least the most obvious) way that a home movie may bore viewers. Nevertheless, it is not difficult to envisage home movies also inspiring deeper levels of boredom in particular contexts. Before considering these in the following chapters, Heidegger's assertion that boringness 'belongs to the object and is at the same time related to the subject' (84) is worth examining in slightly more detail in relation to home movies and spectators.

As already noted, home movies address a specific audience of participants and family members and this intimate relationship is disrupted when 'inappropriate' spectators join a screening event 
(reluctantly or otherwise), creating a mismatch between private object and socially distant viewing subject. When home movies enter the public domain, this discrepancy becomes almost inevitable. In this sense, the seemingly misplaced recommendations of advice manuals to make films interesting to an implied audience of non-participant or unrelated viewers have inadvertently attained a kind of belated relevance as home movies pass from the seclusion of family screenings into public viewing spaces. For the most part, filmmakers appear to have ignored such advice, actual home movies seldom demonstrating the formal attributes advocated by guide literature. Consequently, if boringness is considered to be a subject-object relation, the relative (potential) boringness of home movies could logically be expected to have expanded in the context of audiences composed of people who were not the intended viewers of such films. But is this actually the case?

In terms of boringness, what belongs to a home movie as an object? What is related to a viewing subject? Benchley of course skims through quite a number of recognisable home movie attributes or 'mistakes' in a matter of minutes. Clearly deficiencies such as the odd framing of shots that leave their subject obscured or headless are irritant properties of the film itself. Yet not everyone present is irritated by these. It is noticeable Benchley chooses, for example, to be intrigued more than annoyed by the anonymity of the man who strolls through a couple of shots minus his head onscreen. Instead, he focuses upon his use of a wide angle lens, which (according to Benchley) has 'worked out pretty well'.

content unavailable

please consult print version

Fig. 2.1. Irritating failure to keep the subject in frame or good use of a wide angle lens? Headless subject in Robert Benchley's Home Movies. Screenshot.

Furthermore, disagreement between Benchley and his wife regarding where various images were 
recorded or who exactly is in them simply gives the couple an active role to play at the screening. Interestingly, even the guests create momentary amusement by poking fun at various shots in the film to enliven the otherwise dull event. An inappropriate audience for the film, Benchley's friends are nonetheless not completely or profoundly bored throughout the entire screening it seems, their comments or laughter registering a persistent, albeit rather lacklustre, degree of participation (prior to exiting the room, that is). This willingness to indulge in some spectatorial effort in order to find something in bad or boring films will be returned to in chapter 5 .

Home Movies is of course a short comedy, not an actual home movie. Like most narrative films, it foreshortens time substantially, condensing far more mishaps into the space of a few minutes than are likely to be found in one reel of even the most 'amateurish' of home movies viewable on YouTube or elsewhere. This exaggeration is played for comic effect. Home Movies is about boredom, but it nevertheless seeks to entertain in a conventional manner. What about actual home movies and non-family spectators at public screenings? According to the wisdom of advice literature, in order to be entertaining (or at least not boring) home movies should tell a story, preferably an exciting one. Yet contemporary viewers presumably do not watch other people's home movies with the expectation of a coherent narrative or entertainment comparable to that of a conventional drama or even a documentary. Despite their characteristic style, not all home movies are 'created equal', however. It is reasonable therefore to imagine that some have a greater propensity to bore than others, depending upon the content and technical proficiency of a particular film and the background or interests of individual viewers.

\section{Technical difficulties, extended snapshots and patterned eliminations}

Basic technical shortcomings (vis-à-vis professional standards of filmmaking) are a distinguishing trait of home movies. Nonetheless, consistently unsteady camerawork, excessively frequent and fast panning or poor exposures can become intrusive and wearisome to watch if they distract from the content of the film. Furthermore, what were relatively low-resolution images in the first instance (usually $8 \mathrm{~mm}, 9.5 \mathrm{~mm}$ or $16 \mathrm{~mm}$ ) are now often also scratched and faded due to wear and tear sustained through repeated projection or storage in less-than-ideal conditions. Lacking the clarity of $35 \mathrm{~mm}$ film, home movies do not necessarily illuminate the finer details of their subjects. Now more often watched as digital copies, home movies are frequently disseminated as heavily compressed video for online viewing. Whether viewers are 
frustrated or bored by such deficiencies is likely to be relative to their expectations and interests, however. Signs of physical deterioration (often visible as 'analogue' artefacts in a digital surrogate) may represent pleasurable nostalgia to the casual viewer. The researcher whose interest lies in a film's content as a source of historical data may be largely untroubled by the limited cinematic quality of the film itself, unless of course its defects significantly reduce the informational value of the film.

Other sources of boredom may include the general style and content of films. As most home movies were not edited, they often seem more like raw footage than a finished film. The common bugbear of advice manuals that home movies do not feature organised, self-contained narratives may be surmountable for public audiences given the familiarity of many activities filmmakers chose to record. Nevertheless, films can be more engaging if the family roles or identities of participants and their relationships to each other are discernible. Making sense of films in this way can be a source of entertainment, particularly if participants display what might be described as individual onscreen personas. Too many 'cameo' appearances by friends and relatives or, even more confusingly, by people simply encountered in public spaces can become a disruptive presence amongst a film's principal cast of characters. Home movies that are overly baffling in this manner may be less interesting to watch in comparison with those that feature the same group of easily recognisable individuals throughout, such as the parents and children of a nuclear family, or a select group of friends. ${ }^{8}$

The way in which people are filmed may also be perceived as boring. Alexandra Schneider describes a scene from an early amateur travel film recorded in the Swiss Alps featuring an encounter between local dairy farmers and urban tourists. The farmers appear unfamiliar with the medium of film, standing stiffly as if for a photograph, whereas one of the tourists waves at the camera in order 'to bring some movement into the moving image' $(2006,166)$. Yet one does not need to be an isolated mountain dweller unacquainted with cinema to make this mistake, either as subject or filmmaker. It is not unusual to find scenes in home movies depicting largely inanimate groups assembled before the camera at family gatherings, or individuals posing beside monuments or in the foreground of scenic vistas whilst on vacation. On occasions when simply documenting who was present took precedence over any activities

8 This is sometimes discernible in comments attached to home movies online. One reviewer, for example, describes a home movie called 'The Saga of the Happy Wanderers', which depicts an easily identifiable couple and their daughter on holiday, as a 'MUST SEE' on the Internet Archive https://archive.org/details/Sagaofth1957 
that occurred, arranging subjects in a row (or several, if steps were available) in a manner suitable for a snapshot was an effective, albeit less than dynamic way of recording a family event. Posed in such a way, subjects often appear awkward or uncomfortable, conscious of the camera's gaze but at a loss what to do in its presence. Needless to say, if the assembled crowd is unknown to the viewer this kind of recording can lack obvious points of interest. ${ }^{9}$ Unsurprisingly, guide literature explicitly counselled against posing subjects in this manner. The 'photographic hangover' (Howe 2014, 41-5) seen in many home movies is nonetheless a potential boon for those studying the appearances of people, including the clothing and hairstyles of a particular era.

The extended snapshot approach to subjects, which seemingly failed to make the most of medium specificity, was not solely reserved for recordings of people. Generic postcard-style shots of empty landscapes or tourist sights conspicuously lacking human presence can appear especially lifeless and clichéd. ${ }^{10}$ Furthermore, many home movies contain a preponderance of random shots depicting unrelated subjects, sometimes only a few seconds in duration. While such variety might conceivably prevent viewers becoming bored by a film in some instances, a complete absence of continuity can simply appear chaotic and relatively meaningless.

At the other end of the scale, too much similarity may be equally inclined to bore. Home movies tend to be repetitive and mundane in terms of content both within and between collections. If 'nothing of interest happens' in home movies, it noticeably does not happen again and again. The same family milestones and rituals are filmed with monotonous frequency. The redundancy (in Klapp's terminology) of such recordings is illustrated particularly well by a

9 'Home Movie: 10562: Unititled' [sic] on the Internet Archive provides plenty of examples of subjects lining up to pose beside monuments or even indigenous people at tourist centres, occasionally waving at the camera to bring some life into the picture https://archive.org/details/10562_brt40con 133 hm_unititled Online reviewer 'Spuzz' describes the recording as '[r]ather dull vacation footage... surprisingly boring footage here which didnt keep my interest' [sic]. 'Amateur film: Texas Farm Family' offers an awkward variation of this kind of shot, the photographer panning down his wife(?) when she initially seems unsure what action to undertake in front of the camera. (Later on in the film she playfully demonstrates her ability to blink one eye, then the other, performing very directly and purposefully for the cinematic gaze.) https://archive.org/details/TexasFar1952

10 Again, the Internet Archive provides plenty of instances of the landscape extended snapshot. 'Home Movie: 97105: Unidentified' https://archive.org/details/97105 hm_unidentified and 'Home Movie: 97455: Unidentified' https://archive.org/details/HMUnidentified97455, for example, both devote a substantial amount of their running time to sweeping views of mountain scenery and rivers mostly devoid of human activity, the holidaymakers who enjoyed these locations appearing on camera only intermittently. Reviewer 'Spuzz' describes the mostly 'touristy locale shots' of 'Home Movie: 97069: Vacation West 1955' https://archive.org/details/97069_hm_vacation_west_1955 as '[n]ot badly shot, but somewhat dull all the same' and claims to have fallen asleep watching the empty scenery of 'Home Movie: 11778: Vacation West, CA Coast' https://archive.org/details/HMVacationWestCAC11778 
montage of excerpts posted on YouTube by the Nebraska State Historical Society. Personally intrigued, archivist Dwight Swanson ponders 'why everyone films their kids opening Christmas presents' (2012, 60). Looking at a sequence such as 'Raikes Family Christmas home movies (excerpts 1941-1970)' that features a series of murky shots of pyjama-clad children and presents in front of a Christmas tree, the answer to this question is far from obvious. The most striking aspect of this Nebraskan family's annual Yuletide ritual is its banal homogeneity. Despite the thirty-year span of the recordings, the images of each Christmas are largely indistinguishable, resembling one another so closely the montage could more-or-less be rearranged in any order, quite possibly without the viewer noticing. Furthermore, a casual glance through any number of other Christmas home movies available online (which, given YouTube's algorithmic logic, are immediately offered in accordance with the viewer's presumed interests) will confirm that the Raikeses were in no way unusual in their filming habits. There are possibly hundreds, if not thousands, of family Christmas recordings on YouTube or other video-sharing sites. Given sufficient exposure to so many near-identical Christmas celebrations dutifully carried out by mostly anonymous strangers, the viewer who could withstand mounting boredom would be an exceptional one indeed.

content unavailable

please consult print version

Fig. 2.2 \& 3. One Christmas looks much the same as another in 'Raikes Family Christmas home movies'. Screenshots.

Even when activities are more varied than those usually witnessed in Christmas recordings, home movies are generally conspicuously tame. Tension between participants, for example, is usually absent. Home movies very rarely depict anything too intimate or threatening, such as visible disagreement between family members. Instead, onscreen relations are sanitised, everyone smiling happily for the camera (Odin 2008, 262). Not only is there a 'patterned 
elimination' of anything that might involve conflict (and thereby add drama to a film), even in the case of (supposedly) happy events, such as weddings or childhood, 'more is left out than included'. Film stock was usually reserved for the main event or important milestones, not dress rehearsals or changing dirty nappies (Chalfen 1987, 93). The exclusion of trivial or humble occurrences might reasonably be expected to reduce boringness. Yet the kind of 'special reality' seen at Christmas, weddings or children's birthday parties, for example, arguably has greater soporific potential than many more ordinary aspects of day-to-day life that may at least have changed substantially over time and therefore accrued historical curiosity value.

While the characteristic style and content of home movies may not be entirely conducive to audience engagement, one of the most significant impediments to viewing pleasure is perhaps simply a technical one, namely, the absence of sound. Prior to the addition of magnetic sound stripes on Super-8 film in the early 1970s, preserving sound directly on small-gauge formats was both difficult from a technical point of view and expensive. While a number of earlier soundon-film cameras were produced for the amateur market, their limited audio fidelity and hefty price tag ensured they did not meet with commercial success (Czach 2008, 128). Unsurprisingly, few home moviemakers (as opposed to their amateur ciné-club counterparts) chose to record sound films, the extra effort and expense probably seen as unnecessary by filmmakers and participants accustomed to live narration at home screenings. For spectators with no personal relationship to a home movie, the absence of sound may compound other limitations such as narrative incoherence, unimaginative filming techniques or largely inanimate subjects. Moreover, silence is likely to exacerbate any confusion about participant relationships, filming locations or even onscreen activities that are no longer a recognisable or familiar part of everyday life, for example. In short, viewers may be bored if it is difficult to discern what exactly is going on in a home movie.

Conversely, remedying their most obvious deficiencies (according to conventional cinematic wisdom) does not necessarily render home movies automatically more exciting. It might be assumed, for example, as did much advice literature, that sound would alleviate the tedium supposedly imposed by silence. In particular, moviemaking guides recommended music as an ideal solution to the problem (ibid., 126). Music could allegedly 'make watching second rate films less of an endurance test', furnishing dull footage with 'life and interest' (131). Czach notes that numerous background music and sound effects records were in fact released 
specifically for accompanying home movies (142), although it is difficult to ascertain the extent to which such recordings were actually used for their intended purpose. Other suggestions for enlivening home movie screenings included pre-scripted (or even pre-recorded) commentary, predictability apparently being valued over spontaneity (152-4). If filmmakers did employ more imaginative means than impromptu dialogue to animate their screenings, any ephemeral soundtracks are of course now lost to contemporary audiences. Yet what if onscreen conversations could actually be heard? Would home movies be more interesting, or at least less boring?

\section{All personal sound}

As there are a relatively limited number of extant home movies recorded with sound, it is difficult to make generalisations about them. A couple of examples offer an interesting test case regarding the relationship between sound and entertainment. An excerpt of Pennsylvanian filmmaker Fred McLeod's 'All Personal Sound Movies'11 recorded at Christmas in 1962 demonstrates some of the limitations of home movie sound. The sequence opens with the filmmaker's sister descending the front steps of a house and speaking to Fred who remains behind the camera. They exchange comments about the weather, some of which are rather muffled. The next shot depicts their elderly mother seated next to a Christmas tree watching a boys' choir singing carols on television. She fidgets in her chair, adjusts her jewellery and wipes her mouth. Fred and his mother are then seen sitting at a dining table with a large microphone on it. Aside from when his mother says 'hi' directly into the microphone, the sound reproduction is poor and much of their banter inaudible. Lastly, Fred's brother-in-law appears in medium close up clutching the microphone. He waves at the camera, laughs and glances from side-to-side seemingly looking for inspiration before comically announcing there will be a 'brief word from our sponsors'. He then points at the camera and instructs Fred to 'knock it off back there'.

The shots are particularly well lit - Fred's mother shading her eyes suggests the use of fill lights and the camera placed securely on a tripod. The steady camerawork and unusually rich colours for an interior recording bestow a certain vibrancy upon the scene. Yet the cumbersome equipment restricts the movement of the participants if they are to be both seen and heard.

11 Fred McLeod also produced sound films of trains that were distributed by Blackhawk Films in the 1950s and 1960s. His personal collection of $16 \mathrm{~mm}$ films is housed at the Orgone Archive in Pittsburgh. The Christmas footage can be viewed on the Internet Archive. 
Furthermore, they display a certain awkwardness about speaking directly into the microphone, the only way in which their voices are captured with any degree of clarity. The five-minute sequence viewable on the Internet Archive certainly has curiosity value, if only for its rarity. There is also perhaps something inherently amusing about someone hauling expensive, heavy equipment to his family Christmas in order 'to capture the most banal activities imaginable' according to an online reviewer who facetiously describes the sequence as 'Oscar bait for sure'. Nonetheless, the reviewer's expressed enthusiasm for watching two hours of such material in preference to a Hollywood action movie might be construed to indicate more about perceived shortcomings of the latter rather than the actual entertainment value of McLeod's recording techniques per se.

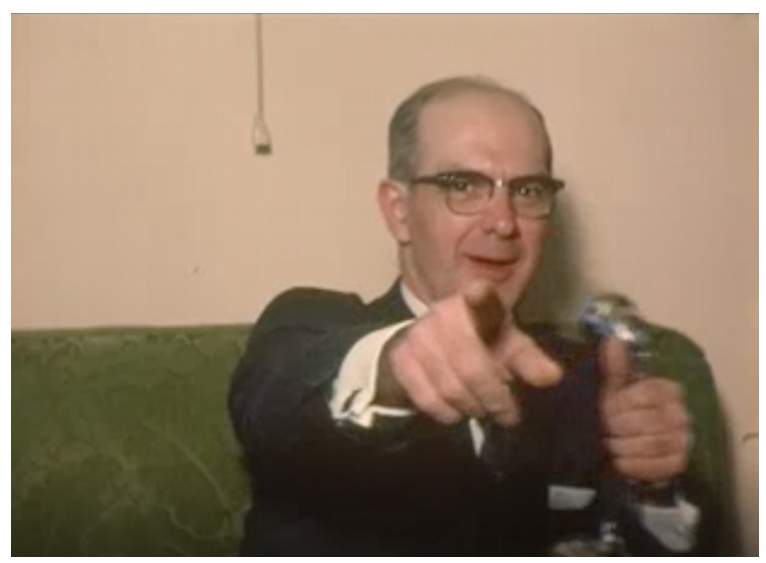

Fig. 2.4. 'Knock it off back there!' Participants appear less than enamoured of the cumbersome microphone in the midst of a family Christmas in Fred McLeod's 'All Personal Sound Movies'. Internet Archive. Screenshot.

Another serious moviemaker, Archie Stewart purchased an RCA Victor 16mm camera in 1935, the first optical sound camera released for the amateur market. The microphone in this bulky, hand-cranked camera was best suited to picking up the voice of its operator (Kattelle 1986, 55). Consequently, curator Bruce Posner's claim 'that we can not only see what Archie saw but hear what he heard' on Stewart's recordings included in Unseen Cinema (2005) 12 is somewhat of an exaggeration: we in fact frequently hear only what Archie said whilst filming. He does utilise the soundtrack to provide pertinent information about dates and locations, although the technical details he mentions, such as the lens, exposure or lighting set up used, are probably of interest

1233 minutes of Archie Stewart's early sound footage (c.1936-39) is included on Anthology Film Archives' Unseen Cinema: early American avant-garde flm, 1894-1941 DVD series curated by Bruce Posner. Stewart was a resident of Newburgh (New York), his extensive film and video collection, recorded between 1928 and 1996, now residing at Northeast Historic Film in Maine. 
only to the more specialised viewer (or the filmmaker himself). More curiously, in some instances he also identifies the people onscreen as if to assume some non-family viewer for whom such information is not readily apparent. Perhaps Stewart anticipated his descendants watching the films at some distant future moment. Alternatively, he may have been observing the type of advice for amateurs discussed in the previous chapter. From his commentaries, it is clear Stewart was interested in the more technical elements of filmmaking. He was also evidently prepared to spend more money on his hobby than most amateurs, purchasing an expensive sound camera. It is not difficult to envisage therefore that he read advice publications in order to make best use of his purchases.

In general there is diaristic flavour to the filmmaker's comments. He notes ephemeral details such as the weather, as well as contributing the occasional psychological insight. Filming a blimp hovering over Miami beach, Archie explains the family had to forego a ride when his younger daughter 'set up a big howl', a response he attributes to seeing images of the Hindenburg disaster, which had occurred six months earlier. Like McLeod, Stewart also converses with those in front of the camera, adding little dramatic flourishes such as cueing his daughter and another child to grimace in order to demonstrate their disgust with a less-thansuccessful fishing trip, the soundtrack imparting motivation that might otherwise be lost upon the viewer. In other sequences Stewart makes more expansive use of his camera's sound capabilities. There is a performative quality to many scenes, events seemingly staged for the camera. Various members of the Stewart family and their friends are seen singing, dancing to music, playing the piano, reading aloud and setting off firecrackers. Perhaps Stewart specifically chose to record these activities as sound is an integral element of them. Certainly, his daughter's reading is presented as an exercise to document her ability at a particular age rather than just another moment of family life. The recording would therefore appear more dependent upon hearing than seeing. Stewart also adds orchestral music to enliven shots of tourist sights and his daughters unwrapping a Christmas present, two home movie subjects that can easily appear repetitive or dull.

Posner describes Archie's record as 'intimate and endearing' While the soundtrack provides a number of insights into the Stewart family's activities beyond what could be conveyed with images alone, it is not without disadvantages from a viewer's perspective. Due to the camera microphone's narrow audio spectrum, when voices aside from the filmmaker's own are 
captured, the results are not always favourable. The extremely shrill voices of his children, for example, are not only somewhat uncomfortable to listen to but often difficult to decipher as well. Furthermore, as seen in McLeod's film, onscreen movement is restrained by the equipment, resulting in a staged feel to many sequences in which the participants adopt a presentational style clearly conscious of keeping within the parameters of a static frame and the microphone's sensitivity. Even Archie's addition of non-diegetic instrumental music to a couple of scenes has a clichéd feel. Presumably derived from popular phonograph records, the choices of soundtrack seem an incongruous match with the images onscreen, the rather unwieldy imposition of a somewhat grandiose Hollywood-style sound aesthetic upon humble family activities appearing more curious than mood enhancing. Again, this perhaps reflects Stewart's efforts as a serious amateur to follow the directions of advice manuals, even if the actual result feels more awkward than engaging.

From these examples it might be deduced that a general effect of sound, far from increasing the liveliness of home recordings, is to instigate a rather staid quality, whereby the usual spontaneous feel - often considered an appealing attribute of home movies - is replaced by an awkward stiffness. Even the Stewart children's squabbles (an unusually dramatic feature in a home movie) exhibit a somewhat theatrical character, as if overplayed for the benefit of the microphone. Similarly, Archie's attempts to add humour to his commentary can appear strained; he refers to his wife and daughters, for example, as 'not lobsters' (like the floatations they carry at the beach) but 'crabs from being crabby'. Regardless of their shortcomings, Archie Stewart's films are not entirely devoid of interest, particularly given their status as a rare example of early amateur sound practices. They may also have other kinds of historical value. Despite their slightly unnatural timbre, the recordings could be of interest to researchers of mid-century vernacular American speech, for example. Yet watching Stewart's and McLeod's films, it is easy to feel a sense of relief that the majority of home moviemakers chose to maintain a reposeful silence in preference to sound, even when more practical means of audio recording became available in the 1970s. Given the typical banality of everyday exchanges, the words spoken by home movie subjects are in many instances perhaps best left to the viewer's imagination.

\section{A question of presentation}

As a property of home movies, boringness would appear to be far from a straightforward problem (if indeed it is a problem at all). Amending features of home movies that might be 
construed as boring does not necessarily improve the watchability of films. Sound home movies are not inherently more interesting or entertaining than silent ones. Elements that might ordinarily be expected to enliven films - music, onscreen dialogue, narration, humour - can simply detract from the usually unstudied nature of home recordings. If spontaneity is considered one of the principal charms of home movies, the clumsy or staged feel resulting from increased attention to technical details may amplify rather than diminish boringness. With the use of more complex equipment, filming technique to some extent displaces content as the primary concern of home movies. This shift could be seen to lessen their 'real life' value or documentary evidence of 'what people really did in the past' (aside from staging movies in their spare time, that is). Moreover, the limitations of amateur equipment did not enable home moviemakers to replicate professional standards of technical perfection. Amateur aspirations to transcend the basic form of home movies therefore have a tendency to draw attention to the difficulty of creating an aesthetically polished film in a domestic space with rudimentary equipment and a cast of family and friends.

Whether viewers are intrigued, annoyed or bored by specific formal attributes of home movies will of course depend greatly upon individual tolerances and interests. If home movies are valued as a seemingly authentic source of historical information, films that appear less manipulative of their subjects may hold greater appeal. Viewers more concerned with home movies as a particular kind of filmmaking practice may be fascinated by footage deploying unusual techniques, even those that might irritate spectators solely interested in a film's content. Yet this understanding presupposes spectators have very particular reasons for watching home movies. Viewers seeking to use or interpret home movies for predetermined purposes may be satisfied simply if their specific criteria are met, that is, they find what they are looking for. What about more general audiences who watch home movies either at public screening events or casually online in the comfort of their own home?

In the absence of specialised research agendas, viewing becomes a much less instrumental activity. For viewers without clearly defined motives for watching home movies, appreciation could be linked to a general curiosity about the past or the pleasures of nostalgic recognition, while boredom may derive from aforementioned deficiencies such as clumsy or uninspired filming techniques and excessively banal or repetitive content. In short, time drags or time is made meaningful for casual viewers. At face value this appears to be a simple situation: films are 
either engaging or boring, and viewers find some source of meaning or lose interest altogether. As Heidegger notes however, an object may in fact bore on one occasion and not another (83). Watching the same film repeatedly is of course likely to become boring, although conversely familiarity can also be pleasurable for some viewers, hence the development of fan cultures around certain films and filmmakers. While home movies do not typically accrue cult status, it is possible a viewer might watch the same film more than once, becoming bored on one occasion and not another. What factors might determine this difference in response?

Firstly, a spectator's general disposition on any given occasion might reasonably be assumed to affect his or her viewing experience. Viewers who are tired, agitated or otherwise distracted from their immediate surrounds are probably less likely to find a film engaging than those who are better able to give their full attention to the screen in front of them. Could something more specifically related to the film itself significantly alter a viewer's reaction, however? Pondering the distinction between objects that bore and those that interest, Henri Lefebvre concluded that more-or-less everything 'can become interesting. It is merely a question of getting the presentation right'. By 'meeting a few technical requirements' (such as surprise or suspense), Lefebvre suggested seemingly dull objects can be transformed into ones that fascinate (1995, 260). Extrapolating from this assumption, it might be concluded that a second factor influencing a viewer's reception is likely to be the context in which a film appears. That is to say, films could be interesting or boring according to the parameters of their presentation. The following two chapters consider the extent to which professional filmmakers and archivists get the presentation of home movies 'right' in various contexts by directing the attention of viewers in certain ways. Given the prevalence of informal, participatory archiving practices in today's media environment, it seems fitting to preface this by initially looking at a few examples of amateur attempts to present amateur footage in the public domain. Leaving aside for now the question of whether or not it should be considered an archive (an issue that will be returned to in chapter 5), YouTube is a veritable treasure trove of home movies made available for a public audience.

\section{'on the edge of your seat as you contemplate what does this all mean?'}

Digital technologies have simplified some of the more technically complicated or expensive elements of filmmaking, such as editing and sound, that were previously spurned by the majority of home moviemakers working with small-gauge formats. It is perhaps not surprising 
therefore that some of those who make digital copies of home movies available on YouTube or other video-sharing sites choose to manipulate their original footage in ways that would have required significant effort at the time of filming. While one can usually only speculate as to the individual motives of those who upload old home movie footage for public viewing, sharing family films easily with relatives or friends is probably an incentive for many people. Yet a quick glance at a random selection of home movies on YouTube (or elsewhere) indicates that some of these films are watched by hundreds, even thousands, of online viewers. If family members were indeed in many instances the intended primary audience for online movies, a great many (presumably) complete strangers would appear to be watching as well. Given this (potentially) sizable public audience, one might speculate how this influences the presentation of home movies online.

The volume of content on YouTube is immense and the means of finding home-mode material rather haphazard (a basic search for 'home movies' offers numerous episodes of an animated series of that name as well as actual home movies). Any generalisations about the YouTube career of home movies must therefore be approached with caution. Although most people appear simply to upload digitised copies of their home movies 'as is', some YouTube users choose to edit their films. This can involve recutting footage and adding titles indicating pertinent information such as locations and dates, or other kinds of effects. Perhaps the most common addition to home movies online is a soundtrack. At its simplest, this might be the whirring noise of a projector (added either deliberately or perhaps inadvertently, if films were digitised simply by recording the image at a home screening). ${ }^{13}$ The 'authentic' atmosphere supplied by the familiar rhythm of a projector's mechanism is at the very least more animated than silence, and might therefore be construed as pleasurable (tech)nostalgia. Alternatively, some viewers might perceive the noise as an irritating tick, especially if the sound is obviously added only for effect.

More often home movie soundtracks take the form of a musical arrangement derived from a pre-existing recording. The success or functionality of such soundtracks varies greatly, depending largely upon the individual ability of the home editor to select a complementary score for a particular film. Thematic associations aside, The Nutcracker's 'Waltz of the Flowers', for example, appears awkwardly dramatic in comparison with a rather mediocre recording

13 For an example, see Fritz Schone's YouTube upload, 'Wellington City Scenes - 1963' https://youtu.be/3yGysMM2wHg or 'old home movie, Christmas 1966' https://youtu.be/s680saj-4lw 
entitled 'Vintage Christmas Movie 1950s 1960's'. ${ }^{14}$ In this very washed-out, heavily compressed YouTube upload a room is seen decorated for Christmas. Children enter and proceed to open presents in a typical fashion. The only moment when the musical accompaniment really seems to align in any way with the onscreen activity, however, occurs in a shot depicting the children joining hands to dance briefly in a circle. Interestingly, the same film is also available with a Nat King Cole soundtrack, perhaps uploaded by another member of the same family. ${ }^{15}$ The imposition of a popular tune, 'The Christmas Song' (first recorded in 1946), contributes a nostalgic quality to what is already for many a nostalgic subject. This arguably provides a better (or at least less incongruous) match with the footage than that seen in The Nutcracker version of the film. Popular covers of other Christmas songs, such as those of Bing Crosby, or more traditional carols are also common choices to accompany Christmas scenes, soundtracks which appear selected for their nostalgic effect. ${ }^{16}$ Whilst the addition of music does to some extent enliven a monotonously repetitive and rather banal subject, 'White Christmas', 'Jingle Bells' and 'O Christmas Tree', amongst other songs, feature on so many videos uploaded to YouTube, the use of such tunes as home movie soundtracks already feels clichéd, tempting the viewer simply to mute the audio track altogether.

A rather more successful attempt to make Christmas footage entertaining can be seen in 'A Reynolds Family Christmas, 1958 (Portland, Oregon)'. ${ }^{17}$ Although poorly compressed (and possibly digitised from a VHS tape rather than the actual film), the video is nonetheless lively. Featuring a more contemporary soundtrack, it arguably transcends the simple nostalgia of most home movie Christmases. The video opens and closes with footage shot through the windscreen of a moving vehicle so that its choice of song, Chris Rea's 'Driving Home for Christmas', has a stronger relationship with the images than most soundtracks selected for home movies. While the accompanying music could itself now be deemed nostalgic (Rea's recording was first released in 1986), it nevertheless originates from a more recent time period to that of the images. 'A

14 The title of upload was changed in 2018 from 'A Vintage Little Christmas 1960's'.

15 Since its upload by 'Jenniesworld' in March 2007, The Nutcracker version has had over 55,000 views. The Nat King Cole version was uploaded on the same day by 'Jerrysworld' and has had only about 400 views. There is also a third, shorter version of the film (uploaded a year earlier) containing only some of the footage and featuring a simpler piano score, which again might be described as nostalgic.

16 Christmas recordings by the Edwards family of Pompton Plains are a good example of the former type of soundtrack https://youtu.be/rZTOekPpybk while another uploader 'waxing a bit nostalgic', for example, adds carols to 'Christmas 1970' https://youtu.be/XyPIDcGXYSY Innumerable other examples of similar soundtracks can be found on YouTube. Footage of many other subjects is also uploaded with the addition of a music track, including period appropriate pop tunes. See https://youtu.be/IVK1i32HvNo for an example.

17 It has presumably been created by communications consultant Garr Reynolds (who appears in other videos uploaded under the same YouTube user name). 
Reynolds Family Christmas' is therefore a more layered staging of nostalgia than that experienced through the pairing of music and images approximately contemporary with one another. This affective difference might be conceptualised in terms of Svetlana Boym's distinction between restorative and reflective forms of nostalgia. The former desires a return to or reconstruction of a lost past, whilst the latter 'dwells on the ambivalences of human longing and belonging', cherishing 'shattered fragments of memory'. Restorative nostalgia is concerned with 'truth and tradition', whilst reflective nostalgia implies a more critical or wistful longing for the past that does not seek to recover an 'absolute truth' or restore an 'original image' of it (2001, xviii, 49). The presentation of 'A Reynolds Family Christmas' suggests a reflective distance from the moment of filming, which seems lacking in most attempts to overlay Christmas footage with correspondingly themed music.

The Reynolds footage itself is also somewhat more varied than that seen in many Christmas movies. The usual images of children unwrapping presents or family gathering around a dinner table are complemented by less typical scenes such as a forest excursion to fell a tree. Furthermore, the length of shots appear edited to harmonise with the tempo of the tune, creating a four-minute sequence that has as much in common with a music video as the average home movie. Although many images contained in the video are similar to those of a great number of other Christmas recordings dating from the postwar era, the Portland family's Christmas in its edited version has an agreeably refreshing tone in comparison with more standard entrants in the genre available on YouTube.

Restorative nostalgia is alluded to in the very title of a film uploaded as 'Home Movie of The Good Old Days America 1940's'. Yet its overall effect is somewhat more complex. ${ }^{18}$ Taken from a 16mm black-and-white film, 'The Good Old Days' depicts pre-mechanised haymaking with a horse-drawn cutter on a farm in New York State, as well as other outdoor scenes such as children swimming and rafting, pitching horseshoes and al fresco dining. The images are steady and well framed without obvious editing aside from the addition of a soundtrack to the first five minutes of footage. Rather than utilising period music, the uploader has chosen a contemporary instrumental arrangement, which, combined with the style of imagery, imparts a documentary feel quite unlike the grainy Kodachrome of postwar Christmas movies. Given the film's obvious elements of historical interest, the soundtrack seems largely unnecessary to offset viewer

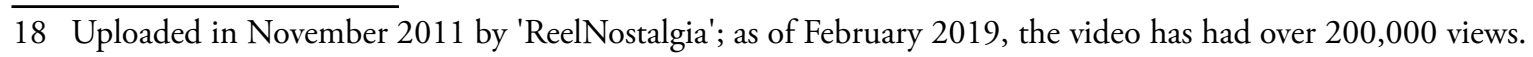


disengagement, something that becomes readily apparent when the images suddenly plunge into silence.
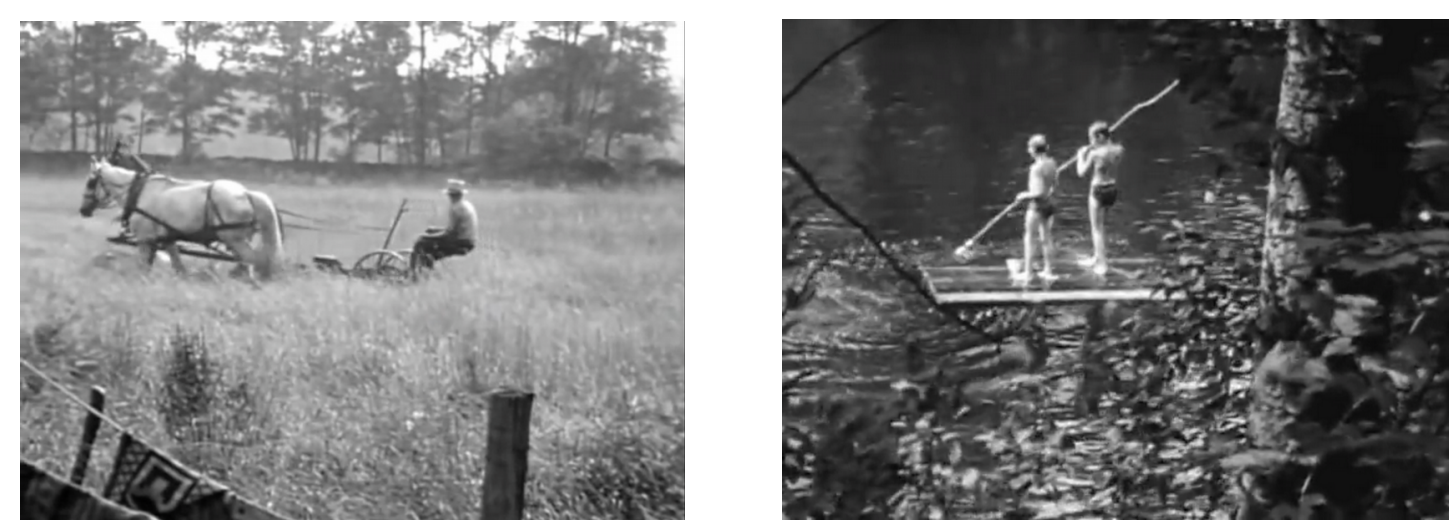

Fig. 2.5 \& 6. Monochrome photography imparts a documentary feel in 'The Good Old Days'. YouTube. Screenshots.

Although the presentation of 'The Good Old Days' does not create a straightforward eulogy to a lost golden age, many of the comments attached to the film (discussed further in chapter 5) reflect a nostalgic belief that life was simpler, healthier and less materialistic in the past. Unsurprisingly, Christmas films, such as 'Vintage Christmas Movie', also attract similarly nostalgic remarks, albeit couched in somewhat different terms given the consumerist nature of Christmas celebrations. The very ubiquity of such commentary on YouTube suggests nostalgia plays a significant role in the appreciation of home movies online, viewers frequently expressing a yearning for a bygone era or a return to the vanished world of their childhood. Soundtracks selected to accompany home movies typically reinforce such sentiments, although not necessarily in a simple or unambiguous manner.

If nostalgia is a primary appeal for many viewers, can home movies be manipulated to appear less nostalgic - or at least less specifically framed as nostalgia - and also not boring? As the previous example illustrates, clearly footage of subjects that have seen greater historical change since their time of filming have the potential to be interesting in a way recordings of annual celebrations, which have altered considerably less, do not. The most noticeable feature of Christmas movies is their similarity across time and space, home décor and people's appearances aside. One way to increase the appeal of home movies would of course be simply to cut out the 'most boring bits'. Even quite ordinary scenes of daily life may be enlivened with the excision of excessively banal, repetitive or technically haphazard footage. An edited clip such as 'Memory Lane: growing up Australian in the 1950s', which features fairly typical scenes of rural 
childhood, is at least brimming with boisterous movement, its ceaseless exuberance somewhat compensating for the film's similarity to countless other recordings of the time. ${ }^{19}$

A rather more sophisticated use of editing techniques is seen in the travel films recorded by Dutch filmmaker Michael Rogge from the late 1940s onwards. ${ }^{20}$ A serious amateur filmmaker, photographer and archivist, Rogge utilises an array of sound effects to construct complex soundscapes for his otherwise silent films. 'From Holland to Copenhagen in winter 1963', for example, features the 'diegetic' sounds of cars, trains, the ocean, ferry horns, seagulls, crowds, bells, footsteps and a marching band during a changing of the guard sequence, as well as nondiegetic folk music and yodeling. Although not synchronous with the images, the sound design conjures a rather more immersive flavour of 'being there' than the usual silence of home movies or a continuous music track bearing little relationship to onscreen activity. Carefully edited, Rogge's films, although originally intended for family viewing, seemingly anticipate a public audience seeking a holistic viewing experience rather than merely random images culled from the past. The general effect is not exactly one of simple nostalgia (although given the age of the film, nostalgic responses would presumably be possible, especially amongst those familiar with the places depicted). As the film was recorded in winter, the images are rather dark with the streets of Lübeck and Copenhagen appearing somewhat grim. As such, the film does not construct the kind of inviting scene into which one might readily wish to step back in time from the present day. Instead, 'From Holland to Copenhagen' appears framed primarily to be historically informative as well as pleasurable for YouTube viewers to watch.

Even more concerned with imparting historical information, the narrator of 'Progress in Farm Technology' describes innovations in machinery used on a grain farm in Minnesota during the years 1938 to $1958 .{ }^{21}$ The seven-minute documentary is illustrated with images taken from $8 \mathrm{~mm}$ films shot by the narrator's father and mixes technical details with more personal ones

19 This is somewhat accentuated by the film being uploaded at a frame rate faster than the one it was recorded at. It is unclear whether this has been done for humorous effect, however, the movement appears more natural if the sequence is viewed at a slower speed. The clip features obvious edits (indicated by wipes and dissolves). Initially, it included an audio track as well (removed due to copyright infringement. Subsequently, the entire video has been blocked in New Zealand, an unavoidable hazard of studying the content of such a transient repository as YouTube. The effect of an increased frame rate can be seen in another sequence of home movie footage provided by the same uploader https://www.youtube.com/watch?v=Q0V7hKWIw38 )

20 Rogge, who grew up in Amsterdam, lived in Hong Kong from 1949 to 1955 and then in Japan, before returning to the Netherlands in the 1960s. His work has screened on Dutch television and been exhibited in Japan (Bateman 2009). Rogge has made 'From Holland to Copenhagen' as well as hundreds of other travel films and personal interviews available on YouTube.

21 This and other footage recorded by the father of the uploader ('Slim5819') can be viewed on YouTube. 
such as the identification of various family members. Presumably reading from a prepared script, the filmmaker's son narrates the film in a matter-of-fact tone of voice, informing the viewer about the operation of different implements that replaced one another over successive years. Despite the assiduous attention to the description of historical developments, the narrator does not hesitate to add private reminiscences, such as his fear as a child of being submerged completely under the harvested crop, should his father forget he was ensconced in the corn wagon (visible in shot as a tiny, dark shadow). In other films, the filmmaker's son explains his choice of accompanying songs, inspired by his parents' religious observance or favourite carols to play at Christmas. He even digitally replicates his father's penchant for running footage backwards through the projector in 'Just for Fun'. Consequently, although the films are presented foremost as a record of mid-twentieth century agricultural history, they are nevertheless infused with an intimacy not readily available in home movies without narration. This very personal touch bestows a warmth and humour upon the films that might otherwise be lost amidst the components of harvester mechanisms and types of baling twine.

content unavailable

please consult print version

Fig. 2.7 \& 8. Interweaving agricultural and personal history in 'Progress in Farm Technology'. The dark shadow in the corn wagon (right) is the narrator as a child. YouTube. Screenshots.

A largely unsentimental description embracing modernisation, 'Progress in Farm Technology' finds a wistful counterpart in a one-minute montage entitled 'Saying Goodbye to the Last Horses' in which a man (possibly the filmmaker) is seen kissing a draft horse on the nose before it is led away down the road, the short sequence perhaps indicating the son's reflection upon what was sacrificed in the name of progress and efficiency.

Personal reminiscence comes to the fore in the presentation of 'Morris Family Home Movies 1954-1975 England-New Zealand'. ${ }^{22}$ The now elderly filmmaking couple, who immigrated to

22 By February 2019 the video, which was uploaded February 2014, had received about 2,000 views. 
New Zealand from the English Midlands during their early married life, have recorded their conversation while watching their home movies, presumably for the first time in many years. The resulting soundtrack might best be described as idiosyncratic. By way of introduction, the uploader (perhaps one of the children who feature in the films) invites the viewer with playful irony to

[t]ake a journey back in time as Jack and Audrey Morris take you on the ride of a lifetime with their live commentary from the couch, from Banbury to Brighton, Palmerston North to Taupo, [sic] Never before has a documentary been made that will excite the senses [as presumably this one will] and leave you on the edge of your seat as you contemplate what does this all mean?

What follows is a series of weddings, christenings, backyards, beaches, picnics and fairgrounds with little to distinguish the recordings from any number of other home movies dating from the postwar era now available on YouTube, save the inclusion of the couple's rambling stream of consciousness. Husband and wife contradict, correct and repeat each other, very often simply describing what can be observed directly from the images themselves. ${ }^{23}$ While information such as the identities of numerous relatives who appear intermittently in the films and the locations of various houses might be of interest to family members, for the most part, the commentary simply underscores the very banality of the footage. Given Jack and Audrey's banter is not so dissimilar to that of Benchley and his wife in Home Movies, it might be wondered just how many non-family YouTube viewers (aside from this one) have watched the two-hour sequence of narrated films in its entirety.

There is one significant feature of this YouTube upload that should not be overlooked, however. The experience of watching 'Morris Family Home Movies' does evoke something of the atmosphere of an actual family screening event. This is in stark contrast to the other types of soundtrack described above. In this sense, boringness might be considered the main asset of the Morris family films. One might even concur with Dwight Swanson's observation that 'the less "interesting" a film is, in the conventional sense, the more fascinated [he is] as to why it was filmed in the first place' (2003). YouTube has created further questions in this regard. Like the Morris films themselves, the very informal tone of the accompanying commentary seems in many ways ill-suited to a public audience. As a simple record of family history, the narration

23 This response is seemingly not uncommon. Nico de Klerk, for example, notes that '[o]nce home movies have left their intended settings, original participants tend to become spectators' $(2008,149)$. That is to say, their comments are often similar to those of non-participant viewers. 
forms a perfectly adequate supplement, mirroring the homespun quality of the images. The point of intrigue is perhaps therefore not so much why either the films or the narration were recorded in the first place, but why this particular recording has (along with thousands of other home movies) migrated into the public realm via YouTube, presumably uploaded by a member of the family whose life is glimpsed in the films.

content unavailable

please consult print version

Fig. 2.9. Ordinary family moments abound in 'Morris Family Home

Movies'. YouTube. Screenshot.

What conclusions might be drawn from these different attempts to alter or improve home movies for dissemination in the public sphere? The addition of soundtracks to home movie images and, in some instances, the editing of footage might be read as indications that many YouTube users perceive that silent films in their raw form could be construed as somewhat underwhelming, perhaps even boring. By enlivening home movies with music, sound effects, commentary or faster pacing, the amateur archivists of YouTube presumably seek to present their films in an engaging manner. That is to say, they seemingly wish to dispel the likelihood of 'an acute attack of sleeping sickness' (Shultz and Shultz 1972, 14) amongst viewers caught in a Heideggerian state of limbo due to a film being boring in its boringness.

Some attempts are noticeably more successful than others. With the obvious exception of 'Progress in Farm Technology', the examples discussed above appear concerned primarily with creating an enjoyable viewing experience rather than necessarily an informative one. Both the selection of music tracks and comments of viewers suggest that the pleasure of watching home movies is for many people linked to nostalgic recollection. In this way, soundtracks may 
potentially aid viewers to discover personal resonances in other people's home movies. Nevertheless, as the uploader of the Morris family films suggests, meaning is seldom explicit in home movies, even if the soundtrack features 'live commentary from the couch'. More radical alterations to home movie form than the relatively simple modifications typically made by YouTubers would seem necessary to construct less ambiguous viewing experiences. If boredom is assumed to have an inverse relationship with meaningfulness, not being bored seemingly requires a certain amount of contemplative effort on the part of YouTube viewers who watch home movies online, with or without the modest manipulation of footage. In contrast with such efforts, the following chapter considers more extensive, organised and meticulous uses of home movie footage in contexts further removed from the home. 


\title{
Chapter 3
}

\section{The alchemist's touch \\ Or not becoming bored by recycled home movies}

\begin{abstract}
the apparent guilelessness of home movies or amateur footage can be really deceptive, and that's something not every viewer is alert to... what we really still lack is a consensus view on the politics of home movie re-use.
\end{abstract}

Whether or not decisions in preservation or presentation are explicitly or implicitly motivated through the ideologies or politics of those responsible, what are the further implications of narrativizing or mobilizing particular histories through home movies? Is the focus on content or context? In other words, what are the politics of recycling old media in new ways? ... which of the countless home movies from private individuals should become a part of broader public discourses? ... whose history is it?

- online comment (top) by Snowden Becker in response to post (below) by Daniel Mauro (2012)

The potential significance of everyday images, if Steve Anderson is to be believed, is 'poised to expand dramatically' in a digitised world where making, distributing and reusing moving images has become the province of increasing numbers of people. Moreover, he notes that 'control over the writing of history is at stake in the appropriation and reuse of film and video images' $(2011,92)$. With this in mind, the present chapter examines various types of moving image works that incorporate found or recycled home movie footage. The reuse of amateur footage within another film represents one of the earliest ways that home movies entered the public domain. From the 1960s onwards, filmmakers including Malcolm Le Grice, Ken Jacobs, Jerome Hill, Michelle Citron, Alan Berliner, Ross McElwee and Péter Forgács have reused home movies within new works. Other experimental filmmakers - most notably Jonas Mekas and Stan Brakhage - have deliberately recreated a home movie aesthetic in films intended for public viewing. Amateur footage has migrated into the public sphere via television, often incorporated into popular history documentaries. There are even series compiled almost exclusively from home movies. They have also found a place in contemporary art galleries; with the proliferation of digital screens and projectors, home movies have become part of video installations. Music videos, official or otherwise, featuring amateur images are scattered across the Internet. In the twenty-first century, the reuse of home movie footage is rife.

What are the effects of all this home movie reusage? How do filmmakers, artists and television 
producers envision us as viewers thinking and feeling about home movie images and the past they enable us to see? As outlined in the previous chapters, home movies are not especially well suited to entertaining viewers who were not their intended ones. Their range of content and disjointed form can vex spectators who want home movies to be meaningful in a manner not directly connected with recalling their own past. It is probably a safe assumption that those who reuse home movies, whatever their intentions, do not typically (if indeed ever) want us to feel bored watching their work. Filmmakers, as noted in the previous chapter, are very much cognisant of the effects of time passing too slowly for viewers, who may become disengaged if nothing much of interest seems to transpire onscreen. It is not too surprising then that home movie footage that makes its way into the public sphere within other productions is usually altered quite considerably. Speaking of the work of Péter Forgács, Bill Nichols describes the Hungarian filmmaker's manipulations as 'a form of alchemy, transforming the dross of home movies into the gold of social history and philosophic meditation' (2011, vii). Praising Forgács as a master of suspense and identification, Nichols suggests such attributes 'make the charge of boredom seldom heard in relation to his films' (xvii).

Once home movies have been indelibly marked by the hand of an intermediary it may of course be difficult to know if they would have appeared meaningless or boring to audiences in their original form. Recycling speaks to an aspiration to bring forth (or impose) something that is not immediately discernible within original footage. In this sense it is implicitly (if not explicitly) ideological. It involves understandings of the past both individual and collective, technological and social. Recycling might be seen as a form of recovery or clarification of meanings lurking just below the surface of home movies. It may reflect upon the meanings of images with the benefit of hindsight. It could even involve putting back into history what was not actually there in the first place. Home movies may enchant the eye with their soft, grainy texture and rich colours that afford a beguilingly lusher-than-life image of a vanished world. The seemingly artless exterior of home movies can be deceptive, inducing historical awareness more affective than factual or analytical.

The following discussion is not intended to be a comprehensive survey of productions that recycle home movie footage, an undertaking well beyond the scope of a single chapter. Instead, this chapter offers an overview of some general tendencies seen within a range of productions that recycle home movies. The reuse of home movie footage is prolific and varied. No single 
linear narrative or argument can neatly account for all the individual examples one might cite. In view of this great abundance, the specific selection discussed here is necessarily somewhat arbitrary, in part determined according to the availability of viewing copies of what are (at least in some instances) relatively obscure works. Nevertheless, a number of recurrent tropes can be observed across different productions. Whether accepted or critiqued, the authentic, evidential or representative nature of home movie images play an important role in their reuse, along with their affective dimensions, which may invoke identification, a sense of nostalgia or pleasurable voyeurism. Moreover, the use of home movies within new works is always to an extent concerned with engaging a public audience. Although many of the films discussed do not 'kill time' or entertain in a conventional manner, they do (almost certainly) intend to stave off the kind of meaningless experience that holds a spectator in limbo counting down the minutes as if stranded at Heidegger's lonely rural railway station. That is to say, the job of the home movie alchemist is to ensure viewers do not become bored by (what they perceive to be) a boring film. If this discussion proceeds from an overall assumption then, it is that the recyclings of home movies examined all have at least one thing in common: a desire to rise above meaninglessness.

\section{Home movie footage and different kinds of alchemy}

Not all alchemists are as skilled or inventive as Forgács. Yet most home movie recyclers share one propensity; in new works the images of home movies are retained but seldom in a form closely resembling their original one. Films are re-edited and interspersed with other types of footage. Soundtracks are added. Silence is filled with music or commentary. 'Diegetic' noise is recreated. Sometimes alterations are an even more radical departure from a film's original form. Footage is not just recut but slowed, frozen, rewound or repeated. Part of an image may be enlarged in order to zoom in upon a specific element. Images may be superimposed over one another. They may be deliberately degraded. While many films discussed in this chapter predate the advent of computer editing, digital technologies have considerably increased the ease of manipulating images, and with it the ease of directing the attention of viewers in particular ways.

In order to be truly engaging all these alterations must logically be concerned in some way with making films entertaining or meaningful to viewers. Narrative is the dominant method of constructing meaning in cinema and entertaining audiences. It is also probably the simplest way to make personal footage accessible to viewers unable to recall an extra-filmic event associated 
with an image; it is a means of filling duration with eventfulness. Even without explicit narratives, films do not necessarily bore audiences, however. Some spectators find experimental films, for example, which may arouse sensations more difficult to quantify than stories in terms of meaning, pleasurable to watch; others will become bored by plotless films that rely upon some alternative form of coherence. The relationship between interest and boredom, meaning and entertainment is a complex one. Narrative is a significant contributor to both meaning and entertainment, but not an indispensable one.

In examining the reuse of home movies within other productions, Roger Odin distinguishes different modes a film may take in order to construct meaning and affect. Home movies in their original settings belong to the private mode. They enable participants to revisit past experiences, their value linked to reminiscence and reinforcing ties between family members. In another context, a home movie assumes a different function. It may be used as documentary footage to inform viewers about historical experiences $(2008,255-6)$. This is perhaps the most common form of reuse, particularly in television productions. In this mode home movie images act as visual evidence of the past. Alternatively, a home movie might become a vehicle for analysing a discourse, telling a fictional story, creating moments of pure spectacle, or stirring the emotions of spectators through the rhythm of sound and images (255). These functions come to the fore when the informational content of home movies is of secondary importance to the affective or formal qualities of images. Of course, home movie footage can also operate on multiple registers within the same production. Viewing amateur images as historical information, for example, need not preclude affective responses, aesthetic pleasure or critical distance. ${ }^{24}$

In its original context, according to Odin, 'the home movie works well when it is badly made' by professional standards. The more disjointed or fragmentary its succession of images, the less likely a home movie is to conflict with the memories of individual family members $(2014,17)$. In public contexts, images that fail to coalesce into a self-contained, unified whole may simply frustrate viewers. The aesthetic choices of filmmakers working with home movies can therefore be pivotal. More than just engaging viewers, they influence how home movie images are received. Recycled footage can invoke an aura of nostalgia, stir nationalist sentiment, or simply

24 Odin discusses these modes principally in terms of reception. He notes, however, they can also be considered from the perspective of direction (268n). These may or may not coincide given a viewer could receive a film in a different mode from the one intended by its director. For example, a documentary filmmaker might seek to inform an audience, while an individual viewer could enjoy the visual spectacle of the film, paying little heed to its value as information. 
conjure a vague sense of pastness. Alternatively, uses may be more analytical or self-reflexive. Source material or historical experiences can be interrogated, encouraging audiences to question the reality they are seeing. These transformations intimate a need - perceived or actual - for the alchemist's handiwork. Yet the benefits are not universally accepted it seems. As will be seen, home movies also occasionally appear in new works with a minimum of reworking, presented in a manner much closer to raw footage. It might be wondered of course if this simply returns viewers to the possibility of becoming bored by other people's home movies.

The recycling of home movies transpires in many forms. Productions that reuse old footage are sometimes distinguished by terms such as 'compilation film' or 'found footage film'. The former is often used to describe documentaries that purportedly present historical realities through the use of archival footage, whilst the latter may refer to experimental films that recycle footage in order to question notions of historical evidence or deconstruct 'facts'. In practice the boundaries between compilation film and found footage film may be relatively indistinct (Baron 2014, 8) ${ }^{25}$ Certainly not all films discussed in this chapter fit into straightforward categories. Some acknowledge the limitations of amateur images whilst simultaneously using them to illustrate historical narratives. Nor do all films that recycle home movies make obvious gestures to appeal to their public audiences. The three key works looked at in the next section are not overtly preoccupied with entertainment in a conventional sense, even as they engage in complex manipulations of footage. They do not display a pronounced 'fear of boredom', or an abundance of 'time-killing' techniques. By way of introduction, they do nonetheless illustrate different approaches to home movie footage particularly effectively, drawing attention to specific attributes of private images and the contingencies of their reuse.

\section{Recycling home movies: aesthetics, evidence, contingency}

British avant-garde filmmaker Malcolm Le Grice's Little Dog for Roger (1967) is an early example of the recycling of a home movie. The original black-and-white footage, shot on $9.5 \mathrm{~mm}$ film stock by the filmmaker's father fifteen years earlier, depicts a young Malcolm, his brother and their mother (but not the eponymous Roger) playing with a boisterous pet, the kind of familiar family scene that might readily lend itself with the passing of time to

25 Similarly, Baron notes that terms such as 'archival footage', 'found footage', 'stock footage' and 'recycled footage' may be used relatively interchangeably to describe the source material used for new productions (8). 'Found footage' is sometimes taken to imply acquisition from an unofficial source, such as discarded reels that have been 'lost' and subsequently 'found' at a garage sale or in a dumpster, for example. However, 'found footage films' frequently use material from public or private archives as well. 
sentimental forms of appreciation. Yet at first glance, the presentation of this potentially nostalgic material largely eschews the possibility of such affect. Initially, only a blur of film strip moving up the screen is visible. Gradually its subject comes into focus. Central sprocket holes in view, the film image is played erratically, advancing unevenly and then appearing to jam in the projector, freezing the image - and its canine subject in mid flight - before advancing once more, sometimes frame-by-frame. The film strip is looped and replayed; it slips side-to-side across the screen, occasionally with a second strip running parallel to or superimposed over the first. Sometimes the image is in focus, sometimes not. Scratches, dust and signs of deterioration are often more readily discernible than the ostensible subject matter of the film. Intermittently, the screen goes blank, the image is seen in negative or even appears upside down. This medley of processes intended to draw attention to the materiality of the film strip and the cinematic apparatus more generally is accompanied by the cracking strains of old gramophone records, heard fading in and out on the soundtrack, the unmistakeable noise of the needle at one point scraping across the grooves. Sound and image are fractured and degraded, imperfectly replayable, like memory itself.

content unavailable

please consult print version

Fig. 3.1-3. Central sprocket holes, focal dips and side-to-side slippage draw attention to the materiality of the film in Malcolm Le Grice's Little Dog for Roger. The home movie subject remains visible, however. Screenshots.

Fifty years on from its making, in its foregrounding of the film medium Little Dog for Roger has obvious potential to invoke an unintended sense of technostalgia. With time, the film experiment has acquired a certain poignancy in its technical self-awareness, like an ode to a long obsolete medium, the characteristic central sprocket holes of the $9.5 \mathrm{~mm}$ format dominating the field of vision. In hindsight, Le Grice has also noted that in his fascination with materiality and medium something essential was overlooked: 'I forgot that one of the boys was me, the other was my brother, the young woman was my mother - now dead - and behind the camera in 1952 was my father' (n.d.). For all its formal manipulations, Little Dog for Roger's source 
material remains very recognisably a home movie, a depiction of a family event that transpired before an amateur camera. It is therefore also a record capable of reawakening memories at a later date, in spite of efforts to efface its original mode of being in favour of a work concerned with the material properties of the physical artefact. John Sundholm suggests that in those moments when the projection of the film synchronises with its speed of recording (albeit imperfectly), the dog (as lost object) is revived, that is, the past is briefly resurrected onscreen, potentially evoking a sense of loss for what has been. Thus, at the level of content the film does not eliminate the possibility of nostalgia entirely for the viewer, who might easily conjure a comparable memory of family life, even if it is constantly displaced by awareness of the cinematic object $(2005,59)$. Furthermore, the insistence upon the materiality of the film might be seen to parallel (or perhaps allude to) the constructed or 'poetic' nature of memory itself (56). The events of one's past are always recalled inconsistently, the mind lingering upon some moments while passing over others; likewise, the scratchy film strip dips in and out of focus, plays, pauses and replays. Moreover, Little Dog for Roger's 'aesthetics of materiality' involve an 'act of pointing' to the traces of its own production, something Sundholm assumes to be both ethical and political in the sense of implicitly invoking questions such as by whom was it created? when? why? (62) Accordingly, it might be argued that Le Grice's film exceeds simple critique of the indexical function and narrative tradition of cinema, creating a complex play between film as physical medium and film as depiction of its (historical) subject (60).

Questions of who, when and why are addressed more explicitly in Ernst Star and Steven Zeitlin's 1975 documentary, Home Movie: An American Folk Art, which was produced for the Smithsonian Folklife Festival. Presented in a tone of rather scholarly seriousness, the twentyminute film to some extent seeks to inform more than entertain. Indeed, Richard Chalfen has commented that despite the film's useful ability to stimulate classroom discussion, students have a propensity to find Zeitlin's lecture style of delivery somewhat 'tedious' (1980, 246). Although not the first documentary to incorporate amateur or home-mode footage, ${ }^{26}$ Home Movie is noteworthy for taking home movies as its central object of inquiry. In short, it is a film about home movies, rather than one that simply uses home movie footage to illustrate or explore some other topic or issue.

Home Movie opens with a shot of toddlers in a backyard paddling pool, which Zeitlin proceeds

26 Chalfen lists several films made in the early 1970s that include home mode images $(1987,145-7)$, including some of those discussed below. 
to identify as an image of himself and his brother as children. He then appears to switch off the projector, turning to the viewer to explain those features of home movies pertinent to the folklorist, drawing particular attention to the highly selective nature of home recordings and the significance of this as a representation of the values and ideals of American families. This introduction is followed by an extended montage of typical home movie subjects: happy parents, children and babies, backyard games, beaches, birthdays, Christmas trees, weddings, graduations and so forth. Accompanied by the melancholic piano of Satie's Trois Gymnopédies on the soundtrack, the sequence seems calculated to stir feelings of nostalgia. This effect, however, is immediately situated within what Zeitlin describes as a seemingly universal human desire to construct a personal 'golden age' upon which to look back. Reconciled with the narration, the film's deliberate exaggeration of the potentially nostalgic or sentimental attributes of home movie imagery assumes a reflexive dimension.

Shifting focus from the production of home movies to their subsequent viewing, Home Movie instigates what has since become a standard strategy of the genre, albeit often within a less critical investigative framework. As in many subsequent documentaries composed of recycled home movies, filmmakers or their relatives are asked to watch their family films and comment upon them. Home Movie very clearly attempts to replicate typical family viewing situations. The decision to retain in the final film laughter, unintelligible murmurs and cries of disappointment when footage is underexposed, for example, might appear somewhat curious at first glance as such utterances contribute little of informational value. This largely phatic dialogue between participants nevertheless effectively underlines the social function of home movies as familial communication or, in colloquial terminology, 'family bonding'.

There is no specific reflection upon any potential shortcomings of the use of home movies as an aide-mémoire for initiating participant interviews. Zeitlin's intermittent onscreen presence as documentary-maker influencing and interpreting the screenings does provide a counterpoint to more vérité moments in the film. Participants are encouraged not only to reminisce about the content of films, but also to reflect upon their value as personal memory objects. Interviewees express a desire to remember 'the good times' rather than less pleasant experiences (during the Depression, for example) and question the extent to which home movies reinforce or potentially create memories, particularly for the youngest members of a family. One filmmaker's daughter even recalls that her mother refused to watch her husband's films after he died. Zeitlin therefore 
concludes on the rather sombre note that the buoyant images of home movies belie any sorrow they may evoke for individual family members, cautioning that to non-family it may seem that home movie subjects are 'simply waving to us from a dream of happiness'. The documentary has a rather homespun, self-conscious quality that arguably suits its discussion of amateur moviemaking quite well. (Notably, Star and Zeitlin were themselves students at the time of production rather than professional filmmakers (Folkstreams n.d.)). By not disguising its formal construction - or that of its source material - Home Movie tempers the affective appeal of its imagery with critical distance from its subject.

content unavailable

please consult print version

Fig. 3.4 \& 5. Home movie nostalgia is undercut by critical reflection from the filmmaker in Home Movie: An American Folk Art. Screenshots.

Critical distance is also a noticeable feature of Péter Forgács's Wittgenstein Tractatus (1992). Forgács is perhaps the filmmaker most readily identifiable with the home movie found footage film, having produced numerous film and video works incorporating amateur material, including the Private Hungary series (1988 onwards). Wittgenstein Tractatus is neither Forgács's most characteristic, nor his most accessible work. Nonetheless, viewed as a kind of oblique meta-commentary on the Hungarian filmmaker's general oeuvre, Wittgenstein Tractatus is quite illuminating in terms of what it suggests about home movies and their reuse within another production.

Unlike in many of his other works, Forgács does not use home movie footage in Wittgenstein Tractatus as a source of historical information about specifically identified people, places or events. Instead, he uses amateur images to illustrate a philosophical discourse, albeit hardly in a straightforward manner. The film is presented in seven sections, each one introduced with a 
proposition from Ludwig Wittgenstein's Tractatus Logico Philosophicus (1921) and featuring a montage of images taken from amateur films that mostly appear to predate World War II. On the soundtrack, excerpts from the treatise, along with more personal observations from Wittgenstein's notebooks, are read in halting, accented English. These statements are often repeated, either verbally or as text superimposed over the images (usually in both English and Hungarian). Occasionally, a woman's voice interrupts, whispering utterances unintelligible to an English-language speaker. There is no direct relationship between the film's words and images, although in certain instances Wittgenstein's statements do align in some way with what is visible onscreen: people resting during a countryside excursion stare blankly at the camera lens and thus, by implication, the viewer ('How hard I find it to see what is right in front of my eyes!'), a writhing pig is repeatedly prodded by a booted foot ('The horrors of hell can be experienced within a single day. That's plenty of time.') In other instances, there is no explicit connection between what is seen and what is heard. In this way, Forgács appears to give visual form (somewhat paradoxically) to Wittgenstein's meditations upon the discrepancy between showing and speaking. The precise interpretation of any particular image-text combination is left largely open to the viewer, however.

content unavailable

please consult print version

Fig. 3.6 \& 7 . Subject and statement align: a woman stares at the camera ('How hard I find it to see what is right in front of my eyes!') and a writhing pig ('The horrors of hell can be experienced within a single day. That's plenty of time') in Wittgenstein Tractatus. Screenshots.

If Wittgenstein Tractatus contains a central preoccupation as a film (distinct from the emphasis of the treatise itself), it is perhaps the contingent nature of events and the images that preserve them. The film's often badly scratched and deteriorated images are repeatedly torn apart and reassembled (rather crudely in the videographics of the time). This recurring motif seemingly underscores the fortuitous and fragile nature of archival images. Moreover, Wittgenstein 
declares, 'Everything we see could also be otherwise. Everything we can describe at all could also be otherwise', statements that seem to characterise both Forgács's source material and his arrangement of it. In a companion essay of the same name, Forgács describes private film as 'a veritable stock of fact-images', which acquire the appearance of 'affirmative statements' or definitive versions of an event - 'the only way it could have been' - and yet at the moment of recording 'any accident of circumstance can be fixed as fact by the captured image' (2008, 51, 54). Forgács's subsequent combinations of text and images often appear relatively arbitrary, or at least ordered according to a rationale fully comprehensible only to the filmmaker himself. As sequences of found footage, the images could seemingly be rearranged, or replaced with different images altogether, conceivably to similar effect. The incidental, often haphazard quality of amateur films and the experiences they record therefore find a parallel in Forgács's idiosyncratic reuse of home movie footage in Wittgenstein Tractatus.

Unlike the two previous examples, Wittgenstein Tractatus is not exactly a film about home movies per se. It does nonetheless allude to the fluid or indeterminate nature of images culled from any archive of private history in terms of meanings that can be attached to them. Forgács notes the impossibility of those who look out of a film's 'local time' into our own foreseeing their future and that of their recorded images. As 'wise spectators' with the hindsight of our own time, we watch from an historical vantage point (56). We can therefore attribute significance to images that transcends the experiences of subjects at the moment of filming. Footage of departing soldiers climbing aboard a goods train with carriages that resemble cattle trucks, or a man of Jewish appearance glancing at a soldier with a gun slung across his shoulder might well have been recorded in quite innocuous circumstances in comparison with the horrors of war and genocide that such images call to mind. Indeed, according to Forgács, the apparently tormented pig is afflicted by a nervous disorder, not suffering wanton abuse at the hands (or feet) of its owner. The suffering animal arouses the viewer's sympathy, yet also demonstrates the inability of an image to convey either interior states of being or broader social contexts. Given this, Tyrus Miller questions whether our sympathy has a genuine object, asking 'what can we humanly know of how a pig with a nervous disorder feels?' (2011, 180-1). Miller suggests therefore that the images of home movies 'evoke a zone of irreducible hiddenness that lies beyond the limits of the visually manifest'. Even if its subject is human not animal, a film's original personal meanings are lost as found footage, leaving 'only a set of signs that can be seen and, as seen, seem to possess a meaningful character; but what they mean one cannot really say' 
(182). Private history challenges our ability to make sense of its artefacts, particularly in a way that coheres with actual lived experience. Quoting from Wittgenstein, Forgács concludes both film and essay with the pronouncement, 'Whereof one cannot speak, thereof one must be silent' (56). Despite this impenetrability, or perhaps precisely because of it, Wittgenstein Tractatus does suggest alternative possibilities for appreciating private films.

The impossibility of definitive readings of the images in Wittgenstein Tractatus arguably favours analogical understandings, whereby the particular (albeit not specifically identified) comes to stand in for broader historical or anthropological experiences. That is to say, Forgács is not concerned (in this instance) with one-to-one correspondences between the images he utilises and the specific persons or events they document. It is not therefore, according to Miller, 'a matter of missing information, as if watching the film with an archival finding aid would yield a better viewing' (183). Rather, in their indeterminacy, the amateur images invoke a more general social and historical terrain shared with and familiar through other representations of a particular milieu (specifically, a mid-twentieth century Central European bourgeoisie). Even more generally, home movies can be used to represent a collective human experience of living, such as the capacity for joy (a man leaping exuberantly before the camera), or any sentient creature's capacity for suffering (the afflicted pig, a rabbit with partial paralysis, a carthorse collapsed in the street) (183-4). Beyond even the analogical, the scratched images of anonymous home movie subjects might potentially stimulate less critical and more affective responses, producing a vague identification with the past in the form of recognition that it was once alive (Pierson 2009, 7, 14), just as we are in the present. Without being explicitly meaningful, the home movies of Wittgenstein Tractatus conjure a sense of pastness, of social context, of being-inthe-world. On the whole, Forgács's interest would seem to lie as much in tracing the limits of what can be said about amateur films as in crafting a more broadly meaningful work from them (Miller 2011, 185).

As explications of home movie materiality, social function and epistemological indeterminacy respectively, Little Dog for Roger, Home Movie: An American Folk Art and Wittgenstein Tractatus have a conspicuous perceptibility with regard to the nature of their source material. Amateur images do not masquerade as indisputable evidence, but are animated as particular kinds of artefacts and visions of the world. In their refusal of straightforward narrative, these films do, however, risk being boring, perhaps as much, if not more so than the raw footage from which 
they have been assembled. Presented like a series of ifs, buts and maybes, the limits of home movie representation are visibly on display, even when not of central concern. According to Wittgenstein, 'the picture is a model of reality' (in Forgács 2008, 52). As a representation of its referent, however, its verisimilitude remains uncertain: 'It cannot be discovered from the picture alone whether it is true or false' (49). More precisely, the accuracy of what is stated or implied about an image may not be discerned from viewing it in the absence of any knowledge of its original context of production. By not suturing images into a seamless illusory whole, by questioning their veracity, by making their manipulation readily apparent, filmmakers signal their own role in the construction of any kind of historical truth or meaning that may be derived from amateur films.

Arguably, as examples of recycled and reprocessed home movies, none of these found footage exercises display an overt concern with entertaining an audience as such (although this is certainly not out of the question). Indeed, they might be considered tedious, unnecessarily didactic or esoteric, or just plain dull, depending upon the individual inclinations and tolerances of viewers. While these works all presuppose a viewing public of some kind, their makers presumably did not anticipate a general public of the heterogeneous nature that a commercial feature film or television broadcast, for example, is likely to reach (although notably all three films are now accessible on the Internet). Nevertheless, they exhibit a number of techniques and preoccupations that resurface in many other productions incorporating home movie footage - including those that would appear to have a broader audience in mind - albeit often within less transparent or critical structures for articulating meaning and affect. The rest of the chapter examines how the material, social and epistemological dimensions of home movies - foregrounded in relatively undisguised fashion in the films discussed above - play out within a variety of productions that make use of amateur footage, often in much less conspicuous ways. Before looking at some examples of these, it is worth initially considering a somewhat different kind of 'home movie', one that seems to 'flirt with features of home mode practice' (Moran $2002,73)$.

\section{'Home movies' and the construction of credibility}

The basis of Le Grice's experiment in Little Dog for Roger is undoubtedly an actual home movie, recorded by the filmmaker's father fifteen years prior. Aside from reusing old footage, filmmakers also record films that approximate the appearance of home movies. Films that 
display what James Moran calls 'fuzzy resemblances' $(2002,71)$ deliberately mimic a home movie aesthetic. This mimesis is quite revealing vis-à-vis perceptions of actual home movies, something that in turn points to ways they may function when recycled in new productions. In other words, 'home movies' cast a certain light upon the reuse of home movies.

Fuzzy resemblances are often seen in avant-garde cinema, most notably in the use of smallgauge formats and frequent recourse to domestic images of home and family. These features, combined with the amateur status (in both the economic and etymological sense) of many avant-garde filmmakers, blur the distinction between home movies and their more experimental counterparts. Avant-garde films that look like home movies in a number of respects might nevertheless be delineated as a practice distinct from more typical home-mode production on the basis of intention. The specific cultural purpose of avant-garde filmmaking is generally somewhat different to that of home movies. Avant-garde or experimental films are typically regarded as works of art and are usually intended for a public context. Furthermore, they are often concerned with reformulating existing systems of values, including the aesthetic and political. Home movies usually function (at least initially) as private records viewed in a domestic space. Moreover, while home movies are made and consumed outside industrial production networks, they tend to preserve and legitimate existing social beliefs. As images of a family's past, they offer a sense of continuity between generations, whereby family history and values are reiterated and passed on. Thus, social and formal function (personal record or artwork), audience (family or public) and ideological purpose (conservation or transformation) suggest points of reference that may be used to isolate different filmmaking practices that share 'textual affinities' (ibid., 71, 74). As Moran points out, there is nonetheless a certain amount of overlap between home movies and avant-garde 'home movies' (70). This is seen perhaps most prominently in the works of Jonas Mekas and Stan Brakhage, both of whom had a tendency to conflate amateur, avant-garde and home movie in their theoretical writings (73-4). Confusion between personal and private forms of filmmaking has, according to Moran, subsequently resulted in critical arguments that position home movies 'as a corrupted amateur practice' (67), one that could be radical and innovative given its potential for freedom of expression, but quite simply isn't. Bearing this ideological division in mind, the emulation of a home movie aesthetic by avant-garde filmmakers might appear somewhat at odds with a radical agenda. The formal intersection is marked by complexity and ambiguity, however. 
Chalfen describes the films of Mekas and Brakhage, amongst other filmmakers, as '"home movies" only in the sense of sometimes being shot "at home" with simple and comparatively inexpensive filmmaking technology' (1987, 143-4). This would seem to understate the case quite considerably; the resemblances and correlations extend well beyond material practicalities of production. To cite an exemplary example of the convergence of avant-garde and home-mode filmmaking, A Visit to Stan Brakhage demonstrates not only the avant-garde propensity to situate itself within the domestic, but also a number of other home movie attributes, albeit in substantially modified form. In this 13-minute film shot by Mekas in 1966 (subsequently released in 2006 as part of the First Forty series) at the Brakhages' home in Colorado, images of children, pets and domestic activities recorded in the dimly lit interiors of a log cabin mirror typical home movie scenes, as does the jerky, handheld photography. However, Mekas's signature use of rapid montage, including single-frame images producing an effect of fragmentation and accelerated movement, clearly distinguishes his work stylistically from a conventional home movie. While it is impossible to discern the extent to which it has been subsequently reworked, the film is nevertheless carefully structured, incorporating inter-titles and bookended with images of Mekas's journey to and from Colorado. Unlike most home movies, the film also features a soundtrack incorporating the presumably diegetic but asynchronous sound of children's voices and the Lili Boulanger choral arrangements that Brakhage (according to an inter-title) played during Mekas's visit, the incongruous mix of sounds both accentuating the ordinariness of the setting and imposing a rather quaint grandeur upon the humdrum of everyday life.

content unavailable

please consult print version

Fig. 3.8 6 9. Family scenes in Jonas Mekas's A Visit to Stan Brakhage. Screenshots.

In major works such as Reminiscences of a Journey to Lithuania (1972), Mekas's first-person 
narration, which retains his 'off-the-cuff remarks and grammatical errors, recalls the impromptu discussions of family screenings. Its poetic quality nonetheless alludes to the orchestrated nature of his films (Ruoff 1991, 8, 20). Drawing upon a home movie aesthetic to evoke the kinship and nostalgic associations of the form, Mekas, an émigré filmmaker without a family home in America, constructed a substitute family in exile from the avant-garde community, most noticeably in Lost, Lost, Lost (1976), which charts his initial sense of displacement and gradual integration into New York's art world. Consequently, the avant-garde 'home movie' may be said to share certain cultural functions with home movies, not just elements of their aesthetic (Moran 2002, 70, 75). In its public intentions however, Mekas's body of work is clearly distinct from actual home-mode production.

Aspects of home movie imagery can also be seen in the works of many other avant-garde filmmakers. Brakhage's handheld photography and domestic subject in Window Water Baby Moving (1959) share obvious affinities with an actual home movie, however, the film is both highly edited and far more explicit, the rapid intercutting of a lyrical bathing scene and visceral birthing scene including numerous close ups of anatomy. Brakhage created a nightmarish sense of home in Scenes from Under Childhood, Section One (1967) with swift editing and distorted images disrupted by blank screens of flickering colour. In their avoidance of cuteness, ordinary domestic scenes become uncanny; a toddler attempts to feed a younger sibling cast in eerie shadows, shots of floorboards suggest an unsettling, constricted 'child vision'. At another extreme, in James Broughton's This is It (1971) images of a toddler playing in a garden and nearby suburban streets are elevated to Biblical mythology whereby the filmmaker's son(?) becomes a two-year-old Adam in Eden, the enclosed paradisal world providing everything the child (or humanity) requires. Ken Jacobs also displays a fascination with the domestic in Nissan Ariana Window (1969), recording images of his wife while pregnant and of their baby. However, again there are indications that this is something other than a home movie. Despite the appearance of spontaneity, most noticeable in the antics of their kittens and the baby's stubborn refusal to stay in frame, the absence of handheld photography and studied close ups of naked body parts, pot plants and other household items trace a somewhat different terrain.

One might pursue a list of 'home movies' very much in inverted commas relatively indefinitely, citing numerous lesser-known entrants in the category of films with 'fuzzy resemblances'. Constance Beeson's films (Holding 1971, Grow Old Along with Me 1974), for example, combine 
domestic subjects with carefully composed rhythmic editing, superimposed images and sexually explicit content. The silent Super-8 films of New Zealand artist Joanna Margaret Paul might even be mistaken for simple home movies due to their technical and stylistic similarities and subjects drawn from daily life. ${ }^{27}$ Some were exchanged with the filmmaker's sister 'to bridge a geographical gap' (Paul 1985, 10), a not uncommon practice amongst home moviemakers anxious to strengthen ties with relatives overseas. Paul's films are nevertheless the work of an exhibiting artist and in this sense exceed home-mode production. Although edited in-camera, her images appear carefully selected, attuned to a feminist perspective upon the quotidian by a woman who, in her own words, did not 'wish to separate the significant and everyday actions but to bring them as close as possible together' (n.d.). In a not dissimilar vein, Margaret Tait attentively documented her surroundings, family and everyday life in Scotland. ${ }^{28}$

The merging of life and art is often a feature of avant-garde discourse, arguably less attainable in practice if art is assumed to require some degree of critical distance from the everyday; the very idealism of home movie representation might in fact seem to justify such a conclusion. Moran nevertheless suggests that 'by their efforts to construct a utopian vision of the world, the avantgarde and home movies intersect in their imagination of social alternatives'. Home movies may not be radical, yet, according to Moran, produced within the less regulated sphere of personal leisure, neither are they 'wholly expressive of dominant ideology' (75-7). This is not to say their idiosyncratic form cannot be co-opted into more mainstream cultural expressions, where their use (or, more commonly, their fabrication) is, in some respects, more directly revealing than within avant-garde cinema.

Commercial feature films sometimes incorporate pseudo home movies into fictional narratives. Examples include Peeping Tom (1960), Raging Bull (1980), Paris Texas (1984), Philadelphia (1993) and The Limey (1999). While the exact purpose of this visual trope varies between films, 'home movie' sequences are often used to indicate a time period coded as somehow more innocent or happier than the diegetic present (Erens 1986, 99-100). In other words, home movie imagery may recall earlier times through a nostalgic lens. As representations of the past, home movies can also play another role, offering insight into subsequent events or the

27 This can be seen in Thorndon (1975), Napkins (1975), Aberhart's House (1976) and Task (1982), for example.

28 Tait was a prolific filmmaker. Not all of her films display a 'home movie' aesthetic, although examples such as Milano (1949), Portrait of Ga (1952), Happy Bees (1954), Edinburgh General (1955), Splashing (1966), Growing Up (1970) and Tailpiece (1976) fall within this general description. 
psychology of a particular character. In this sense, home movies become 'the bearer of truth', documentary evidence within a fictional diegesis (ibid.).

A somewhat disconcerting variation of this is seen in Sarah Polley's Stories We Tell (2012), a documentary about the director's parents that incorporates faux home movies alongside real ones. Both bona fide and fabricated movies are used to illustrate Polley's narrative and offer evidence of her deceased mother Diane's vivacious personality, the two intercut so smoothly it is often difficult to discern which were recorded in the present day. Only towards the end of the documentary is it revealed that Polley has in fact staged many of the home movies, which up until that moment could potentially be mistaken for films dating from the 1970s. Despite Polley's insistence the film's participants should be allowed to articulate their own versions of her mother's life, there are few major discrepancies between her interviewees' recollections of the events leading up to Sarah's birth. Rather, various family members and friends fill in different details to which they were privy in order to paint a broader picture of the film's absent central figure. The home movies often match these descriptions quite closely. Consequently, the pseudo home movies in Stories We Tell arguably function in much the same manner as the real ones, 'authentic' in the sense of conjuring the flavour of Diane Polley's life, if not its actual moments. By recording the reconstructions on Super- 8 to resemble actual family films, Polley invokes a strong sense of pastness that contrasts with the crisp video footage of the present-day interviews. Reminiscences and home movies coincide rather too neatly at times, potentially raising questions in the minds of viewers as to who could possibly have been filming certain scenes (prior to the eventual revelation that many were staged). In the end however, it seems almost irrelevant whether the viewer can pick which individual home movies are real and which have been created specifically for the documentary. They all look real enough to illustrate the narrative effectively, regardless of whether they are evidence in the sense of actual family records, or represent dramatisations of an interviewee's testimony.

The use of home movie imagery to evoke a sense of time passing, nostalgia or truthfulness may be pursued even more blatantly in advertising. The 2013 Christmas advertisement of UK supermarket chain Tesco, for example, is a medley of stereotypical footage of family gatherings, starting with recordings on $8 \mathrm{~mm}$, followed by VHS and finally digital video as the sequence condenses half a century into the space of one and a half minutes. Accompanied by a cover of Bob Dylan's 'Forever Young' (1974), the sentimental presentation of home-mode images invites 
the viewer to indulge in a nostalgic reverie, only disrupted in the final seconds with the implicit message that the wholesome goodness on display can be purchased (at least in its more material manifestations) from Tesco. In sum, the combination of home movie intimacy and nostalgia adds a veneer of emotive sincerity to what is otherwise a straightforward commercial promotion.

\author{
content unavailable
}

please consult print version

Fig. 3.10 \& 11. Home movie imagery evokes nostalgia, wholesomeness and sincerity in Tesco's 2013 Christmas advertisement. YouTube. Screenshots.

The affective appeal of home-mode imagery has particular epistemological significance, as Chalfen suggests:

\footnotetext{
The home mode image seems to lend an air of authenticity, of certain reality, of unquestionable truth to forms of persuasive discourse... [It is] used to promote an untampered, unmediated (read "unstaged") view of reality which, in turn, helps readers/viewers believe that they are gaining "an inside look". In short, we are witnessing an exploitation of home mode imagery in the construction of credibility (1987, 156, added emphasis).
}

Chalfen concludes that by usurping 'the look of reality' (ibid.) many uses of home-mode images (actual or fabricated) position viewers to accept apparent spontaneity as evidence of the real (or a diegetic reality within a fictional mode). This 'authenticity effect' of home movie imagery actually fulfills a comparable function across a variety of contexts, whether it be in advertising, dominant cinema or avant-garde film. In the case of fictional narratives and particularly advertisements the purpose of using home-mode images to construct a given 'truth' may be relatively easy to discern. The appeal to home-mode production as a source of credibility is not necessarily as obvious in the case of avant-garde cinema, however. What exactly did filmmakers 
hope to persuade us was 'true'? The following passage written by Mekas is quite illuminating in this respect:

\begin{abstract}
The avant-garde film-maker, the home movie maker is here... surrounding you with insights, sensibilities, and forms which will transform you into a better human being. Our home movies are manifestoes of the politics of truth and beauty, beauty and truth. Our films will help to sustain man, spiritually, like bread does, like rain does, like rivers, like mountains, like sun... some of the most beautiful movie poetry will be revealed, someday, in the $8 \mathrm{~mm}$ home-movie footage (in Chalfen 1987,
\end{abstract} 143).

Leaving aside the obvious hyperbole and implicit cultural elitism of Mekas's declaration, the avant-garde 'home movie' is clearly positioned as an aperture to social or personal enlightenment. Viewers will be aesthetically nourished and morally uplifted by watching films that share the attributes of home movies. The power of this avant-garde sensibility to reveal a more culturally refined mode of existence is premised largely upon an unaffected truthfulness presumed to be found in home movies. In this way, despite their divergent objectives, avantgarde filmmakers, commercial filmmakers and advertisers all play upon the authentic feel of home movie footage. Whether it is used to encourage audiences to purchase certain products, accept a dramatisation of purportedly real events, believe in a fictional world, or see their own in a new light, home-mode imagery imparts a persuasive sense of veracity. For all their 'textual affinities', 'home movies' are nevertheless typically distinguished by their more carefully orchestrated form. Particularly in the case of avant-garde film, the unfettered honesty of home movies seemingly required a metamorphosis into 'home movies' in order to disclose some revelatory truth.

\title{
Television and authenticity: home movies as national history
}

If avant-garde film and home movies often share a similar look and feel, they likewise have a propensity to be deemed boring. However, while avant-garde films are typically screened to select audiences of cinéastes, film students or gallery patrons, ${ }^{29}$ home movies have been incorporated into numerous television series, presumably with the intention of capturing a relatively undifferentiated spectatorship en masse. This is not to suggest that the former are

29 Online screening platforms including YouTube, Vimeo, UbuWeb and Kanopy have of course belatedly created an obvious exception to this. As with all Internet content, however, an almost limitless potential audience does not guarantee an actual audience of any size. 
necessarily less readily bored by material that appears banal, repetitive or 'unpolished'. ${ }^{30}$ Entertainment, at least in a conventional sense, may not be a priority, however, in contexts that are considered primarily cultural (and possibly radical or even elitist) rather than popular or commercial. Television, a medium of mass communication, may be distinguished in this respect. Concessions, if you will, must be made to accommodate varied tastes, predilections and tolerances, heterogeneity being an inherent characteristic of television's diverse viewership. What might be termed 'popular history' documentaries that either incorporate amateur footage or are compiled entirely from home movies are a common way for private films to gain a public audience on television. Compilation programmes of archival film that feature home movies, exclusively or otherwise, have appeared in various national contexts including Our Century (Australia 1999), Super 8 Stories (Northern Ireland 2003-2006), Scotland's Home Movies (2015) and Decades in Colour (New Zealand 2016-2017), to name just a few. How does the need to entertain (that is, not bore) a very general audience influence the construction of such television documentaries? What kinds of effects does this have in terms of potential understandings and perceptions of their source material?

Before addressing these issues, it is worth revisiting the consideration, raised in a somewhat speculative manner at the beginning of the previous section, that 'home movies' suggest a particular frame of reference for interpreting the reuse of actual home movies. If filmmakers, both commercial and avant-garde, seek to incorporate home movies' 'air of authenticity' into their own works, then perhaps predictably, the perceived value of actual home movies for social history documentaries is a comparable one. As a source of visual evidence illustrating 'how life really was in the past', home movies seem to offer an intimate view upon everyday activities seldom recorded elsewhere. Employed in an evidential capacity, amateur film becomes akin to a 'scientific tool' enabling access to its pro-filmic world, according to Ryan Shand. It has the power to reveal changes that the passage of time has wrought upon people and places (2008, 47). Moreover, visual evidence is deemed to have a 'privileged status' in the eyes of the general public, so Shand argues (49). Yet as evidence of history, home movies are not self-explanatory ${ }^{31}$ - at least in Shand's view - requiring knowledgeable commentaries from people able to interpret their images. Without such expertise, home movies risk becoming 'relatively

30 Michael Zryd (2007, 111) and Fredric Jameson (1997, 73-4), for example, discuss boredom in the context of teaching avant-garde cinema to film students and attending an experimental screening respectively.

31 This belief is not limited to home movies. Nathan Carroll suggests that expert mediation, a feature of archival presentations of early cinema, implies film history more generally is not considered self-explanatory (2006, 62). This is discussed further in Chapter 4. 
meaningless' (47) (and presumably quite possibly boring). Consequently, when home movies are used to illustrate television documentaries, interpretation plays a significant role in determining how they may be understood by viewers (48).

In the documentaries mentioned above (and others like them), home movies typically function in one of two ways (albeit with some overlap). They are used either as relatively straightforward illustration, or as an aide-mémoire assisting interviewees to recall the past, the latter approximating the films' original contexts more closely. In either instance, television documentaries tend to be very much concerned with reminiscence, be it personal or as part of a wider national community (ibid.). The 25-part Australian series Our Century, which Screen Australia declares 'reflects the struggles and triumphs of the last 100 years', is a good example of reminiscence in the service of national history and identity. Home movie footage appears throughout the series interspersed with newsreels and other professionally made films, although it features more prominently in some episodes than others, relative to the theme under discussion. 'Eyewitness', for example, notes the importance of amateur filmmakers as eyewitnesses to historical events but in fact includes only a brief montage of home movie images before showing news footage of one of Australia's 'most famous amateur cameramen', Prime Minister Robert Menzies, using an 8mm camera on tour. 'Best Years of Our Lives', which focuses on childhood in Australia, features a number of images from home movies, again mostly edited into montages of brief shots accompanied by music. Perhaps unsurprisingly given the popular history ethos of the series, the presentation of images of children's backyard games and pets seems intended to elicit a nostalgic response from viewers. The audience is even reassured from the outset that it is only in hindsight that children will come to recognise the truth of the cliché expressed in the episode's title. The veracity of this image of childhood is seemingly never questioned. The amateur footage included in the episode does not stand out in this respect, however. Most images are taken at simple 'face value' in terms of their ability to illustrate the past effectively. ${ }^{32}$ Moreover, most footage, amateur or otherwise, is used pragmatically throughout the series as evidence of a narrative of Australian vitality and progress throughout the century, usually with little regard to original contexts of production.

32 There are a few notable exceptions to this (albeit not amateur related). The narrator contradicts favourable images derived from newsreel footage depicting wartime 'orphans' from Britain (whose parents were often still alive) and Aboriginal children taken from their families being educated, noting that in fact many of these children led hard lives, frequently performing unpaid labour. In the 'Eyewitness' episode, a Japanese propaganda film showing happy, well-nourished and even financially remunerated PoWs is compared with documentary footage of liberated prisoners in 1945. 
In a series such as Our Century home movies are intercut with other types of archival footage to become part of a 'coherent national history' (Simon 2006, 192). In general, the specificity of home-mode production is of little concern. There are nonetheless a few exceptions to this rule. Although most footage contained in 'Best Years of Our Lives' is derived from newsreel sources, it concludes with an acknowledgement of the contribution of home movie images to the series and a sequence taken from one of Australia's earliest-known home movies of five-year-old Wally Albion's birthday party in 1921, again given a rather sentimental inflection accompanied by orchestral music. This film is returned to in 'Family Flicks', an episode devoted specifically to home moviemaking. Here the popular format of using home movies to stir the memories of filmmakers or their relatives comes to the fore. The films under discussion are nevertheless extensively re-edited with sound effects (such as horses' hooves or crowd noises) and popular music dating from a similar era added to the silent footage. These alterations are seemingly intended to create a lively and nostalgic ambiance beyond what the raw images alone might impart. Footage is also played in some instances for comic effect. The rather garrulous narration repeats information supplied by an English émigré interviewee, for example, lest the local Australian audience fails to comprehend his northern accent. Ultimately, the episode concludes with the pronouncement that home movies are filled with pretty basic and 'pretty boring stuff' (unless it's your own family of course), this sudden admission of subjective value somewhat undercutting the preceding twenty minutes of films the producers apparently 'thought you'd like to see'.

On the whole, home movies have a rather ambivalent position within the series, alternating between general illustration and evidence of the 'pretty basic' hobby filmmaking practised by ordinary Australians (and their prime minister). This potentially leaves the viewer of Our Century with an overall impression that home movies make authentic and nostalgic national history, but are far less interesting in and of themselves, whether viewed as a particular kind of cinematic record or evidence of specific personal experiences. Even with the involvement of filmmakers or their relatives who provide background details, footage must seemingly be enlivened through editing, sound or humour to be of interest to the nation rather than the kind of 'boring stuff' likely to make the eyes of television viewers glaze over.

\section{Personal reminiscence, collective nostalgia and the 'home movie effect'}

The use of home movies as an aide-mémoire is more significant within what Jane Simon terms 
'histories of particularity' (2006, 193). This can be seen in a series such as Super 8 Stories, ${ }^{33}$ which features short segments devoted to the films of an individual or family, with participants narrating the sequences. ${ }^{34}$ There is no generalised history of either the nation or the medium itself. Instead, 'commentaries reflect the singular and particular experience of subjects in specific places at specific times' (ibid.). Even where filmmakers refer to historical events, such as 'The Troubles', the perspective remains essentially personal. The footage is nevertheless edited into montages accompanied by period music, with the occasional freeze frame and zoom in, often to a close up of someone's face, highlighting a particular moment in time. Despite these manipulations, the interest value of individual sequences is very much dependent upon the combination of images and narration. In 'Self Build House', for example, the story of transforming a derelict cottage into a family home is noticeably recalled on the soundtrack by the couple who undertook the renovation project rather than seen in the images onscreen, little of the actual work presumably captured on film. Before and after shots provide evidence of the cottage's remarkable overhaul, this sizable feat alone seemingly deemed sufficient to maintain audience interest. Another participant's recollections inspired by family wedding footage offers somewhat less compelling viewing, however. Only the authenticity of ordinariness seems to qualify these stereotypical images, which resemble thousands of others, for inclusion in the series.

One way of negotiating the banality of home movie footage is to focus upon those made by celebrities, who are obviously already of interest in the public eye. Elizabeth at 90: A Family Portrait (2016) uses the standard technique of having the filmmaker (in this instance the British monarch) and members of her family reminisce about the content of her $8 \mathrm{~mm}$ home movies, recorded both at home and during her many official trips abroad. Arguably, the films are deceptive in the sense of depicting what appears be to a very normal, albeit affluent family, who in private life are much like any other. The overall picture that emerges from the films is that the business of being royal is exactly that, a professional occupation largely separate from family leisure time. (Her grandson even refers to the Queen as both his 'boss' and his grandmother.) This intimate view of royalty has a humanising effect due to the similarity of their home movies to those of ordinary people (footage of children rolling on the lawn, riding ponies, buried under

33 The title is actually a misnomer as the series includes footage that predates the release of Super-8 in 1965.

34 The 'modular' quality of the series is accentuated by the uploading of single sequences on the Northern Ireland Screen Digital Film Archive website. While it is possible to watch the sequences in the order that featured in the original broadcasts, this information is not readily obvious. Viewers are therefore presumably more likely to pick and choose on the basis of titles or thumbnails that appeal to them. 
autumnal leaves or sand at the beach...) This coalesces with Odin's suggestion that home movies bring us 'closer' to celebrities, encouraging us to reflect upon what we have in common. While this establishes an empathetic relationship between subject and spectator, it also discourages any questioning of the accuracy or limitations of home movie representation. Viewers receive images in a comparable way to watching their own family films $(2014,24)$. To this extent, Odin concludes that 'one of the great functions' of family films on television is 'an attempt to restrict the possibilities of the emergence of a critical inquisitiveness among spectators' (25).

This ideological role actually mirrors one of the original functions of home movies within the family: 'avoiding problems, creating consensus, and perpetuating the position of the institution' (26). The considerable disparity between the private origins of home movies and their public dissemination on television is thus reconciled in a sense. Moreover, Odin argues that 'familial productions offer themselves so naturally to the mode of authenticity that we may actually talk of a home movie effect' whereby spectators become disinclined to dispute the truthfulness of what they are seeing (ibid.). A sequence of Super 8 Stories featuring footage recorded in colonial Nigeria depicting the comfortable lifestyles of a European community waited upon by local Nigerian servants offers a good example of this. As the series affords only personal perspectives, the home movies simply illustrate the 'great experience' the participants enjoyed during their sojourn in Africa, unencumbered by any analysis of the effects of colonialism on the local population who are glimpsed as domestics and railway workers. No alternative interpretation of these images is offered, nor indeed is it ever suggested such images could or should be read in a different light.

content unavailable

please consult print version

Fig. 3.12 \& 13. Just like any other home movie family? A young queen and her son, Prince Charles, in a home movie and watching films at home many years later in Elizabeth at 90: A Family Portrait. Screenshots.

A rather more sophisticated version of the 'home movie effect' operates in Decades in Colour. 
Although ostensibly about home movies, the three-part series is actually a more general social history of postwar New Zealand. Much like Our Century, the New Zealand series uses archival footage to illustrate a narrative of national progress and growing sense of identity. Compiled almost exclusively from Kodachrome home movies, Decades in Colour positions itself as an intimate and authentic 'inside' view of everyday life. While its montages of footage with added music, sound effects and narration are similar to those seen in other documentaries featuring home movies, Decades in Colour also incorporates a second layer of montage. Rather than simply presenting sequences focused upon the testimony of individual participants, the series utilises collages of multiple voices interspersed with one another on the soundtrack, only intermittently identifying a particular speaker in a 'talking-head' shot. As home movie footage and participants' recollections seldom noticeably coincide, in effect, anyone who lived through a certain era could have been interviewed about their experiences without substantially altering the programme's overall tenor. Not attributed to any individual filmmaker, most images simply assume a general evidential function. ${ }^{35}$ The integration of personal anecdotes and images into this story of the 'New Zealand family' to which 'we all belong' (incidentally presented by former television newsreader, Judy Bailey, sometimes known as the 'Mother of the Nation' (NZ on Screen n.d.) due to her 18-year tenure on the six o'clock evening news bulletin) creates a convergence of private and public histories. Personal footage substantiates a conventional narrative of baby boomers, outdoor lifestyles and 'Kiwi ingenuity' that only briefly touches upon social issues such as racism or homosexuality prior to decriminalisation. Interestingly, the rather cursory discussion of the racial discrimination faced by Māori is actually illustrated not with home movies but footage from Rudall and Ramai Hayward's 1972 feature, To Love a Maori. The accompanying commentary by male lead, Val Irwin, nevertheless suggests many scenes were comparable to his own personal experiences. For the most part however, Decades in Colour is more concerned with nostalgic remembrance and collective memory than the analysis of social and historical conditions.

Making use of similar aesthetic tropes, Scotland's Home Movies balances nostalgia with a critical history of the medium itself, including recognition of the elitist nature of early films - the daughter of the Duke of Montrose comments on family footage in which the future George VI

35 These observations relate primarily to the first series that takes a chronological format. The second series, thematically organised around the loose titles 'home', 'work' and 'play', is far more attentive to particularity and individual anecdote. Overall however, it continues to celebrate a familiar national narrative of outdoor lifestyles and Kiwi 'can-do' attitudes. 
and his wife Elizabeth appear - and its function as a memory device. Participants display an unusual awareness (at least for the genre) of the limitations of home movie representation, noting films dating from the 1970s, for example, fail to reflect the loss of optimism felt at the time. One interviewee acknowledges home movies record happy moments, not funerals. Watching footage filmed by children he once knew stirs a former youth worker to recall the influx of hard drugs into Scotland in the 1980s and the accompanying loss of life. Even the suggestion that life was simpler and somehow better in the past is immediately countered with the mention of tuberculosis and rickets. This awareness of what lies just beyond the home movie frame sets the series apart from many others like it.

More commonly, the home movie compilation does not attempt any critical analysis of its subject. Accentuated by music and personal reminiscence, films are re-edited with the object of inducing an affective relationship with viewers. The potentially boring and banal is transformed into collective nostalgia and readily digestible versions of national history. We learn relatively little that might challenge conventional historical narratives by watching any of these productions. Rather, they engage our sense of belonging to a national community through the invocation of a shared past. ${ }^{36}$ Although less likely to be effective in this sense amongst viewers who are not white middle class like most of those depicted onscreen, a programme such as Elizabeth at 90 demonstrates that representations of a different social demographic do not preclude levels of identification entirely. If we can be encouraged to believe that even the rich and famous are in some ways ordinary people like ourselves, the 'national family' portrait unsurprisingly seeks to embrace a broad membership, aided by the fleeting inclusion of minority experiences. Primarily concerned with narrative and affect, television documentaries deploy home movie footage as authentic visions supplemented by participants' memories, the reliability of either seldom called into question. In such a context, the reuse of home movies facilitates emotional identification minus critical consciousness. This is hardly surprising. The home movie popular history is entertainment first and foremost. It seeks to draw viewers into an enjoyably reassuring picture of the nation, not create a contemplative space in which spectators might be tempted to sit back and query the validity of this representation. It is the

36 Programmes available online (such as Super 8 Stories) or distributed on DVD can of course also be watched by international viewers (presumably not an intended audience for this type of production). Given the aesthetic similarities of home movies recorded in different parts of the world, audience identification probably exceeds national boundaries in at least some respects. 
aim of such television histories to foster the 'home movie effect', not undermine its ideological power.

\section{Auto/biographical cinema, memory and problematic evidence}

In a somewhat atypical revelation in Super 8 Stories, members of the McBride family recall that as children they were encouraged to move constantly for the benefit of their father's movie camera, resulting in numerous shots of them walking down the garden path or in and out of the sea. ${ }^{37}$ The elder children of the family also mention that as they grew older they became less cooperative about being filmed, leaving the task to younger siblings more inclined to do as they were told. This kind of admission is relatively uncommon in a home movie television series. Casting doubt upon the spontaneity or truthfulness of home movie representation does not align well with the popular history programme's aspirations to inform and entertain without introducing unnecessary complexity into the national narrative.

Occurrences such as the direction of subjects to create a misleading view of how an event unfolded, or the objection of would-be participants to being filmed, are more likely to be acknowledged in productions that interrogate the authenticity of home movies as evidence. Biographical or autobiographical films in particular are often attuned to the (in)ability of home movie images to represent the past accurately. They may unsettle the 'home movie effect', probing private realities buried within stereotypical images. Their representation called into question, home movies no longer offer the complaisant familiar stories of television histories. Auto/biographical films may have to work a little harder therefore to engage audiences as well as reveal something concealed from immediate view. Their narratives are individual, personal and sometimes disquieting, stories potentially more difficult for audiences (to want) to relate to than optimistic national narratives of progress and shared identity. While some biographical films examine the lives of subjects already familiar to the general public, other films are about lesserknown individuals whose stories must be presented in such a way that we become interested in them. Home movies appear in both instances, sometimes functioning as evidence or illustration, other times becoming an object of deliberation, their capacity to bear reliable witness or preserve memories under scrutiny.

37 A couple of participants in Decades in Colour also make similar observations during a short sequence in the first episode that identifies home moviemaking as a newly affordable pastime for many New Zealanders in the postwar years. 
Filmmakers who choose themselves or relatives as subjects may resort to eccentric or inventive means to interest audiences in private histories that may lack the immediate appeal of collective narratives. Humour offers one solution to the issue. In Jerome Hill's autobiographical Film Portrait (1972), completed just before his death, the artist appears to take wry amusement in recalling youthful escapades, especially those connected with the foibles of home moviemaking. 'We were made to do ridiculous things that normally we would never have done,' Hill recollects. 'Keep moving, these are movies, my father would say. Anything, provided we jumped around a lot... The painting that I had to pretend I was painting wasn't even my own.' His sister, apparently afraid of birds, entered the aviary to 'please the cameraman'. Hill and his brother 'played' instruments while the camera rolled. Born into the family of a wealthy railway magnate, Hill and his siblings staged scenes that turned into 'avant-garde cinema' due to their father's inability to wind an early hand-cranked camera evenly. Coupled with Hill's whimsical narration of his life, images that might be lacking interest in themselves acquire a piquant flavour.

Most of the amateur footage in Film Portrait appears to be presented more-or-less as it was shot. Aside from his father's very early films, Hill includes a sequence of unidentified but fairly typical images recorded in the 1920s in order to demonstrate amateur fascination with the newly acquired ability to record everyday life (or a staged version thereof). Noting their haphazard framings and clumsy execution, he intimates a rather skeptical attitude toward the banal nature and technical limitations of most home movies. The 1920s craze for moviemaking seems in fact to have inspired the young Hill to set his sights upon surpassing such 'feverish stutterings'. Played to comic effect, home movies function as evidence of their own shortcomings rather than of what they depict.

Like many of his earlier works, Film Portrait is actually filled with Hill's playful manipulation of images, albeit for the most part not of home movies. There is one very noticeable instance in which Hill substantially alters the appearance of an amateur image, however. An extended shot presumably taken from a home movie shows a group of adults dancing in hats and coats in the street. Without context, this activity itself appears unheimlich, yet Hill also slows, reverses, replays and freezes the image, accentuating the uncanny sensation through halting, unnatural motion. On the soundtrack Hill describes an adolescence of half-hearted participation in an itinerant lifestyle that affluence afforded, the stilted movement of the accompanying image 
providing a visual metaphor for a period before he had really 'begun to live'. This kind of visual inventiveness becomes another means of retaining audience interest whilst drawing attention to more liminal gestures within amateur images.

The uncanny slowing and repeating of home movie footage is used to somewhat different effect in Michelle Citron's Daughter Rite (1978), one of a number of (semi)autobiographical films in which a female filmmaker re-edits family home movies. ${ }^{38}$ According to Citron, Daughter Rite seeks 'to take the means of producing the visual memory of the family away from the Father' (1999, 25). Initially perplexed by the discrepancy between the smiling family of her father's films and her unpleasant memories of childhood, Citron slowed the footage to reveal a darker side to their ostensively innocuous content. Slowed down and repeated, a small movement of her mother's hand becomes 'an agonizingly intrusive and possessive gesture' (18). Such actions, almost imperceptible at normal speed, suggest the mother's complicity in the patriarchal order, grooming her daughters to be 'proper young ladies'. The simple act of tidying her daughter's hair becomes 'unnatural, constraining, obsessive' (Williams and Rich 1981, 19). While Hill appears to find absurdity in his father's staging of reality, Citron recovers an unsettling subtext, a 'shadow film' $(1999,18)$ embedded within carefully orchestrated scenes of domestic harmony, yet one that at least resolves the gap between image and memory (1986, 94).

content unavailable

please consult print version

Fig. 3.14-21. Slowed down and repeated a simple act captured in a home movie becomes an intrusive, controlling gesture in Daughter Rite. Screenshots.

Not all uses of home movies within autobiographical cinema are concerned with the

38 Other examples include Jan Oxenberg's Home Movie (1972), Merilee Bennett's Song of Air (1987), Su Friedrich's Sink or Swim (1990) and Marina Lutz's The Marina Experiment (2009). 
contradictions between image and experience they may raise. Home movies also fulfill a more straightforward role as evidence, illustration or memory device. These uses are much closer to television 'histories of particularity' in which participants comment upon the content of their own films. They also have similar pitfalls potentially with regard to banality and boredom, if filmmakers cannot point to something comical or unexpected. Unlike a series such as Super 8 Stories in which home movies act as a provocation for recalling a brief anecdote, an auto/biographical film need not hinge specifically upon events that happened to be captured in a home movie. Instead, home movies tend to be interspersed with other kinds of footage to build a larger picture of someone's life. They could simply be used to illustrate what someone looked like at a given point in time, for example. In this way, images that might be relatively mundane in themselves can add something of interest to a narrative. Nevertheless, such footage becomes more engaging still if a filmmaker is able to offer a more expansive or layered reading than what is immediately visible.

An example of this can be seen in Amalie R. Rothschild's Nana, Mom and Me (1974). Much of the film is composed of interviews or conversations between its participants with family home movies offering moments of visual variation. More specifically, in some instances the home movie footage coalesces directly with the participants' recollections. The filmmaker's mother, for example, describes a personal shift to being 'herself'. Her non-permed hair from about the age of thirty seen in the home movies becomes the external symbol of this, indicating her new disregard for conventional notions of female beauty. Although home movies frequently record personal milestones, particularly birthdays, weddings or graduations, inward transformation cannot of course be read directly off an image itself. A spectator might register a subtle change in a subject's appearance; combined with oral testimony however, it takes on a specific resonance that cannot be discerned from the image alone.

Another way of drawing meaning from outwardly unremarkable home movies is to juxtapose the image they paint against those suggested by other kinds of personal records. In Un'ora sola ti vorrei (For One More Hour with You 2002), Alina Marazzi 'resurrects' her mother who committed suicide following years of psychiatric treatment when the filmmaker was seven years old. On the soundtrack the mother 'speaks' from beyond the grave, addressing her daughter and reading extracts from her letters, diaries and medical reports. Her anxiety and professed inability to look after her children adequately contrasts with the happy family moments captured in 
home movies. Yet the affection and longing she expresses for her children suggest these scenes contain a shard of truth nonetheless, that fleeting moments of joy perhaps existed even in a life tragically scarred by mental illness. The home movies are certainly not representative of the Marazzis' experience as a whole, but through the collage of different texts a more complex picture emerges of their family life than that suggested by any one source on its own.

Ross McElwee also uses family home movies to revive a deceased parent. During the filming of Time Indefinite (1993), 'a sort of home movie' in itself, McElwee's father died suddenly. Motivated by this event, McElwee watches an uncle's Super-8 footage of his parents when young. The home movie enables them to have a 'vicarious presence', despite the physical absence of death. McElwee's interest lies less in the extent to which home movies can illustrate the past effectively as the role home recording plays in keeping family 'alive in some sort of time indefinite'. He does note in Bright Leaves (2003), however, that a decade on the same images of his father appear less 'real', his earlier perception not invalidated but now wrapped 'in a nostalgic glow' (Cuevas 2013, 21-2). Taken together, McElwee's meditations on family footage encapsulate both the presence and pastness home movies invoke as a memorial device able to recover ephemeral moments indefinitely, as well as underscore their gradual fading from memory. Again, there is nothing exceptional about the McElwee family footage. It is through the filmmaker's subsequent reflections upon the value of these rather mundane, stereotypical images that they acquire significance. McElwee's observations also take on a more universal dimension if viewers make a connection with their own family images and memories related to them.

McElwee's cinema is surely one of Misek's 'conscientious objectors' to the killing of time with its leisurely exchanges between participants, meandering (non)plots, moments of introspection and contemplation of time itself. His films are also more likely to be found in a festival programme than on broadcast television and do not seem to anticipate an audience who require a conventional narrative structure or even a goal-oriented protagonist-filmmaker to keep them engaged. Other documentary-makers seemingly display a more 'apprehensive attitude' (Misek $2010,777)$ as far as the tolerance of viewers is concerned. Rather than being used as a 'technology of thought' (Anderst 2013, 232) during a reflective interlude, home movies serve more straightforward illustrative purposes or become a means of uncovering something in stories recounted with a greater sense of narrative momentum. 
Filmmakers who use personal recordings to explore the lives of well-known people may also rely to an extent upon the celebrity status of their subjects for audience appeal. As in television documentaries, home movies may be used to kindle a sense of intimacy between viewers and a famous individual, offering an inside perspective on a private world. In Ingrid Bergman in Her Own Words (Stig Björkman 2015), for example, home movies illustrate carefree moments of family life that contrast noticeably with the newsreel footage of Bergman and her children together in public also included in the film. The informality and apparent warmth of these scenes presents a charmingly sympathetic picture of a person who could easily appear simply glamorous and distant in a biography comprising only more official images. While the evidential value of Bergman's films is never undermined, the very circumscribed nature of the recordings becomes readily apparent. The home movies correspond with her children's recollections of wonderful holidays spent with their mother, but do not of course provide any indication of her frequent absence from their lives. Even if the home movies are a reliable representation of family togetherness, we are informed such moments were in fact a relatively rare occurrence. The impression they create may in essence be truthful, but as in Marazzi's film, it is certainly not the whole truth.

The very narrow frame of home movie vision finds a highly unsettling manifestation in Eva Braun's home movies, which include images of Adolf Hitler and other members of the Nazi elite. While excerpts from Braun's films have now appeared in numerous productions, Philippe Mora's controversial depiction of Hitler as human rather than a homicidal monster in Swastika caused outrage upon its initial release at Cannes in 1973. Devoid of narration, the film intercuts the home movies (which had not been seen in extended sequences or colour previously) with Nazi propaganda films and newsreel footage from the 1930s. The official material creates a symphony of seductive imagery: bucolic lifestyles, industrial progress, Wagner concerts, public rallies and festivities, the Führer's (literally) touching concern for the bereaved relatives of deceased fascist insurrectionists at a memorial service, public demonstrations of affection for (Aryan) children. In this way, Swastika attempts to account for the ideological indoctrination of the German population and acceptance of Hitler as leader and benevolent father figure. In stark contrast to this carefully orchestrated public image, life at the Berghof captured by Eva's camera is conspicuously banal. Although never entirely relaxed in front of the amateur camera, Hitler looks 'less a dictator than a grumpy, well-to-do businessman' (Moorehouse 2010, 59). Despite this, the overall image of Hitler and Eva that emerges is one of a couple fond of children, 
animals and mountain holidays. Aside from the occasional Nazi uniform, the home movies are entirely innocuous. Eva's films therefore raise the disquieting possibility 'that Hitler was a man like us' (Odin 2008, 262), their similarity to other home movies enabling viewers to recall family holidays or gatherings (Guerin 2011, 220). Only knowledge of the participants' identities makes these scenes repellant (xxii). Mora deliberately withholds images of war and genocide until the end of Swastika, making this private view in which Hitler looks 'like a man, not a demon from Jupiter' (Deans 2017) all the more disconcerting. Both the footage itself and the context in which it appears raise questions about the extent to which Eva Braun's films might be regarded a naïve or innocent depiction of her surroundings, or if they represent a consciously framed vision of an idyllic Nazi lifestyle, an amateur equivalent to public propaganda (Guerin 2011, 272).

Many of the same images appear in Jay Rosenblatt's Human Remains (1998), an 'autobiography' of twentieth century dictators. Rendered in black and white and slow motion, home movie footage of Hitler appears far less intimate than its colour source material. The film offers no context, assuming the viewer is already aware of Hitler's public role in history. In a fictionalised first-person narration, the dictator reveals intimate details of his private life and personal daily habits, including his dietary preferences due to flatulence, obsession with his appearance, presumed attractiveness to women, difficulty sleeping or making even small decisions, fondness for pornography. Seen with his German shepherd Goldie, he confides in the viewer, 'you know, all those pictures of me with dogs, or with children, propaganda pure and simple'. The voice is heard twice on the soundtrack, as if to suggest the first is the authentic voice of Hitler speaking in German, the second the filmmaker's translation into English. Combined with the images, the effect is eerie and chilling. Hitler appears an almost comically maladjusted neurotic and yet also uncomfortably human. The film is allegedly based on extensive biographical research (Graham 2000). Even so, the sheer accumulation of detail has a distancing effect whereby the viewer may call into question the veracity of the narration (Guerin 2011, 278). (Could there really be an historical source for such comments? Is it fabricated by the filmmaker, at least in part?) Like Swastika, Rosenblatt's portrait of Hitler as a private individual seen in scratchy amateur footage is far removed from the more familiar public image of this reviled historical figure, but no less disquieting. 
content unavailable

please consult print version

Fig. 3.22 \& 23. Hitler appears uncomfortably human in the banal home movie scenes of Swastika (left). The same footage takes on a much eerier quality as grainy black-and-white images in Human Remains (right). Screenshots.

Hitler's notoriety is probably sufficient in itself to raise Eva Braun's films to the level of public curiosity, even without alteration or added context. Certainly, the popularity of the films on YouTube would seem to support such a conclusion. ${ }^{39}$ Auto/biographical films examining the lives of more ordinary individuals must find other ways to justify making public what was once private. This may involve suggesting (however implicitly) some kind of resonance or magnitude beyond the merely personal, which might enable viewers to relate to the lives of others. Home movies, due to their stereotypical nature, help to bridge disparities between the experiences of film subject and spectator. However, while television documentaries frequently engage in a nostalgic affirmation of familiar narratives, auto/biographical films are inclined to take a more cautiously analytical approach to personal images. Home movies can become a means of reflecting upon the connections between memory and family recording practices. This may be occasioned by manipulating images or through juxtapositions with other sources to reveal something of significance lurking beneath the surface of a family movie. In auto/biographical cinema, home movies are positioned more often as half-truths than whole ones. They acquire new frames of reference, encouraging us to see stereotypical images with a fresh eye. What we find may be amusing, empathetic or unsettling, but seldom is it merely nostalgic. One might wonder, however, if much of the appeal of home movies is lost once their nostalgic properties arguably their most accessible and readily enjoyable attribute - are stripped away in service of critical reflection. Or does there remain some kind of innate pleasure to be had as viewers in simply seeing what we were not supposed to see?

39 Even the number of uploads onto YouTube is staggering. A quick search 'Eva Braun home movies' yields about 3,440 results (3 September 2017). 


\section{Trespassing upon intimate moments and voyeuristic pleasure}

One of the most striking (if not disconcerting) aspects of Swastika is that we do not merely see Hitler in private, we also hear him. Reconstructed via lip-reading, the dialogue in the home movie sequences has been recorded with German actors (Deans 2017) and could even be mistaken as genuine. While the snatches of conversation heard on the terrace of the Berghof are largely banal and incidental - much like the images themselves - the voyeuristic effect of intercepting casual remarks unwittingly captured for posterity is remarkable.

To some extent voyeurism is more-or-less inherent in making domestic footage public. To watch any home movie is to watch something that was not intended for general public consumption. A tacit awareness of the illicit nature of this act might account at least partially for the interest displayed in other people's personal records. The effect of this 'sneak peek' into the private affairs of others is potentially magnified in the case of the famous (or infamous) who, in an unguarded moment away from prying public eyes, might conceivably reveal a hitherto shrouded 'authentic self'. Any home movie offers voyeuristic opportunities, however. While it is perhaps reasonable to assume few people are likely to feel much compunction about violating Hitler's privacy, the subjects of more ordinary home movies are arguably due a certain level of dignity. Amid his fulsome praise for the 'democratic history' home movies seem to offer, Peter MacNamara calls upon producers nonetheless to refrain from using them as a 'peep-show'. He does not elaborate upon what kinds of usage might be deemed exploitative (although he identifies 'cheap television' as a likely forum) (1996, 44). The notion of a 'peep-show' in this particular context seems to signal that inappropriate uses of home movies do exist, or perhaps that some films are too private to be screened in public. Yet the very appeal of home movies as evidence is of course premised upon their intimate view and an assumed corresponding absence of the kind of ideological filters that images recorded with more public aspirations are likely to accrue.

The enticing nature of the private made public is noticeably played upon in the opening sequence of Decades in Colour in which Judy Bailey explains that the series reveals 'a hidden history' 'unearthed' by the producers. Moreover, she claims the footage is 'seen here for the first time'. Given the likelihood that the filmmakers and their families had previously watched the footage, this statement effectively equates to 'seen publicly for the first time'. The promise of revelation combined with authenticity is reiterated throughout the introduction. This is history 
'filmed by the people who witnessed it', in other words, an assuredly authentic 'inside' view. Unsurprisingly, spectators are not encouraged to feel like voyeurs. Far from intruding, the viewer is likely to be made 'a welcome guest to the family screening' by television compilations (Cuevas 2013, 20), in this particular instance invited by the 'Mother of the Nation' and guided by the movies' participants or makers. Such commentaries arguably create a 'buffer' against the sense of intrusion an audience might otherwise feel watching private images (Simon 2006, 193). Participants are not always willing or available to perform a mediating role, however.

Jaimie Baron suggests 'trespassing' is a suitable metaphor for entering the private spaces seen in home recordings, either uninvited or when an invitation is arguably inappropriate $(2014,95)$. Yet how revealing are home movies? How far can they really satisfy voyeuristic curiosity? Adam Capitanio describes home movie representation as 'a public self, privately consumed' (2012, 29). As already noted, home movies seldom document extremely intimate or socially disagreeable behaviours, at least on the surface. Furthermore, home moviemakers tended to take advantage of natural light, often recording in public or semi-public outdoor spaces, such as fairgrounds, sports fields, beaches or backyards. In this sense, home movies are hardly very revealing. Albeit for home viewing, they typically present a public face of the family. To find something else, one often has to look very hard indeed.

The strictures of home moviemaking may be thrown into relief via comparison with home video. A comparatively cheap technology better suited to filming indoors, video can also capture direct sound (albeit not necessarily control it effectively) and extended takes, enabling the family to be easily recorded in 'all its moments of pettiness and all its instances of rivalry and conflict... words that might best be forgotten' (Odin 2014, 19). This elimination of 'patterned eliminations' (Chalfen 1987, 93) illuminates the extent to which home movies depict a savory and possibly sanitised version of everyday life. Two high-profile documentaries, Capturing the Friedmans (Andrew Jarecki 2003) and Tarnation (Jonathan Caouette 2003), both of which include Super- 8 and home video footage, have been widely discussed in terms of what they illustrate about medium specificity in home-recording practices. ${ }^{40}$ The home movies included in Capturing the Friedmans are of interest primarily due to their contrast with the subsequent footage (shot on video) of the family's disintegration after Arnold and his son Jesse were accused of child molestation. Unlike the video recordings, the earlier home movies depict stereotypical

40 Marsha and Devin Orgeron (2007), Elizabeth Czach (2008) and Jaimie Baron (2014), for example, all discuss the films from this perspective. 
family togetherness, scenes which Baron describes as 'hardly objectionable (and very likely boring) if it were not for the scandal hidden beneath the surface' (95). Although Jarecki adds present-day commentary casting doubt upon seemingly innocuous images, it is the video footage that presents another side to the Friedman household, documenting prolonged instances of family members quarreling and berating each other. Leaving aside questions about why the Friedmans recorded and subsequently allowed this footage to be made public, the allure of such scenes (and to some extent Jarecki's film as a whole) is primarily voyeuristic. Ultimately, we are not offered conclusive evidence with regard to the Friedmans' guilt or innocence. Instead, we are exposed to a sometimes excruciatingly intimate view of their tribulations (Orgeron 2007, 53). The home movies, in their silence and apparent normality, contribute comparatively little to this cinematic exposé. As viewers, we may want them to disclose a secret, dysfunctional history of the Friedman household in view of later events, but no matter how hard we look, frustratingly, their home movies appear similar to any other family's. One could also arrive at a relatively benign reading of the films; that is to say, not only do they not reveal anything but that there is essentially nothing of interest to reveal about the Friedmans' family life and relations (at least with each other) prior to the accusations. If they have anything to hide, it may simply be the petty disagreements between family members that most home movies conceal from view.

Sound is also a revealing element of an autobiographical film by Marina Lutz. Following her father's death, Lutz inherited his 10,000 recordings documenting her childhood, a selection of which appear in The Marina Experiment (2009). While many of the Super-8 films and photographs appear obsessive or invasive (Marina naked, asleep or using the toilet), it is actually the reel-to-reel audiotapes heard on the soundtrack that foreground the transgressive nature of the recordings most clearly. As a small child, Marina is coerced by her father to sing for the microphone, despite voicing her objections to doing so; she is told she did not receive a doll from Santa because she was a 'bad girl'; as a teenager she is interrogated after attending a dance. Similarly, it is perhaps the camera's microphone more than its lens that registers the full extend of Jonathan Caouette's persistent haranguing of family members in Tarnation in spite of them voicing objections to being recorded, or their incapacity to do so (Caouette's grandmother is seen after a stroke, his mother displaying the effects of brain damage following an overdose). By comparison, home movies seldom appear so invasive; silence creates ambiguity, potentially circumscribing both degrees of intimacy and the promise of voyeurism. 
The impact of recording sound is far from straightforward, however. The presence of a microphone may exacerbate self-consciousness, something which is noticeable in the sound home movies discussed in chapter 2. Alternatively, the capacity to record audio may encourage a deliberately performative mode of address, such as confessions directed to the camera or role play (seen in Capturing the Friedmans and Tarnation) (Baron 2014, 93-9). Despite its greater potential to divulge the minutiae of everyday life in all its squalid detail, sound recording may in fact influence the onscreen behaviour of subjects in such a way as to eschew spontaneity. Detracting from the verité feel of much silent footage, sound can undermine the 'home movie effect'. Moreover, if participants appear to present a 'performed self' specifically for the camera, peeking into their lives may feel rather less sneaky. Audiovisual home-recording practices would therefore seem to have as much potential to frustrate voyeuristic desires as facilitate them, suggesting less may sometimes be more when it comes to capturing the little daily doings that constitute private life.

\section{Fictional biography and the universal image}

Focusing upon the commonalities of home movies might be a rather less voyeuristic way to enjoy them. Due to their stereotypical nature, home movie images have a certain interchangeability, something which can establish an affective connection with spectators. The use of home movie footage for general illustrative purposes, for example, discloses little about (usually anonymous) participants, yet the familiarity of many subjects enables viewers to relate to images that are not their own. A series such as Decades in Colour, which often separates footage and participant anecdotes, is concerned not so much with the particularity of images as with their general representability, something Odin describes as an extraordinary 'psychic force' (2008, 261).

This generalised or universal aspect of home movie images finds much fuller expression in Alan Berliner's first feature, The Family Album (1986), which is assembled from anonymous home movies and the audiotaped conversations of families, many of which were purchased at garage or estate sales by the director (Cuevas and Muguiro 2002, 125). The film is structured around the various stages of the human life cycle from birth to death. Images of babies, children, weddings, family life and finally old age form a fictional collective biography of the United States in the mid-twentieth century, the sequencing of shots drawing attention to the repetitive 
character of home movie content. ${ }^{41}$ Childhood, for example, is represented by a series of different babies seen crawling across lawns, various small children are pictured clutching reassuring adult hands as they attempt to master wobbly legs, and so forth. The film's soundtrack features a collage of voices discussing family life, which correspond in some way with the images onscreen. As the films and audiotapes were acquired independently of each other, their relationship is merely a thematic one (ibid., 126). The absence of specificity encourages the viewer to identify with the familiar scenes of life events. The overall effect is, however, somewhat different to that of Decades in Colour or other television series, which tend to play upon the nostalgic appeal of home movies.

Although its soundtrack includes some mawkish commentary from both adults and children, The Family Album seeks to counter the stereotypical home movie image of family life, which Berliner describes as 'one long summer day at the beach' (ibid., 129). Scenes of what appears to be play fighting, for example, are accompanied by dialogues about genuine family disagreements, those of smiling couples are undercut by admissions of publicly concealed emotional strife. Although much more experimental in form than television compilations using similar material, The Family Album shares some of their conventions, including tightly edited montages and a soundtrack combining personal stories, music and other effects. The film's psychic force lies in its recognition of the complexities of ordinary life, however, rather than a nostalgic resurrection of the past.

content unavailable

please consult print version

Fig. 3.24 \& 25. Stories recalled on the soundtrack of The Family Album provide a counterpoint to generic images of home movie subjects partaking in happy events. Screenshots.

41 Vitaly Manski's Private Chronicles: Monologue (1999) is another found footage exercise compiled from anonymous home movies acquired from multiple sources in order to construct a collective history or biography of a nation. 
Other filmmakers, such as Abigail Child, have used anonymous home movies to construct fictional narratives in a more particularised way. The Future is Behind You (2004) recounts a story of two part-Jewish sisters growing up in 1930s Bavaria, crafting a fictional biography out of found footage. Unlike The Family Album, the film utilises a single family collection and makes reference to specific historical circumstances. The use of one (unknown) family's footage to illustrate the experiences of another (fictional) family nonetheless entails a certain kind of loss. The original family of this orphaned footage is effectively erased in favour of finding something else in it. The fictional story may enable the viewer to identify to some extent with named (albeit somewhat elusive) individuals in a manner that is obviously distinct from the appeal of Berliner's work. In both instances however, there remains an implicit assumption that one person's images of home and family can be satisfactorily drawn into a comparison with, or even substituted for (nonexistent) images of other (imaginary) people. In this way, we may find private images meaningful and therefore interesting. Michael Roth describes this as a 'happy, optimistic side' to human understanding, the ability to relate one thing to another $(2008,66)$. He also notes, however, that the 'problem of home movies is the problem of particularity, trying to find a way to make sense of something individual, on its own, distinct, without erasing its individuality, its oneness, its distinction' (65). Erasure is a 'frightening, sad side' to the construction of meaning (66). The recycling of home movies into purely fictional works may be the best representative of this kind of effacement whereby the individual distinctiveness of images, at least in their original form, is sacrificed in favour of new meanings - and audience appeal.

\section{Experimental micro-history and the affect of historical presence}

A very different approach to the deliberate (mis)appropriations of entirely fictional recyclings of home movies can be found in films that might be described as experimental micro-histories examining the relationship between private and public historical experiences. Péter Forgács is certainly the most well-known and widely discussed proponent of this type of filmmaking, ${ }^{42}$ although other directors, such as Jan Šikl (Private Century 2005-7), have also produced work within a similar vein. According to Forgács, his films 'compose something that could be called a private history in front of the curtain of the public history', specifically exploring the relationship 'between the elegy (of private saga) and the structure (of a historic perspective)'

42 A number of essays have been published together in Cinema's Alchemist (Nichols and Renov 2011). This quite considerable volume is by no means an exhaustive survey of writing on Forgács's work, however. 
(Spieker 2002). Ernst van Alphen describes watching other people's home movies as 'usually a rather boring experience', not only because amateur films may be 'rather bad and sentimental', but moreover because 'what we see does not concern us'. However, when combined with an historical framework, as in Forgács's films, identification with people in home movies becomes possible, thereby anchoring the viewer into history $(2011,69)$. In this way, the boring or inconsequential moments of private life become captivating as historical evidence (Balint 2014, 196).

Many of Forgács's films revolve around the work of a particular amateur filmmaker. Those onscreen are often identified in captions and home movie images are supplemented with biographical details or diary entries read on the soundtrack. This intimate view of private worlds is then framed by evidence of a broader historical context: news footage, public speeches, Nazi laws and regulations. Yet home movies very noticeably continue to depict happy moments in spite of looming catastrophe. Consequently, personal and historical time appear to be in 'radical tension' with one another (van Alphen 2011, 60). People smile and go about their ordinary activities in the face of encroaching war and genocide. Forgács notes 'the suspense is a Hitchcockian tension: we know their forthcoming drama and the twists, as we are aware of the would-be victims' future, but not able to communicate our knowledge' (Spieker 2002). Not only is this true of the Holocaust films, such as The Maelstrom (1997), in which the protagonists are seen making naïve preparations for their journey to Auschwitz; we are informed at the outset of El Perro Negro (2005), for example, that amateur filmmaker Joan Salvans will be murdered during the Spanish Civil War and so we watch this cheerful bourgeois - blissfully ignorant of his impending fate - knowing his life will soon be cut short by the events of history. Unperturbed by civil unrest, Salvans enjoys a camping trip with friends in the Pyrenees, shooting comic sketches, recording his wife and children. Part way through the film's narrative, Salvans's personal story ends abruptly with his death. In the Danube Exodus (1998), we witness passengers eating, praying, dancing, even marrying aboard the crowded riverboat they hope will transport them to safety, observed by the watchful eye of Captain Andrásovits's camera. The very ordinariness of these scenes appears almost in defiance of the extraordinary circumstances in which the film's subjects find themselves. Excerpts from passengers' diaries read on the soundtrack describe their fears and the deprivations experienced aboard The Queen Elizabeth, offering a counterpoint to the sanguine home movie images. Although some of Forgács's films 
do include images of war, more often disaster occurs offscreen. The amateur camera persistently records a seemingly untroubled banality.

content unavailable

please consult print version

Fig. 3.26 \& 27. Daily life continues in home movies of the Salvans family in El Perro Negro and passengers aboard The Queen Elizabeth in Danube Exodus despite impending war. Screenshots.

The effect of Forgács's filmmaking is as much an emotional as an intellectual one. Aesthetic manipulations including slow motion, freeze-frames, tinting, intermittent sound effects and the eerie, minimalist music of frequent collaborator, Tibor Szemző, combine 'to make history affectively perceptible' (Odin 2011, 155). The subtle textures and pulsating rhythms of Szemző's soundtracks in particular contribute not only to the formal unity of Forgács's films, but influence how we feel about what we see, albeit in a relatively indeterminate manner. Other devices, such as freeze-frames of a subject looking directly at the camera - and therefore at us implicate the viewer, creating a 'moral imperative' in William Wees's view to reflect upon not just the past but also our relation to it $(2011,89)$. Although historical, the private footage of Forgács's films depicts worlds and lifestyles that are nevertheless recognisably modern and therefore not entirely distant from our own. Moreover, knowledge of civil war and genocide that has occurred since World War II may instill a sense that the distance between 'then' and 'now' is perhaps uncomfortably slimmer than 'we might like to think' (Baron 2014, 40). For audiences, it is this combination of emotional and intellectual appeal that gives Forgács's recycling of home movies meaning and contemporary relevance.

Even in the absence of critical reflection, the 'intensified presence' enacted by a returned gaze at the camera or a focus upon human bodies exerts, according to Michele Pierson, a 'singularly affective pull' upon the viewer. This facilitates a kind of 'sympathetic identification with the 
past' whereby inarticulate feelings, emotions and imagination become the basis for engagement with history $(2009,6-7,11)$. What might be loosely termed 'affective history' is largely 'concerned with offering an experience of another time' rather than a representation specifically focused upon historical events or structures (2). Pierson suggests that through the use of techniques that appeal principally to an emotional spectrum, silent film footage can become not only watchable or entertaining to contemporary audiences, but also capable of 'seducing' viewers (8). Pierson's discussion focuses upon filmmakers such as Bill Morrison and Gustav Deutsch, who work largely with early nitrate footage. Home movies have been used in a comparable way to evoke a primarily emotional connection with the past, however.

From Scotland With Love (Virginia Heath 2014), which combines amateur and professionally recorded footage drawn from multiple sources into an extended montage of scenes depicting mid-twentieth century life in Scotland, is arguably more successful as a 75-minute music video for King Creosote (the stage name of composer and lyricist Kenny Anderson) than the poetic 'archive and music' documentary described on the film's promotional website. Given the film's absence of narration, the viewer is unlikely to gain any critical appreciation of Scottish history of the period, nor necessarily even be able to identify some of the activities seen onscreen. (Digging peat, for example, may be unfamiliar to a non-Scottish audience). Furthermore, many sequences, such as those depicting fairgrounds or dance halls, are relatively indistinguishable from footage recorded elsewhere in the British Isles. As its title alludes, From Scotland With Love appears intended to stir a romantic nostalgia and patriotic sentiments amongst Scottish audiences (or those of Scottish descent elsewhere) swept along by the rhythmic editing and somewhat twee neo-folk soundtrack, the lyrics of which encourage viewers to imaginatively look for named characters within the archival footage (film website 2014). Pierson suggests the strength of this kind of found footage practice lies in its ability to engage viewers by enabling the past to emerge 'not as museum relic but as lived'. A film such as From Scotland With Love seeks to captivate and entertain, encouraging an affective recognition of the past as 'havingbeen-alive' $(14,19)$. In this sense, a film functions largely as a product of an audience's emotional engagement, the psychological activity of viewers imbuing images of the past with vitality (7). Uses of archival footage, including home movies, primarily concerned with affect seem unlikely to foster desire for nuanced understandings of historical conditions, however. Affective history may be lively, even fun to watch, but as found footage cinema, it is hardly critical or informative, nor does it specifically intend to be. 
The desire to experience the past (rather than necessarily understand it) can also be satisfied in other ways. Jaimie Baron notes, for example, the persistent marketing of 'lost' or recently 'found' colour footage of events such as World War II in documentaries that offer a 'revelatory affective experience' rather than any new historical information or analysis $(2014,124) .{ }^{43}$ Decades in Colour, for example, notably prides itself on presenting 'a brand new full-colour picture of life in New Zealand'. Philippe Mora likewise argued that seeing Hitler in colour home movies brought a new reality to audiences, who in 1973 were used to seeing official black-and-white footage of the dictator (Wilson 1973, 145). Mora's film is of course intended to play upon the affective qualities of amateur images in order to present a new appreciation of the rise of fascism in Germany, although it has been noted that in the absence of narration, Swastika risks simply replicating the effect of the Nazi propaganda machine (ibid.). Moreover, Baron suggests there is an inherent danger in affective uses of found footage - what she terms the 'archive affect' - particularly those invoking nostalgia for an idealised past. By obscuring darker aspects of history such as colonialism or racial discrimination, films may become complicit in the objectification of subjects as exotic 'others', or nurture an uncritical longing for a utopian past that never existed (128-130).

The archive affect is particularly noticeable in music videos, either officially commissioned or fan generated, that incorporate home movie footage. The phenomenon of YouTube 'tribute' videos to Eva Braun commemorating her as a tragic historical figure (discussed further in chapter 5) is an especially unsettling manifestation of the archive affect of home movies. The combination of music and montage can nonetheless function to intimate a more reflective stance towards the past. The video for 'Bedded Deep in Long Term Memory', a track by The Caretaker (the experimental sound collage project of James Leyland Kirby), for example, seems to combine affective historical presence with an awareness of the fragility of memory and its material artefacts. The audio track consists of a looped 78-recording of ballroom music, while the video features repetitions of sometimes jittery and badly deteriorated home movie images (including boys playing croquet, a couple kissing in a crowd and people on a boat), the scratched sound recording and images appearing to 'stutter' in tandem with each other. The imperfections of both music and image track eschew simple restorative nostalgia, producing instead a melancholic but 'self-conscious awareness of the past as past' (Baron 2014, 130).

43 Colourised footage can fulfil a similar role in productions such as Peter Jackson's They Shall Not Grow Old (2018) and British Pathé's Revolution in Colour (2016). 
The use of home movie footage in gallery installations may also blend its affective qualities with critical distance. Andrew Dearman's Disappearance (2015), for example, uses digital compositing of images from different 1950s home movies in a single-channel installation featuring a woman, boy and a 'tall thin man in a broad brimmed hat' resembling the feared figure of child-abductor identikit pictures printed in newspapers. The installation is intended to evoke the increasing sense of anxiety that developed during the 1960s about children playing in the street ${ }^{44}$ the relatively crude digital manipulation of footage perhaps drawing attention to the constructed nature of 'stranger danger'.

content unavailable

please consult print version

Fig. 3.28. Digital compositing combines images from different home movies in Disappearance. Screenshot.

More esoteric or niche audience oriented combinations of affect and critical reflection presumably have greater potential to alienate viewers, especially those unfamiliar with decoding the aesthetic tendencies of a particular kind of work. For those who are not regular patrons of contemporary art galleries, experimental music or other avant-garde practices, boredom in the sense Fredric Jameson suggests, that is, a rejection of 'other people's cultural practices and their threat to our own rationalizations about the nature and value of art' $(1997,72)$, seems an entirely plausible response.

\section{Against the narrative impulse: uninflected footage as worthy subject}

Discussing the films of Péter Forgács, William Wees raises the question whether, given the historical significance and emotional impact of war images, home movies could simply be shown in their original form. He immediately counters this suggestion, however, arguing that

44 This interpretation is derived from the artist's notes in the Contemporary Art Centre of South Australia's Contemporary 2015 exhibition catalogue (12) and is not necessarily readable directly off the installation itself. 
Forgács's formal manipulations enable viewers to see more than the raw footage itself makes visible $(2011,87)$. The notion that montage creates meaning and affect beyond that of home movies in their original state would in fact seem to form the underlying justification for the range of re-editing techniques witnessed in the various types of production discussed in this chapter.

In one sense, the reuse of home movies performs a paradoxical manoeuvre. By drawing attention to time that has passed since the moment of recording, they provide a window on a vanished world, underlining the status of home movies as archival footage. In this sense, they force a certain recognition of time. Found footage and compilation films that reuse home movies do not generally encourage the viewer to be aware of time passing whilst watching, however. The films and television series discussed above all indulge in 'time-killing' techniques, albeit to a lesser or greater extent. Re-editing footage into montages, juxtaposing it with other kinds of images and the addition of music or sound effects all contribute to the way viewers experience watching home movies within other productions. Perhaps most importantly, narration is a feature of many reuses of home movies. Private films are made to tell stories and reveal intimate histories not readily observable from the footage itself. Narration and aesthetic effects enliven films, constructing meaning and affect via the incorporation of conventional cinematic techniques familiar to viewers from dominant cinema, television, advertising, music videos or documentary. Even slowing or repeating footage eradicates dead time by rendering it uncanny, making a curiosity out of it, or revealing some meaning that might otherwise escape the eye. Such strategies amount to an avoidance of boring viewers 'to death' (Misek 2010, 781) (although certainly some films discussed might potentially have that effect, albeit unintentionally). From this, one might easily conclude that home movie images are perceived to be interesting, yet home movies themselves in their original form are not. In order to retain the attention of audiences, home movies would appear to require dramatic rearrangement and a foreshortening of time quite distinct from their 'natural' duration. Indeed, Forgács himself concurs with this position, describing the raw material with which he works as 'full of faults. The majority—let's say 99\% of these home movies are boring. Boring. And bad' (Boyle 2001). By re-editing footage, he removes the visual idiom of home movies (jump cuts, flash frames, dead time and the like), creating something closer to shot-reverse-shot patterns. Steve Anderson concludes therefore that 'Forgács's project simultaneously offers a celebration of individual, amateur vision and a reification of cinematic conventions' (2011, 85). Likewise, many other 
productions appear to valorize amateur images whilst downplaying their specific aesthetic attributes.

Jaimie Baron suggests 'there is both liberation and violence in using home mode documents in a documentary [or any other kind of production]. For home mode documents to have significance for the rest of us, they must be forcibly transformed from private documents into public ones'. While the life (and death) of the private individual potentially becomes socially or historically significant to a wider audience, an editor ultimately controls the story that is told (102). Rick Prelinger offers a rather different perspective on the issue, arguing that 'original materials [including home movies] tell pretty good stories on their own' without the insistent interventions of subsequent storytellers. However, he notes that most archival materials 'don't reach the public without being run through the storytelling Cuisinart' (2009). Unsurprisingly, as an archivist, Prelinger does not deny the importance of background information for understanding archival images. He contends, however, that 'overbearing narration, emotionally invasive music and highly personalized visions of history don't constitute context' and result in 'works that don't really speak to the value of their components' (ibid.).

Taking up his own rallying cry for archivists to engage in production as a remedy to such issues, Prelinger created No More Road Trips? (2013), an 80-minute compilation of home movie footage forming a composite road journey across the United States from the Atlantic to the Pacific coast. There is no narrative beyond the movement from east to west, the audience instructed in the opening titles to create their own soundtrack in order to narrate the otherwise silent film as it screens. ${ }^{45}$ Beyond the selection of sequences and insertion of titles indicating when and where images were recorded, footage is presented essentially uninflected by editorial manipulation. Prelinger has termed this kind of filmmaking, which privileges original documents and relies upon an audience's appreciation of evidence to 'complete' the film, 'evidentiary cinema' (2013). The actual viewing experience could conceivably vary considerably between screenings, depending upon the composition of the audience and their willingness to participate actively in the production of a verbal soundtrack. In the absence of any intimation as to how images should be received, it might be wondered if nostalgic recollection is perhaps a more common response than Prelinger's hoped for reflection upon the nature of road travel

45 The film could of course also be presented with a live music score, which would be likely to alter the viewing experience considerably. A trailer for such an event can be viewed here: https://vimeo.com/180911856 (uploaded 31 August 2016). 
(ibid.). Alternatively, viewers might lapse into a state of boredom, failing entirely to find any meaning in the sequences of images or the pleasures of an emotional connection. This response seems quite likely in fact should the viewer choose to watch the film online at home, particularly for someone who is neither American, nor visited any of the places depicted. ${ }^{46}$ Short of talking to oneself in order to animate the images, the lone viewer is left to contemplate cinematic duration in silence, an experience that may well extend beyond Heidegger's first notion of boredom into deeper levels that will be considered more fully in the following chapters.

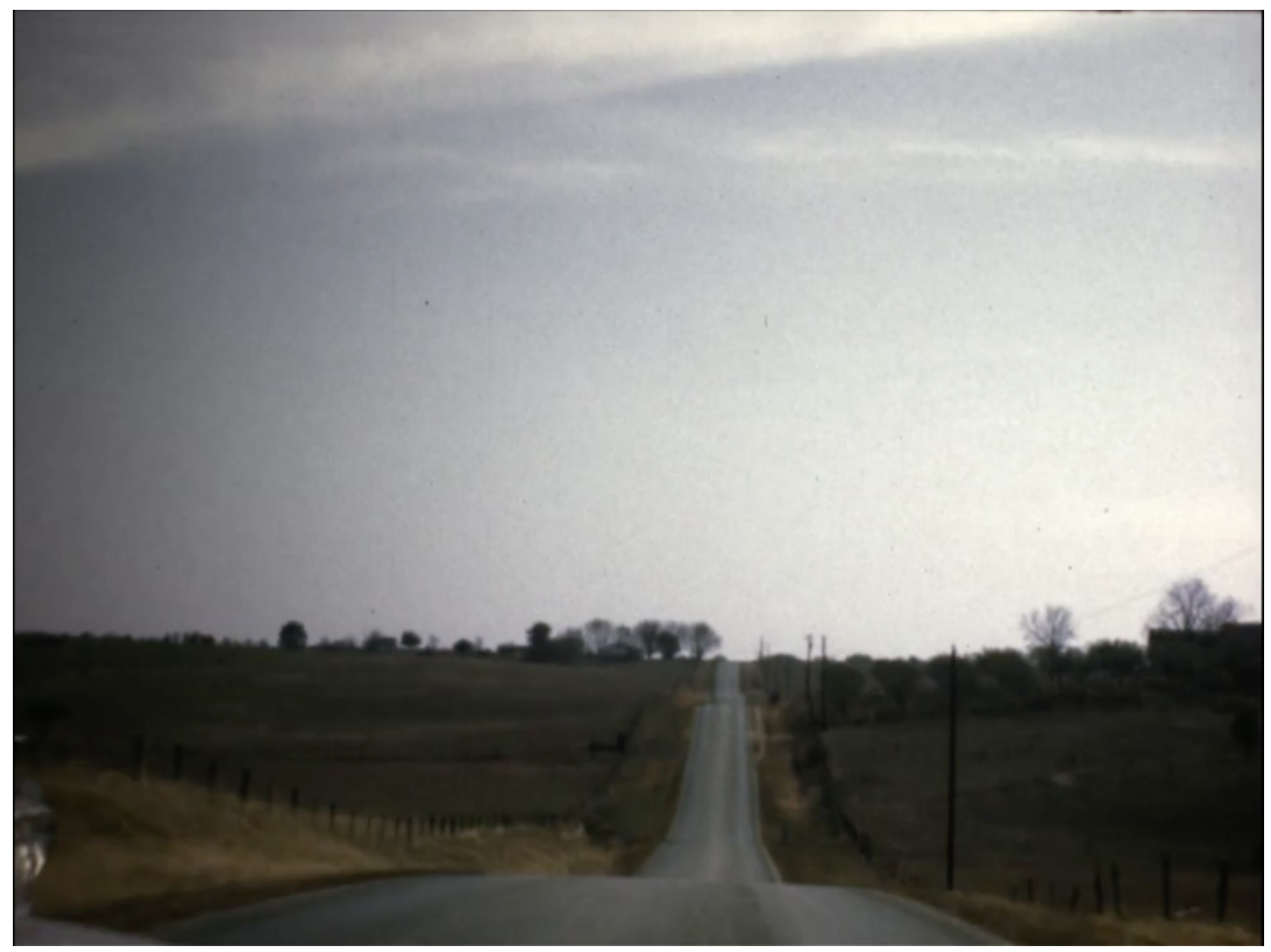

Fig. 3.29. Highway as empty as the soundtrack of Rick Prelinger's No More Road Trips? Screenshot. 


\title{
Chapter 4
}

\section{Archival capital, information overload and not being bored with home movies in the archive}

Information is archival capital, but too much information is a liability.

- Rick Prelinger 2011

\begin{abstract}
bakery, pilgrimage, funeral, cinema, construction site, bar, campground, circus, communion, Congo, dance, zoo, baptism, Epiphany, pigeon racing, Eucharist, party, flower, birth, block party, harbour, autumn, pet, household, marriage, industry, interior view, Youth movement, anniversary, fair, Christmas, kitchen, spring, personal hygiene, baby care, airport, market, mission, Mother's Day, motorsports, music, fanfare, New Year's Day, education, parade, flower parade, procession, carnival parade, horse riding, Easter, picnic, people-institutions, place names, country life, amusement park, marksmen's club, St. Nicholas Day, skiing, toys, playground, game, sports, horse racing, rowing, cycle racing, soccer, box, surfing, theater, music hall, tourism, coastal tourism, WWII, birthday, costume party, engagement, transportation, celebration, store, winter, World's Fair Brussels 1958, sailing, summer, swimming pool (English translation from onscreen text)
\end{abstract}

Intoned by several different voices, these words are spoken without emotion inside a portable kiosk resembling an instant photo-booth. Temporarily located on a city street, this is one of six mobile viewing booths containing a 'Homeless Movie' commissioned by Ghent's museum of everyday life, Huis van Alijn. Each artist's film takes the museum's collection of home movies as a point of inspiration. Katrin Kamrau's Reference features members of the museum's staff reading from a Woordenlijst (word list) on the soundtrack. The viewer might intuit these subjects, most of which are related to everyday life, as ones potentially appearing in home movies. ${ }^{47}$ Instead of illustrating them with corresponding home movie footage as might be expected in this context, with the exception of three images that appear very briefly, the words enunciated on the soundtrack are repeated on a black screen as text in several languages. The effect is to draw attention to the classificatory nature of archiving and, by extension, the contemporary fate of home movies as a detached index of retrievable subjects rather than emotive conveyors of personal memory, the isolated image of a girl (who initially makes the

47 According to an in-house document (Huis van Alijn 2014), the most common subjects seen in the museum's home movie collection are tourism, coastal tourism, procession, birthday, communion and Ghent, while 29 films contain footage of Congo (3-4). 
familiar sign of the cross) motioning an indecipherable gesture perhaps offering a fleeting allusion to the retreat of the latter into oblivion.

Cultural heritage institutions face similar issues to those experienced by filmmakers when dealing with home movies. How can such private memory objects be transformed for public audiences into valuable history or meaningful encounters with the filmed past? Looking at examples of specific methods archives and museums use to present their home movies, this chapter investigates how private films can become engaging, interesting and meaningful to audiences as cinema, as history, as affective experience. Home movies now form a significant element of many film archive or museum collections, especially those with a local, regional or specialised area of interest that may not be well documented by more official sources of visual history. National institutions also collect home movies, albeit often selectively (those of wellknown people, for example), or, as in New Zealand, in the absence of regional repositories. Given this diversity, the examples discussed in the following pages are drawn from both national collections (Ngā Taonga Sound and Vision, Deutsche Kinemathek, EYE Filmmuseum, National Film and Sound Archive of Australia) and regional ones (Yorkshire Film Archive, Texas Archive of the Moving Image, London Screen Archives), as well as museums with a specific focus (Huis van Alijn, Jewish Museum Berlin).

Within cultural heritage institutions, home movies are screened to audiences in a variety of ways. Access ranges from video clips accompanying the catalogue descriptions of archive databases to elaborately curated exhibitions that construct complex historical narratives to online editing tools that enable members of the public to create their own mash-ups of archival footage. The audiences of archival home movies are likewise varied: researchers, students, museum visitors, local communities, online viewers, the casual pedestrians who encounter street installations (such as Reference), those keen to reuse archival images and participate actively in the production of meaning. Archives cater to these different viewers by compiling databases, curating web content, arranging community screenings, commissioning artists to work with films in their collections, using social media, hosting events such as Home Movie Day and running public remix competitions, amongst other activities. Moreover, home movies are not just screened in different ways and settings; they can be framed very differently within them. In the examples that follow, exhibits and screening programmes that incorporate home movies 
encourage a range of cognitive and affective responses to films and interpretations of the past that they allow us to glimpse.

The transition from private aide-mémoire to historical record in a public collection is not a simple one. As suggested in the example above, transplanted from home to archive, home movies have a tendency to become categories of subjects disconnected from the affective dimension of narratives derived from personal memories. Catalogues and databases - standard tools of archival arrangement - enable us to find and peruse films according to archival descriptors or metadata, but do not necessarily communicate individual traits, contexts or meanings effectively. This may be compounded by the repetitive and seemingly nebulous content of many home movies, along with the sheer number of films in many archival collections. Trying to identify something of interest, we can easily become bored with too many films that look overly similar to one another. Film watching is an inherently time-consuming activity. In an archive, the wealth of information available may keep us occupied for hours perhaps even adequately occupied so that we are not consciously aware of time dragging - but can still ultimately leave us feeling empty and frustrated if we do not discover anything of particular relevance to the purpose of our visit.

Digitisation has of course made it simpler and faster to find information about the past than ever before. With millions of historical records, images and artefacts now available in virtual form via the Internet, one can in fact gain a significant degree of intimacy with the past without so much as having to set foot in a physical repository, gallery space or screening venue. One could theoretically watch home movies online more-or-less ad infinitum via archive websites and other video-streaming platforms. Yet access in itself can confound as much as communicate anything meaningful. The weddings, birthdays, pets, holidays, parades, outings and festivities of strangers can certainly fill time, but what, if anything, do such images mean viewed in isolation, without context or connection? Would the persistent home movie viewer ultimately be watching as much ad nauseam as ad infinitum?

The archive can seem a detached or esoteric place, as in Reference, full of categories and obscure meanings. Yet it can equally be an affective or emotive one. The curation of collections can have a transformative effect in terms of forging connections between personal footage and public audiences. It can mitigate 'information overload' through selection and offer us ways of 
understanding home movies and the past they portray so that we do not find ourselves bored with their repetitions and banalities. As discussed in chapter 3 , home movies exude a powerful sense of authenticity, of unaffected real life caught spontaneously on camera. Within the space of an archive or museum, the 'home movie effect' may become amplified. Interpreted as historical evidence of the people, places and activities they depict, home movies have the capacity to colour understandings of the past a variety of shades, some of which may be arguably more informative or insightful than others in the present moment. In their archival afterlife, home movies therefore offer a potentially illuminating example of how images that were once personal can be used to construct visions of history and collective memory for a public viewership.

\section{Making history accessible: collections and stories}

Digitisation has become a key concern in archival discourse and practice. Although digitisation has affected many archival activities, its impact is often most obvious in areas related to public access. For film archives, digital technologies have had the particular advantage of eliminating the necessity of cumbersome equipment to exhibit material, making it easier to take films to communities (rather than expecting them to come to an archive), or play films in a gallery space on a looped format for continuous viewing. The Internet has also expanded audiences beyond those able to attend a one-off screening event or exhibition, while online catalogues often enable researchers to gain significant insight into the content of collections before (or even entirely without) visiting an archive in person. These new forms of access to film materials have obvious advantages for users and may be very important if an archive's funding is dependent upon serving a sizeable community of users. Ray Edmondson notes in Audiovisual Archiving: Philosophy and Principles (2004) that interest in what might be termed 'museum-related aspects' of archival work has led to proactive attempts to foster an audience, signaling a shift away from merely reactive forms of access, such as responding to user requests (39). Some scholars and archivists fear, however, that resources will be channelled into digital initiatives at the expense of other core activities, the production of digital viewing copies supplanting preservation or other forms of access as a primary archival goal. ${ }^{48}$ Many archives have implemented online access to

48 For some examples of this kind of discussion, see Compton (2010), Druick (2014), Newman (2009), Ingravalle (2015) and the National Library of New Zealand (2007). Leo Enticknap (2007) sketches a general introduction to a range of issues surrounding digitisation. Whether digital surrogates should (or indeed have) become acceptable substitutes standing in for the 'real thing' feeds into a much broader debate regarding the importance of medium specificity. Concerns range from largely practical issues, such as the stability of storage formats and the resources required for constant migrations, to more arcane discourses about whether viewing experiences are fundamentally altered through non-celluloid projection, or the extent to which digital copies 
digitised materials, either in addition to or even instead of on-site viewing. Whilst the development of sizeable web-based collections may enlarge an institution's potential pool of users, the apparent plenitude of online resources masks the small percentage of archival holdings actually available via the Internet. Given the labour-intensive and costly process of digitising, describing and uploading analogue film collections, for many (if not most) archives this situation is likely to persist for the foreseeable future. In an age of plenty sometimes more perceived than real, selection and presentation - activities frequently undertaken with slender resources - have an important role in making cinematic history available to both specialised researchers and general viewers alike.

As in the productions that recycle footage examined in the previous chapter, narrative and affect play a role in making home movies engaging and meaningful in the archive. Using home movies to tell stories or telling stories about them can help breathe life into old footage. Stories are not the primary means of organising information within an archive, however. Like a database, an archive is a collection of items structured according to various subjects or categories. With the emergence of digital technologies, arranging information in such a way has assumed great importance both within and beyond the archive. Referring to Jean-François Lyotard's seminal text, The Postmodern Condition: A Report on Knowledge, Lev Manovich argues that in postmodern information societies the database has superseded narrative - 'the key form of cultural expression of the modern age' - as a means of experiencing the world (2001, 218-9). The immense expansion of new media and the Internet in the twenty-first century into seemingly almost every aspect of our daily lives has only served to magnify the significance of this proposition. The retrieval of data from a non-linear arrangement of items is not just a feature of archival research, but also of web browsing. As a means of accessing information, this is in many ways more efficient than the recounting of a narrative, which takes time to digest.

may be said to diminish the aura of an historical artefact. For arguments of this nature, see in particular Cherchi Usai et. al. (2008). (David Francis, for example, notes that digital projection 'is a slightly different experience - unfortunately, it's very difficult to explain the difference in words'. He assumes it is the duty of archives to 'care' about historically authentic viewing conditions, even in the face of audience indifference (104). Referring to Benjamin's notion of aura, Alexander Horwath argues that 'as we know, [reproductive media] tend to develop their own "auras", not so much in the sense of the single object, but as systems'. Reproduction via a different system involves giving up 'some basic characteristics of the first medium' and therefore, according to Horwath, entails a loss of aura (111).) On the topic of digital substitution, Edmondson asks, 'Can a digital clone ever be acceptable as a true substitute for an original analog artefact? Can it permit the original viewing or listening experience ever to be re-created?' (37n). Notably, of the examples discussed in this chapter, only one (Home Movie Day) involves the projection of analogue film. Given the practical difficulties now associated with analogue projection, debates regarding its significance in many instances seem rather academic or abstract in nature, therefore I do not pursue them in any detail. See note 65 re the possibility of aura in a digital viewing environment. 
(Benjamin we may recall lamented the demise of storytelling amidst the hustle and bustle of modern societies $(2007,91)$.) Yet stories have an affective and cognitive dimension that lists or collections of (virtual) objects do not possess on their own in the absence of knowledge or imagination on the part of the beholder. They tell us about causes and effects, and as such can make us think and feel.

Home movies might themselves be likened to miniature databases; they are more often assemblies of discontinuous shots than self-contained narratives (although in the normal process of viewing one does of course watch these shots sequentially, even if beginning at a random point within a film). In this sense, arrangement as archival categories according to content seems to transpire almost naturally from within them. Yet if a home movie appears no more than a (shot) list of subjects with little obvious connection to each other, it can be less than engaging to watch, at least as a whole. Returning to Klapp's analysis discussed in chapter 1, excessive variety without discernible pattern - that is, information overload - is boring. Meaning is what makes a collection interesting. Of course, film collections are not just an array of objects but also time fillers, superficial or otherwise. Not being bored with watching them is contingent upon films not simply 'killing time' but lending it a sense of fullness, the satisfaction of time well spent (Heidegger 1995, 97, 110). In Reference the viewer must find an abstract link between the sequence of words in order to make sense of the film, otherwise it is most likely boring to watch and relatively meaningless overall. In an archive a researcher or curator performs an equivalent gesture, interpretation creating meaningful connections between what might otherwise appear discrete and disparate contents.

Manovich describes database and narrative as 'natural enemies' (225). They represent the world in different and competing ways. The database is, Ernst van Alphen suggests, 'a rather technical notion', however, ultimately difficult to compare with narrative (2014, 9). Studying the contemporary archive, it is perhaps less a matter of comparison as grasping how these two coexist and interweave with one another to make history accessible and meaningful. Archives and especially museums are hybrid spaces. In view of the human need for meaningfulness, narratives appear within and alongside the arrangements of collections or databases. The efficacy of archival taxonomies when it comes to relaying historical information plays off against the potentially more explanatory and affective encounters narrative has to offer as a means of recovering the past. Digital environments in particular afford ample terrain for both. 


\section{Describing and interpreting home movies in the archive}

In the online catalogue of Ngā Taonga Sound Vision (NTSV), the following description accompanies an item listed as 'Personal record. Hayward, R. [Wellington NZ October 1916]':

A woman emerges from doorway calling the family cat, who responds by bounding across the lawn to meet her.

Man playing with cat in back yard.

Lady cuddles and snuggles into the fluffy pet.

Lady poses for camera, then blows kisses to the wind.

Couple with their cat enjoy a cup of tea out in the garden.

Couple pose for camera.

Elderly lady poses for camera.

Man dressed in army uniform poses, before advancing toward camera to salute.

The description is fairly brief (as is the film itself at under two minutes). However, as this catalogue entry for a 'personal record' or home movie is just one of more than 750,000 records in NTSV's database, more comprehensive description of individual items may be neither feasible, nor considered the best use of available resources. Unlike the majority of works listed in the catalogue, this entry also contains a video clip so that the film can be viewed online, making it available to those unable to visit the archive in Wellington or who are simply pressed for time and prefer to watch at home. ${ }^{49}$ Watching the film, its description appears generally accurate, although we could quibble with minor details or the specific choice of words. (Given the film is silent and showing deterioration, can we really be sure the woman glimpsed momentarily in the very brief opening shot is calling the family cat? Why does this 'woman' become a 'lady' thereafter? Is the second 'lady' actually elderly, or simply older than the first?)

content unavailable

please consult print version

Fig. 4.1-3. Online clip of 'Personal record. Hayward, R. [Wellington NZ October 1916]' showing pronounced signs of deterioration characteristic of early nitrate film stock. NTSV. Screenshots.

49 As of January 2019, clips of 2,323 moving image works (out of the 618,860 listed in the catalogue) can be viewed online (that is, $0.3 \%$ ). 
Moreover, we might ponder the relationships between the four people in the film. (The two young people appear to be a couple; are the older woman and man their relatives? What is the participants' connection with the filmmaker?) Depending upon why we happened to watch this particular work and our personal knowledge of early twentieth-century history and cinema, the film may prompt more technical or historical questions as well. (Why is the camera so firmly rooted to the spot in each shot? What has caused the distinctive pattern that seems to swallow the films' subjects intermittently? Did the couple normally take tea in the garden, or has the scene been staged outdoors for the benefit of camera? Why is the older man dressed in uniform? Was the young man also a soldier? Who could afford to shoot films at home in 1916?) The catalogue entry offers few answers to such quandaries that may arise in the minds of viewers. Scrolling to the bottom of the basic archival metadata listed below the main description reveals that 'R. Hayward' is indeed Rudall Hayward, one of the pioneer figures of early filmmaking in New Zealand. However, as the film's genre is simply listed as 'amateur', unless he or she happens to be familiar with Hayward's role in cinema history, this connection is likely to be lost on the viewer.

Entries of this sort in an archival database can help users to find records of interest, as well as watch films online they may not be able to see otherwise. They tell us what is in an archive without having to visit it, but often, as in the example above, not a great deal more. The same clip appears in the online exhibition, Sights and Sounds of World War I (http://anzacsightsound.org), which incorporates audiovisual materials from NTSV and the National Film and Sound Archive of Australia (NFSA). Hayward's recording can be found on a page featuring items about 'Life at Home during the War'. A small thumbnail shows the couple seated at the outdoor table and a title announces the film's content as 'Tea for two, and an unknown soldier'. Upon clicking it, the thumbnail becomes a wallpaper for a curator's comments about the film.

Rather than just a shot list, this description of the film features biographical details of the participants, along with a little insight into home moviemaking of the period and the representation of soldiers (or men?), answering some (but not all) of the questions posed above. The text is still fairly minimal, the unidentified curator choosing not to include much detail about filmmaking in the main section. Perhaps because it is part of a large exhibition primarily about military and wartime social history rather than cinema per se, information (or 
speculations) about the making of this particular film might be considered somewhat tangential to the website's overall emphasis. The 'More Info' does offer those interested in the history of the film itself a few further details, however, including its status as the third oldest family film in NTSV's collection. In comparison with the apparent certainty of the entry above, these notes cast a shadow of doubt as to the film's provenance, although they assure the reader nonetheless that a 16-year-old Rudall Hayward 'would certainly have had the equipment at hand to make such a film'.

content unavailable

please consult print version

Fig. 4.4. Webpage with curatorial notes for Hayward's home movie in online exhibition, ANZAC Sights and Sounds of World War I. Screenshot.

What do these small curatorial insights add to a viewing of this home movie that one does not glean from simply watching it via the entry in the archive's main catalogue? In the first instance, the casual viewer not specifically looking for an early amateur recording or films associated with Rudall Hayward, for example, is probably more likely to find it via the ANZAC site, assuming he or she has at least a passing interest in World War I history. (The reverse may be true for those researching a topic not related to World War I.) Beyond this practicality, background details about some of the people who feature in the film, its (probable) maker and the relative 
rarity of such a recording situate the film within an historical context. Viewers who take the time to browse the rest of the exhibition content at length can make connections with other historical records about the period. (They could compare the use of close ups in this film with the technique seen in other films vis-à-vis the curator's observation, for example.)

The extra-filmic narrative provided by the curatorial notes would also seem to increase the likelihood viewers will have an affective response to the recording. Elements of the film itself may potentially elicit an emotional reaction from viewers. (The young woman's delight in feeding her cat in particular is rather charming and probably easy for many people to relate to as a kind of forerunner of the YouTube cat video.) Simply knowing the tragic fate of the young man little more than a year after this recording was made adds a certain poignancy to the experience of viewing it however, something we cannot attain directly from the images in the absence of this knowledge (although we might imagine this possibility given when the film was made). The very ordinariness of the domestic scene may accentuate this effect, helping the viewer to gain an affective appreciation of history; ordinary people - much like ourselves fought and died in World War I a century ago. Although part of an exhibition that is neither about home movies, nor even about filmmaking per se, the inclusion of an amateur recording is significant in this context. It is not just informative, it is also emotive, the film's intimate view of wartime home life potentially able to arouse feelings less easily stirred by more formal recordings of the era, particularly those that do not include close ups of individuals.

This style of presentation accords with what Giovanna Fossati describes as a 'chaperone model' of distribution, which casts the archival curator in an essentially didactic role. The curator ushers a film into the public domain accompanied by expert opinion and any relevant contextual information that might enable contemporary viewers to appreciate the complexities of historical conditions $(2007,333)$. Not merely 'keepers of the frame', film archivists become in the words of Timothy Wisniewski (2007) - 'framers of the kept' helping to bridge the distance between today's audiences and past cinematic traditions. ${ }^{50}$ Chaperoning assumes archival films presented 'as is' may be less-than-meaningful or engaging for contemporary viewers, necessitating some form of explication. Indeed, as Nathan Carroll suggests, the act of curation more generally implies that film history is not self-explanatory, requiring expert mediation to relate its meaning or significance to public audiences (2006, 61-2).

50 Wisniewski inverts the title of Penelope Houston's 1994 history of film archiving to signal a change in emphasis. 
Home movies were of course not intended to be meaningful to public audiences when they were made, let alone at some future date. On this basis, one might logically surmise that of all archival films home movies are more in need than most of informed interpretation. The two different points of access to 'Personal record. Hayward, R. [Wellington NZ October 1916]' illustrate some potential effects of contextualising a home movie. The catalogue entry's rudimentary account of the film's content tells us little we cannot discover through watching it ourselves, our response likely to be shaped by pre-existing knowledge. The exhibition notes supply background details and imply certain values (the selection of words - 'rare event', 'intimate scenes', 'uncommon portrait' - cue the viewer to perceive the film as something out of the ordinary). The curator's description potentially influences our reception and understanding of the film. In this second context, 'Personal record. Hayward, R. [Wellington NZ October 1916]' not only has meaning, it has accrued affective potency.

What constitutes an acceptable interpretation of a document in a particular time and place may be considered quite erroneous in an entirely different context, however. (Fifty or hundred years from now, how might the interpretation of Rudall Hayward's home movie in the context of World War I history differ? Or within another institution? Or in an exhibition on another subject?) Moreover, a curator need only select those documents that accord with his or her own viewpoint in order to assume an authoritative, if one-sided, stance. In this sense, the interpretation of materials proposed by a cultural heritage institution may be more revealing of its policy or the personal opinions of curators than of the nation or community it purportedly represents (Kelly 2015, 20). Yet what exactly does 'good curation' entail?

\section{Placing a film in its right context}

\footnotetext{
Is a collection a prison for art works and the curator the prison warden who takes his prisoners on an occasional yard walk? A film museum screening then becomes the temporary unleashing of a film that otherwise stays hidden or "lost," its reality documented only by a database title or a catalog (Frieling 2001, 146).
}

There is no straightforward answer to the question of how curation should be practised within film archives or museums. Although recognition of film's archival potential is almost as old as the medium itself - Boleslas Matuszewski advocated the establishment of a depository for this 'new source of history' as early as 1898 - more than century later, Snowden Becker observed that '[d]epending on whom you ask, canonical knowledge for audiovisual archives may be 
considered thin, nascent, or in need of drastic revision' (2013, 246). Peter Bosma describes film curation in particular as 'a slippery subject' lacking rigor and institutional standards $(2015,3)$, while Jesper Andersen notes the absence of established theory with regard to how it should be practised $(2009,7)$. Moreover, there is no single textbook devoted to the subject, although Bosma's Film Programming: Curating for Cinemas, Festivals, Archives (2015) and Edmondson's UNESCO guide, Audiovisual Archiving: Philosophy and Principles (2004), both briefly outline some overarching curatorial concerns, while Nico de Klerk's Showing and Telling: Film heritage institutions and their performance of public accountability (2019) examines several case studies (albeit not home movies), advocating an 'ethics' of curation grounded in contextualisation rather than film as art object. Film Curatorship: Archives, Museums and the Digital Marketplace (Cherchi Usai et al. 2008) takes a rather more idiosyncratic approach in the form of a meandering dialogue between its contributors. Traversing various issues related to screening archival films to public audiences, the book culminates in the following definition of film curatorship:

The art of interpreting the aesthetics, history, and technology of cinema through the selective collection, preservation, and documentation of films and their exhibition in archival presentations (231).

Useful enough in itself, this statement indicates little about how film curation should actually be carried out in practice. Indeed, in the absence of accepted theory or any seminal text, Laura Marks comments that it is almost as if curatorial work should miraculously spring 'from some mysterious internal source of inspiration' $(2004,37)$. Noticeably, the discussion of archival curation is often largely speculative in nature or prescriptive in a most generalised sense. Bosma, for example, identifies three fundamental archival tasks: preservation, presentation and development of a collection by adding value, contemporary relevance and contextualisation to materials (87). According to Bosma, the film curator's task is 'to present all available treasures in an attractive way to an audience' (93), an ideal film archive offering a broad overview of film history, linking past and present film cultures (90). In a provocatively titled article, 'Showing a Film is Not Enough', Andersen similarly agrees that a most important aspect of film curatorship is the creation of 'a contextual experience for the audience - to place films in their right context' $(2009,7)$.

Perhaps unsurprisingly, given the dearth of cohesive theory, discussions of film curation often 
centre upon the figure of the archivist-cum-curator. As it is supposedly the responsibility of this individual not only to frame and promote collections, but also to protect artefacts from misinterpretation or potential misuse, the role has been conceptualised in a number of ways. Opinion as to whether it should be envisaged primarily as that of dispassionate guardian, wary gatekeeper, pedagogic chaperone or conceived in more radically postmodern terms has been profoundly influenced by contemporary currents in broader archival theory. The notion that archival work has an essentially objective or impartial character, or that historical documents offer an unbiased record of the past, has been largely displaced (at least within archival discourse, albeit not necessarily in practice) in the wake of poststructuralist and deconstructionist texts, most notably Michel Foucault's The Archaeology of Knowledge (1972) and Jacques Derrida's Archive Fever (1995). The impact of the work of Foucault and Derrida, with its emphasis upon archival contingency, the indeterminacy of documents and changing discursive possibilities, has been immense, so much so that it has become, as Paula Amad notes, almost a cliché to acknowledge that any meaning to be found within archival records is constructed and ideological rather than innocent or neutral (2010, 18). More than just a storehouse, the archive creates history through the classification and interpretation of its documents. That is to say, the act of archiving 'produces as much as it records the event' (Derrida 1995, 17). Given this, the archive is a formidable institution. Whoever controls it has the power to impose understandings of the past and, by implication, the present, as well as projections into the future. The archive may be used to validate the expertise or authority necessary to interpret the past or make decisions affecting the future. By pointing to 'evidence' in the archive, experts can justify their own claims to historical knowledge. Archival documents are not immutable, factual historical representations however, their interpretation subject to variation over time and according to circumstance (Foucault 1972, 130). In this sense, discourses about the past have not only a meaning but also themselves a specific history (127). If the archive is 'the law of what can be said' (129), the law can effectively be rewritten to suit present needs or values, new interpretations supplanting previous readings of documents.

Contemporary understandings of the archive relate to the presentation of home movies in a number of ways. Home movies tend to elude straightforward archival classification, frequently lacking the metadata associated with other types of films such as titles, cast lists or sometimes even an identifiable filmmaker. Description may therefore rely upon a combination of standard archival terminology and an individual archivist's interpretation of content, both of which may 
affect the subsequent use of a film. Searching moving images in NTSV's catalogue using the terms 'home movie World War I', for example, does not return the entry for Rudall Hayward's recording, which includes none of these specific words. Likewise, searching for a moving image made between 1914 and 1918 containing a 'soldier' does not locate the film either as its fourth participant is described as a 'man dressed in army uniform'. Having found the item in question, the inconsistent use of the word 'lady' noted above arguably conveys certain connotations about the social status of the film's female subjects that the use of the more neutral term 'woman' throughout might avoid. The difficulties of distilling the essential features of home movies in words are myriad indeed. Subjective interpretation creeps into what ideally ought to be impartial description of content, even before wider meanings of a film are considered.

In other respects, home movies have certain advantages over professional productions. Not usually encumbered by copyright concerns, they can enjoy relative freedom in the public domain. The privacy of subjects who neither consented to, nor indeed likely foresaw the possibility of future archival screenings, raises ethical questions around the distribution of personal materials in public spaces, however. Even permission to be recorded in the first instance may be a murky concept if power imbalances existed between filmmakers and subjects. In practice, archivists are likely to make ad hoc decisions on a case-by-case basis with regard to the suitability of personal records for public dissemination (Rao 2010, 106-9, 115-6; Dollman 2017, 232). In such circumstances, the archivist exercises significant authority over films, acting not only as guardian but also gatekeeper. ${ }^{51}$

The users of archives are of course often not aware of behind-the-scenes processes of selection and acts of censorship that may restrict the consultation of certain materials (unless specifically interested in an item that has had restrictions placed upon it, for example). The kind of authority archivists exert over records in their care is more likely to be discernable in the framing of works that have been selected for exhibition. This is not to say curators necessarily draw attention to their activities. Not all prison wardens feel the need to justify their particular choices with regard to which works they take on a yard walk. Chaperoning films into the public

\footnotetext{
51 Citing specific policy, Rachel Bracha notes, for example, that archives may assume the right to defend the 'moral integrity' of their materials, restricting reuse to only those projects that are deemed 'faithful to the conceptualisation of the original' $(2013,137)$. This implies that there is both a 'correct' interpretation of any historical document and that archives - and therefore archivists - have the right and ability to determine exactly what this may be (138). This notion is strikingly at odds with an archival paradigm in which records are considered subject to multiple and shifting interpretative perspectives.
} 
domain may in fact effectively efface the curator's presence, anonymous expertise offering outwardly objective descriptions or contextualisation of works.

The exhibition of moving images presents particular curatorial issues. The practicalities of keeping written text to a minimum in what are intended to be primarily audiovisual experiences do not allow for much complexity in terms of historiographic analysis. Films From the Home Front (http://www.movinghistory.ac.uk) is another online exhibition including archival recordings, this time offering a window on life in Britain during World War II. Although film stock was in short supply, many amateurs continued to shoot films during the war. Albeit valued primarily for their ability to illustrate a range of topics, home movies form a prominent part of the audiovisual material on the site. Resources are arranged according to different themes presented with a short introductory text. An amateur recording described as 'Sheriff Hutton Agricultural and Rural Scenes', for example, illustrates 'Displaced People' and 'Industry in Wartime'.

content unavailable

please consult print version
Fig. 4.5. Home movie showing German PoWs working on the land in Yorkshire during World War II on Films From the Home Front. Moving History, 2005. Screenshot.

Beneath a brief summary is a longer description of the film (including scenes that do not actually feature in the clip provided). An unnamed curator then explains the clip's significance in this particular context (the labourers are identified as German Prisoners of War taking the place of absent British farm workers), but does not ascribe any special status or value to this particular film, nor offer interpretation of elements such as the cheerful demeanour of the 
participants. (Are the smiles simply for the camera, or are the men genuinely enjoying a life of agricultural work after fighting in the war?) Partly due to brevity, the text is rather authoritative in tone, implying expertise that can be relied upon to confer accurate representations of the past. Following a link to the website of the Yorkshire Film Archive (YFA), which holds the $16 \mathrm{~mm}$ original, the viewer can watch a longer excerpt of the film, as well as learn about the filmmaker (now identified), the history of the village with its ruined castle (glimpsed in the background of some shots) and farm machinery companies, amongst other topics somehow connected to the film. Interestingly, the background information on the YFA site (written in 2009) does not mention World War II, PoWs and in fact dates the film a decade later than Films From the Home Front (created in 2005).

'Sheriff Hutton Agricultural and Rural Scenes' complicates the notion of placing a film in its 'right context' (to quote Jesper Andersen). As the two websites demonstrate, it can function equally as part of a narrative about displaced people and industry during the Second World War, local Yorkshire history or family biography, any one of which might assist the viewer to see this as something more than just a slightly shaky amateur recording of men and tractors, a potentially rather dull subject if farm machinery and agricultural work does not happen to be one of your immediate interests. The fact that these interpretations appear to conflict with one another underlines the mutable and subjective nature of historical records. A seemingly factual description of a film's content or context may be less accurate or objective than it initially appears.

Not all curatorial activities take such an authoritative or didactic approach to informing audiences about history or filmmaking. Marks proposes that 'the ethical presenter' is one who advances some kind of argument to create a dialectic between ideas and films (40). Not merely a programmer, the curator should offer an intervention into the field (42), encouraging dialogue or provoking reflection. It is an activity, she notes, that ought to be distinct 'from the bland normalcy of everyday life' (46). While there could obviously be many ways of achieving this, one approach to curation is simply to offer a personal response to a selection of films. The website of the London Screen Archives, for example, features an online collection called 'Paradise Place'. In the introductory notes, curator Emma-Louise Williams comments: 
actions; walking, talking, laughing, playing; gestures and movement through space. But viewed across time this ordinariness works its affect. Now I can bring to these films my own meaning and feeling and memories. I can re-make these films again and again. The flow and the clamour.

More a suggestion for how to look at home movies than a narrative about them, the curator's remarks seemingly invite viewers to 're-make' the films for themselves, to find their own meanings and memories. Although probably not quite what Marks had in mind as the 'ethical presenter', the curator who refuses to curate (at least in the authoritative or pedagogic manner discussed above) leaves meaningfulness largely to the realm of fortuitous discovery on the part of the individual viewer, a potentially more thought-provoking (and, arguably, therefore ethical) approach to presentation.

Taken together, these examples illustrate a contrast between the didactic 'chaperoning' of a film to an audience and more impressionistic, suggestive or personalised ways of curating home movies, that is to say, the seemingly objective versus the transparently subjective. The level of emphasis upon home moviemaking as a specific practice also varies. Emma-Louise Williams draws attention to the domestic and amateur nature of many films included in the selection. Although 'Sheriff Hutton' is clearly identified on both websites as an amateur recording, its ability to represent wartime activities or local Yorkshire scenes respectively is to an extent more important than its status as a home movie. Viewed as war history or local history, 'Sheriff Hutton' is potentially somewhat interchangeable with other kinds of images of the same subjects. As noted in chapter 1, a film may be used to get something else from it. As this particular example demonstrates however, exactly what one gets may vary according to a film's interpretation. Placing a home movie in its 'right context' is not a straightforward matter.

\section{Negotiating messy contingency: separating archival noise and information}

Adding to the difficulties of describing and interpreting home movies accurately is the vast number of films that many archives have in their collections. Looking for a home movie related to a particular topic, one can quickly face information overload, unsure even which archives' collections are likely to be the most helpful or appropriate to peruse. Attempting to locate and wade through all the data on home movies that is currently available to a researcher can be a

time-consuming and frustrating task. One way to assist researchers is to collate resources held in different archives related to the same subject on a single website. Reversing the ethos of the war 
history exhibitions above, which focus on providing users with easily digestible narratives about a select number of recordings, a website can make quantity a priority.

Amateur Filmmakers Record the New York World's Fair and Its Period (www.fairfilm.org) ${ }^{52}$ is, as its very explicit title suggests, a website devoted to home moviemakers' efforts to document the 1939 event. Drawing upon the collections of three separate archives, the site provides descriptions of relevant items and, in some instances, accompanying video files. These can be browsed either according to different zones of the fair through an interactive map of the park (transposed very appropriately from an issue of the Amateur Cinema League's magazine, Movie Makers) or, more conventionally, via predetermined subject categories. Overall, the site contains a wealth of visual media content and related metadata, with numerous links to external resources. Given the very specific nature of the site, combined with the sheer volume of material presented in a simple database structure with few concessions (interactive map aside) to casual browsers, less-than-dedicated researchers of the event may find fairfilm.org overwhelming to say the least (if not overwhelmingly boring). For those with a more serious interest in the 1939 New York World's Fair, it is undoubtedly a useful research tool, however.

Fig. 4.6. Interactive finding aid on Amateur

Filmmakers Record the New York World's

Fair and Its Period. Screenshot.

content unavailable

Another site dedicated to amateur please consult print version

filmmaking, the Home Movie Registry

$(H M R)$ is a recent initiative of the Center

for Home Movies (CHM). Unlike the

previous example, the $H M R$ does not focus on films about any particular subject. It does function in a similar way, however, as an online portal that aggregates catalogue records and video files, enabling users to search multiple archives for amateur film material. ${ }^{53}$ Some entries

52 n.b. This website goes offline intermittently (as does the main website of Northeast Historic Film - the archive that constructed the New York World's Fair site - which may use the same server).

53 A similar kind of aggregate site, the Amateur Movie Database (http://www.amateurcinema.org/) is devoted to more 'polished' amateur films (which it distinguishes from 'rough home movies'). In April 2018 CHM launched a further online directory, the Home Movie Archives Database (http://homemoviearchives.org/), which would seem to overlap in scope and objectives to some extent with the $H M R$. A directory of directories would appear a logical next step in the aggregation of amateur film-related information... 
provide only basic metadata about a film and its physical location; others include embedded video files so that viewers can watch films hosted on the external sites of participating archives. Users do, however, risk missing additional information about a film if they fail to check the source URL. While the $H M R$ is again better suited to serious researchers with specific inquiries, casual browsing according to tags is entirely feasible. There is also provision for themed exhibits curated by professional archivists offering a brief introduction to a selection of films with related content. ${ }^{54}$ Another more 'user-friendly' feature of the site is the incorporation of Google maps, so that users can click on a particular location to find films of interest. A pinpoint on China, for example, offers users a film in the Prelinger Archives described as 'Home Movies: Paris, Times Square, China, etc.'

An obvious limitation of an aggregate site is the inconsistent quality of metadata and video files from different sources. Inadequate or confusing technical data may be replicated from one site to another. Both the HMR entry and its Internet Archive source for the 'Paris, Times Square, China' home movie indicate the film was recorded in Kodacolor, which, digitised without the necessary lenses, appears as black-and-white footage with the vertical stripes characteristic of the format. Of the video upload, an Internet Archive reviewer comments, 'Weird quality home movie footage... Not too sure why though [sic] the quality is so bad, sort of grainy but I don't think that's the film's fault. Apparently there's supposed to be color, but none of that was witnessed either' ('Spuzz' 2014). A layperson minus knowledge of early colour formats viewing via the $H M R$ would most likely be similarly nonplussed. ${ }^{55}$

Whether such quirks irritate or intrigue will vary between viewers. Websites that enable users to access information across multiple archives are practical and potentially efficient research tools. Their usefulness to any individual researcher depends very much upon their interface and cataloging of content, however. A rather dry, technical topic, cataloging data has nonetheless attained great significance in computerised societies dominated by algorithmic retrieval of information and query-based browsing in which search engines and metadata determine access to historical artefacts, or increasingly often, their digital surrogates. Just as a digital archive

54 The website is still in a preliminary stage of development with additional content and features intended to be added over time. As of May 2019, the HMR features two exhibits, 'Home Movies and the African American Community' and 'Home Movies and Television'.

55 The entries of some other Kodacolor films in the $H M R$ do include an explanation as to why colour footage appears black-and-white, but not this one (which, like most entries, simply replicates metadata from its source). 
represents a selection of an analogue archive (itself only a slice of history), so too is metadata a further selection of content, the searchable sliver of what is already - comparatively speaking - a small portion of the past (Lundemo 2014, 26). Moreover, the creation of archival metadata is not an impartial activity akin to scientific observation, but an act of interpretation that precodes documents in particular ways, thereby indicating to researchers what they can expect to find in them. Of course if a film lacks adequate description it becomes difficult to find at all. Comprehensive documentation of ephemeral collection items, such as home movies, may not be a priority if an archive's resources are slim, however.
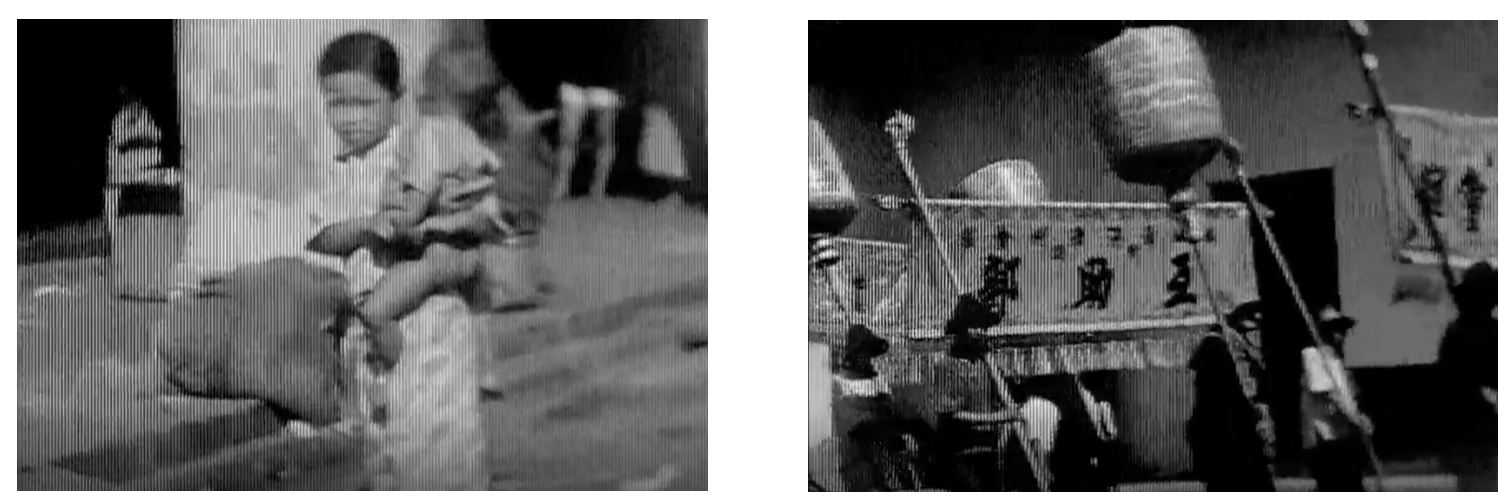

Fig. 4.7 \& 8. 'Apparently there's supposed to be color'. 'Home Movies: Paris, Times Square, China, etc.'

Prelinger Archives, Internet Archive. Screenshots.

On the surface it seems reasonable to assume 'that anything not described at all will not be consulted at all' (Becker 2001, 95). Yet, conversely, more intricate classification may not offer a perfect solution either. The institutional use of 'controlled vocabularies' to standardise archival description and produce consistent search results, for example, may not correspond with the language of users, ultimately impeding rather than assisting research (Andreano 2007, 90-1). In the example above, Rudall Hayward's 1916 film could not be located by searching 'home movie World War I' although these seem perfectly reasonable search terms if one is actually looking for a home movie related to the First World War. Home movies can be both awkward and time consuming to describe, especially in a way that evokes the specific qualities of individual films. Given this, collection-level cataloging that groups films according to provenance or general content, for example, has been suggested as a compensatory measure if discrete items cannot be described in detail (Leigh 2006, 37-8). This unfortunately leaves researchers with the laborious task of sifting through large volumes of material and watching numerous films that may prove to be of little relevance to their inquiries. Like other forms of photography, home movies 
frustrate systematic archival arrangement due to sheer quantity and 'messy contingency' (Sekula 1986, 17). Irreducible to 'conventional lexical units', home movies are, like other photographic images, 'subject to the circumstantial character of all that is photographable' (ibid.).

Paula Amad's description of the 'counter-archival' properties of moving images that disrupt archival order due to 'excessive evidentiary capacities' $(2010,4)$ resonates very well with home movies when they are viewed as historical records. If cinema in general offers an 'undisciplined style of evidence' characterised by disorder, fragmentation and contingency that defies straightforward classification (21), home movies seemingly excel at capturing (what often appear to be) random moments and incomplete events recorded in an indiscriminate or haphazard manner. Even in professional situations it can be difficult to exert precise control over what occurs in frame. The home moviemaker's activity is typically even more subject to the contingent and accidental. Moreover, in mechanical recordings human agency or intention is not always readily apparent. Mary Ann Doane describes this effect of technological recordings as 'the ever-present and consistently disturbing potential of meaninglessness, of providing the spectator with nothing to read'. The presence of indecipherable nothingness prompts questions such as 'What does it mean? and What is it for?' From technology arises a peculiarly modern propensity to record and collect (what appears to be) nonsense, resulting in an 'archive of noise' abundant with nothing of interest $(2002,63-5) .{ }^{56}$

When faced with substantial amounts of information, such as that contained in both an archival database and an archive, one requires some strategy for overcoming Svendsen's boredominducing 'meaning deficit' $(2005,29)$. Archival arrangement is of course premised upon classification affording the means to separate what is sense and non-sense in any given instance. In the two examples of online databases above, users must choose appropriate search terms to distinguish works that are of interest within the context of their inquiries from those that are not. This of course assumes not only the ability to negotiate counter-archival contingency and

56 Doane is here drawing upon the work of Friedrich Kittler, who in distinguishing the 'discourse network of 1900 ' from that of 1800 identifies technological recording media as a significant determinant. Unlike writing, for example, which requires the author to select specific words and phrases, audiovisual technologies can record indiscriminately whatever is simply 'out there'. Mechanical recordings may be characterised by what Kittler calls an 'opaque thisness' - manifest presence without apparent signification - hence the archiving of noise rather than documents that display discernible human intentionality of some kind (64-5). This is not to suggest a recording that appears to be simply noise or nonsense to a receiver did not originally have a specific purpose (although it is certainly possible to record something without intending to make a recording at all by inadvertently bumping a device's record button or neglecting to push stop, for example). 
descriptive insufficiency, but also a notion - no matter how tentative - of what might constitute meaningfulness.

There are various ways one might sort through all the noise to arrive at something meaningful. One method would be to sample the archive for a '"representative" instance'. Ignoring the infinite variations of individual works, an elementary selection transforms 'the circumstantial and idiosyncratic into the typical and emblematic' (Sekula 1986, 17-8). This would of course negate the possibility of arriving at any new understandings to be derived precisely from the subtle differences of otherwise similar works. The two websites above are actually well suited to giving researchers the opportunity to study works with points of similarity. Moreover, even a few 'representative' examples must be framed in some manner in order to clarify their significance. That is to say, a narrative of some kind is necessary to make sense of the contents of a database.

As noted earlier, despite our contemporary reliance on databases, narratives are still fundamental to human comprehension. Finding connections between items in a collection transform them into meaningful information rather than noise that inhibits understanding. Academic researchers bring their own narratives into archival collections in the form of hypotheses to be confirmed or revised. From a scholarly perspective, a collection need only contain the pieces to fill any gaps in a puzzle, not an overarching narrative, to be of interest. A principal determinant of meaningfulness therefore becomes searchability - archival arrangement that enables the scholar to filter relevant data from irrelevant noise in order to find whatever he or she is looking for. Not everyone is an academic researcher with a clearly defined inquiry and specific objectives for watching home movies in mind, however.

\section{Making selections and framing home movies in different ways}

Catalogues and databases are more useful if one is looking for something in particular. As noted earlier however, archives may take steps to cultivate an audience for their films rather than simply responding to the needs of researchers. The two war exhibitions mentioned above demonstrate ways of curating home movies for a more general audience. A small number of films are presented with simple contextual information in order to illustrate historical experiences. Moreover, these exhibitions tap into pre-existing public interest in their subjects, particularly that surrounding World War I during its centenary. The majority of home movies 
were not recorded in the midst of such major world events, however. Consequently, other means of engaging audiences must be found.

Selecting films depicting familiar people rather than events is one possibility. As noted in the previous chapter, celebrity home movies offer the voyeuristic appeal of a 'sneak peek' into the private lives of renowned people. The staged 'home movies' of Hollywood stars such as Mary Pickford were an early method of satisfying public curiosity about what popular actors were supposedly like at home or behind the scenes. Produced for commercial distribution, such films were in reality carefully orchestrated 'reveals' intended to enhance their subjects' public personas (Czach 2002, 200-1). Some archives, particularly those with a national orientation, contain the actual home movies of well-known people, however.

NFSA's YouTube channel includes three clips from the home movies of Gerty Anschel that provide a glimpse of the Melbourne art scene during the 1950s. The films depict various local artists both at work and socialising, as well as a brief appearance by Hollywood actor Melvyn Douglas. Especially prominent is the artist Mirka Mora, the mother of Philippe Mora, who also appears in the movies as a child. Having recovered the $8 \mathrm{~mm}$ collection after Anschel's death, he proceeded to donate the films to NFSA, providing an audio commentary identifying those in them. ${ }^{57}$ Although somewhat rambling and repetitive, Mora's impromptu remarks conjure a general sense of the colourful milieu of his childhood that exceeds what is directly discernible from the images themselves. Probably most fascinating to those with a particular interest in Australian art culture of the postwar era, the combination of images and audio track is itself fairly entertaining, drawing attention to the unconventional (or by the social standards of the time, somewhat disreputable) lives of the films' participants.

The Marlene Dietrich exhibition of the Deutsche Kinemathek in Berlin also features home movie footage. Surrounded by the formal chic of studio portraits and designer gowns accentuated by glass, reflective surfaces and the minimalist colour scheme of the museum space, a home movie of Dietrich brings a sense of humble humanity into an exhibition otherwise exuding the distant glamour of popular imagination. Displayed on a small video screen, the film's inclusion in the exhibition, as with the celebrity documentaries discussed in the previous chapter, seems intended to bring viewers 'closer' (albeit for a brief moment) to the celebrated

57 Mora explains this information in his commentary; it also appears in an article by Tara Marynowsky (whose voice can be heard faintly on the audio track) on NFSA's website. 
actress. Although seemingly quite conscious of posing to good effect in some shots, the Hollywood star appears in other moments almost bashfully unglamorous before the amateur camera. Given this, the home movies feel somewhat out of place in this commercially oriented museum, which presents a very conventional history of great achievements in German cinema. Yet they fascinate in this setting precisely because of their incongruity with their surroundings. A novelty by virtue of their rough and intimate quality, the home movies are a charmingly disruptive presence in the midst of official film history, forming a slender acknowledgment of alternative filmmaking practices.

content unavailable

please consult print version

Fig. 4.9-12. Dietrich consciously posing for the camera (left) and in less guarded moments (right). Screenshots taken from YouTube.

Whether used to illustrate narratives about an event or the lives of people, home movies function first and foremost as a window onto the subject they depict. The last example also suggests another way to present home movies: as part of the history of cinema. Again, just as most home movies are not connected to events with the magnitude of world wars, neither do they feature famous film industry personalities. More-or-less any home movie could be used in an exhibition about amateur filmmaking as a practice, however, even the anonymous footage of orphaned films.

Curators at the Texas Archive of the Moving Image (TAMI) opt for a biographical approach in an online exhibit devoted to amateur film. Perhaps as a way of lending weight and legitimacy to 
a subject that may have more limited appeal than world events or famous people, for example, the selected filmmakers have been accorded the status of 'auteur'. This is underscored with an opening quotation from Maya Deren explaining the etymological meaning of the word amateur as 'one who does something for the love of the thing rather than economic reasons or necessity.' These were people - so the introductory text suggests - who cared deeply about the films they made and put a great deal of effort into highly personal work. In comparison with the ease of digital video production, amateur filmmaking was once 'arduous, expensive, and timeconsuming' (Esquivel and Moya 2017), an undertaking, we might intuit, that is therefore worthy of our interest and respect.

content unavailable

please consult print version

Tilley Brothers, complicates the notion of amateur film. Note the inclusion of references to King Vidor and Harpo Marx. Amateur Auteurs online exhibit, Texas Archive of the Moving Image, 2017. Screenshot.

The style of presentation is quite similar to the war exhibitions: a mixture of clips and brief notes providing some background context. Although many films featured in the exhibit are not home movies as such, their inclusion acknowledges their place in the history of amateur filmmaking. Significantly, the choice of identifiable Texan filmmakers links amateur film to local history, an obvious point of interest for an archive catering primarily to a regional audience.

A connection with local history and community identity represents perhaps the most significant channel through which home movies find an audience. Regional archives and museums are 
some of the most prolific collectors of home movies, which often capture local scenes and activities that may not feature in films contained in national collections. The importance of the local may be evident in the way films are presented. A curator's notes accompanying a home movie described as 'Rural Scenes, This Day, Great Ayton etc' in the Yorkshire Film Archive collection viewable on their website, for example, refer only briefly to technical aspects of the film before discussing various historical connections at length. As the filmmaker of this particular work has not been positively identified, an emphasis on content might be expected. Topics discussed range from the origins of the village, the career of Captain James Cook (who was born there) and an explanation of Rogationtide to the history of water mills and the potential for small-scale hydropower in Britain today, most of which is only tangentially related to the content of the film. Such extraneous information is not necessarily uninteresting; in fact, it may even be of greater interest to some viewers than the actual content of the film. By shifting attention away from the film however, this anonymous recording becomes less a particular type of film, or even a window upon specific activities, than a provocation to embark on a discussion of local (or even national) history. In the context of a regional archive, narratives that explore the history of the area and help conjure a sense of unique local identity may be more important to viewers than details about particular methods of filmmaking or an individual film.

These examples demonstrate a number of different kinds of narratives used to make home movies meaningful to viewers who are not researchers with specialised interests. Different perspectives - world history, biography, film history, local identity, or a combination thereof ascribe a range of values to home movies across different contexts of presentation, or even within the same context. The curatorial notes for the films of Kenneth Raynor (also on the YFA website), for example, describe the filmmaker's background and interests, as well as the effects of wartime on the area where he lived (not necessarily visible in the films) and changes that have occurred since the 1940s. There is some attempt to account for the particular sensibilities of Raynor's work, which is attentive to the idyllic qualities of the landscape and the activities of local young people. Something of Raynor as individual emerges: an avid collector, gifted photographer possibly influenced by László Moholy-Nagy, and conscientious objector to the war. Such contextualisation potentially renders a viewing experience more complex. The curator's enthusiasm for attempting to tease broader significance out of even small onscreen details is arguably excessive in this particular instance, however. Shots featuring classical records from Raynor's collection become a pretext for discussing the lives of British composers, while 
playground games seen in On the Trail of the Fall (1940) are linked to twenty-first century anxieties about children's lack of physical activity. Albeit potentially somewhat distracting, the desire to locate contemporary relevance and meaning within archival home movie footage is very much in evidence.

Narratives about home movies play out across a range of platforms and settings where the material and social dimensions of a viewing space may affect the impact that films have upon audiences. In the examples above, contextualisation is communicated through a variety of means: a recorded narration for a film, a museum exhibition surrounding an installation, a themed exhibit on an archive's website, curatorial notes accompanying a film clip in a database entry. Different screening platforms and their material settings have the potential to affect viewers' reception and understandings of films perhaps as much as the style and content of curation. The following sections investigate the ways in which a number of platforms - social media, exhibition installations, community screenings and participatory projects - intersect with curatorial styles to foster different forms of engagement with home movies.

\section{Platforms and effects I: getting people's attention via social media}

'BBQ in the snow? No problem!' announces NFSA's Facebook post of January 13, 2019. This slightly curious activity can be seen in the 47-second clip of a 1963 home movie featured in a selection of recordings on NFSA's website related to barbecues, which provide 'a fascinating snapshot of Australian life and proof of how significant this outdoor tradition is to our national identity' (Bondfield 2018). Within two days, the snow barbecue clip had received 485 views via Facebook, along with six 'likes'.

If the pursuit of accessible meaning and social relevance has become a key feature of archival practice, so has the promotion of resources and events. Archives utilise social media platforms such as Facebook to draw attention to their activities or collection items, particularly those deemed to be topical in some respect. Although used to publicise a whole range of films, social media is a fairly straightforward way to inform viewers about the existence of home movies in particular. A common style of Facebook post is to offer a brief indication of an item's immediate significance and a clip, either embedded directly in the post or via a link to its source (usually the respective archive's official website). Sometimes the connection to the day of posting is merely thematic, such as a film recorded in summertime (or featuring activities 
normally associated with summer) or depicting Christmas festivities for a December post. In other instances, an archive might employ a more narrative-oriented 'on this day in history' approach.

content unavailable

please consult print version

Fig. 4.14 \& 15. Social media promotion of home movies: Facebook posts by NFSA and NTSV. Screenshots.

The rationale may be relatively slight. The weather - that perennial conversation filler - can be used as a pretext for promoting certain items, for example. Following a rare snowfall in Houston in December 2017, TAMI showcased a home movie recorded in 1973 featuring a similar event. Unexceptional in technique, the film is nonetheless appealing, opening with a delightful scene of students energetically hurling snowballs at one another. Recorded by academic Dr. Thomas F. Freeman, the film also captures the city's African-American community in the early 1970s. After subsequent snowfalls in the state, TAMI offered its Facebook followers a selection of 37 home movies - all featuring snow (16 January 2018).

Twitter may be used in much the same way to promote individual collection items, inserting a film still and link to view it along with a short text that might incorporate appropriate hashtags, enabling those interested in the subject (rather than necessarily archival films per se) to find the tweet. In anticipation of Hogmanay (New Year's Eve), for example, the National Library of Scotland's Moving Image Archive promoted via Twitter a film depicting a group of friends celebrating at home in the 1960s. Recored by George Gibson, a member of a Dundee ciné-club, the home movie is a particularly lively choice, featuring a subsequently added music track to animate shots of dancing around a reel-to-reel tape deck and a considerable amount of what the 
accompanying catalogue entry describes rather euphemistically as 'couples fooling around and kissing'.

content unavailable

please consult print version

Fig. 4.16 \& 17. Social media promotion of home movies: Facebook post by TAMI and Twitter post by National Library of Scotland's Moving Image Archive. Screenshots.

There is now widespread use of social media in the cultural heritage sector. According to one international survey of archives and libraries, social media is most commonly utilised for pragmatic objectives such as the promotion of services, events or showcasing of collections. Of respondent organisations, eighty percent believed they had successfully implemented social media on a 'practical business level', which included achieving greater visibility of content (Liew et al. 2015, 388). The authors of the study nevertheless noted a frequent lack of strategic vision, as well as an absence of frameworks for assessing the impact of social media use or gauging its success (394). Similarly, Marissa Mason concludes there is a lack of 'hard evidence' in recent literature as to the effectiveness of social media usage by cultural heritage institutions, success typically determined via anecdotal rather than empirical sources $(2014,164-6)$.

Social media may in fact be a more productive method of publicising specific events than collections in general. An in-house report compiled by North East Film Archive (NEFA), for example, concludes that online engagement (including the use of social media) in the lead up to its Newcastle on Film screening was highly successful, exceeding 630,000 views, 'likes' and shares of related promotional content across its event-partner sites (13), with additional screenings of the programme (all of which sold out) required to meet audience demand (6). 
content unavailable

please consult print version

\begin{abstract}
Fig. 4.18. 'CineSecrets', an interactive series of questions that encourage viewers to respond in the comments section, is used regularly by NEFA and YFA to build audience interest prior to an event.
\end{abstract} Screenshot, 5 March 2018.

Where social media promotion does not culminate in a specific event, evaluation of its success is more difficult. Simple measures such as the number of views an online video receives may not be an accurate indication of how many people watched an item in its entirety (or even for more than a few seconds). Moreover, viewing statistics fail to account for levels of audience satisfaction,

'likes' offering a rather perfunctory measure not necessarily indicative of the extent of actual appreciation. (Did only six out of 485 viewers really enjoy the snow barbecue, or did only six feel sufficiently motivated to click 'like'?) ${ }^{58}$ Such data does nonetheless help archives gauge the extent of online 'traffic'. Moreover, social media enables archives 'to meet users where they are' (Mason 2014, 160) and in this sense has advantages over more traditional ways of publicising an organisation's materials and activities. Social media is, however, very much a space in which attention is likely to transpire in a state of distraction. Chin et al. note that on 'social media, many people are not very focused and browse the posts very quickly' (2015, 583). Facebook users can even watch embedded videos whilst continuing to scroll down their feeds. Viewers may have neither time, nor inclination to absorb background information about films,

58 There is not a significant amount of existing research regarding online 'like'-clicking behaviours. Chin, Lu and Wu (2015) suggest a range of factors that motivate Facebook users to click 'like', not all of them necessarily related to actual appreciation of posted content. Motivations included hedonic (e.g. content perceived to be fun or entertaining), utilitarian (has prize, reward, benefit etc.), compliance (fulfilling expectations of others/following authority figures), conformity (liking content that is already popular), affiliation (seeking approval of others/maintaining social relationships), attitudes and subjective norms (e.g. desire for positive comments vs. fear of triggering negative ones). Specifically in the case of cultural heritage content, some of the above factors affecting motivation to 'like' a post would presumably be more relevant and influential than others. 
particularly if it is provided on another website. Regardless how topical or amusing a promoted item may be, viewed in relative isolation, an archive's 'film of the day' is in danger of becoming what Jan Baetens and Jan Van Looy refer to as a 'dematerialised sign' or text separated from the full complexity of its historical character $(2007,5)$. In this sense, films that are short and show familiar activities, rather than those likely to benefit from more in-depth contextualisation, may be better choices for social media promotions, unless used to involve viewers in a guessing game (à la 'CineSecrets'), for example. The divided attention of the cyber-flâneur traversing social media sites may not be the most conducive to sustained viewing or more contemplative appreciation of films. Nevertheless, social media can be a useful place of discovery, introducing viewers to materials they may not have encountered otherwise, as well as enabling them to find out what is taking place in their local communities.

\section{Platforms and effects II: installations and (inter)active experiences}

Almost paradoxically, digitisation has also transposed the home movie into the realm of the terrestrial flâneur. The digital screen on which a video sequence is exhibited in a looped format, endlessly repeatable, has become a staple feature in the repertoire of contemporary art gallery and museum displays. Depending upon exactly where it is located, a video installation may be watched by viewers who, potentially surrounded by fewer distractions in comparison with cyberspace, are in theory better placed to remain attentive. The very fact that museum or gallery patrons have made the effort to visit a physical place, as well as possibly paid an entry fee, implies a certain commitment to a more sustained view, if not of any given work, then at least of a collection as a whole.

Museums and galleries are (or can be) places of serendipitous discovery. There is no need after all to formulate a specific inquiry in order to receive an object for one's perusal; visitors can meander through a gallery without much forethought and be surprised by the contents of an exhibition. A visit to a particular institution or exhibition is of course often prompted by some prior knowledge of what one is likely to find there, which may to some extent curtail opportunities for encountering the unexpected. At its simplest, however, the installation happened upon quite by chance in a truly public space - the street, park, mall or other civic area where pedestrians have free right of passage - is very much suited to capturing the roving attention of the flâneur or passerby. 
To take an example, NTSV's View Finder Mata Kimihanga, a video screen installed in the window of Auckland Central Library that runs 24 hours a day, featured a compilation of footage from different films as part of the library's Let's Dance! exhibition (21 September 201730 January 2018). Excerpts from two amateur films were included in the selection, one showing folk dances at Wadestown Primary School in Wellington in 1943, the other people dancing at a function probably held in a woolshed that was recorded by Frank Diack in 1955 (the latter of which is also viewable on NTSV's website). In order to make the most of this kind of arrangement, a viewer obviously needs to linger on the pavement for an extended period. However, unless an installation happens to be conveniently positioned near a seat or some other location where people are likely to gather, it is really better suited to a passing glance than a prolonged gaze. In the circumstances, boredom would seem not so much a concern as distraction. Quoting Edmond Jaloux, Benjamin lamented the lot of the modern flâneur in The Arcades Project:

\begin{abstract}
A man who goes for a walk ought not to have to concern himself with any hazards he may run into or with the regulations of a city. If an amusing idea enters his head, if a curious shopfront comes into view, it is natural that he would want to cross the street without confronting dangers such as our grandparents could not have imagined... If he tries to collect the whimsical thoughts that may have come to mind, very possibly occasioned by sights on the street, he is deafened by car horns, stupefied by loud talkers..., and demoralised by the scraps of conversation, of political meetings, of jazz, which escape slyly from the windows (435).
\end{abstract}

With the twenty-first century addition of mobile devices to the manifold distractions of the street, the window installation has much to compete with for the urbanite's attention. A rather more studied variation of the installation, cubicles housing video screens erected around the city of Ghent as part of Huis van Alijn's exhibition, Homeless Movies (15 October 2016-15 January 2017), effectively shielded viewers from the hustle and bustle of the street. Whereas Mata Kimihanga relies upon the eye-catching appeal of a parade of images dancing before the eyes of passersby, the film-booth presents a curious structure intended to entice the spectator in for 'a few minutes of isolation from the outside world' (exhibition notes 2016). The advantages of an enclosed 'black box'59 in terms of the viewer's concentration are readily apparent. This is perhaps of especial relevance given the booths' content. The Let's Dance! footage of Mata Kimihanga was somewhat self-explanatory, albeit displayed more-or-less in a contextual

59 See footnote 64. 
vacuum. A passerby might begin watching at any given moment and still enjoy the pleasures of witnessing people dance across the screen, even without visiting the associated exhibition inside the library. The Homeless Movies appear to assume a viewer who watches from start to finish, however.

Drawing upon the museum's own collection of home movies, visual artists connected with the city were invited to create a short film for each booth. These are not therefore home movies as such, but found footage films incorporating amateur images. As artist's films, they are selfcontained more than self-evident, relying very much upon the viewer's ability to decode the language of experimental cinema in order to make some kind of sense of the works. Eva Giolo's Gil (Scream), for example, combines an ominous score with a montage of black-and-white home movie images and fairly obscure text ('What happens to all the things that nobody sees? They grow, in the dark... taking more and more space.') It is essentially left to the viewer to decide exactly what the film's subject (that which grows in the dark) might be. Gil contains many images of children, the most striking of which is perhaps that of a toddler tugging, letting go and anxiously retaking an adult hand, presumably belonging to the camera operator (quite likely the child's parent). Given the familiar quality of home movie images, in this instance rendered uncanny through montage and soundtrack, viewers might summon their own

content unavailable

please consult print version memories of childhood anxieties to fill the film's deliberate lacuna. Katrin Kamrau's Reference, discussed at the beginning of the chapter, is similarly oblique in terms of possible meanings.

Fig. 4.19. Huis van Alijn's Homeless Movies viewing booth. Facebook post, 27 April 2018. Screenshot.

Whether individual viewers find such works intriguing and absorbing, or baffling and overly esoteric, will of course vary. The audience for these artist works is a very general one: any passerby inquisitive enough to stop and enter the booth, not necessarily one familiar with 
experimental film. An enclosed booth does at least increase the likelihood a viewer will be able to concentrate upon the film for its duration, comparatively free of external distractions. A disadvantage of the arrangement is that only one, possibly two, spectators can comfortably watch at any one time. (The boredom of waiting to enter might be off-putting to some potential viewers.) Upon entering the booth however, modest comfort and seclusion beyond that of the pavement may extend the viewer's attention span and with it the likelihood of finding something meaningful within the Homeless Movies.

Video installations in public spaces favour materials that are either self-contained or remain appealing with little or no exposition. A scarcity of information could even be beneficial in certain respects, forcing the viewer's imagination to compensate by filling an explanatory void (Prelinger in Vonderau 2009, 58). By mentally referencing personal memories or cultural knowledge, viewers engage in a more active mode of spectatorship, which could prove more satisfying for some than passively observing a presentation rich in expository detail.

Inside a museum space, the kinds of readings installations invite are likely to be influenced as much by the context of presentation as by the content of the video itself. Many aspects of an exhibition - the overall topic, style and quantity of written text, selection and arrangement of objects on display - will affect a visitor's experience of it. There is nevertheless almost always some level of interactivity required on the part of the visitor. Unless shunted along a designated route, visitors have a degree of freedom to chose a physical path through an exhibit, for example, as well as where to linger and for how long (Kinder 2011, 251). This in turn influences the perception of individual materials and the kinds of connections to be made between them. To take an example, in the Jewish Museum Berlin a screen situated in an area focused upon daily life displays a home movie recorded by Ilse and Hans Ascher in the early 1930s. No specific interpretation of the film is offered and in a large museum filled with a great variety of objects and stories, this screen might easily be overlooked. ${ }^{60}$ If, rather than simply glancing momentarily and passing on to the next object, one pauses to watch at length, what becomes readily observable is the similarity of this particular home movie to so many thousands of others. There is in fact nothing recognisably Jewish about this footage at all. It depicts ordinary events and holiday scenes: swimming, skiing, boating, skating, a pet dog, a baby on a lawn. In a museum essentially devoted to the specificity of Jewish historical experience, this

60 During my own visit to the museum, I did not observe another visitor pausing to watch the sequence in its entirety. 
unremarkable home movie underscores commonplace things shared by Jewish and non-Jewish alike, diminishing any sense of alterity that may arise for some visitors within such a space. Viewed in this light, the Aschers' home movie takes on a particular role that is fully apparent neither at a quick glance, nor if considered in isolation only, rather than within the context of its surrounds.

Disruption to an overarching narrative is a prominent feature of what Marsha Kinder calls 'database documentaries' (239). While the term might include films that incorporate archival footage, exhibitions that expose the underlying mechanics of a database demonstrate most effectively how historical artefacts can be arranged to serve particular narratives. Kinder finds a key example in Péter Forgács's installation, The Danube Exodus: The Rippling Currents of the River, which premiered at the Getty Center in 2002. ${ }^{61}$ The installation expanded upon and reworked material from Forgács's earlier film across multiple screens and spaces with visitors able to determine via interactive touch-screens which video sequences to view and in what order. As with the film version, The Danube Exodus installation featured three narrative arcs: that of Eastern European Jews fleeing to Palestine in 1939, of émigré German farmers returning to their homeland following the Soviet annexation of Bessarabia in 1940 and, thirdly, of the riverboat captain, Nándor Andrásovits, who transported both groups along the Danube, and the river itself. Andrásovits was also an amateur filmmaker, attentively documenting the voyages and his passengers. Re-edited into short sequences by Forgács, this footage was supplemented by contemporary interviews with survivors and other personal materials viewable in the side spaces of the exhibition.

Archival footage often functions as evidence and can therefore be used to substantiate claims to represent historical truth (Baron 2014, 6). The multiple narratives of The Danube Exodus, which competed for onscreen space and the viewer's attention, highlight the many possible versions of history. Reconstituted from a database of possibilities, different narratives acquired screen time according to the selections of individual viewers. In effect, the database installation represents a chain of selections, amateur filmmaker, found footage artist and exhibition visitor all in turn making choices with regard to what aspects of history should be witnessed and how they should be arranged and understood. Kinder notes that audience reaction at the Getty Center varied

61 The installation has been archived in part online. My comments are based upon the website's content and the source film in conjunction with Kinder's detailed description of its exhibition at the Getty Center. The Danube Exodus has subsequently been exhibited at various other locations around the world. 
considerably, with some visitors actively seeking to control the screens, others content to watch (or even re-watch) whatever sequences happened to be screening during their visit. The overall design of the installation gave visitors the opportunity to become 'interactive performers' of a database narrative. By determining which storylines took precedence within the exhibition space, participants were able to shape both their own experience and that of other visitors (252$3)$.

Forgács's 2013 EYE exhibition, Looming Fire: Stories from the Dutch East Indies 1900-1940, repeated the multi-screen installation approach. ${ }^{62}$ Although visitors were not given the power to select which materials were projected from a database, they could of course choose their own paths through the array of screens. As with the earlier exhibition, Looming Fire encouraged the viewer to reflect upon the contingent, incomplete and subjective nature of historical evidence. The installations combined re-edited images from EYE's collection of colonial home movies with sound bites featuring excerpts of letters describing life in the former Dutch colony, the overall effect one of striking contrasts between the two. Whereas the home movies offered an innocuous picture of family life - celebrations, holidays, river excursions, agricultural work on plantations, social gatherings and dances - the accompanying soundtracks were filled with expressions of anxiety. In a 24-minute sequence 'Rien's Letters', for example, Rien Kuyck describes various concerns: the difficulty of servants only speaking Malay or being influenced by communist ideas, the constant comings and goings of friends and the resulting superficiality of friendships, composer János Másik's score imbuing Kuyck's words with a sense of urgency or uncertainty. In 'Philistines and Idealists', journalist William Walla Vendors states, 'We do not belong here and the longer we stay, the more we degenerate. Our stay here has no purpose other than gathering possessions, which legally belong to others.' This pronouncement contrasts with claims in another sequence that the local Javanese were more at risk from their own wealthy, Arabs or Chinese, Europeans being the only 'ethical' people. In 'Auspicious Spring', the letters of paleontologist and geologist, Tan Sin Hok, whose wife Eida was European, complain of prejudice against Chinese, despite their economic parity with Europeans. Tan's words undercut images of domestic contentment: washing a baby, swimming, a family celebration.

In another sequence, a cacophony of male and female voices decry the nature of social relations

62 I viewed the individual video sequences of Looming Fire at EYE's research archive in conjunction with English translations of the audio tracks and floor plans. My comments therefore focus primarily upon the exhibition's content rather than its installation. 
in the colony, effectively summed up in its title, 'We Europeans are charming against each other'. Non-home movie footage of soldiers, however, seems to allude to a more serious side to colonial unease; both Tan and Vendors had violent deaths. Jaime Baron notes that archival footage tends to exude an aura of historical authority, suggesting it was not fabricated by the filmmaker (7). Home movies in particular may appear authentic, unmediated records. The Looming Fire visitor was unlikely to be taken in by such 'epistemological seduction'. By attending to the omissions and inconsistencies of his source material, Forgács makes clear any desire for 'revelatory truth' (ibid.) about the past is not to be fully satisfied; there are simply individual voices and perspectives sometimes speaking in unison, other times undermining one another.

An emphasis upon point of view rather than objective truth is a rhetorical strategy of artworks that seek to interrogate the evidential claims of the archive (van Alphen 2014, 9, 13). Archival footage can nevertheless be used to reiterate, as well as disrupt, established historical narratives. The contradictions and gaps between records can be either foregrounded (as in Forgács's work) or smoothed over to create an illusion of completeness and continuity (Kinder 2011, 243). Sound, in particular, may function as a key means of constructing juxtapositions or creating an impression of seamless unity. The audio narratives of Looming Fire paint a very different historical picture to the images onscreen. Sound recordings may nonetheless be selected to complement rather than contradict home movie images. The exhibition PET (2014) at the New Zealand Film Archive (now NTSV) examined the relationship between humans and animals. ${ }^{63}$ Audio recordings featured participants recalling stories about their pets, while multiple screens of mostly amateur footage depicted animals at home, the beach and children's pet days, the combination of sound and image accentuating the nostalgic aspects of both memory and home movies. Across the room the viewer was, however, confronted by more recent video images of dog fighting, acknowledging a darker side to human-animal relations not usually witnessed in home movies. This footage acted not so much to undercut the dominant narrative of beloved family pets fondly remembered. Rather, it contributed a minor subplot, the familiar and the disquieting in this instance existing in parallel within the space of a single exhibition.

Emotive qualities may have a significant impact in terms of whether viewers find installationbased exhibitions pleasurable and meaningful. Notably, even Forgács, despite taking a highly

63 PET was curated by Gareth Watkins. I visited the original exhibition in Wellington (13 February-12 April 2014). 
analytical approach to his materials, makes extensive use of immersive attributes such as music and ambient sound effects that help to evoke a particular time and place; hence, spectators are drawn into an historical experience (Kinder 2011, 247) even whilst encouraged to witness from a critical distance. Strategies that invite (inter)active audience engagement may also increase the likelihood visitors will find an exhibition personally meaningful. Even purely practical issues will affect a visitor's individual experience, such as the length of a visit (too long and it becomes tiresome, too short and only the most superficial grasp of an exhibition is likely).

Arrayed against the possible pleasures of the video screen are more off-putting features of the 'white cube'. ${ }^{64}$ Artist installations may appear difficult or unnecessarily obscure, particularly to those with limited previous exposure to such works. Moreover, the potentially alienating effects of distracting spaces may strain the concentration of even the most dedicated patron. ${ }^{65}$ In this regard, Daniel Fairfax's evocative description of viewing installations in a gallery space in a recent issue of Senses of Cinema (2018) devoted to film and the museum is worth recalling at length:

we will invariably be confronted with a substandard projection screening in broad daylight, with a soundtrack muffled and distorted by the sonic bleed from neighbouring works and the general hubbub of the gallery-going public. Any attempt to see the work in its entirety, or at the very least give it the prolonged consideration it should merit, will be thwarted by the looped nature of the screening (a throw-back of sorts to pre-war entrée permanente movie-houses) and the near-total absence of seating. In the end, we will join the other patrons who insouciantly give the piece the bare minimum of their time and attention before moving on to take in the rest of the museum's collection. An artist who was capable of keeping us transfixed for two hours-plus in the cinema struggles to detain our gaze for more than a few minutes in the gallery... Despite the veneer of "high culture" legitimacy afforded by the institution of the museum, and the clamour of avant-garde militancy bruited about in the contemporary art world, when the moving image is transported to the museum, it all too frequently conforms to the distracted, skittish mode of viewing common to television, the Internet and the assorted "new" media of 21 st century capitalism.

64 The term'white cube' and its correlative 'black box' are used to distinguish the experience of the moving image work in the space of the art gallery from that of the cinema proper, which according to Adrian Martin must include, if not the projection of celluloid, then at least 'the beam of light, the screen, the captive audience, the screening-time session' $(2007,37)$. The terms were coined by film theorist Raymond Bellour.

65 Having viewed the component parts of Looming Fire at a desk in EYE's research archive, I cannot comment directly upon the extent to which distraction was specifically an issue in the original exhibition space. A YouTube video uploaded by Forgács, which depicts the arrangement of screens in situ, does create an impression of sensory bombardment, however. Although each screen had its own audio 'shower', there appears to be a certain amount of bleed between each. It might also be noted that as galleries frequently have wooden floors the noise of patrons moving about within an exhibition space is almost inevitably amplified rather than dampened (cf. cinemas, which often have carpet to absorb the sound of any late arrivals' footsteps). 
From Fairfax's description, one might be forgiven for concluding that the contemporary gallery offers no greater repose than the street for sustaining a prolonged gaze without unwelcome disruptions impinging upon one's pleasure.

\section{Platforms and effects III: community screenings and affective engagement}

If the 'white cube' is less than conducive to maintaining a spectator's attention, a 'black box', or space that at least approximates a traditional cinema experience, may offer more amenable viewing. Given the brevity of home movies, a common format is to screen either a series of amateur works or a compilation programme comprising different types of footage, usually with a related theme. Despite the advantages in terms of audience concentration, a formal cinema setting does not lend itself neatly to the viewing of home movies, which, although silent, were not usually watched in silence at a family gathering. Likewise, to sit in total silence for the duration of a 90-minute programme at a public screening would most likely feel rather unnatural to the majority of viewers who, accustomed to cinema with sound, presumably expect to hear as well as see at such an event. 'Silence' can even be distracting, encouraging the viewer's mind to wander in order to fill the void or, more irritatingly, to focus upon the incessant shuffling of fellow members of the audience or even the ticking away of time itself. Those screening home movies in public, cognisant that spectators are conditioned to anticipate both aural and visual interest, often add music or commentary (either live or prerecorded) to otherwise silent material. Beyond this alignment with audience expectations, what are the specific pleasures of watching home movies collectively in public? Clearly, they will vary according to viewers and the actual content of individual screenings, although two prevalent themes might be discerned. Archival presentations commonly champion an appreciation of amateur filmmaking for its own sake, or the value of home movies as local visual history.

For Amateur Night: Home Movies from American Archives (Dwight Swanson 2010), produced by the Center for Home Movies, 16 amateur films from various sources were blown up to $35 \mathrm{~mm}$, initially screening at New York's Anthology Film Archives (and subsequently shown elsewhere in the US and Europe). Noticeably, for the most part, these are not really films one would describe as typical home movies, although many contain elements of such. Sound has also been added to silent footage, either in the form of recorded commentaries by the filmmakers' children or music specially composed. Familiar tropes discussed elsewhere in this chapter recur: the celebrity film (Hitchcock, Nixon), a very early home movie $(28 \mathrm{~mm}$ recording made in 
1915), minority experience (African American, Sioux, Japanese, Jewish), footage of historical events (gathering of the Sioux Nation in 1934, bombed-out buildings in post-World War II Innesbruck, an atomic test in Nevada, the aftermath of Hurricane Katrina), novelty films with curiosity value (a Christmas doll comes to life via stop-motion animation, a bizarre 'infant abuse' comic sketch in which a baby is placed in a cardboard box, dragged behind a vehicle and rolled down a bank into a river, only to emerge miraculously unscathed) and animals (a pet squirrel and 'Smokey' the bear cub) all find a place in the programme. Some films appear to be included for their combination of social and film historical elements; the National Film Registry-selected Our Day (Wallace Kelly 1938), for example, is both a carefully crafted home movie and a closely observed day-in-the-life portrait of an affluent family living in a Depression-era American south. 'Dramatic, funny, poignant and even strange' according its press kit, Amateur Night contains plenty of variety. With most films or excerpts only a few minutes in length, spectators are unlikely to become bored by the individual items. Moreover, by foregrounding home movies 'not as illustrative footage, but as complete works to be viewed on their own terms' (CHM 2011), viewers are encouraged to recognise amateur filmmaking (and watching) as a meaningful occupation in itself, quite aside from its value as records of the past.

A rather different, but potentially no less engaging way to exhibit home movies is to include amateur material within thematic compilations. Regional archives in particular often use this approach to give local audiences a glimpse of their own past, while larger archives may develop outreach programmes for particular communities. For the 2013 Newtown Festival, for example, the New Zealand Film Archive (now NTSV) presented Newtown on Film, a compilation of excerpts from newsreels, home movies, television and other sources featuring footage of the suburb. Home movies contributed images of elephant rides at the zoo, tennis and boxing matches, fair and playgrounds, and the final tram journey to Newtown Park in 1964. Reel Life in Rural New Zealand, a touring programme that screened in Hawke's Bay, Wairarapa (March 2013), Otago and Southland (February 2016), followed a similar format with material from different sources, this time focusing upon the history of farming. The 'variety show' design conveniently allowed for variations between screenings to include items of local interest, the Otago-Southland programme, for example, featuring home movie footage of Mt. Aspiring Station and Puketoi. Items were arranged largely according to date (rather than grouped into related content or type of film), opening with the oldest film and progressing through time 
toward the present day. Home movies therefore become just one type of archival moving image amongst many, valued first and foremost for their ability to illustrate local histories rather than because they are home movies. Even though the particularity of their status as amateur film may be somewhat diminished (Noordegraaf and Puow 2009, 84), home movies nevertheless make a distinctive contribution to local screenings, ensuring they do include locally recorded images precisely the main drawcard of community exhibition.

Community-oriented archival screenings of this nature fulfil Klapp's model that interest (that is to say, the avoidance of boredom) thrives upon variety with a meaningful pattern. Again, the brevity of most films or excerpts, combined with the diversity of content in such programmes, seems likely to ensure that engagement remains if not absolutely unwavering for everyone, then at least sufficient to keep local viewers in their seats for the duration of the screening. Localism is the unifying centre of meaning at community screenings. Along with satisfying intellectual curiosity about local history, seeing familiar locations and activities that occurred nearby may resonate with viewers on an emotional level. Michelle Pierson suggests archival film brings 'spectators to an affective realization of the past as "having-been-alive"' $(2009,14) .{ }^{66}$ At community screenings this is not just any past but a very specifically local past of particular relevance to viewers, one that potentially engenders a sense of belonging and identity. ${ }^{67}$

The affective dimension of local screenings may be enhanced by where they take place. Community programmes are shown in whatever suitable space is available, not necessarily in a conventional auditorium that is tiered to reduce an individual's awareness of other members of the audience. The ability to see one's fellow spectators, along with sharing the space with the projector itself, may foster a greater sense of intimacy and community (Ross 2013, 449). The Rural New Zealand screenings took place in historic woolsheds, for example, Newtown on Film in the (non-tiered) theatre of the suburb's community centre. In this kind of setting, home

66 This effect is demonstrated quite well through absence. The National Science and Media Museum in Bradford, for example, has a large collection of amateur film equipment, but does not collect home movies. One of the oldest exhibitions in the museum, the 'Kodak Gallery', which provides a history of photography and film focused upon technical developments rather than social usage, has a rather dated feel about it. Minus the affective dimension of moving images, the contents of the gallery's glass display cases seem to be very much inanimate museum relics belonging to a past long dead.

67 Asked what they considered the highlight of NEFA's Newcastle on Film screenings, for example, $48 \%$ of respondents indicated 'sense of place/personal connection', whereas only $12 \%$ claimed 'interest in local history' (10). Furthermore, NEFA's report notes that local film content often provoked 'emotional reactions' amongst viewers (16). 
movies seem almost 'at home' with members of a local community standing in for a family audience. $^{68}$

The correspondence between family and community potentially extends beyond simple communal intimacy. Just as they enable family members to recover a private golden age, home movies may conjure a comparably rose-tinted past for communities. As noted in chapter 1, Klapp regarded 'good' redundancy 'an exceedingly important component of social life', one that provides a sense of continuity and identity $(1986,119-120)$. The more 'redundant' elements of a community screening may in fact be its most significant point of appeal, audience engagement deriving not so much from interest in local history per se as its onscreen transformation into a collective mythology. In other words, nostalgia becomes a key source of pleasure, kindling a sense of (potentially uncritical) pride in a shared heritage (Boym 2007, 8-9).

The perception of archival films as heritage and markers of nostalgia arguably imbues them with a certain kind of aura, potentially elevating the otherwise quite ordinary above its ordinariness. ${ }^{69}$ At community screenings the familiarity of the local, the distance of pastness, the intimacy of the setting and the grandeur of occasion feed into a multi-layered affective experience. Physical attributes of a screening may enhance these elements. For practical reasons, archives frequently utilise digital projection for compilation programmes. Visible traces of an analogue source, such as dirt or scratches on the original film, may still evoke a sense of technostalgia, however, even in the absence of a whirring film projector. An aura of nostalgia may be accentuated by the use of historic buildings as screening venues and the sense of occasion such events can inspire, especially through the incorporation of elements of live performance. The Newtown Community Centre theatre was originally built as an Italianate-style church in 1915 and the

68 Both programmes have also been screened in NTSV's auditorium, which to some extent diminishes the sense of localism of the original screenings. Personally, I saw Rural NZ at NTSV and Newtown on Film at the community centre in 2013 (and again when it re-screened for Wellington Heritage Week in 2018); as I have a farming family background and live in the suburb of Newtown I would presumably be amongst the anticipated audience demographic for both programmes (cf. note 71).

69 As a reproducible medium, film does not have an aura in the strictest Benjaminian sense (and certainly not its digital surrogate. Prior to digitisation, home movies represented an interesting case as they usually existed as a unique original without a negative. As such, they were not easily copied.) Bolter et al. offer a revisionist notion of aura as 'personal and cultural significance that an object or place holds for an individual or a group of viewers' $(2006,23)$. They suggest various ways in which a digital environment could be considered auratic, such as the combination of reproducible with a unique place or experience (24), a 'sense of distance-throughproximity' (29), indications of technological obsolescence discernible in reproductions and the causal relationship between original and copy (30). Moreover, any archived object might be construed to have an aura according to this rather more expansive definition. Thomas Osborne, for example, suggests archiving itself confers a certain aura upon the ordinary $(1999,62)$. 
screening included live musical accompaniment with silent films (including the home movies). NEFA and YFA favour presenter-led screenings intended to communicate to audiences that they are attending 'something special' (NEFA, 19). ${ }^{70}$ The 2017 screening of Leeds on Film took place at the century-old Hyde Park Picture House, with each film given a brief introduction directly before it screened by YFA manager, Graham Relton. Writing for the University of Leeds's student newspaper, Charlotte Perry captured the general ethos of the event:

The showing was an absolute joy to watch; it was entertaining (the evening performance sold out) and it raised awareness of both the archive and Leeds's history. I believe that people always have and always will have fascination in the lives of others - these films were engrossing and extremely charming because they simply showed everyday moments of everyday people. The joy from the audience was palpable, and the diversity of ages in the audience was heart-warming to see; it felt as if everyone (from current students to the elderly) was united by a love for Leeds and an interest in engaging with the past. There was something extremely nostalgic about the experience (even for those us of who were not alive when most footage was filmed) and did lead me to question the extent to which it is possible to watch films such as these and not romanticise life in previous decades (2017)..$^{11}$

Perry's description accords with what Katharina Niemeyer calls a 'false' nostalgia that technology enables in the form of 'a pleasure-seeking yearning for former times that we have not, in fact, lived', or even for 'a past that has never been' (2014, 9-10). Yet even if we affirm Perry's quandary with regard to the inescapably romantic vision of the past that old films occasion for contemporary viewers, as noted in previous chapters, nostalgia does not have a uniform character. A viewer's attention can be drawn in different directions. An intimate space may nurture a sense of social connection and belonging, but minor disturbances in the room can leave spectators distracted rather than immersed in the screening. A presenter both lends a ceremonial quality to the proceedings and, by contextualising a film or its content, provides an informative history lesson. Music can be used emotively or in counterpoint. Similarly, nostalgia

$7034 \%$ of Newcastle on Film exit survey respondents actually indicated 'the presenter-led style' as their event highlight (10).

71 Perry's description in general concurs with my own observations with regard to audience reaction at the evening screening. I would, however, distinguish between content that could be construed as nostalgic and my personal experience of watching it as a non-local viewer in the context of a doctoral research project (that is to say, not the envisaged spectator for such an event). That this was a community screening intended specifically for a local audience was emphasised to me when asked to complete the exit survey; the person conducting it was very surprised to discover I was from New Zealand (albeit attending with a relative who lives nearby. My father was also born in Yorkshire.) 
can be experienced as a longing to return to a past (that has never been) or a more ambivalent reflection upon the irrevocable passing of time (Boym 2007, 13-15). ${ }^{72}$

Community screenings, such as Leeds on Film or Rural New Zealand, do not cater to academic or more specialised interests in home movies (or any other kind of archival film), nor are they intended to do so, and may therefore disappoint anyone seeking a comprehensive history of a region's filmmaking. Such events do nevertheless raise awareness of an archive's resources and stimulate interest in online content. Perry notes, for example, that she subsequently explored the YFA website and watched the full version of her favourite excerpt in the cinema programme. ${ }^{73}$ If one assumes, like Rick Prelinger, that original materials offer 'good stories' minus alteration (2009), watching them in full rather than as excerpts surely has considerable advantages in terms of historical understandings, especially for those inclined to resent the editorial acts of curators or filmmakers recycling images. Moreover, home movies are very often screened with music, which arguably distorts the experience of watching them. For some this may be a pleasurable addition that staves off boredom, for others a tiresome irritant, especially if the choice of music is perceived to be emotionally manipulative or an inappropriate match with the images.

The empty soundtracks of Prelinger's No More Road Trips? (2013) and Lost Landscapes series (2006-), which leave audiences to fill the silence unhindered by the emotional sway of music or the imposition of curatorial perspectives, replace common techniques of engagement with the allure of interactivity. While spectators sometimes murmur amongst themselves, point at the screen, or even call out if they happen to recognise someone onscreen, for example, ${ }^{74}$ active

72 The online promotional trailer for Leeds on Film (presented previously in 2015) is quite interesting from this perspective. The combination of rhythmic montage and triumphant music seems to emphasise very strongly collective mythologising and pride in local heritage (in a way not dissimilar to a film such as From Scotland with Love). While these elements were not absent from the actual screening, as clips were interspersed with informative commentary and music added to silent films only, it did maintain quite a different flavour to that suggested by the programme's online advertiser.

73 Another visitor also expresses her intention to look at the YFA website in a short post-screening video interview posted to Facebook https://www.facebook.com/watch/?v=3001324923218797 (17 May 2019). According to YFA manager, Graham Relton, it is not unusual for screenings to increase interest in website content (personal conversation in York, 31 October 2017). Exhibitions may also be archived online, enabling audiences to revisit materials. Aside from The Danube Exodus website mentioned above, Huis van Alijn's Homeless Movies can be watched on the museum's Vimeo channel, for example, along with various other amateur-related films. The online archive of the Deutsche Kinemathek's Berlin Wall exhibition, Moments in Time 1989/1990, also contains a large number of home movies. Films can become decontextualised across these secondary uses, however, if presented without accompanying text or other materials.

74 Personally, I have noticed viewers are more inclined to make audible comments (albeit usually in a relatively subdued tone) at community archival screenings than at commercial or festival screenings, for example, situations where silence is usually expected (even if not always rigorously adhered to). Various authors, 
audience contribution is not an essential element of community screenings. Participatory cinema is quite different in this respect. Interactive events are popular, the annual Lost Landscapes of San Francisco attracting around 1,400 people. Prelinger suggests the license to express oneself volubly in a manner that would normally be considered transgressive at the cinema influences the desire to participate. However, he also notes that 'the excitement of making noise in the movies' can outweigh any loftier ambitions a presenter might have, with spectators not necessarily inclined to address complex or difficult issues during a screening (in Cook et al. 2015, 176-77). Moreover, participatory screenings are shaped by the members of an audience who feel 'freest to speak' (180), leaving those who feel less able or inclined to do so to either enjoy or be irritated by the flow of comments from other spectators. Boredom, whether it is experienced at participatory or more conventional screenings, may be an effective critical response, a way of distancing oneself from displeasing points of view or sentiments not shared.

\section{Platforms and effects IV: Co-curation, remixing film history and the 'clearing house' of meaning}

There is no political power without control of the archive, if not of memory. Effective democratization can always be measured by this essential criterion: the participation in and access to the archive, its constitution, and its interpretation (Derrida 1995, 11n).

Although home movies are often donated to archives by members of the public, it is usually archivists and curators who decide how they will subsequently be made accessible. Interactive exhibitions and screenings give viewers a certain amount of control over their experience of archival images, albeit within a structured framework, a curator having predetermined the overall range of content, as well as the general parameters of participation. Public co-curation projects can expand the contribution of audiences further in a number of ways, however.

One obvious example of co-curation is an event such as Home Movie Day (HMD) at which participants have the opportunity to supply screening material from their own personal collections. Local iterations of the annual international event need not be officially connected to a cultural heritage institution, but may rely upon the support of a local museum or archive for a venue, equipment, expertise or additional content. London HMD, for example, takes place at the Cinema Museum in Lambeth, the 2017 event (which I attended in person) including a

including Miriam Ross $(2013,452)$ and Jonathan Dennis $(1994,123-6)$, have also commented upon this phenomenon at community screenings. 
screening of material from the London Community Video Archive, along with amateur footage of The Beatles on set during the making of Help! (1965). This pre-organised programme (which noticeably included the familiar tropes of celebrity film and localism) reverted to a conventional presentation format with the assembled audience assuming a largely passive mode of viewing, aside from occasional murmurs of recognition. The central and most distinctive feature of HMD is undoubtedly the 'BYO' aspect of the event, however, which enables members of the public to take a curatorial role.

At the Cinema Museum a number of $8 \mathrm{~mm}$ projectors and small screens were set up around the room, leaving patrons to move about freely according to whatever caught their eye. Participants who brought their own films generally offered some commentary as they screened, identifying people or places they recognised, or simply chatted informally to those around them. ${ }^{75}$ Very much a community of interest event, HMD is to some extent not so much about location per se - some home movies included scenes recorded elsewhere in the UK or even overseas - as a fascination with (one's own) private filmmaking of the past and obsolete technology.

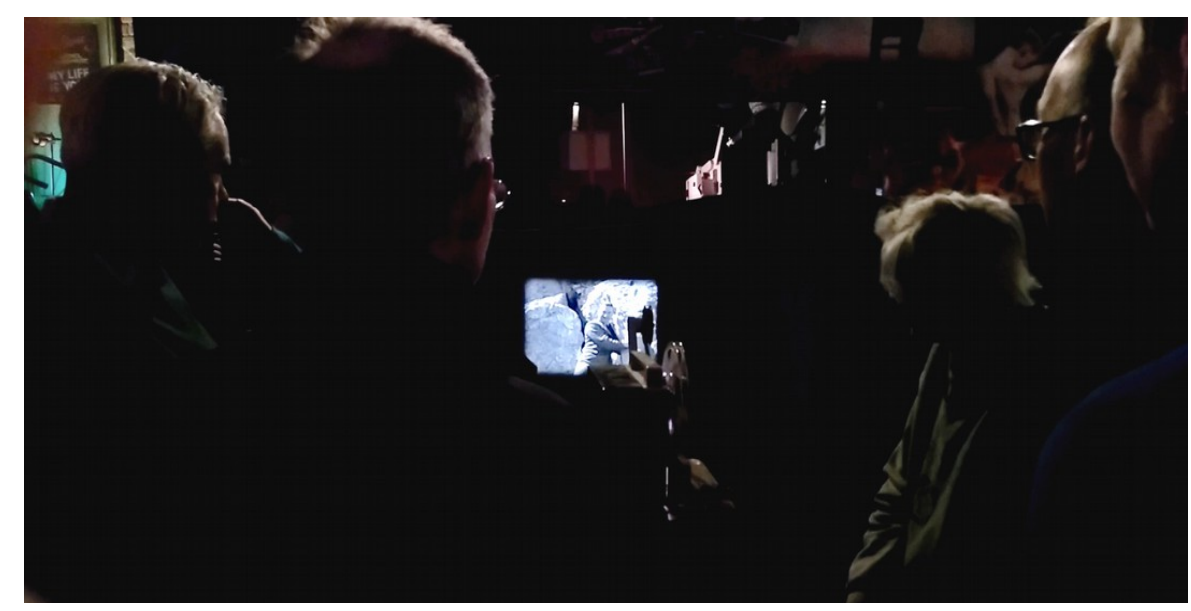

Fig. 4.20. Patrons of London HMD watching an $8 \mathrm{~mm}$ film. Author's photograph, 18 November 2017.

The enthusiasm of patrons for screening their own family movies to a bevy of interested spectators might best be described as infectious, overriding the relatively mundane quality of many films. Although a public event, the setting recalls the informal intimacy of a domestic screening, albeit with usually only one actual family member present, other HMD patrons

75 An example of this can be seen in a clip recorded at a similar 2009 HMD event in Pittsburgh https://youtu.be/ q2Tww9MwjGk 
filling in for absent relatives who would normally participate in a dialogue prompted by the images. For viewers, engagement is therefore dependent upon making this imaginative leap, in effect becoming 'one of the family' for the duration of the screening.

Along with its nostalgic qualities, HMD offers the excitement of serendipity. Participants do not necessarily know what images their own reels contain, especially if they have inherited films or been unable to view them for a long time. One patron of London's 2017 event also brought a bundle of orphan films, which quite coincidentally turned out to contain footage recorded in New Zealand during the 1960s. (The reels, which included some beautifully degraded aerial footage, were subsequently gifted to me as the only person present with a connection to their place of filming.) As a vehicle of discovery, Laura Mulvey suggests old film offers 'all the childish and playful pleasure of the treasure hunt' $(2006,193)$. By providing the expertise and technical means to reanimate obsolete media, HMD gives patrons the opportunity to find their own buried treasure.

HMD enables ordinary people to participate in the screening of film history, not just as viewers but as curators and narrators of it, thereby bestowing value upon personal media practices irrespective of whether individual films would be considered of historical significance by a public archive. This kind of 'shared authority' involving people in the presentation of their own history also extends into the realm of the digital (Ketelaar 2003, 17). As discussed above, social media is widely used to promote interest in archival collections or events. More than just a oneway broadcast, so-called 'Archives 2.0' implies a participatory media culture. In order to stimulate curiosity about historical artefacts, 'CineSecrets' (see fig. 4.18) or NFSA's weekly mystery object, for example, encourage users to comment, rather than simply informing them about available resources or upcoming events.

Social media can also be used to solicit information directly from members of the public that is not known to an archive. Crowdsourcing enables archives to leverage the knowledge of source communities (Liew et al. 2018, 93), which may be particularly useful for smaller organisations with limited resources to undertake their own research and cataloguing. User tagging represents another solution to finite resources. TAMI, for example, allows users to mark sections of a video and add a description. The willingness of unpaid volunteers to improve archival metadata in this way suggests a certain satisfaction in doing so. Moreover, 'folksonomies' or the vernacular 
language of users can make collections easier to navigate than if formal archival vocabularies are used to catalogue items. Unfortunately, inconsistencies and erroneous comments can also limit the functionality of user metadata (Andreano 2007, 88-92), ${ }^{76}$ unless an archivist intervenes as an 'editor of knowledge' who distinguishes 'sense from nonsense' (Noordegraaf 2010, 17). Moderation inevitably returns control to the archive itself, however, somewhat diminishing the democratic appeal of user content creation (Liew et al. 2018, 102-103).

Fig. 4.21. Archives 2.0 at its simplest: add your suggestion in the comments section. NFSA Facebook post, 9 May 2018. Screenshot.

content unavailable

please consult print version

For those not excited by metadata, interactive remixing projects offer a more imaginative platform for participation. In terms of interpretative control of the archive, projects that allow members of the public to reuse materials arguably represent a kind of democratic apex. Competitions such as London Recut (2010) and EYE's Celluloid Remix (2012) tap into the contemporary fascination with digital interactivity in the service of 'crowd curation'. By offering the opportunity to reedit archival moving images, remix projects enable participants to construct their own discourses about the past and present them to an online audience. The fragmented, nonnarrative quality of so many home movies arguably renders them particularly fitting for playful reuse (Ingravalle 2015, 85-87). It is not too surprising then that home movies featured amongst

\footnotetext{
76 Although over a decade since the time of writing, Kevin Andreano's 2007 examination of the advantages and limitations of user-generated metadata in comparison with more conventional archival description remains largely relevant (albeit the complexity of online searches has increased due to the massive expansion of video content). Andreano assesses the discoverability of copies of the same film in collections that rely upon user metadata and in those that do not (88-92). Informal online archives or collections, such as the Internet Archive and YouTube, have a high dependency upon users to facilitate searchability.
} 
the selection of 140 archival films that London Recut provided for participants to make a short video about London that was 'meaningful' to them (Chitty 2011, 416).

content unavailable

Fig. 4.22. Appealing for information via social media. YFA Facebook post, 14 February 2018. Screenshot.

please consult print version

Amateur footage appears in one of the winning entries, Stevie Gee's Playing Out. The film features a series of images of children at play - in the street, the playground, swimming, snow fights, fairground rides and so forth - accompanied by a montage of children's voices and instrumental music on the soundtrack. Gee apparently intended the film to reflect her fond memories of playing in London's streets and canals before the prevalence of digital devices and perceived dangers of public spaces encroached upon children's time and freedom in the outdoors (ibid., 418). Contemporary concerns about child safety are not referenced directly in the film, however. The contrast between Playing Out and the other winning entries, which appear to draw primarily upon newsreel and public information film footage, is quite revealing in terms of popular perceptions about home movies. ${ }^{77}$ Whereas the other winners eerily evoke wartime air raids, social paranoia, urban alienation and the exhilaration of life in the metropolis,

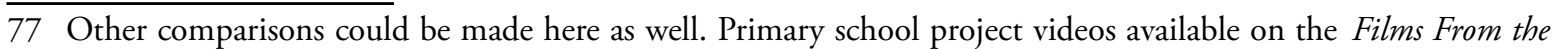
Home Front website in which children created voiceover commentaries to accompany amateur footage of a school air raid drill, for example, share formal similarities with Playing Out. As guided, educational exercises concerned primarily with increasing students' awareness of historical contexts rather than the production of an aesthetically pleasing or entertaining work, these short videos are far less nostalgic in orientation, however. Given its thematic similarities, Andrew Dearman's installation, Disappearance (discussed on page 123), offers another interesting point of comparison with Playing Out. 
Playing Out uses amateur images, mostly recorded on Kodachrome, to create a gentle, nostalgic picture of carefree childhood in postwar London. Although the four winning films were selected by an expert panel, the initial shortlist for London Recut was determined via online voting by viewers (ibid., 417), suggesting Playing Out's combination of home movie images and nostalgic sentiments aligned with audience sensibilities.

content unavailable

please consult print version

Fig. 4.23-24. Gentle nostalgia in Stevie Gee's Playing Out contrasts with themes of paranoia and alienation in Nicola Jaberi's London! A Guide for the Anxious. Finalists in London Recut. Screenshots.

Remixing projects enable archives to engage public audiences and exhibit materials in a manner commensurate with contemporary expectations regarding the participatory nature of media culture (Ingravalle 2015, 87). This subversion of traditional archival hierarchies in favour of viewer agency can compromise the historical complexity of moving images, however. Archival films become items to be sampled from a database of images, the pleasures of imaginative juxtapositions potentially outweighing concern for historical contexts or critical insight (92-93). The aestheticisation of archival footage through montage and the addition of music can construct simplistic or generic images of the past that are romanticised, nostalgic or politically ambiguous (Druick 2014, 321). Baetens and Van Looy suggest an 'interactive reading does not automatically imply a very active reading' $(2007,4)$. Looking at London Recut, it is easy to arrive at the conclusion home movies in particular are well suited to conservative and nostalgic reuses.

Grazia Ingravalle notes that although 'the democratic potential of remix is obvious, nevertheless it comes with the risk of historical forgetfulness' (92). Participatory projects weigh the benefits of engaging audiences against an archive's mandate to preserve the status of their documents as historical evidence, not simply image banks of stock footage (Liew et al. 2015, 381). Home 
movies acquire a new life as the instruments of creative mash-ups in the hands of viewers who might otherwise find little of interest in such footage. In this way, democratic participation in the archive has significant potential to facilitate pluralistic presentations of historical moving images that are relevant, enjoyable and meaningful to contemporary viewers. The imposition of new, potentially ahistorical, interpretations can obscure previous contexts of circulation and understandings related to these, however, resulting in 'the archive serving as a kind of "clearing house" of meaning' (Sekula 2003, 445).

\section{Serving a certain vision of history?}

Archives and museums transform what were once private recordings into something meaningful for public audiences by invoking different narratives and contexts, as well as utilising a variety of platforms and styles of presentation. The curatorial emphasis of screenings and exhibitions reflects the general ethos of public cultural heritage institutions towards the provision of viewing experiences that are both pleasurable and informative, as well as anticipated audiences who include users within the education sector and, in the case of regional archives, local communities. TAMI director Caroline Frick, for example, describes the Texan archive's orientation as educational, 'a fourth grader' envisaged as a 'key user' $(2013,45)$. Presentations such as Amateur Auteurs provide short, easy-to-read explanatory texts to accompany audiovisual materials. TAMI's website also incorporates resources and activities designed for school-age students accordingly, while Films From the Home Front includes primary school creative projects specifically developed from materials on the site. Concise narratives that are easy to comprehend offer students and other non-specialist audiences, who may not possess extensive historical knowledge, guided introductory encounters with the past through a modest assortment of resources, prudent selection and pedagogy countering the threat of information overload and meaningless archival noise.

Making archival films such as home movies accessible to general public audiences has become an important aspect of archival practice. Archives and museums are in the business of transforming film history into cinematic heritage worthy of the public resources necessary for its preservation. Heritage has become a naturalised and socially accepted concept, according to Frick, its conservation regarded as common sense $(2011,5,15)$. The value of films connected with major events or those featuring prominent people, for example, appears relatively unquestionable in this light, making them obvious choices for screenings, exhibitions or online 
viewing. Other home movies may require some assistance to be 'upcycled' into valuable heritage. They often lack distinctive markers of local identity beyond recognisable locations. Private films can nevertheless be recast as regional public heritage by invoking historical narratives thrown up by their content or context of production. This can be seen in the notes accompanying films on the YFA website, for example, as well as the compendia of local stories that feature in screening programmes such as Leeds on Film, which encourage viewers to feel a connection with their community's past. As evidence of local (hi)stories, home movies are more likely to be engaging, meaningful and therefore valuable to audiences keen to see how their forebears lived or the extent to which familiar landscapes have altered over the years. Home movies seldom contain coherent narratives, but curation can effectively (and affectingly) append stories where only the merest hint of one existed. Projects that enable members of the public to reuse archival footage to tell their own stories also encourage viewers to find value and relevance in home movies and other images, but have the potential to result in ahistorical or naïve renditions of the past.

Curatorial activities used to engage wider audiences and make film history interesting may have drawbacks. In the shift from archival classification to historiographic narrative a few representative examples come to stand in for the varied and complex nature of historical experience, almost unavoidably serving 'a certain vision of history' at the expense of other possible interpretations (Druick 2014, 318-9). Curation is very much dependent upon the skill of the individual curator to make compelling selections, indicate salient points of interest and provoke reflection amongst viewers. The frequent combination of brevity and didacticism can simplify the complexities of historical records, encouraging audiences to accept information at face value, a curator's perspective becoming an unvarnished truth rather than a particular interpretation of a film. As Benjamin suggested in 'The Storyteller', information 'shot through with explanation' may leave little for its recipient to mull over, unlike stories that require at least some degree of effort to interpret $(2007,89)$. More complex curatorial strategies, such as those seen in the multi-installation exhibitions of Péter Forgács, require greater effort and time on the part of the viewer to fully appreciate, however, as well as space conducive to sustained concentration.

Reducing history to a manageable size and level of complexity offers those with less-specialised interests a useful point of entry, but may not furnish serious researchers with the best possible 
means to accomplish in-depth investigations. Many archives have very limited resources to carry out their activities. By making screenings and exhibitions aimed at general audiences a priority, archives can fulfill a public heritage mandate. This has the advantage of connecting wider communities, rather than just a select few researchers, with audiovisual history. The use of finite resources for public outreach activities in preference to increasing the content of databases or improving access to general collections, for example, has the potential to underserve researchers, however. If non-digitised materials are not readily accessible or widely consulted, they can become effectively lost to sight, along with whatever they have to reveal about the past. Understandings of history may be diminished if the scope of research agendas are curtailed out of practical necessity to focus upon easily available digital resources. ${ }^{78}$

Projects such as the Home Movie Registry represent an alternative trend toward making as much information as possible accessible to researchers, but are of course dependent upon the ability of users to navigate the contingencies of noise and excess. Moreover, a great deal of time is often required to study all available resources on a particular topic. Marlene Manoff concludes that 'the digital both fosters and threatens the archival record' $(2010,395)$. The success, or otherwise, of archival presentation might be measured according to the correspondence between the specific needs of archive users and available forms of access to resources, the more diverse an archive's constituency, the greater the requirement for both introductory narratives and comprehensive forms of access.

\section{The perfect unmanageable and incomplete history-making project}

Computerised societies are information rich. Digitisation, and especially the Internet, has made the past much more immediately accessible to large numbers of people. Greater access does not in itself ensure greater understanding of history or cinema, however. Living in a culture of image saturation can confound as much as expand critical awareness (Baylis 2014, 3). Database efficiency places a superabundance of information within easy reach, yet the persistent desire for narratives within new media, according to Manovich, testifies to a dissatisfaction with the computer solely as an encyclopaedia or catalogue of effects $(2001,237)$. Narrative remains central to our experience of the world as a repository of meaning.

78 At EYE, for example, there is a fee for viewing any analogue recordings that have not been digitised. Obviously this kind of policy constrains researchers to watching only the number of analogue films their budgets can accommodate and those materials that have already been digitised. 
In accordance with the 'postmodern condition', there is widespread acceptance that archival records do not have a fixed or inherent meaning but a subjective 'meaning for someone' within a particular context (Ketelaar 2012,23). The archive is currently a disputed territory in terms of who should determine the use of images and what they mean. Popular and participatory forms of engagement have expanded interest in the past beyond the traditional academic and educational audiences of cultural heritage institutions. This could come at a cost, however. If popularity and palatability determine the allocation of resources for archival programmes, the cinematic past risks being transformed into an anachronistic memory serving only a narrow spectrum of present interests, pleasurable nostalgia masking historical complexity.

The affective qualities, both of cinema in general and home movies in particular, can override more critical cognitive responses to archival films. Nostalgia in particular creates a powerful, emotive connection with images of the past. Indeed, it may be a way of transforming what might otherwise be perceived as a boring object or experience into something meaningful (Weir 2013). This is not inherently a bad thing. Nostalgic feelings can represent a reflection upon the continuum of time and one's place within it, or a desire to restore the past (or some mythical version thereof). Nostalgia can be a source of social cohesion, or of misguided patriotism. By addressing audiences across a range of platforms, archives at the very least give viewers the opportunity to shift between superficial and more in-depth levels of engagement with historical moving images.

Home movies offer an insightful example of archival involvement in the construction of what counts as history, heritage and collective memory in the digital age. Baron has argued that the most easily accessible digital documents 'may come to dominate the historical record and be accorded a role that may be out of proportion to their original historical significance (which we can, of course, only infer)' $(2014,143)$. Although digital finding aids and video uploads encourage the consultation of archival films, the Internet also threatens the existence of anything not on it. Moreover, the algorithmic logic of the Internet ensures some materials are more visible than others. Making archival documents accessible and engaging is not simply a matter of interest or boredom, but a terrain involving an epistemology of the past and a politics of public memory.

The pluralistic aspect of digital dissemination may be more imagined than actual. Home movies 
can be used to support dominant or popular narratives rather than to diversify available accounts of historical experience, thereby neglecting the postmodern potential of the contemporary archive. Audiences are not of course compelled to accept unsatisfactory curation or 'getting the presentation wrong'. In this sense, boredom could be deemed to have an ethical component. As a response to the style or content of a presentation, boredom defends the spectator against the imposition of particular visions of the past. Boringness may also encourage viewers to search for new insight and meanings in films or collections that at first glance appear essentially random and meaningless.

The ideal film archive is perhaps best conceived as one that is simultaneously all things to all people. It remains a utopian vision. Yet the incompleteness of the twenty-first century film archive seems to reflect, if not an archivist's ideal, then at least a Benjaminian one. Like The Arcades Project, which in its existing form privileges 'remains of the past' without 'synthesizing them into a tidy narrative' suited to the ideological demands of the present, the current film archive (in its totality) Janna Jones suggests 'is the perfect unmanageable and incomplete history-making project of the twentieth century', perfect archival order disturbed by the nightmare of random, heterogenous, unruly contents (2012, 14-16). 'Its unfinishedness,' according to Jones, 'seems to be exactly the point' of The Arcades Project (11). Home movies are just one part of this unruly history-making project. What Baines and Owen call 'the massive mess of mass memory' (1996) might represent home movies' greatest defence against the homogenising effects of a popular digital culture. 


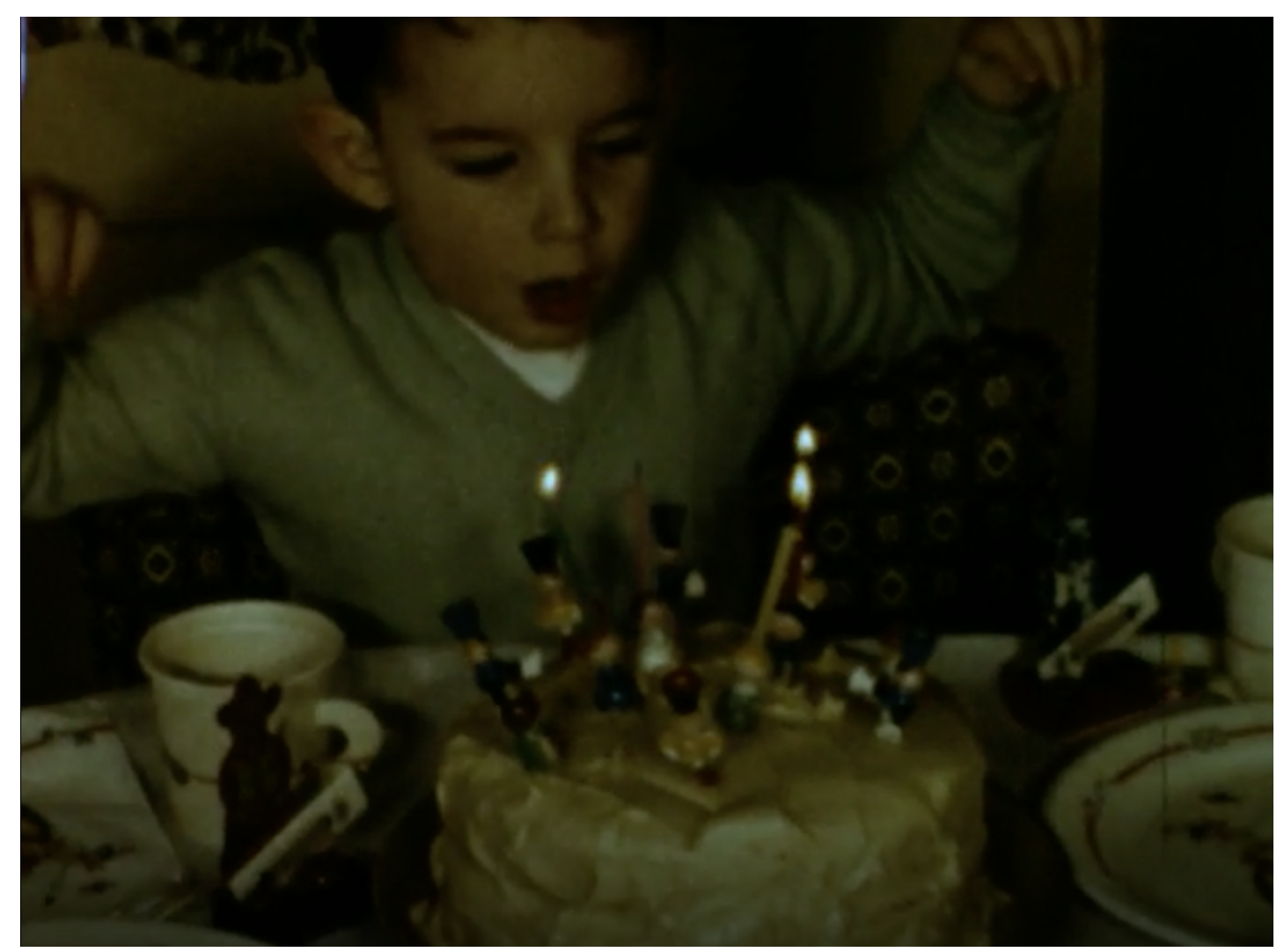




\title{
5. Conclusion
}

\section{Home movies in the 21 st century and (mind) wandering through cyberspace}

\begin{abstract}
We are living in an era of extraordinary online abundance. But the films you find in these venues might not be the ones you think you want (or need). In these virtual spaces, narrative films are outnumbered by the neglected bounty of the 20th century: early film artifacts, small-gauge formats, amateur genres, short cinemas and literal film fragments.
\end{abstract}

- Katherine Groo 2018

This study concludes by returning to where it began: with a rumination upon the place of the orphaned home movie seemingly adrift in cyberspace. Many, perhaps even the majority, of dayto-day encounters with home movies occur outside formally organised viewing situations in the comparatively unregulated space of the Internet. Unlike the professional moving image productions and curated exhibition spaces that incorporate home movies discussed in the previous chapters, video-sharing platforms such as YouTube (or online repositories like the Internet Archive that enable video sharing), which allow users to upload their own videos, offer relatively little guidance on how to navigate vast troves of material, or how to interpret it. Interpretation, if it exists at all for a given item, is largely a byproduct of viewing activity. Using the Internet Archive's review option, a viewer who goes by the name of 'Spuzz' sketches the following picture of toddler Bruce's birthday film, 'Home Movie 97177: Unidentified' (described in the opening passage of this thesis) -

Subject: Happy Birthday! Now if I can only find the table...

Lots of birthdays are to be had in this film, the family consists of a young couple and their son (I think a younger baby is introduced later?) and we get a few nice outdoor play scenes. But then it goes indoors, and for the most part, it's dark and murky. We do see some kids on occasion, and in a great scene, darkness all of a sudden turns into a big old bird (turkey?) being served for a birthday. Who serves turkey on a birthday? Anyways, at least 4 bdays are shown here (February 28, 2015). 
This kind of 'folksonomic' or vernacular description - the only information available about this particular recording in fact, aside from its contributing archive - affords a small window upon what twenty-first century viewers make of home movies uploaded to the Internet. Upon watching 'Home Movie 97177', it becomes evident that the online reviewer's interpretation of onscreen activity is probably inaccurate. The turkey would appear to be served at Christmas, rather than a birthday. (Lights twinkling in the gloom imply a tree decorated with fairy lights, while young Bruce is glimpsed delving into a stocking.) The number of birthdays (or at least birthday cakes) is actually five, possibly six (if one without candles indicates yet another birthday). Although hardly a review in the more expansive sense of a critical appraisal, Spuzz's description does at least offer some indication of the film's content (family birthday celebrations), its dominant aesthetic ('dark and murky'), plus a hint of the writer's feelings about this particular movie (the appearance of the oddly luminous turkey is 'a great scene'). The banality of the description ('nice outdoor play scenes') mirrors that of the recording. What are we as viewers to make of this mediocre movie? It is difficult to say beyond the film's fairly obvious potential to inspire boredom or indifference. Accompanied by only a brief and somewhat flawed description, 'Home Movie 97177' seems pretty nebulous in its more-or-less contextless cyberspace existence. Uploaded in May 2013, it has received just over 600 views six years later. Spuzz gives the film a rating of three stars (out of five) signaling modest appreciation, but he(?) is the sole viewer who has chosen to comment upon this particular recording.

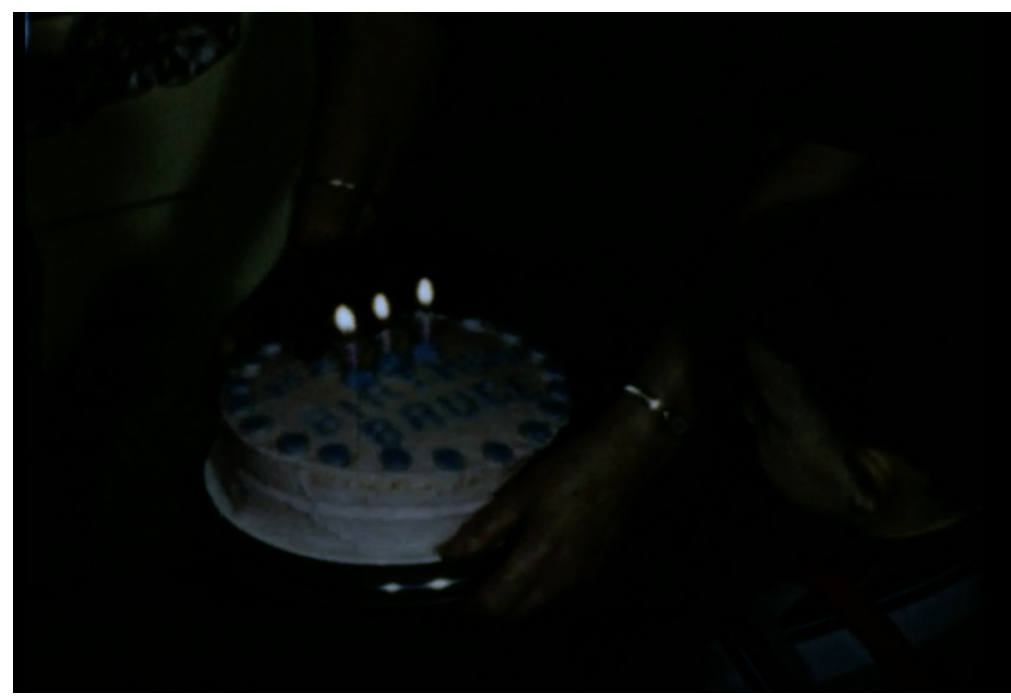

Fig. 5.1. Birthday cake 'searching' for the dining table seemingly lost in the under-lit scene. Bruce is barely visible in the lower righthand corner of the frame. 'Home Movie 97177: Unidentified'. Prelinger Archives, Internet Archive. Screenshot. 


\section{Getting the presentation right?}

As fragmentary remnants of private pasts, home movies cannot have a straightforward relationship with the public sphere. They are simultaneously highly personal and often monotonously conformist. We may recognise their familiar rituals and gestures, but cannot access the exact meanings these once held for their makers and participants. Looking at an anonymous family recording such as 'Home Movie 97177', we can simply add our voice to those already 'speaking on the subjects' behalf and speculating about these strangers' lives' (Dollman 2017, 244). The efforts of filmmakers, curators and viewers to find something in home movies could be considered an ameliorative gesture, a way of filling silence and striving to overcome the unknown (and often largely unknowable). Alternatively, the dissemination of private footage in public spaces might be seen as a means of freeing home movies from the strictures of individual and family history, a platform for re-evaluating them within a broader historical trajectory of cultural production and collective memory.

The approach of this thesis has been to look initially a little backwards with a view to also casting an eye forwards to the possible future(s) of analogue home movies. By reviewing the past and present lives of home movies in terms of their positioning as inducers of boredom or objects of interest, it has hoped to illuminate shifts in their valuation and usage, along with the potential impact of these. Boredom and boringness in this study has acted as a provocation, a reason to look a little harder into how and why we present home movies in specific ways, and what kinds of effects (or affects) these might give rise to amongst viewers. In this sense, the thesis has not been concerned with determining whether home movies are or are not in any definitive sense boring (surely an impossible task). Rather, by examining a changing public appraisal of home movies and their appearance within different spaces, the study has hoped to reveal certain trends in the constitution of their 'meaningfulness', taken here as the determining factor governing whether a given work is likely to be experienced by a viewer as boring or of interest in some respect.

Although a popular pastime during the middle years of the twentieth century, home moviemaking was frequently derided. Seemingly synonymous with boredom in the public consciousness, home movies were cast in the mould of cinematic failures by guidebooks and humorists, films that did not successfully tell a story or convey a message of any kind; in other words, meaningless films of little merit. Home movies were boring films and boring films were a 
problem. Viewers required entertainment comparable to that of professional cinema in order to avoid an attack of sleeping sickness, or so it was argued. Continuity and an exciting plot were the kinds of ingredients needed to enliven this usually staid genre of filmmaking, yet they were rarely a feature of home movies.

Their reputation largely redeemed in recent decades, home movies are now widely considered objects worthy of attention. This reversal of fortune is due in no small part to the pioneering efforts of scholars such as Patricia Zimmermann, Richard Chalfen, Roger Odin and Heather Norris Nicholson, whose work has helped cement the place of home movies within academic study. Alongside this, popular events, such as Home Movie Day and community screenings of archival films, have created interest beyond academia. Moreover, digitisation and especially the Internet have greatly improved public access to private films. It has been noted, however, that much of this interest has a tendency to gloss over what could be considered one of the defining traits of home movies, namely a certain kind of inherent boringness - or at least the potential to bore - embedded within their aesthetic form. This boringness, much like that of any other object, is very much a condition of a particular subject-object relation, between the expectations and desires of a viewing subject and the specific qualities of the film he or she chooses to watch. As Heidegger concluded, the boredom that boring things make us feel is 'partly objective, partly subjective'.

The relative nature of boringness has been crucial to the reappraisal of amateur film. Recognition that home movie narratives existed in the individual and collective memories of participant-viewers rather than in the films themselves has been instrumental to the reassessment of amateur recording practices. At home screenings participants acted as narrators, connecting sequences of otherwise disjointed images in order to recount family history. As the images of home movies functioned as catalysts to private reminiscence, they were imbued with personal meanings and therefore presumably not boring to family audiences. In this respect, Chalfen's delineation of appropriate and inappropriate viewers represents a major advance in the appreciation of home movie aesthetics. Jettisoned into the public arena however, home movies are bereft of their original narrators and raison d'être.

Those with an interest in home movies approach the retreat of personal associations in different ways. Academic studies often focus upon the value of home movies as some kind of evidence. 
Interpreted as histories of everyday life, geographical change, private media practices or memory objects, films that might otherwise appear banal, incoherent or simply too commonplace to be of interest to anyone outside an original family circle take on that all important factor in the negation of boredom: meaning. By reading films as documents and selectively transforming individual works into certain kinds of history, scholars can downplay some of the more tedious aspects of home movie production. Outside the home the 'patterned eliminations' of Chalfen's 'special reality', along with the general ubiquity, silence and often clumsy filming techniques of home movies, culminate in a loss of original meanings and may lead to perceptions of excessive repetition or randomness. Klapp defined such characteristics as 'noise' that inhibits interest and understanding, resulting in what Svendsen refers to as a 'meaning deficit' and ultimately boredom. This study has taken on board Lefebvre's suggestion, however, that a boring thing can be made interesting; it is simply a matter of 'getting the presentation right'.

The creation of a context for home movies is a prevalent theme in the preceding chapters. The widespread reuse of home movie footage within other kinds of productions examined in chapter 3 illustrates a range of ways to interest viewers. Richard Misek notes that filmmakers tend to employ 'time-killing' techniques in order to entertain viewers who could otherwise become bored by a film. Within works that recycle home movies, narrative and affective engagement are principal means of maintaining audience interest. While the impact of narrativisation and affect can vary considerably between different works and genres, the appeal of home movies within new productions is often more emotive than intellectual, arising from the (tech)nostalgic possibilities of amateur images.

Narrative might overcome the meaning deficit of home movies, but it can also play a deceptive role. Used to tell a story, home movies may seem relatively transparent in terms of meaning and evidential value. Home movies are often filled with ambiguities, however. 'Facts' documented by the amateur camera may be less than factual, offering at best a partial view of lived experience. The images of home movies may conceal more than they reveal. What is captured on film may be carefully selected or, alternatively, quite haphazard, even accidental. In reference to the contingent nature of amateur recordings and their epistemological indeterminacy highlighted in Péter Forgács's Wittgenstein Tractatus, Tyrus Miller points to a 'zone of irreducible hiddenness' beneath the surface of amateur images. They maintain a certain level of impenetrability. Yet home movies are often presented as relatively unproblematic evidence, 
particularly within popular history documentaries that offer complacently familiar and reassuring narratives about a nation's past and identity. The apparent authenticity of home movie footage - what Roger Odin refers to as the 'home movie effect' - finds a powerful outlet in the television compilation that declines to question what lies beyond the edge of the frame or the truthfulness of all that appears within it. The persuasive credibility of amateurism is perhaps best exemplified not by home movies themselves, however, but by their imitation within other films. In works with 'fuzzy resemblances' or films-within-a-film, the home movie aesthetic embodies verisimilitude.

Home movies, actual or in inverted commas, can also evoke a strong sense of pastness, often with nostalgic overtones. Devoid of context, the stereotypical nature of home movies may seem boring, yet this represents a boon for filmmakers. The affective dimension and familiarity of so many home movie images foster viewer identification. Images recorded in one context can be inserted into another, erasing their particularity in service of a general representability and audience appeal. 'Affective history' conjures an emotive experience of the past through the use of archival footage rather than investigating specific historical events. A film such as From Scotland With Love uses a combination of music and rhythmic editing to encourage audiences to appreciate that the past was once alive, enabling viewers 'not only to know the past but also to feel it' (Baron 2014, 128). In the absence of any recognition of the complexities of historical representations, however, the past is imbued with a romantic nostalgia as much as a sense of aliveness. The emotive attraction of home movies can nevertheless work in tandem with an analytical framework, as demonstrated in the work of Péter Forgács, to promote a more critical historical consciousness amongst viewers. The affective potential of home movies can be utilised for quite different ends.

The very malleability of amateur footage is perhaps its most intriguing characteristic within other productions. The effect of recycled images can vary considerably. Home movies can bore or fascinate according to the parameters of their presentation or ability to kill time effectively in a given context. Identification with home movie images can act in service of critical consciousness, or against it. The reassuring familiarity of home movies may be turned on its head; we can be induced to identify with images that have associations we may find disturbing, as in Swastika. What may seem a covert pleasure - watching private lives through a private lens - can thwart would-be voyeurs with an absence of revelation. There is also the possibility that 
viewers receive images in a manner not intended by the recyclers of home movies. Just as filmmakers may gesture towards something unforeseen by the original creators of home movies, spectators can in turn read footage 'against the grain' of reuse. They can doubt 'evidence'. They can find emotional manipulation, such as the addition of sentimental music, tedious. And they can become bored by something that was almost certainly intended to arouse interest.

Narrative and affect are also central features of the archival access and exhibition strategies looked at in chapter 4. Digitisation has enabled archives to make their catalogues and databases, along with a small percentage of materials, available online. This increases the possibility of reaching a greater number of users, including those at a geographical distance, but often does not communicate the meanings of films very effectively. The desire to serve a wider community than just dedicated researchers has led many archives to undertake a range of public outreach activities that cater to more general audiences. Again, creating an appropriate context for home movies is often a feature of their presentation. This helps viewers to appreciate meanings that may not be readily apparent simply by watching films located through an archival search tool containing very limited indication of a work's significance. Nevertheless, as an example such as the Yorkshire Film Archive's 'Sheriff Hutton Agricultural and Rural Scenes' demonstrates, placing a film in its 'right context' can be an ambiguous and subjective undertaking, depending upon what background information is available to curators and their individual interpretation of the content of recordings.

Different kinds of narratives are used to frame home movies. Examples discussed in chapter 4 include major world events, famous lives, local history and community identity, as well as the history of cinema itself. Curatorial styles and screening platforms, which may also have a significant impact upon audience reception, are equally varied. Despite prevailing postmodern conceptions of the archive as a keeper of historical records that are ideological in nature and subject to variable and contested interpretation, the didactic 'chaperoning' of films into the public sphere remains a prevalent style of presentation. In order to create engaging encounters with the cinematic past for audiences minus specialist knowledge, curators provide brief explanations and simple narratives to contextualise films within exhibition spaces. Reducing film (and especially home movie) history to an amenable size and intelligibility combats the potential boredom of information overload and seeks to ensure audiences are not 'left empty' by viewing experiences that might otherwise underwhelm through an absence of accessible 
meaning. Yet such curation can downplay the complexities of home movies as historical records in favour of readily comprehensible stories and audience identification.

As with films containing recycled home movie footage, the appeal of archival screening programmes can be both affective and intellectual in varying degrees. In exhibitions such as Looming Fire or Homeless Movies the viewer is confronted with competing voices or enigmatic motifs. At community screenings audiences are invited to join in a collective embrace of local history that nurtures a sense of shared identity and nostalgic belonging. Participatory projects create pluralistic and inclusive opportunities for members of the public to contribute their own voices, knowledge and perspectives to the appreciation of archival footage, but also represent a wild card that may lead in some instances to the archive functioning as a 'clearing house' of meaning (Sekula 2003, 445).

By suturing home movies into history or collective memory, by bestowing a semblance of coherent order upon images that oftentimes appear random or disorderly, potentially engaging and meaningful viewing experiences may be constructed across a range of screening situations and forms of reuse. Taken as a whole, such activities could be conceptualised in terms of a general project to make meaningful what might otherwise be perceived meaningless. The impact of resituating home movies within the public sphere varies greatly across different contexts and styles of presentation. While some filmmakers and curators seek to interrogate the formal possibilities and limitations of home movie representation, others rely upon affective qualities to interest viewers, or some combination of intellectual and emotional engagement. Nonetheless the emotive appeal of images of a bygone era that appear more attractive than real life has a tendency to instill nostalgic affect as the central locus of meaning, potentially at the expense of more critical awareness of history.

The continuity of nostalgia across different platforms including television, cinema, archival screenings and remix projects underlines its significance as a means of engaging with home movies. Particularly within the rich and often well-preserved colours of Kodachrome film stock, life as witnessed in home movies can seem to justify sentiment that the past was somehow more radiant than the present. With its powerful ability to captivate audiences, ensuring spectators are neither held in limbo nor left empty, nostalgia is perhaps the most accessible form of meaning to be found in home movies once they have transcended the domestic realm. 
The first large-scale study of the public presentation of home movies that attempts to trace correspondences in usage across multiple contexts, this study adds a cautionary note to the recent celebration of home movies in academia (and beyond) that arguably casts new public interest in private home movie footage in an overly favourable light. Existing monographs tend to place an emphasis upon the films themselves within an historical trajectory that does not account for how contexts of presentation affect the way we experience films as contemporary viewers, while shorter studies that focus on context usually consider isolated examples. In particular, the study offers a new perspective by examining the role boredom and boringness in the construction of meaning. Drawing attention to the desire of home movie recyclers and curators to make meaningful what might otherwise be perceived meaningless (that is to say, boring) by audiences reveals a tendency to construct a particular politics and aesthetics of the past. The desire for meaning can have unsettling ramifications, fostering nostalgia or sentiment in the form of uncritical longing or celebration of local and national history or historical figures, a possibility not limited to any one specific context of viewing. Even archives - organisations explicitly concerned with the representation of history - are seemingly not immune to 'nostalgising' or celebration of the past through home movies. Discrepancies between postmodern theories of the archive and the actual dissemination of materials, often marked by didacticism and sentiment, links this study to a broader analytical terrain of historical representation through visual media. Furthermore, while specifically focused upon examples of home movie reusage, the insights of this study could be applicable to other areas of film and media studies where boredom and audience disengagement potentially manifest (non-theatrical archival films, avant-garde works, slow cinema, 'B' movies, dominant cinema that fails to entertain). Perhaps most importantly, there has been very limited recognition elsewhere of the significance of informal, online encounters 'curated by code', as suggested above, possibly the most prevalent way viewers now watch home movies. This is perhaps unsurprising. Inherent difficulties attend the study of online video-watching behaviours (concealed algorithms, the representability of viewer comments if, as is common, they account for less than one percent of a video's audience, the frequent absence of contextual information, to name a few). How does one locate meaning within such viewing activity?

In chapter 2 it was noted that becoming bored by a film or being bored with a film were not the only possible ways for viewers to experience tedium. Heidegger also described a more profound 
state of deep boredom in which one is left alone with oneself to contemplate being-in-theworld. Films that 'bore to death' or appear quite meaningless may release viewers from the expectation of cinematic entertainment or fulfilment, encouraging mental drifting or introspection instead. Whilst this kind of reaction is certainly possible to more-or-less any of the examples discussed in the preceding chapters, it seems most likely to occur in relation to a work such as No More Road Trips? in which meaning is largely dependent upon the activity of viewers who receive little guidance from the filmmaker with regard to how they should respond to what they see onscreen.

The primary focus of this study has been formal contexts of exhibition including cinema, television, archives, museums and galleries, structural entities all well established during the twentieth century, even if home movies were not always part of their repertoire. Moreover, they are curated spaces, arranged and presented according to some kind of expertise, whether it be cultural, commercial or artistic in nature. By comparison, the relatively laissez-faire participatory video-sharing platforms of the Internet are something of an unruly twenty-first century wilderness, a place where home movies can elude the edifying or classificatory imperatives of knowledgeable curators and archivists, the commercial objectives of television producers, or the artistic impulses of filmmakers. Even uploaded to a commercial platform such as YouTube, home movies are likely to be too niche interest to have economic value in terms of generating revenue for the site (via pre-roll advertisements, for example, which appear on some popular videos). Rather, they become part of what Daniel Fairfax describes as 'the unwanted refuse' that accumulates on YouTube - those materials frequently minus a readily identifiable owner and which are not 'seen as a potential source of profit' (2018b).

\section{The greatest archive of noise and detritus}

YouTube is the world's greatest archive, but it is an archive, chiefly, of detritus. It is the digital equivalent of a dumping ground, an ever expanding scrapheap of audiovisual flotsam and jetsam. It is thus the flip side (the dark side, even) of the "real" archives: whereas these organisations preserve what is judged to be worth keeping, YouTube stores precisely what is judged not to be worth keeping (Fairfax 2018b).

A superabundance of flotsam and jetsam are not the only issues to be encountered on YouTube. There are other disadvantages too. Amateur recordings that appear on YouTube (or the Internet Archive for that matter) are frequently uploaded minus background information or sometimes 
even a title offering the smallest clue as to a film's content. Navigation of such material can be haphazard indeed. In what Giovanna Fossati describes as the 'oceanic flow of the online archive' seemingly everything is accessible (everything, that is, of little monetary value), just 'as long as one can find it' (2009b, 459-60). It may be available many times over in fact as 'Golden Gates', a collage of home movie footage posted to the Web, eloquently demonstrates. Assembled by mash-up artists Wreck and Salvage, the video utilises a split-screen effect to depict simultaneously 36 different but equivalent recordings of travelling across the San Francisco bridge. In under three minutes, the spatial montage highlights the repetitive and ubiquitous nature of amateur recordings, as well as the contemporary trend towards 'showcasing the banal in an unabashed public and collective setting' (Proctor 2012). However, like 'Golden Gates' itself - in eleven years the video has received just 245 and 453 views on YouTube and Vimeo respectively (February 2019) - individual home movies may remain effectively buried in the Internet's avalanche of content competing for our attention.

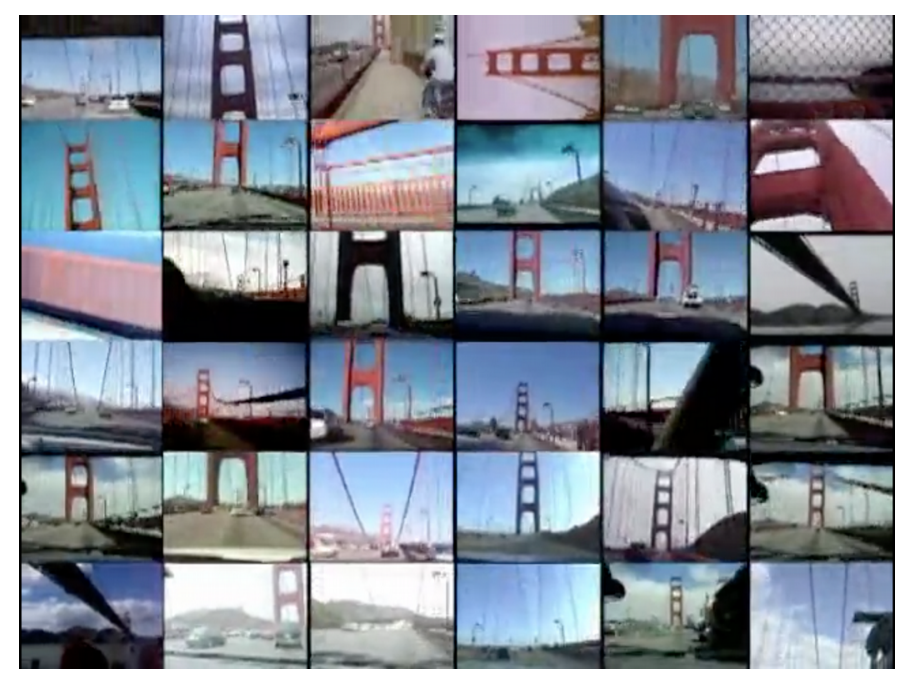

Fig. 5.2. The ubiquity of the banal in amateur recordings as seen in Wreck and Salvage's mash-up, 'Golden Gates'. Screenshot.

Returning to some of the films uploaded to YouTube discussed in chapter 2, the propensity of algorithmic search and retrieval to reveal or conceal content according to a logic indecipherable to the user is underlined. Uploaded on the 19th of March 2007 by 'Jenniesworld' and 'Jerrysworld' respectively, the same recording has received well over 55,000 views under the title 'Vintage Christmas Movie' but a mere 400 as 'Little Christmas 1960's' (February 2019). The only apparent difference between the actual videos is the use of The Nutcracker on one soundtrack and a Nat King Cole recording on the other (although the uploads contain slightly 
different metadata, Cole receiving a credit whilst Tchaikovsky does not). Neither choice of music fits particularly well with the film, failing to enhance the rather dull, faded recording of a family Christmas much like any other. Such shortcomings have not deterred viewers, however, at least in the case of 'Vintage Christmas Movie'.

Orrin Klapp described entertainment media as one of the 'veritable Christmas trees loaded with vicarious placebos' $(1986,146)$ that mitigate the prevalence of boredom in modern societies. The metaphor is uncanny in the case of home movies, Christmas celebrations being one of the most frequently filmed events. However, as noted in chapter 2, perhaps no other home movie subject appears so inanely repetitive as children opening Christmas presents. It is tempting to hypothesize only those at a proverbial loose end would be tempted to watch what seems a ne plus ultra of boredom for amusement (that is, essentially to escape boredom). The Christmas ritual performed by anonymous strangers seems so inherently inclined to bore and yet - if the view counters of YouTube are to be believed - such scenes are watched, in some instances thousands of times. The family Christmas movie, seemingly boring in its very boringness, provides entertainment nonetheless for at least some online viewers. This vicarious participation in other people's celebrations of yesteryear may seem curious on the surface, yet it seemingly speaks to a widely embraced longing to recover the past in visually tangible form.

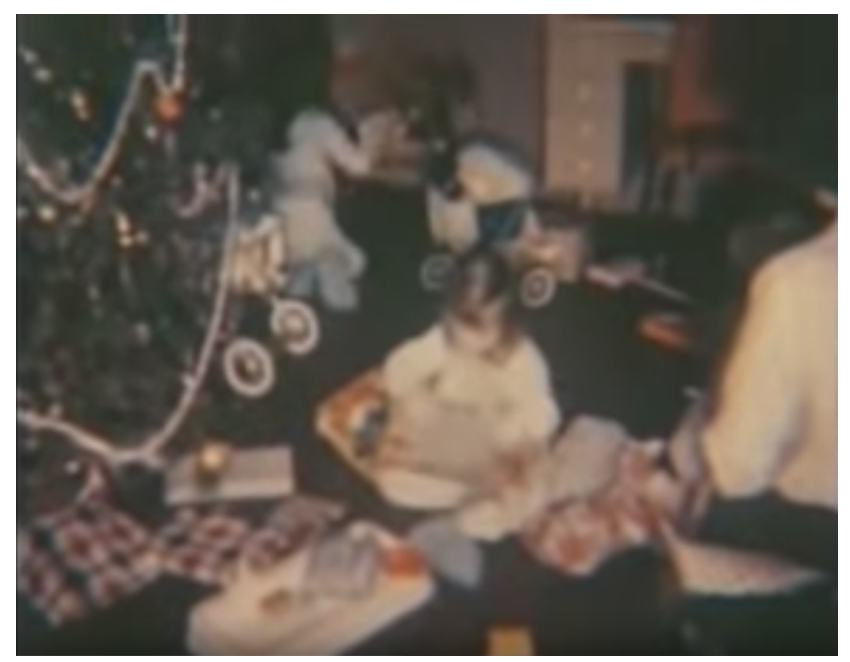

Fig. 5.3. Generic Yuletide scenes in 'Vintage Christmas Movie' seemingly accord with viewer sensibilities in spite of decidedly blurry images. YouTube. Screenshot. 
Scrolling through viewer comments for a 'Vintage Christmas Movie', a prevalent theme is readily discernable. Unperturbed by the mediocre quality of both the original recording and low-resolution YouTube upload with its incongruous soundtrack, viewers, by and large, express favourable sentiments couched in terms of nostalgic yearning for times that were allegedly simpler, happier and more 'magical' than the present:

makes me think of my dear old mum! it would be lovely if $i$ could just have a coffee with her again.

Most of us have fond memories of simpler times when family was young and all together and Christmas was so exciting. It is valuable that some families were wise enough to catch these memories on film that we can identify with and enjoy.

oh my goodness....just to be there again for one moment

I remember these days well. This is when Christmas was Christmas!

Social History captured for all to see. Amazing times. Thankyou for very special memories.

It was all so warm glowing and loving and friendly back then..fun happy a lot of food family friends thanks so much for reminding us how magical Christmas was in this era when children actually appreciated all they got whether it was a sack of marbles or even just this one in a year meal which meant love!!

Take me back 50 to 60 years and let me live in happier times.

i want to go back to this time so bad........

Whoever disliked this video has no soul (selected user comments, 11 February 2019)

The success, if you will, of such a mundane movie must be attributed, at least in part, to its context of presentation. The 55,000 views 'Vintage Christmas Movie' has received dwarfs that of 'Home Movie 97177' on the Internet Archive, despite the recordings displaying comparable (lack of) merit. In their introduction to The YouTube Reader, Snickars and Vonderau suggest that '[e]very initiative a film archive might launch on the Web will be measured against YouTube's ease of access' $(2009,14)$. It is little wonder some official archives choose to sacrifice a certain amount of control over their materials in favour of the popular platform's prodigious capacity 
for online exposure. ${ }^{79}$ By going where viewers are already browsing, archives avoid creating silos of content elsewhere on the web. It is, however, relatively easy to copy, re-edit and repost footage from popular sites (à la Wreck and Salvage). Moreover, short of blocking them altogether, user comments may be difficult and time-consuming for an archive to moderate on an external platform. For better or worse, to participate in Web 2.0 video sharing is almost unavoidably to participate in an archive not only of detritus but also one of ever expanding noise.

\section{If I could take a train back in time...}

In effect, YouTube and other video-sharing platforms have become not just archives of moving images, but archives of popular sentiment about them. Such remarks, often as clumsily prosaic and repetitious as the films themselves, form a vernacular discourse of opinion about home movies, part of their unfolding history of reception in the age of the Internet. Klapp argued noise and banality have 'a natural tendency to increase', especially during periods of rapid change, as 'they are easier to make than meaningful signals' (129). The repetitive quality of both home movies and comments about them on YouTube could be interpreted, however, in terms of the 'good redundancy' Klapp associated with familiar customs, rituals or memories upon which a sense of culture and identity is based. If the Christmas example above is anything to go by, viewers find resonance in home movies by watching them with a nostalgic eye, transforming generic images of strangers into something personally affecting. Images of pre-mechanised farming seen in the 'The Good Old Days' (also discussed in chapter 2) seemingly inspire equivalent revery amongst viewers apparently convinced rural America of the 1940s represented a more wholesome time and place:

\footnotetext{
I really enjoyed watching this. It made me very sad to know that we people today will never experience this way of life. All the simple moments are gone and lost forever, most of us never had the opportunity to live it.
}

This was a wonderful walk down memory lane ... people were hard working, perhaps poorer but certainly stronger in their faith and core values... something that is lacking today.

79 According to web traffic analysis company Alexa Internet, YouTube is the second-most popular site in the world. The Internet Archive is ranked 247 (https://www.alexa.com/siteinfo/archive.org, updated 9 February 2019). Gerty Anschel's home movies in the National Film and Sound Archive of Australia discussed in chapter 4 are an example of an official archive's use of YouTube as a screening platform. 
I look at those healthy, fit folks in this film having a big ol' family dinner outside, eating all the [sic] want without a worry, because in a couple of hours, when its [sic] time for chores, they'll be out there working it off.

those were the good ole days-no tv, computer nor cell phone to take away family time. and they ate real food!

A great representation of Americana!

Incredible lives they have there. America was so positive and less corrupt.

If I could take a train back in time I would jump right on and have it take me back to the 40's! I think I was born in the wrong generation! (selected user comments, 12 February 2019)

Adam Capitanio suggests that '[b]ecause home movies present us with images of the past, and the "stuff" of nostalgia is similar to the content of many home movies, it is unsurprising that they take on nostalgic qualities' (2012, 22-3). Images of family togetherness may awaken personal memories for viewers, whilst those of rural labour link to the archetypal image of heroic pioneers breaking in the land prevalent in former settler societies such as the United States or New Zealand. Interestingly, even the relatively unsentimental representation of agricultural work seen in 'Progress in Farm Technology' garners similar remarks from viewers:

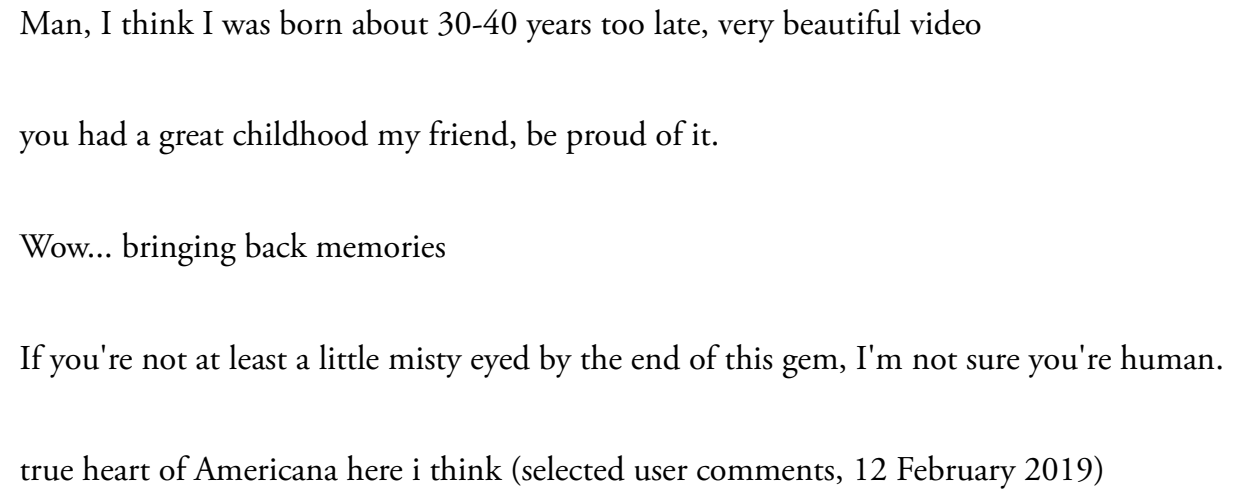

Uploads such as 'Vintage Christmas Movie', 'The Good Old Days' and 'Progress in Farm Technology' are placebos in more than just an entertainment sense. They offer a reassuring image that affords viewers the security of retreating (albeit temporarily) into a past characterised by social cohesion and symbols of a pioneer heritage. Watching old home movies on YouTube therefore functions as part of a larger cultural pattern of recovering meaning from the past by turning history into personal or collective mythology (Boym 2007, 8). Nostalgia enables viewers 
to form an affective connection with home movie images that might otherwise seem boring. Boringness may even be an assert in this respect, increasing the likelihood the minds of viewers will wander beyond the content of a film itself, recalling private memories or projecting values and beliefs not contained in the images themselves ('children actually appreciated all they got', 'certainly stronger in their faith and core values', 'America was so positive and less corrupt'). Nostalgia becomes 'a way to transform the past by imagination' (Niemeyer 2014, 10) and in this sense is more about the needs of the present moment than an actual past as it transpired. In chapter 4 it was noted that home movie footage may stir a 'false nostalgia' for a past we have not lived or one that never existed. The desire to 'take a train back in time' exemplifies this notion. Although such yearnings can appear relatively benign on the surface, popular belief in a romantic, idealised past can obscure darker aspects of history.

This is perhaps most evident within footage that has been recut by YouTubers. Certainly not all recyclings are as shrewdly playful as Wreck and Salvage's work. The Internet is just as capable of throwing up disturbingly acritical mash-ups of home movie footage as thought-provoking ones. Frances Guerin draws attention to the recycling of Eva Braun's home movies into 'tribute videos' celebrating her as a tragic historical figure. As Adolf Hitler's lover, Braun is perhaps understandably the subject of public curiosity. As discussed in chapter 3, her home movies are not inherently different to those recorded by more ordinary people. Without contextualisation, they paint an alarmingly attractive picture of life amongst the Nazi elite. Re-edited into montages accompanied by arguably inappropriate soundtracks, Braun's films are transformed into sentimental and melodramatic music videos. 'The Life and Death of Eva Braun' by YouTube uploader 'Mishima1970', for example, intercuts glamorous studio portraits and other stills of Braun with home movie footage illustrating her athleticism and apparently lively charm, the ten-minute sequence overlaid with a haunting music track by Enya seemingly intended to heighten the sense of drama and tragedy of Braun's existence. Guerin describes such recyclings of Braun's films as 'a form of amnesia' $(2011,285)$. Not confronted with the wider historical context of her home movies, viewers can receive these aestheticisations simply as confirmation of Eva's loveliness. ${ }^{80}$ Devoid of historical discourse, YouTube mash-ups of her films become a pretext for unreflective and often racist comments, sometimes directed at those allegedly responsible for her tainted public image.

80 As of February 2019, the video has had over 296,000 views and 950 'likes' (compared with a mere 78 'dislikes'). 


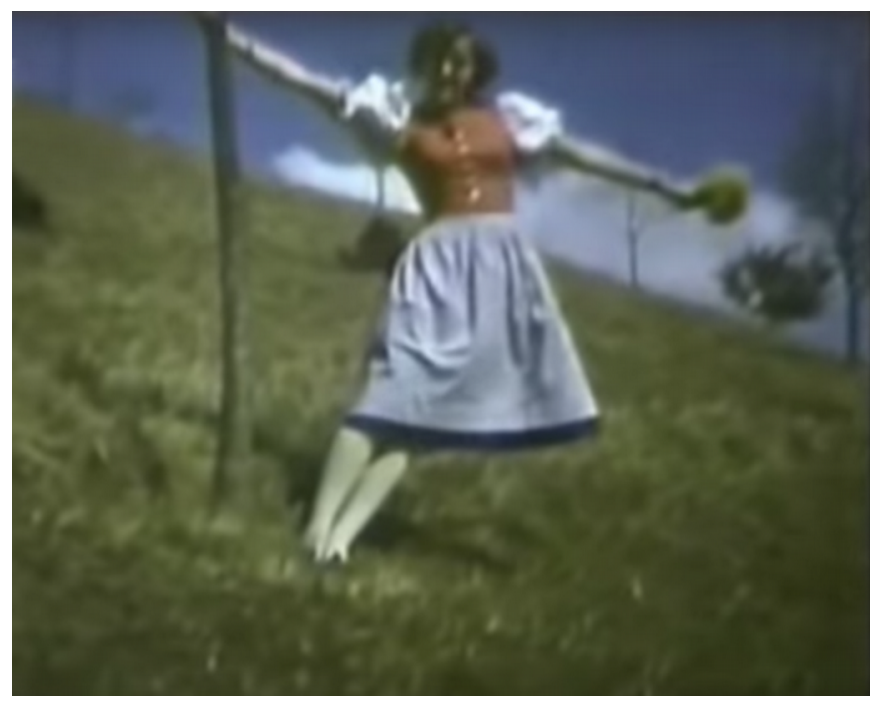

Fig. 5.4. Braun becomes an attractive heroine leading an idyllic lifestyle amongst the Nazi elite in popular YouTube mash-up, 'The Life and Death of Eva Braun'. Screenshot.

Viewers are also prompted by images of a rural past or Christmas of a bygone era to identify who or what is supposedly to blame for a perceived loss of American values. Corporations such as Monsanto, bureaucracy, bankers, technology, Chinese imports and the collapse of national industries, junk food, narcotics, genetic modification, lack of manual labour, illegal immigrants, poor schooling, left-wing politics, 'liberal egghead ideas', materialism, narcissism and greed are all suspect forces in the demise of the good old days (user comments for 'Vintage Christmas Movie' and 'The Good Old Days'). This venting of personal opinion as to why 'the land of promise' became 'the land of disillusion' recalls Thomas Osborne's observation in reference to Foucault's The Lives of Infamous Men that 'the testimony of writing is even in a perverse way a kind of ironic compensation for being a victim of power' (1999, 61). There are also acts of resistance, some comments offering a critique of Braun's ignorance of Nazi atrocities or the golden image of the past. References to white privilege, historical racism, material shortages ('specially of underpants! I don't miss that'), infant and maternal mortality rates, polio epidemics, financial hardship, or even simply that only the wealthy could afford movie cameras ('must have been selling moonshine!') disrupt the otherwise relatively homogenous discourse of nostalgic longing with voices of dissent. 


\title{
Curation by code and the mind-wandering cyber-flâneur
}

\begin{abstract}
if we look at the type of the flaneur and the type of the web surfer, they actually seem to express similar predispositions and strategies. Benjamin's flâneur would surely be interested in logging on to flickr or YouTube to gain an insight in the everyday lives of random people - to look at what is on their lunch plates - since he is an "observer" who feels an "intoxication of empathy" (Lindgren 2007, 8).
\end{abstract}

Studying the Internet career of home movies is no simple task. Personal motivations for watching or contributing specific content are frequently not explicit. (What compelled Spuzz, for example, to sit through 28 minutes of indistinct footage of strangers mostly eating cake and then write about it?) Most viewers leave no outwardly visible trace as an individual, merely raising a video's view count by one. Although many videos do attract a sizable number of 'likes' or comments, particularly on YouTube, these may nevertheless equate to only a tiny percentage of the total number of views an item has received. ${ }^{81}$ Moreover, the algorithms that influence and monitor user behaviour are obscured, our viewing regulated or 'curated' by unseen code. ${ }^{82}$ Given such constraints, it is perhaps none too surprising that examinations of the online afterlife of analogue home movies have been relatively few. Discussions of the circulation of amateur moving images, such as those of Michael Stangelove (2010) and Lauren Berliner (2014), tend to focus on video produced since the Internet's inception rather than films that were made long before the possibility of online distribution could be foreseen. Video-sharing sites have drastically altered the relationship between the production of amateur images and their anticipated audiences. Home movie or video is arguably no longer an appropriate designation for recordings intended to be broadcast not only to friends and relatives but also to complete strangers via the Internet. This stands in stark contrast to the intimate embrace of the family screening ritual of former times. Even if home moviemakers or participants foresaw that their recordings might have some possible future archival value, they could scarcely have envisaged the sheer scale of public viewership the World Wide Web has made possible. The Internet engenders new forms of intimacy, however.

81 'The Good Old Days', for example, has attracted 200,223 views, 633 likes (plus 28 dislikes) and 214 comments (approximately $0.1 \%$ of total views) (12 February 2019).

82 A non-profit organisation, the Internet Archive indicates the only user statistics it records are the number of views an item receives (Frequently Asked Questions) and that its recommendations for 'similar items' are based on metadata (one unidentified home movie reviewed by Spuzz leads to another and so forth). The operators of commercial websites are typically less transparent about exactly what information they collect and how this affects our online experiences, or any other use of data about our online habits, thereby disguising the extent of web surveillance by corporate entities. 


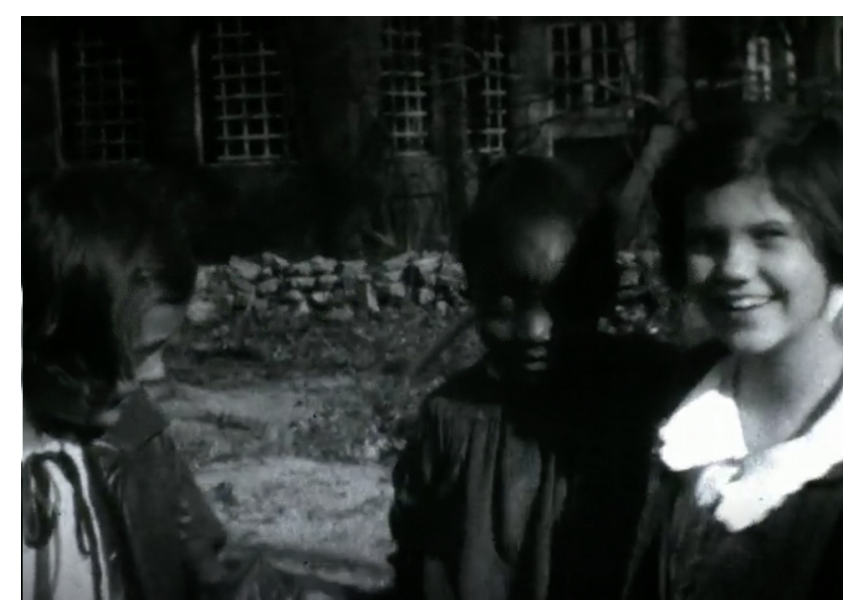

Fig. 5.5. 'All of them get along quite nicely, which is really nice', according to Spuzz. 'Home Movie 98543: January 1929'. Internet Archive. Screenshot.

As Simon Lindgren suggests above, the most mundane, trivial details of private life made public can induce an 'intoxication of empathy' in the observer. The delayed public exposure of home movies may even accentuate this effect. Svetlana Boym notes that given 'the universality of its longing', modern nostalgia 'can make us more empathetic towards fellow humans' $(2007,9)$. It is not only obviously nostalgic home movie subjects such as rural life or Christmas that prompt expressions of empathy from viewers, however. Spuzz likes a 1929 recording of white and African-American children playing together ('Home Movie 98543') in the hope that the apparent interracial harmony of the scene was genuine, for example.

The greatest sympathy, however, is perhaps reserved not for humans but for beasts of burden. Spuzz notes the 'SPCA would have a field day' viewing a 23-second recording of a dog struggling to pull a cart, whilst another reviewer suggests '[p]erhaps the dogs should have been in the cart and the humans pulling them' ('Amateur film: Dog Cart'). Moreover, a thread of historical consciousness seems to weave its way through such comments. Spuzz describes the use of a horse to power an elevator the 'hardest scene to watch' in a 1919 amateur film of harvesting ice ('Amateur film: Ice Harvest, Pocono Manor'), whilst the dog cart according to another viewer provides 'similar enjoyment as comes from viewing a Norman Rockwell painting'. A viewer of 'The Good Old Days', presumably envisaging the tiresome heat and heavy burden of the load of hay, playfully suggests 'you can see the one horse say to the other "This is b__sh_."' Even if, as suggested in chapter 3, we cannot humanly know what an animal 
actually feels or suffers, viewers certainly attempt to fill in the 'irreducible hiddenness' of home movies via imagination.
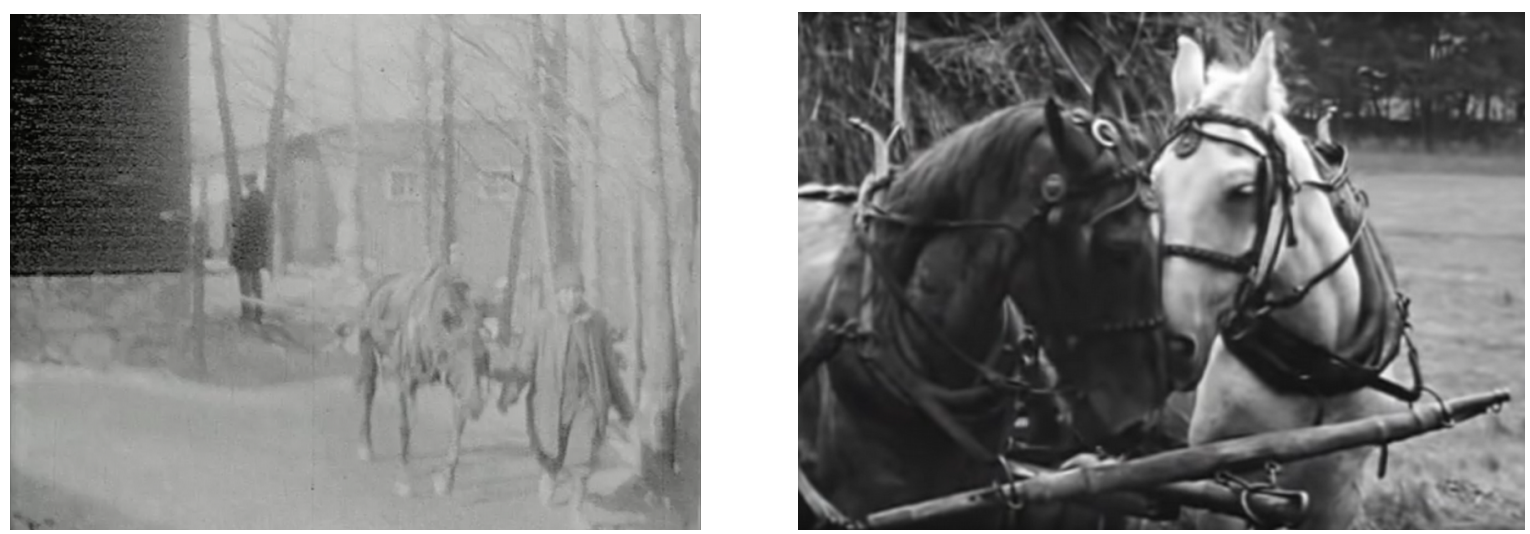

Fig. 5.6 \& 7 . Freezing winter and hot summer work: horses arouse the sympathy of contemporary viewers in 'Amateur film: Ice Harvest, Pocono Manor, 1919' and 'Home Movie of The Good Old Days America 1940's'. Internet Archive and YouTube. Screenshots.

The minds of viewers also run in other directions in the absence of background information. A rather nondescript 1930s recording titled 'Bohemian Grove' depicting middle-aged men lining up for an outdoor meal, for example, becomes grist for viewers to imagine sinister activities that supposedly transpire when 'mega-powerful men' gather at the exclusive Californian gentlemen's club (planning world domination or a police state, naked rituals, satanic worship around a bonfire...). 'Unfortunately,' as one viewer notes, it is 'not even a satanic buffet' that is actually seen in the film in question. Such fantasies nevertheless spice up a rather dull scene with an enticingly conspiratorial sense of mystery.

How does the web surfer or cyber-flâneur happen upon such obscure amateur recordings? Quite likely in a somewhat incidental manner. Query-based searches have a propensity to return what one (thinks one) is looking for. (A Google search for videos of 'Bohemian Grove' offers numerous uploads with titles promising the revelation of 'dark secrets' and conspiracies.) Moreover, users are directed to the most popular or relevant - according to an algorithm search results. This kind of 'efficiency' potentially works against what may constitute one of the chief pleasures of flânerie: to find what one is not looking for. With this in mind, Rick Prelinger describes serendipity and surprise as 'endangered species' within contemporary database culture (Jose 2013). Video content itself is not actually computer-readable, however, leaving sites such as YouTube or the Internet Archive dependent upon 'crowd-sourced' metadata (willingly or 
unwittingly) contributed by users. Searching for a home movie featuring a particular subject is therefore a rather haphazard exercise, should all relevant uploads be accompanied by insufficient or inaccurate descriptions. The more eclectic, eccentric or obscure can in fact be difficult to find through concerted effort. Compared with looking for something specific buried in poorly annotated uploads, it is easy to wander from one film to another that an algorithm has offered us. By selecting whatever title or thumbnail happens to appeal from an algorithmically determined list of possibilities, the cyber-wanderer relies upon curation by code as much human volition, but may chance upon pleasing surprises amidst the unwanted refuse.

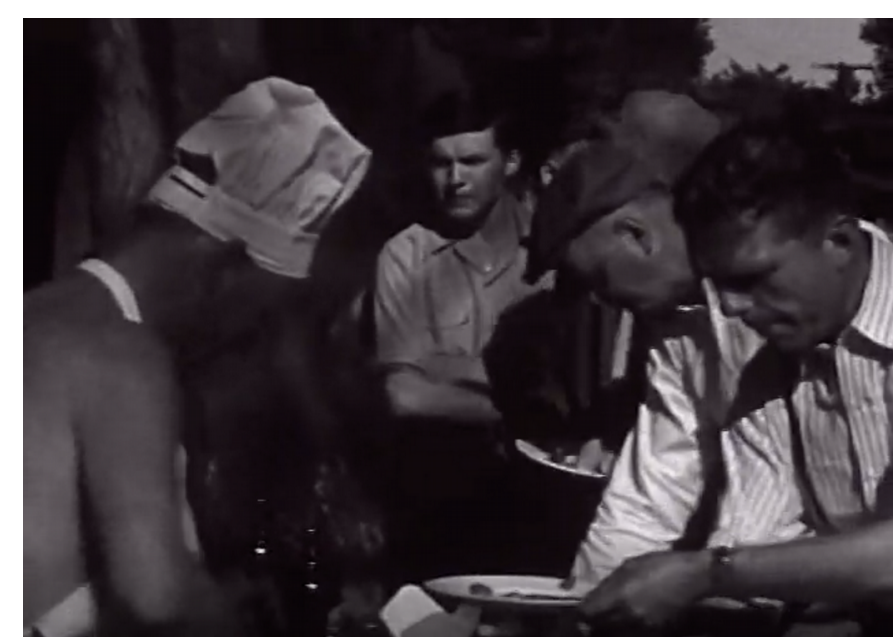

Fig. 5.8. 'So What? Nothing at all interesting or informative. Just a clip showing a group of men being served food outdoors in the 1930s' (according to one viewer)... or prelude to more sinister goings on...? 'Amateur film: Bohemian Grove'. Internet Archive. Screenshot.

Perhaps at first glance boredom seems in many ways personified by noisy online archives overflowing with commonplace detritus in disarray. Yet an archive of noise clearly has a happy side. Meaninglessness offers scope for the imagination. Drawing upon reception theory, Nanna Verhoeff suggests viewers feel a deep-seated need to construct narratives as a means of addressing the fragmentation that characterises twenty-first century existence. What she describes as an archival poetics, a 'code for readability', transforms fragmented cultural detritus into interests, anxieties, desires and novelties $(2006,26)$. From the film fragment in particular, 'even if there is no clear fabula that structures an internal logic, a sense of narrative emerges and captures you' (31). Perhaps this is the chief appeal of home movies in cyberspace. In the absence 
of provenance, useful metadata, biographical associations or curatorial frameworks (at least of the human kind), they become objects of speculation, junctures where the rituals and foibles of past lives meet contemporary eyes, intimating a plethora of meandering, spectral alleys and backroads through which our minds may freely roam.

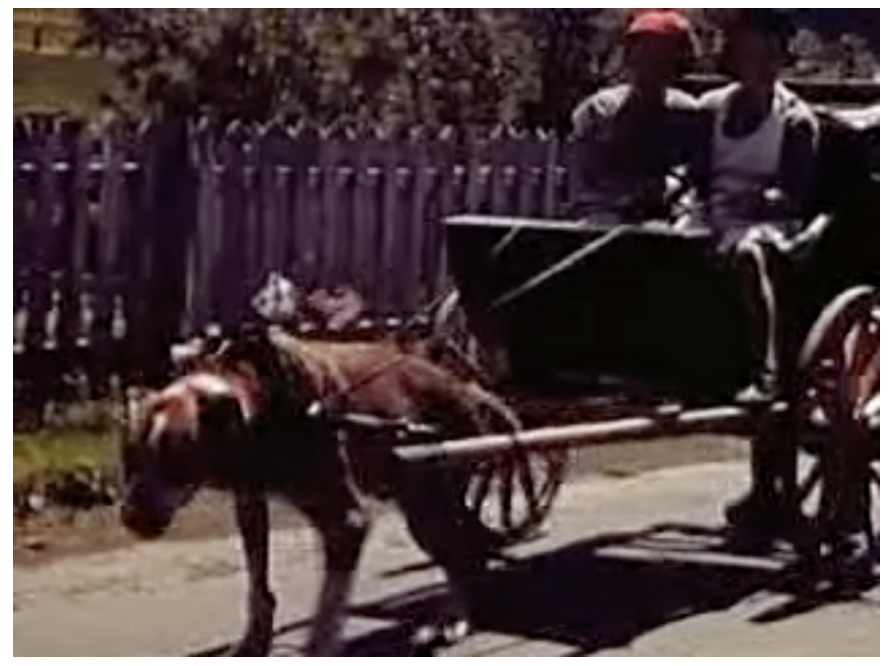

Fig. 5.9. 'Could be interesting with some theorizing. The film itself is not much, but imagining the surroundings, people watching from off camera, what happened before and after the shoot will make it interesting [...] Take a look'. Viewer comment, 'Amateur film: Dog Cart'. Internet Archive. Screenshot.

\section{Ideal archive of the perfectly boring, or watch on your smartphones and laptop screens as we sink...?}

The algorithms of computer software decide how one can use the digital archive, but are themselves inaccessible to the user. The organizational principle structuring what is accessible and stored is itself irretrievable. The epistemological and political consequences resulting from the digital configurations of analogue materials make the archive a privileged place for addressing the selections making up the past today (Lundemo 2014, 19).

Strictly speaking, YouTube is not an archive at all in the sense of a repository with a preservation mandate. Anything can disappear at any moment. Yet it 'might as well be an archive' given that 'in the public mind it is not simply an archive', so Prelinger argues, 'but an ideal form of archive' (2009b, 268). Certainly, it has remained one of the most popular sites on the Web for the past decade and this in itself arguably makes it a valuable source of information about online video watching (Thelwall 2018, 304). By comparison, an ostensibly similar platform (from a video-viewing perspective) such as the Internet Archive (or even Vimeo) has a much smaller audience. In the case of ephemeral films, the Internet Archive does nonetheless appear to attract its own fan culture distinct from anything readily discernible on YouTube (Spuzz, for 
example, turns out to be a prolific reviewer of home movies), perhaps fostered by the appeal of largely public domain material freely available for download and reuse, along with a refreshing absence of commercialism.

Digitisation, participatory video sharing and a philosophical shift towards opening up archives to a broader range of users have contributed to an unprecedented circulation of historical moving images in our daily lives. The Internet has also generated much greater presence of the personal in public forums, including materials that were originally intended only for private use. The public distribution of home movies (or, more precisely, their digital surrogates) are part of this trend. Access is merely a starting point for appreciating the visual records of private histories, however. Disparate fragments must still coalesce somehow to stir our thoughts and feelings.

According to Benjamin, 'history decays into images, not into stories' (1999, 476), an observation that seems particularly apt when home movies leave their own home and enter someone else's. Perhaps this is one factor contributing to the persistence of more traditional forms of film exhibition in the twenty-first century, despite the convenience of online video sharing. Curators and filmmakers imbue historical images with meaning through the kind of contextualisation and analytical perspectives that are frequently lacking on platforms such as YouTube or the Internet Archive. Terrestrial screenings of home movies are largely ephemeral affairs, however, for the most part leaving little trace of how audiences responded to what they saw. Even the official online ventures of formal archives usually indicate little about how the public may have interacted with them.

More than a decade ago Henry Jenkins lamented a platform such as YouTube could be a forum for meaningful exchange rather than its persistent scattered assembly of commentary, which is 'superficial at best and filled with hate speech at worst' (2008). Despite its shortcomings, YouTube does nonetheless function as a record of popular sentiment about (or simply inspired by) moving images, however fragmented and incoherent it may be. Referring to Benjamin's fascination with bric-à-brac and cultural marginalia, Joe Moran suggests 'the value of the boring is that it does not try to conceal death or ruination', nor does it obscure everyday banalities through the 'coherence of narrative' $(2003,175)$. Perhaps haphazardly arranged and policed cultural dumping grounds such as YouTube (or even their archived remains courtesy of the 
Wayback Machine) may similarly prove to be an insightful window upon popular perceptions and mentalities in the early twenty-first century at some future moment.

Perusing comments attached to online videos it can of course be difficult to decipher what viewers really think and feel about home movies. For better or worse, in cyberspace the majority of viewers choose not to comment, whilst the remarks of those that do seldom offer more than a sketchy indication of the writer's thoughts. Expressions of nostalgic longing for a past supposedly untroubled by present sources of disillusionment represent the most conspicuous response. The irony of those 'nostalgising' with the aid of contemporary technologies is not lost on a viewer of 'The Good Old Days' who issues an acerbic warning to 'watch on your smartphones and laptop screens everyone as we sink'. Yet this remark does not oppose nostalgia itself, nor propose any alternative vision. A viewer who suggests the ice harvest recording should be 'required viewing for those of us who fly off the handle whenever the most expected conveniences are not met' hints at a more reflective stance in relation to historical development and the laborious aspects of everyday life before the inception of modern technologies. The potential of prosaic personal recordings adrift in cyberspace to encourage a kind of ruminative mind wandering amongst viewers might be seen as a means to transform the perfectly boring home movie into the perfectly boring home movie. In this sense, home movies seem to embody in a small way the hopes of Benjamin, Heidegger or Kracauer that boredom could lead us towards reflection upon the nature of our lives, or our place within the continuum of history.

Presenting amateur images to a public audience is a serious business, one that should be examined with a critical eye. The screening of personal footage in public has the capacity to diversify historical perspectives, arouse critical reflection amongst viewers and connect communities with their own past. As a thought-provoking and democratic history, home movies can be appealing visual records, but this is not their only point of ideological significance in the public sphere. Roger Odin's concluding remarks in his contribution to the now seminal anthology on amateur film, Mining the Home Movie (2008), are no less relevant today than a decade ago. He asks what lies behind the contemporary fascination with amateur film, noting that relations 'between democracy and amateur documents are neither always simple nor always positive'. He suggests one of the effects of home movie usage can be to conceal sources of 
conflict through affect, replacing the possibility of meaningful communication with the catharsis of communion (266-7). This echoes Svetlana Boym's warning that nostalgia may tempt us 'to relinquish critical thinking for emotional bonding'. The idealised past of home movie images can seem to hold out the attractive promise of a 'guilt-free homecoming' unburdened by the complexities of history $(2007,9-10)$.

This is perhaps most clearly evident on the Internet, a space in which the presence of historical amateur images is likely to grow through public and private efforts to digitise and upload surviving records of the past. Sentimental, ahistorical mash-ups, such as 'The Life and Death of Eva Braun', are one legacy of amateur footage in the digital era, something Guerin suggests 'can be held up as evidence of why we need to take archival images seriously' (286). There are also more hidden but no less disquieting aspects to our travels in cyberspace. What William Uricchio has dubbed the 'algorithmic turn' (2011) may enable data-miners to predict our broader tastes, lifestyle choices and political affiliations on the basis of cultural consumption (Morris 2015, 455, 459-60). (What might home movie watching in particular indicate about viewers according to an algorithm?) The social and political implications of 'curation by code' are potentially far-reaching, albeit often difficult to trace directly (448).

In the twenty-first century some of the most watched amateur images exist in some of the least supervised spaces in terms of curatorial expertise and historical knowledge, algorithms effectively determining what is seen and by whom. This can be a happy bonus for the pleasures of mind wandering whereby viewers find their own beauty and value in home movies in the absence of background information. But there is also a darker side to the separation of films from their historical contexts of production. The beguiling authenticity of amateur footage the 'home movie effect' - can discourage critical contemplation amongst viewers. Boym cautions that 'unreflective nostalgia can breed monsters' determined to restore a certain vision of the past regardless of the consequences (10). What responsibility do those screening, reusing, uploading, watching or commenting upon home movies in public have to ensure they are not simply lending support to a mythologising of the past, Kodachrome-tinted 'evidence' offering visual confirmation that yesteryear was more radiant than the present day? The quest to find something of interest in home movies that could easily be perceived boring may have unforeseen and unintended repercussions for collective memory that are sobering indeed. 


\section{Bibliography}

\section{Museum and archival collections consulted in person}

Deutsche Kinemathek, Berlin

EYE Filmmuseum, Amsterdam

Huis van Alijn, Ghent

Jewish Museum Berlin

National Library of Scotland Moving Image Archive (SMIA), Glasgow

Ngā Taonga Sound and Vision (NTSV), Wellington

Yorkshire Film Archive (YFA), York

\section{Additional collections consulted online}

London Screen Archives

National Film and Sound Archive of Australia (NFSA)

Prelinger Archives, Internet Archive (PAIA)

Texas Archive of the Moving Image (TAMI)

\section{Written sources}

Amad, Paula. 2010. Counter-Archive: Film, the Everyday, and Albert Kahn's Archives de la Planète. NY: Columbia UP.

Andersen, Jesper. 2009. 'Showing a Film is Not Enough.' Journal of Film Preservation 81, 5-24.

Anderson, Steve F. 2011. Technologies of History: Visual Media and the Eccentricity of the Past. Hanover: Dartmouth College Press.

Anderst, Leah. 2013. '"I've spent a lot of time looking at these images": The "Viewing 'I'" in Contemporary Autobiographical Documentary.' a/b: Auto/Biographical Studies 28:2, $212-$ 241.

Andreano, Kevin. 2007. 'The Missing Link: Content Indexing, User-Created Metadata, and Improving Scholarly Access to Moving Image Archives.' The Moving Image 7:2, 82-99. ANZAC sightsound.org. n.d. 'About - Sights and Sounds of World War I'. Accessed 22 March 2018. http://anzacsightsound.org/about 
— n.d. 'Tea for two, and an unknown soldier'. Accessed 10 January 2019.

http://anzacsightsound.org/videos/personal-record-hayward-r

Baetens, Jan and Jan Van Looy. 2007. 'Digitising Cultural Heritage: The Role of Interpretation in Cultural Preservation.' Image and Narrative 17.

Baines, Iola and Gwenan Owen. 1996. 'The Massive Mess of Mass Memory.' Journal of Film Preservation 52, 7-14.

Balint, Ruth. 2014. 'Representing the Past and Meaning of Home in Péter Forgács's Private Hungary.' Amateur Filmmaking: the Home Movie, the Archive, the Web, edited by Laura Rascaroli and Gwenda Young, 193-206. London: Bloomsbury.

Baron, Jaimie. 2014. The Archive Effect: Found Footage and the Audiovisual Experience of History. London: Routledge.

Bateman, Nadine. 2009. Interview with Michael Rogge. South China Morning Post. Posted March 15. http://www.scmp.com/article/673373/michael-rogge

Baylis, Gail. 2014. 'A Few Too Many Photographs? Indexing Digital Histories.' History of Photography 38:1, 3-20.

Becker, Snowden. 2001. 'Family in a Can: The Presentation and Preservation of Home Movies in Museums.' The Moving Image 1:2, 88-106.

- 2013. '2012 Archival Education and Research Institute: July 9-13, 2012, Los Angeles.' The Moving Image 13:1, 245-247.

Benjamin, Andrew. 2005. 'Boredom and Distraction: The Moods of Modernity.' Walter Benjamin and History, edited by Andrew Benjamin, 156-170. London and NY: Continuum.

Benjamin, Walter. 1999. The Arcades Project. Translated by Howard Eiland and Kevin McLaughlin. Cambridge, MA: Belknap Press of Harvard UP.

— 2007. 'The Storyteller.' Illuminations, edited by Hannah Arendt and translated by Harry Zohn, 83-110. London: Fontana.

— 2008. 'The Work of Art in the Age of Its Technological Reproducibility.' The Work of Art in the Age of Its Technological Reproducibility, and Other Writings on Media, edited by Michael Jennings, Brigid Doherty and Thomas Levin, 19-55. Cambridge, MA: Belknap Press of Harvard UP. 
Berliner, Lauren. 'Shooting for Profit: The Monetary Logic of the YouTube Home Movie.'

Amateur Filmmaking: the Home Movie, the Archive, the Web, edited by Laura Rascaroli and Gwenda Young, 289-300. London: Bloomsbury.

Blanchot, Maurice. 1987. 'Everyday Speech.' Translated by S. Hanson. Everyday Life Special Issue. Yale French Studies 73, 12-20.

Blondfield, Mel. 2018. 'Let's Fire Up the Barbie.' NFSA. Posted 21 December. https:/www.nfsa.gov.au/latest/celebrating-aussie-summer-bbq

Bolter, Jay David, Blair MacIntyre, Maribeth Gandy and Petra Schweitzer. 2006. 'New Media and the Permanent Crisis of Aura.' Convergence 12:1, 21-39.

Bosma, Peter. 2015. Film Programming: Curating for Cinemas, Festivals, Archives. NY: Columbia UP.

Boss, Matthew. 2009. 'Metaphysics and the Mood of Deep Boredom: Heidegger's

Phenomenology of Mood.' Critical Studies 31, 85-107.

Boyle, Deirdre. 2001. 'Meanwhile Somewhere: A conversation with Péter Forgács.' Millennium Film Journal 37. http://www.mfi-online.org/journalPages/MFJ37/DeirdreBoyle.htm

Boym, Svetlana. 2001. The Future of Nostalgia. NY: Basic Books.

— 2007. 'Nostalgia and Its Discontents.' The Hedgehog Review Summer 07, 7-18.

Bracha, Rachel. 2013. 'Artists and the film archive: re-creation-or archival replay.' Archival Science 13, 133-141.

Çağlayan, Emre. 2016. 'The Aesthetics of Boredom: Slow Cinema and the Virtues of the Long Take in Once Upon a Time in Anatolia.' Projections 10:1, 63-85.

Camper, Fred. 1986. 'Some Notes on the Home Movie.' Journal of Film and Video 38:3-4, 914.

Capitanio, Adam. 2012. The Electrical Transformation of the Public Sphere: Home Video, the Family, and the Limits of Privacy in the Digital Age. PhD thesis, Michigan State University. Carroll, Nathan. 2006. 'Mitchell and Kenyon, Archival Contingency, and the Cultural Production of Historical License.' The Moving Image 6:2, 52-73.

Center for Home Movies. 2011. 'Amateur Night: Home Movies From American Archives.' Electronic Press Kit.

Chalfen, Richard. 1975. 'Introduction to the Study of Non-Professional Photography as Visual Communication.' Folklore Forum 13, 19-25. 
- 1980. Review of Home Movie: An American Folk Art by Ernst Star and Steven Zeitlin. The Journal of American Folklore 93:368, 245-246.

- 1987. Snapshot Versions of Life. Bowling Green: Bowling Green State UP.

Cherchi Usai, Paolo, David Francis, Alexander Horwath and Michael Loebenstein. 2008. Film

Curatorship: Archives, Museums, and the Digital Marketplace. Vienna: Synema.

Chin, Chih-Yu, Hsi-Peng Lu and Chao-Ming Wu. 2015. 'Facebook Users' Motivation for

Clicking the "Like" Button.' Social Behavior and Personality 43:4, 579-592.

Chitty, Andrew. 2011. 'London Re-cut: Reclaiming History through the Co-curated Remixing of Film.' Curator: The Museum Journal 54:4, 413-418.

Citron, Michelle. 1986. 'Concerning Daughter Rite.' Journal of Film and Video 38:3/4, 93-94.

- 1999. Home Movies and Other Necessary Fictions. Minneapolis: Minnesota UP.

Compton, Margaret A. 2010. 'Collecting Georgia's Hometown Movies: Acquisition,

Ownership, Preservation, and Access.' The Moving Image 10:1, 89-101.

Cook, Sophie, Beatriz Bartolomé Herrera and Papagena Robbins. 2015. 'Interview with Rick Prelinger.' Synoptique 4:1, 165-191.

Corrigan, Timothy and Patricia White. 2015. The Film Experience: An Introduction. 4th edition. Boston: Bedford/St. Martins.

Crary, Jonathan. 1999. Suspensions of Perception: Attention, Spectacle, and Modern Culture.

Cambridge, MA: MIT Press.

Cuevas, Efrén. 2013. 'Home movies as personal archives in autobiographical documentaries.'

Studies in Documentary Film 7:1, 17-29.

— and Carlos Muguiro. 2002. 'The Reasons of a Personal Cinema.' The Man Without a Movie

Camera: The Cinema of Alan Berliner, edited by Efrén Cuevas and Carlos Muguiro, 119-

142. Madrid: Ediciones Internacionales Universitarias.

Czach, Elizabeth. 2008. Careless Rapture: Artifacts and Archives of the Home Movie. PhD thesis, University of Rochester, NY.

Deans, Zev. 2017. 'Singing a Song of Swastikas.' Interview with Philippe Mora. OZY. Posted 3 March. http://www.ozy.com/good-sht/singing-a-song-of-swastikas/76034

Dearman, Andrew. 2015. Artist's notes for Disappearance. CACSA Contemporary 2015 exhibition catalogue. 
de Klerk, Nico. 2008. 'Home Away from Home: Private Films from the Dutch East Indies.' Mining the Home Movie: Excavations in Histories and Memories, edited by Patricia Zimmermann and Karen Ishizuka, 148-162. Berkeley and LA: California UP.

- 2019. Showing and Telling: Film heritage institutions and their performance of public accountability. Delaware: Vernon Press.

Dennis, Jonathan. 1994. 'Restoring History.' Film History 6:1, 116-127.

Derrida, Jacques. 1995. 'Archive Fever: A Freudian Impression.' Diacritics 25:2, 9-63.

Deutsche Kinemathek and Bundeszentrale für politische Bildung. n.d. Moments in Time 1989/1990 Internet Archive.

https://www.wir-waren-so-frei.de/index.php/Splash/Index/lang/en US

Doane, Mary Ann. 2002. The Emergence of Cinematic Time: Modernity, Contingency, The Archive. Cambridge, MA: Harvard UP.

Dollman, Melissa. 2017. 'Opening the Can: Home Movies in the Public Sphere.' Amateur Movie Making: Aesthetics of the Everyday in New England Film, 1915-1960, edited by Martha McNamara and Karan Sheldon, 229-252. Bloomington: Indiana UP.

Druick, Zoë. 2014. 'Sampling Heritage: The NFB's Digital Archive.' Cinephemera: Archives, Ephemeral Cinema and New Screen Histories in Canada, edited by Zoë Druick and Gerda Cammaer, 312-325. Montreal: McGill-Queen's UP.

Eastman Kodak. 1928. Junior Scenarios for Home Movies. Rochester, NY: Eastman Kodak. Eco, Umberto. 1991. The Limits of Interpretation. Bloomington: Indiana UP.

Edmondson, Ray. 2004. Audiovisual Archiving: Philosophy and Principles. Paris: UNESCO. Enticknap, Leo. 2007. 'Have Digital Technologies Reopened the Lindgren/Langlois debate?' Spectator 27:1, 10-20.

Erens, Patricia. 1986. 'Home Movies in Commercial Narrative Film.' Journal of Film and Video 38:3/4, 99-101.

Esquivel, Alicia, and Madeline Moya. 2017. 'Amateur Auteurs' web exhibit. Texas Archive of the Moving Image. https://www.texasarchive.org/amateurauteurs/

Fairfax, Daniel. 2018. Introduction. Cinema and the Museum, Senses of Cinema 86 (March).

— 2018b. 'The Archive of Detritus.' Stardust Memories: Cinephilia and Nostalgia, Senses of Cinema 87 (June).

Films From the Home Front. 2007. Accessed 23 February 2018.

http://www.movinghistory.ac.uk/ 
Folkstreams. n.d. 'Home Movie: An American Folk Art.' http://www.folkstreams.net/film,112 Forgács, Péter. 2008. 'Wittgenstein Tractatus: Personal Reflections on Home Movies.' Mining the Home Movie: Excavations in Histories and Memories, edited by Patricia Zimmermann and Karen Ishizuka, 47-56. Berkeley and LA: California UP.

— and the Labyrinth Project. 2002. The Danube Exodus: The Rippling Currents of the River [Library]. Accessed 23 April 2018. http://www.danube-exodus.hu/

Fossati, Giovanna and Nanna Verhoeff 2007. 'Beyond Distribution: Some Thoughts on the Future of Archival Films.' Networks of Entertainment: Early Film Distribution 1895-1915, edited by Frank Kessler and Nanna Verhoeff, 331-339. New Barnet: John Libbey Publishing.

-2009. From Grain to Pixel: The Archival Life of Film in Transition. Amsterdam: Amsterdam UP.

— 2009b. 'YouTube as a Mirror Maze.' The YouTube Reader, edited by Pelle Snickars and Patrick Vonderau, 458-464. Stockholm: National Library of Sweden.

Foster, Frederic. 1944. 'Make Your Movie Tell a Story.' Home Movies 1:xi, 13 \& 38-40.

Foucault, Michel. 1972. The Archeology of Knowledge. Translated by A.M. Sheridan Smith. NY: Pantheon.

Frick, Caroline. 2011. Saving Cinema: The Politics of Preservation. Oxford: Oxford UP.

— 2013. 'An Interview with Caroline Frick.' The Velvet Light Trap 71, 42-46.

Frieling, Rudolf. 2001. 'Storage and Space: Notes on Collecting, Archiving, and Presenting Digital Moving Image Works.' The Moving Image 1:2, 146-152.

From Scotland with Love: the film. 2014. 'An Analogue Film for a Digital Age.' Film website. Accessed 19 October 2017. http://www.fromscotlandwithlovethefilm.com/the-film/ Fujiwara, Chris. 2007. 'Boredom, Spasmo, and the Italian System.' Sleaze Artists: Cinema at the Margins of Taste, Style, and Politics, edited by Jeffrey Sconce, 240-258. Durham: Duke UP. Gamsby, Patrick. 2012. The Black Sun of Boredom: Henri Lefebvre and the Critique of Everyday Life. PhD Thesis, Laurentian University, Ontario.

Gardiner, Michael E. 2012. 'Henri Lefebvre and the Sociology of Boredom.' Theory, Culture and Society 29:2, 37-62.

Gleason, Marion. 1929. Scenario Writing and Producing for the Amateur. Boston: American Photographic Publishing Co. 
Goodstein, Elizabeth. 2005. Experience Without Qualities: Boredom and Modernity. Palo Alto: Stanford UP.

Graham, Rhys. 2000. 'Human Remains.' Senses of Cinema 10 (Nov). http://sensesofcinema.com/ 2000/cteq/human/\#3

Gregg, Melissa and Gregory Seigworth. 2010. 'An Inventory of Shimmers.' The Affect Theory Reader, edited by Melissa Gregg and Gregory Seigworth. Durham: Duke UP.

Grierson, John. 1979. 'The Course of Realism.' Grierson on Documentary, edited by Forsyth Hardy. London: Faber and Faber.

Groo, Katherine. 2018. 'FilmStruck wasn't that good for movies. Don't mourn its demise.' The Washington Post. Posted 3 December.

https://www.washingtonpost.com/outlook/2018/12/03/filmstrucks-demise-could-begood-movies/

Guerin, Frances. 2011. Through Amateur Eyes: Film and Photography in Nazi Germany. Minneapolis: Minnesota UP.

Heidegger, Martin. 1995. The Fundamental Concepts of Metaphysics: World, Finitude, Solitude. Translated by William McNeill and Nicholas Walker. Bloomington: Indiana UP. Home Movie Registry. n.d. 'Home Movies: Paris, Times Square, China, etc.' Accessed 14 March 2018. http://www.homemovieregistry.org/wp/home-movies-paris-times-square-china-etc/ Houston, Penelope. 1994. Keepers of the Frame. London: BFI.

Howe, Maija. 2014. 'The Photographic Hangover: Reconsidering the Aesthetics of the Postwar 8mm Home Movie.' Amateur Filmmaking: the Home Movie, the Archive, the Web, edited by Laura Rascaroli and Gwenda Young, 39-50. London: Bloomsbury.

Huis van Alijn. 2014. 'Overzichtsfiche filmcollectie Huis van Alijn'. Ghent.

— 2016. 'Homeless Movies' exhibition notes. Ghent.

Ingravalle, Grazia. 2015. 'Remixing early cinema: historical explorations at the EYE Film Institute Netherlands.' The Moving Image 15:2, 82-97.

Internet Archive. n.d. 'About the Internet Archive.' https://archive.org/about/ Jameson, Fredric. 1997. Postmodernism, or, the cultural logic of late capitalism. Durham: Duke UP.

Jenkins, Henry. 2008. 'From YouTube to We'Tube.' Blog entry, February 12. http://henryjenkins.org/blog/2008/02/from youtube to wetube.html Jones, Janna. 2012. The Past is a Moving Picture. Gainesville: Florida UP. 
Kattelle, Alan D. 'The Evolution of Amateur Motion Picture Equipment 1895-1965.' Journal of Film and Video 38:3/4, 47-57.

Kelly, Emma Jean. 2015. The Adventures of Jonathan Dennis: Bicultural film archiving practice in Aotearoa New Zealand. New Barnet: John Libbey Publishing Ltd.

Ketelaar, Eric. 2003. 'Being Digital in People's Archives.' Archives and Manuscripts 31:2, 8-22.

— 2012. 'Cultivating Archives: Meaning and Identities.' Archival Science 12, 19-33.

Kinder, Marsha. 2011. 'Reorchestrating History: Transforming The Danube Exodus into a Database Documentary.' Cinema's Alchemist: The Films of Péter Forgács, edited by Bill Nichols and Michael Renov, 235-255. Minneapolis: Minnesota UP.

Klapp, Orrin. 1986. Overload and Boredom: Essays on the quality of life in the information society.

NY: Greenwood Press.

Kracauer, Siegfried. 1995. The Mass Ornament: Weimar Essays. Edited and translated by Thomas Levin. Cambridge, MA and London: Harvard UP.

Lefebvre, Henri. 1991. Critique of Everyday Life, vol. 1 [1947]. Translated by J. Moore. London: Verso.

- 1995. Introduction to Modernity. Translated by J. Moore. London: Verso.

Le Grice, Malcolm. n.d. 'Film/Video 1960s.' Filmmaker's website. Accessed 23 June 2017. https://www.malcolmlegrice.com/1960s

Leigh, Andrea. 2006. 'Context! Context! Context! Describing Moving Images at the Collection Level.' The Moving Image 6:1, 35-65.

Liew, Chern Li, Gillian Oliver and Morgan Watkins. 2018. 'Insight from social media use by memory institutions in New Zealand: participatory vs curatorial culture.' Online Information Review 42:1, 93-106.

Liew, Chern Li, Shannon Wellington, Gillian Oliver and Reid Perkins. 2015. 'Social Media in Libraries and Archives: Applied with Caution.' Canadian Journal of Information and Library Science 39:3-4, 377-396.

Lindgren, Simon. 2007. 'From Flâneur to Web Surfer: Videoblogging, Photo Sharing and Walter Benjamin @ the Web 2.0.' Transformations 7:15.

Lundemo, Trond. 2014. 'Archives and Technological Selection.' Cinémas: Revue d'Etudes Cinematographiques Journal of Film Studies 24:2-3, 17-39.

Lyotard, Jean-François. 1984. The Postmodern Condition: A Report on Knowledge. Translated by Geoff Bennington and Brian Massumi. Manchester: Manchester UP. 
MacNamara, Peter. 1996. 'Amateur Film as Historical Record - A Democratic History?' Journal of Film Preservation 25:53, 41-44.

Manoff, Marlene. 2010. 'Archive and Database as Metaphor: Theorizing the Historical Record.' Libraries and the Academy 10:4, 385-398.

Manovich, Lev. 2001. The Language of New Media. Cambridge, MA: MIT Press.

Margulies, Ivone. 1996. Nothing Happens: Chantel Akerman's Hyperrealist Everyday. Durham and London: Duke UP.

Marks, Laura U. 2004. 'The Ethical Presenter.' The Moving Image 4:1, 34-47.

Martin, Adrian. 2007. 'Black box/white cube: cinema in the gallery.' Artlink 27:3, 36-38.

Marynowsky, Tara. 2014. 'The 1950s Melbourne Art Scene: Philippe Mora and the Home Movies of Gerty Anschel.' NFSA. Posted 27 November. https://www.nfsa.gov.au/latest/philippe-mora-1950s

Mason, Marissa K. 2014. 'Outreach 2.0: Promoting Archives and Special Collections through Social Media'. Public Services Quarterly 10, 157-168.

Massumi, Brian. 2002. Parables for the Virtual: Movement, Affect, Sensation. Durham: Duke UP. Matuszewski, Boleslas. 1995. 'A New Source of History.' Translated by Laura U. Marks and Diane Koszarski. Film History 7:3, 322-324.

Mauro, Daniel. 2012. 'Private Pasts and Future Publics.' In Media Res, October 16. http://mediacommons.org/imr/2012/10/14/private-pasts-and-future-publics

Miller, Tyrus. 2011. 'Reenvisioning the Documentary Fact: On Saying and Showing in Wittgenstein Tractatus and Bourgeois Dictionary.' Cinema's Alchemist: The Films of Péter Forgács, edited by Bill Nichols and Michael Renov, 177-194. Minneapolis: Minnesota UP. Misek, Richard. 2010. 'Dead time: Cinema, Heidegger, and boredom.' Continuum 24:5, 777785.

Moorehouse, Roger. 2010. DVD review of Swastika. History Today 60:1, 59.

Moran, James. 2002. There's No Place Like Home Video. Minneapolis: Minnesota UP.

Moran, Joe. 2003. 'Benjamin and Boredom.' Critical Quarterly 45:1-2, 168-181.

Morris, Jeremy Wade. 2015. 'Curation by code: Infomediaries and the data mining of taste.' European Journal of Cultural Studies 18: 4-5, 446-463.

Moving History. 2005. Films From the Home Front. http://www.movinghistory.ac.uk/ — 2005. 'Films: Sheriff Hutton Agricultural and Rural Scenes.' Films From the Home Front. http://www.movinghistory.ac.uk/homefront/films/ya7.html 
Mulvey, Laura. 2006. Death $24 x$ a Second: Stillness and the Moving Image. London: Reaktion. National Library of New Zealand. 2007. Creating A Digital New Zealand: New Zealand's Digital Content Strategy. Wellington.

National Library of Scotland Moving Image Archive. n.d. 'A Happy New Year' catalogue entry. http://movingimage.nls.uk/film/9024

Newman, Joanna. 2009. 'Lost in Cyberspace: the place of uncatalogued collections and online indexes in a digital New Zealand.' Archifacts October 2008-April 2009, 161-166.

New Zealand Film Archive. 2013. 'Newtown on Film 1900-2009' programme notes. Wellington.

Ngā Taonga Sound and Vision. 2016. 'Reel Life in Rural New Zealand: Otago and Southland, 1913-2007' programme notes. Wellington.

— n.d. 'Personal Record. Hayward, R. [Wellington NZ October 1916]' catalogue entry. Accessed 10 January 2019. https://www.ngataonga.org.nz/collections/catalogue/catalogue-item? record $\mathrm{id}=82062$

Nichols, Bill and Michael Renov. eds. 2011. Cinema's Alchemist: The Films of Péter Forgács. Minneapolis: Minnesota UP.

Niemeyer, Katharina. 2014. Introduction. Media and Nostalgia: Yearning for the Past, Present and Future, 1-23. London: Palgrave Macmillan.

Noordegraaf, Julia. 2010. 'Performing the Archive: Archivists as Editors of Knowledge.' Paper presented at Reimagining the Archive: Remapping and Remixing Traditional Models in the Digital Age conference, UCLA.

— and Elvira Pouw. 2009. 'Extended Family Films: Home Movies in the State-Sponsored Archive.' The Moving Image 9:1, 83-103.

Norris Nicholson, Heather. 2012. Amateur Film: Meaning and Practice, 1927-77. Manchester: Manchester UP.

North East Film Archive. n.d. Newcastle on Film: Evaluation Report. Middlesbrough.

Northeast Historic Film. n.d. 'Stewart, Archie Collection.' Accessed 11 June 2017. http://oldfilm.org/collection/index.php/Detail/collections/170

- 2011. Amateur Filmmakers Record the New York World's Fair and Its Period. http://www.fairfilm.org/

Northern Ireland Screen Digital Film Archive. n.d. 'Super 8 Stories.' http://digitalfilmarchive.net/search?keywords=Super 8 Stories 
NZ on Screen. n.d. 'Judy Bailey.' Accessed 2 April 2019.

https://www.nzonscreen.com/person/judy-bailey

Odin, Roger. 2008. 'Reflections on the Home Movie as Document: a Semio-pragmatic Approach.' Mining the Home Movie: Excavations in Histories and Memories, edited by

Patricia Zimmermann and Karen Ishizuka, 255-271. Berkeley and LA: California UP.

- 2011. 'How to Make History Perceptible: The Bartos Family and the Private Hungary

Series.' Cinema's Alchemist: The Films of Péter Forgács, edited by Bill Nichols and Michael

Renov, 137-158. Minneapolis: Minnesota UP.

- 2014. 'The Home Movie and Space of Communication.' Amateur Filmmaking: the Home

Movie, the Archive, the Web, edited by Laura Rascaroli and Gwenda Young, 15-26.

London: Bloomsbury.

Orgeron, Devin. 2006. 'Mobile Home Movies: Travel and "le Politique des Amateurs".' The Moving Image 6:2, 74-100.

— and Marsha Orgeron. 2007. 'Familial Pursuits, Editorial Acts: Documentaries after the Age of Home Video.' The Velvet Light Trap 60, 47-62.

Osborne, Thomas. 1999. 'The Ordinariness of the Archive.' History of the Human Sciences 12:2, 51-64.

Osterweil, Ara. 2004. 'Andy Warhol's Blow Job: Toward the Recognition of a Pornographic Avant-garde.' Porn Studies, edited by Linda Williams, 431-460. Durham: Duke UP.

Paul, Joanna Margaret. 1985. 'Shibusha.' Cantrills Filmnotes 47-48, 10-11.

— n.d. Circuit notes for Napkins. http://www.circuit.org.nz/film/napkins

Perry, Charlotte. 2017. Review of 'Leeds on Film: proof that student life truly has not changed much in 30 years.' The Gryphon. Posted November 10.

http://www.thegryphon.co.uk/2017/11/10/leeds-on-film-proof-that-student-life-trulyhas-not-changed-much-in-30-years/

Petro, Patrice. 2002. AfterShocks of the New: Feminism and Film History. New Brunswick, NJ: Rutgers UP.

Pierson, Michele. 2009. 'Avant-Garde Re-Enactment: World Mirror Cinema, Decasia, and The Heart of the World.' Cinema Journal 49:1, 1-19.

Prelinger, Rick. 2009. 'Taking history back from the "storytellers".' Blog entry, June 22. http:// blackoystercatcher.blogspot.co.nz/2009/06/taking-history-back-from-storytellers.html 
— 2009b. 'The Appearance of Archives.' The YouTube Reader, edited by Pelle Snickars and Patrick Vonderau, 268-274. Stockholm: National Library of Sweden.

— 2011. 'Do Physical Objects Have the Right to Exist?' Open Space. Posted March 29. openspace.sfmoma.org/2011/03/do-physical-objects-have-the-right-to-exist/

— 2013. 'No More Road Trips?' Blog entry, March 8. http://nomoreroadtrips.blogspot.co.nz/ Proctor, Jennifer. 2012. 'Home Movies, YouTube, and Mashup.' In Media Res, October 19. http://mediacommons.org/imr/2012/10/12/home-movies-youtube-and-mashup Rao, Nina. 2010. 'Representation and Ethics in Moving Image Archives.' The Moving Image $10: 2,104-123$.

Ross, Miriam. 2013. 'Interstitial film viewing: community exhibition in the twenty-first century.' Continuum: Journal of Media and Cultural Studies 27:3, 446-457.

Roth, Michael. 2008. 'Ordinary Film: Péter Forgács's The Maelstrom.' Mining the Home Movie: Excavations in Histories and Memories, edited by Patricia Zimmermann and Karen Ishizuka, 62-72. Berkeley and LA: California UP.

Ruoff, Jeffrey K. 1991. 'Home Movies of the Avant-Garde: Jonas Mekas and the New York Art World.' Cinema Journal 30:3, 6-28.

Russell, Bertrand. 1930. The Conquest of Happiness. London: George Allen and Unwin.

Schneider, Alexandra. 2003. 'Home Movie-Making and Swiss Expatriate Identities in the 1920s and 1930s.' Film History 15:2, 166-176.

— 2006. 'Homemade Travelogues: Autosonntag - A Film Safari in the Swiss Alps.' Virtual Voyages: Cinema and Travel, edited by Jeffrey Ruoff, 157-173. Durham: Duke UP. Schneider, Greice. 2016. What Happens When Nothing Happens: Boredom and Everyday Life in Contemporary Comics. Leuven: Leuven UP.

Schultz, Ed. and Dodi. 1972. How to Make Exciting Home Movies \& Stop Boring Your Friends and Relatives. NY: Doubleday.

Screen Australia. n.d. 'Our Century.' Accessed 16 February 2018. https://www.screenaustralia.gov.au/the-screen-guide/t/our-century-1999/12696/

Sekula. Allan. 1986. 'The Body and the Archive.' October 39, 3-64.

- 2003. 'Reading an Archive: Photography between labour and capital.' The Photography Reader, edited by Liz Wells, 442-452. London: Routledge.

Shand, Ryan. 2008. 'Theorising Amateur Cinema: Limitations and Possibilities.' The Moving Image 8:2, 36-60. 
Shouse, Eric. 2005. 'Feeling, Emotion, Affect.' M/C: A Journal of Media and Culture 8:6. http:// journal.media-culture.org.au/0512/03-shouse.php

Simon, Jane. 2006. 'Recycling Home Movies.' Continuum: Journal of Media and Cultural Studies 20:2, 189-199.

Slaby, Jan. 2010. 'The Other Side of Existence: Heidegger on Boredom.' Habitus to Habitat II: Other Sides of Cognition, edited by S. Flach and J. Söffner, 101-120. Bern: Peter Lang.

Snickars, Pelle and Patrick Vonderau. eds. 2009. Introduction. The YouTube Reader, 9-21. Stockholm: National Library of Sweden.

Sobchack, Vivian. 1999. 'Toward a Phenomenology of Nonfictional Film Experience.' Collecting Visible Evidence, edited by Jane Gaines and Michael Renov, 241-254. Minneapolis: Minnesota UP.

Spieker, Sven. 2002. 'At the center of Mitteleuropa, a conversation with Péter Forgács.' Art Margins Online. Posted May 21.

http://www.artmargins.com/index.php/5-interviews/354-at-the-center-of-mitteleuropa-aconversation-with-peter-forgacs

Spuzz. 2011. Review of 'Amateur film: Ice Harvest, Pocono Manor, 1919.' Posted August 21. https://archive.org/details/amateur_film ice harvest_pocono manor 1919

— 2014. Review of 'Home Movies: Paris, Times Square, China, etc.' Posted April 6. https://archive.org/details/6195 HM Paris Times Square China etc $01 \quad 00 \quad 43 \quad 17$

— 2014. Review of 'Home Movie 98543: January 1929.' Posted October 11.

https://archive.org/details/HMJanuary98543

— 2015. Review of 'Home Movie 97177: Unidentified.' Posted February 28.

https://archive.org/details/97177 hm unidentified

Strangelove, Michael. 2010. Watching YouTube: Extraordinary Videos by Ordinary People.

Toronto: Toronto UP.

Sundholm, John. 2005. 'I am a rhinoceros': memory and the ethics and aesthetics of materiality in film.' Studies in European Cinema 2:1, 45-64.

Svendsen, Lars. 2005. A Philosophy of Boredom. Translated by John Irons. London: Reaktion Books.

Swanson, Dwight. 2003. 'Reviving and Preserving Alexander Forbes's 28mm Home Movies.' Paper presented to Northeast Historic Summer Film Symposium. 
http://oldfilm.org/content/reviving-and-preserving-alexander-forbess-28mm-home$\underline{\text { movies }}$

— 2012. 'The Tantalizing Challenges of the Home Movie Archive.' The Velvet Light Trap 70, 59-60.

Tepperman, Charles. 2014. Amateur Cinema: The Rise of North American Moviemaking, 19231960. Berkeley: California UP.

Thelwall. Mike. 2018. 'Social media analytics for YouTube comments: potential and limitations.' International Journal of Social Research Methodology 21:3, 303-316.

Todd, Peter. 2015. 'Through a Different Lens / Film Work by Joanna Margaret Paul.' Posted 18 November. http://www.circuit.org.nz/

Uricchio, William. 2011. 'The algorithmic turn: photosynth, augmented reality and the changing implications of the image.' Visual Studies 26:1, 25-35.

van Alphen, Ernst. 2014. Staging the Archive: Art and Photography in the Age of New Media. London: Reaktion Books.

— 2011. 'Towards a New Historiography: The Aesthetics of Temporality.' Cinema's Alchemist: The Films of Péter Forgács, edited by Bill Nichols and Michael Renov, 59-74. Minneapolis: Minnesota UP.

Vaneigem, Raoul. 2012. The Revolution of Everyday Life. Translated by Donald NicholsonSmith. Oakland: PM Press.

van Leeuwen, Marco. 2009. 'The Digital Void: e-NNUI and experience.' Critical Studies 31, 177-201.

Verhoeff, Nanna. 2006. The West in Early Cinema: After the Beginning. Amsterdam: Amsterdam UP.

Vonderau, Patrick. 2009. 'Vernacular Archiving: An Interview with Rick Prelinger.' Films that Work: Industrial Film and the Productivity of Media, edited by Vinzenz Hediger and Patrick Vonderau, 51-61. Amsterdam: Amsterdam UP.

Wees, William C. 2011. '"How It Was Then": Home Movies as History in Peter Forgacs's Meanwhile Somewhere... 'Wittgenstein at the Movies: Cinematic Investigations, edited by Béla Szabados and Christina Stojanova, 82-91. Plymouth: Lexington Books.

Weir, Kirsten. 2013. 'Never a dull moment.' Monitor on Psychology 44:7, 54.

Williams, Emma-Louise. n.d. 'Paradise Place.' London Screen Archives. Accessed 21 March 2018. https://www.londonsscreenarchives.org.uk/public/gallery.php?id=4 
Williams, Linda and B. Ruby Rich. 1981. 'The Right of Re-Vision: Michelle Citron's Daughter Rite.' Film Quarterly 35:1, 17-22.

Wilson, David. 1973. 'Swastika.' Sight and Sound 42:3, 144-145.

Wisniewski, Timothy. 2007. 'Framers of the Kept: Against the Grain Appraisal of Ephemeral Moving Images.' The Moving Image 7:2, 1-24.

Yorkshire Film Archive. n.d. Context for 'Christmas 1940-1943.' Accessed 17 March 2018. http://www.yorkshirefilmarchive.com/film/christmas-1940-1943

— n.d. Context for On the Trail of the Fall. Accessed 17 March 2018. http://www.yorkshirefilmarchive.com/film/trail-fall

— n.d. Context for 'Rural Scenes, This Day, Great Ayton etc.' Accessed 19 March 2018. http:// www.yorkshirefilmarchive.com/film/rural-scenes-day-great-ayton-etc

— 2009. Context for 'Sheriff Hutton Agricultural/Rural Scenes (1955-1957).' http://www.yorkshirefilmarchive.com/film/sheriff-hutton-agriculturalrural-scenes

Zimmermann, Patricia. 1995. Reel Families: A Social History of Amateur Film. Bloomington: Indiana UP.

Zryd, Michael. 2007. 'Avant-Garde Films: Teaching Wavelength.' Cinema Journal 47:1, 109112.

\section{Audiovisual sources}

Akerman, Chantal. 2015. No Home Movie. France, Belgium: Liaison Cinématographique, Paradise Films.

'Amateur film: Bohemian Grove.' c.1938. PAIA. Uploaded 16 July 2002. https://archive.org/details/Bohemian1938

'Amateur film: Dog Cart.' c.1947. PAIA. Uploaded 16 July 2002. https://archive.org/details/DogCart1947

'Amateur film: Ice Harvest, Pocono Manor, 1919.' PAIA. Uploaded 1 December 2008. https:// archive.org/details/amateur film ice harvest pocono manor 1919

Anschel, Gerty. c.1953-1954. 'Melbourne in the 1950s: Philippe Mora, home movies and the art scene', parts 1-3. NFSA. Uploaded 12 November 2014.

https://youtu.be/EfWTMJmorm8

Beeson, Constance. 1974. Grow Old Along with Me. USA.

- 1971. Holding. USA. 
Berliner. Alan. 1986. The Family Album. USA: MOMA, FMC, Milestone.

Bornstein, Sarah. 'Memory Lane: growing up Australian in the 1950s.' Uploaded 12 July 2012. https://youtu.be/tdO4c6r7mTo

Björkman, Stig. 2015. Ingrid Bergman in Her Own Words. Sweden: Mantaray Film.

Brakhage, Stan. 1959. Window Water Baby Moving. USA.

- 1967. Scenes from Under Childhood, Section One. USA.

Bridcut, John (producer). 2016. Elizabeth at 90: A Family Portrait. UK: BBC.

Broughton, James. 1971. This is It. USA. Available on UbuWeb.

http://www.ubu.com/film/broughton it.html

Burnford, Paul. 1948. Your Movie Camera and How to Use It. USA: The Hollywood 35mm Film Company. PAIA. Uploaded 14 June 2012.

https://archive.org/details/0838 Your Movie Camera and How to Use It 110055 $\underline{26}$

Caouette, Jonathan. 2003. Tarnation. USA: Stephen Winter, Jonathan Caouette.

Child, Abigail. 2004. The Future is Behind You. USA.

Citron, Michelle. 1978. Daughter Rite. USA: Iris Films.

Cruz, Richard. 'The Caretaker - Bedded Deep in Long Term Memory (Music Video).'

Uploaded 15 June 2011. https://vimeo.com/groups/151623/videos/25142344

Davies, Will (producer). 1999. Our Century. Australia: Film Australia, Look Film Productions, NFSA.

Dearman, Andrew. 2015. Disappearance. Australia: CACSA Contemporary 2015. Uploaded 2016. https://vimeo.com/169203635

Diack, Frank. 1955. 'Personal Record. Diack, Frank. [Woolshed Function].' NTSV. https://www.ngataonga.org.nz/collections/catalogue/catalogue-item?record $\mathrm{id}=88877$ Eastman Kodak. 1963. Using the Camera. UK: Eastman Kodak. BFI. Uploaded 7 October 2016. https:/www.facebook.com/BritishFilmInstitute/videos/1294816583893831/ Forgács, Péter. 1998. The Danube Exodus. Hungary: Lumen Film.

— 2005. El Perro Negro. Hungary: Lumen Film.

— 1998. The Maelstrom. Hungary: Lumen Film.

— 2013. 'Peter Forgacs The Looming Fire - Stories From the Dutch East Indies exhibition at EYE Amsterdam.' Uploaded 5 October 2013. https://youtu.be/X-BtQYqaNaQ 
- 1992. Wittgenstein Tractatus. Hungary: EAI. Uploaded 20 October 2014. https://youtu.be/

\section{QewCXEG5ALM}

Gee, Stevie. 2010. Playing Out. UK: London Recut, Mosaic Films. Uploaded 26 August 2010.

https://youtu.be/Dfe oN3vMZU

Giolo, Eva. 2017. Gil. Belgium: Huis van Alijn. Uploaded 14 February 2017.

https://vimeo.com/204019533

Hayward, Rudall. 1916. 'Personal Record. Hayward, R. [Wellington NZ October 1916].'

NTSV. https://www.ngataonga.org.nz/collections/catalogue/catalogue-item?

record $\mathrm{id}=82062$

Heath, Virginia. 2014. From Scotland with Love. UK: Faction North.

Hill, Jerome. 1972. Film Portrait. USA: Heptagon Films. Uploaded 18 July 2011.

https://vimeo.com/26576318

'Home Movie 98543: January 1929.' PAIA. Uploaded 21 November 2012. https://archive.org/ details/HMJanuary98543

'Home Movie 97177: Unidentified.' PAIA. Uploaded 30 May 2013.

https://archive.org/details/97177 hm unidentified

'Home Movies: Paris, Times Square, China, etc.' PAIA. Uploaded 4 August 2012.

https://archive.org/details/6195 HM Paris Times Square China etc $01 \quad 00 \quad 43 \quad 17$

Howarth, John. 1955-1957. 'Sheriff Hutton Agricultural/Rural Scenes (1955-1957).' YFA.

http://www.yorkshirefilmarchive.com/film/sheriff-hutton-agriculturalrural-scenes

Jaberi, Nicola. 2010. London! A Guide for the Anxious. UK: London Recut, Mosaic Films.

Uploaded 7 September 2010. https://youtu.be/ENcd8MQ8saU

Jacobs, Ken. 1969. Nissan Ariana Window. USA. Available on UbuWeb.

http://www.ubu.com/film/jacobs nissan.html

Jarecki, Andrew. 2003. Capturing the Friedmans. USA: HBO.

Jenniesworld. 'Vintage Christmas Movie 1950s 1960's.' Uploaded 19 March 2007.

https://youtu.be/a7jcuciF Y0

Jerrysworld. 'Little Christmas 1960s.' Uploaded 19 March 2007.

https://youtu.be/PjXXUkwm7-s

Jose, Emilio. 2013. 'Interview with Rick Prelinger for Steal This Film 2: Online Archives,

Creativity \& Serendipity.' Uploaded August 12. https://youtu.be/hstxA 2vKAQ 
Kamrau, Katrin. 2017. Reference. Belgium: Huis van Alijn. Uploaded 14 February 2017. https://vimeo.com/204019717

Lavery, Diarmuid (producer). 2003-2006. Super 8 Stories. UK: BBC NI, Doubleband Films. Available on Northern Ireland Screen Digital Archive.

https://digitalfilmarchive.net/collection/super-8-stories-7

Le Grice, Malcolm. 1967. Little Dog for Roger. UK. Available on UbuWeb. http://www.ubu.com/film/legrice dog.html

Lutz, Marina. 2009. The Marina Experiment. USA.

McElwee, Ross. 2003. Bright Leaves. USA: Homemade Movies, WGBH.

- 1993. Time Indefinite. USA: Homemade Movies.

McLeod, Fred. 1962. 'All Personal Sound Movies (Excerpt).' Uploaded 31 August 2007. https://archive.org/details/homemovie fred mccleod

Marazzi, Alina. 2002. Un'ora sola ti vorrei (For One More Hour with You). Italy.

Mekas, Jonas. 2006. First Forty: A Visit to Stan Brakhage. USA.

- 1976. Lost, Lost, Lost. USA.

- 1972. Reminiscences of a Journey to Lithuania. USA.

Mishima1970. 'The Life and Death of Eva Braun.' Uploaded 2 November 2006. https://youtu.be/xjLg3GWzS3A

Mora, Philippe. 1973. Swastika. UK: VPS.

MorryVision. 'Morris Family Home Movies 1954-1975 England-New Zealand.' Uploaded 17 February 2014. https://youtu.be/yDoI6E0I3sk

Nebraska State Historical Society Moving Image Collections. 'Raikes Family Christmas home movies (excerpts, 1941-1970).' Uploaded 27 February 2014.

https://youtu.be/CXsgDzKS7uk

Oddie, Alan. c.1970. How to Make Home Movies Your Friends Will Want to See Twice. USA: Blackhawk Films. Uploaded 8 January 2007. https://archive.org/details/How to Make Home Movies

Paul, Joanna Margaret. 1976. Aberhart's House. New Zealand.

https://www.circuit.org.nz/film/aberharts-house

— 1975. Napkins. NewZealand. https://www.circuit.org.nz/film/napkins

- 1982. Task. New Zealand. https://www.circuit.org.nz/film/task

- 1975. Thorndon. New Zealand. https://www.circuit.org.nz/film/thorndon 
Pinder, Matt. 2015. Scotland's Home Movies. UK: BBC.

Polley, Sarah. 2012. Stories We Tell. Canada: National Film Board of Canada, Palace Films.

Prelinger, Rick. 2013. No More Road Trips? USA: Creative Capital. Uploaded 5 July 2013. https://vimeo.com/69781280

Reed, Alex (producer). 2016. Decades in Colour. New Zealand: Greenstone.

ReelNostalgia. 'Home Movie of The Good Old Days America 1940's.' Uploaded 4 November 2011. https://youtu.be/4XoiWud3F48

Reynolds, Garr. 'A Reynolds Family Christmas, 1958 (Portland, Oregon).' Uploaded 22

December 2012. https://youtu.be/vqhuZVUXqTM

Rogge, Michael. 'From Holland to Copenhagen in winter 1963.' Uploaded 6 November 2010. https://youtu.be/Ow7hYKQzjzk

Rosenblatt, Jay. 1998. Human Remains. Denmark: Locomotive Films, Danish Film Institute.

Rothschild, Amalie. 1974. Nana, Mom and Me. USA: New Days Films.

Slim5819. 'Family Christmas 1939.' Uploaded 11 February 2008. https://youtu.be/j8-

$\underline{Z g l 1 n v 24}$

— 'Farm Technological Progress, 1938-1958.' Uploaded 11 February 2008.

https://youtu.be/bgqCStaXZVY

— 'Just for Fun Trick Photography.' Uploaded 11 February 2008. https://youtu.be/hmsEqUb2GPw

— 'Saying Goodbye to the Last Horses.' Uploaded 11 February 2008.

https://youtu.be/xZuxT5zyIZo

Star, Ernst and Steven Zeitlin. 1975. Home Movie: An American Folk Art. USA: Smithsonian Institute. Available on Folkstreams. http://www.folkstreams.net/film-detail.php?id=112 Stewart, Archie. 2005. 'Stewart family home movies c.1936-39'. Disc 6: 'The amateur as actor: discovering paradise in pictures.' Unseen Cinema: early American avant-garde film, $1894-$ 1941. DVD curated by Bruce Posner and produced by David Shephard. NY: Anthology Film Archives.

Swanson, Dwight. 2010. Amateur Night: Home Movies from American Archives. USA: Center for Home Movies. Uploaded 20 April 2017. https://vimeo.com/214114256

'Tesco Christmas Ad 2013.' Uploaded 6 April 2014. https://youtu.be/hurYR8d5I8Y

Wrangell, Basil. 1940. Home Movies. USA: MGM. Uploaded 13 February 2011. https://www.youtube.com/watch?v=qaXV4A jRNI 
Wreck and Salvage. 2007. 'Golden Gates.' Uploaded 25 June. https://vimeo.com/221342 and 6 July. https://youtu.be/BDOWpwc7o-Q Accessed 8 October 2018.

Yorkshire Film Archive. 2015. 'Leeds on Film with Yorkshire Film Archive.' Event trailer. Uploaded 21 October. https://youtu.be/wsMQcZ-Wh2M 